


\title{
Corporeality: a haptic space
}

by

Nona Arezehgar

Bachelor of Architectural Science, Ryerson University, 2017

\author{
A thesis \\ presented to Ryerson University \\ in partial fulfillment of the \\ requirements for the degree of \\ Master of Architecture \\ in the program of \\ Architecture
}

Toronto, Ontario, Canada, 2020

(C) Nona Arezehgar, 2020 



\section{Author's Declaration}

I hereby declare that I am the sole author of this thesis. This is a true copy of the thesis, including any required final revisions, as accepted by my examiners.

I authorize Ryerson University to lend this thesis to other institutions or individuals for the purpose of scholarly research.

I further authorize Ryerson University to reproduce this thesis by photocopying or by other means, in total or in part, at the request of other institutions or individuals for the purpose of scholarly research.

I understand that my thesis may be made electronically available to the public. 

Corporeality: a haptic space

Nona Arezehgar

Master of Architecture 2020

Ryerson University

\section{Abstract}

The hegemony of vision and the suppression of other sensory realms has led to an architecture distanced from the human body. Undoubtedly, vision has the ability to receive the greatest amount of information from our surroundings; hence, it has been considered as primary to our perception. However, its interconnection with other bodily sensations is essential to perceive the totality of space; this connection also compensates for the limitations of sight. The purpose of this critique is not to demonize visuality; it is to consider the rhizomatic and interconnected nature of haptic perception of space. Approaching corporeality results in haptic spaces that enhance or suppress our bodily experience of spatial qualities while sharpening our visual experience. A haptic space will introduce more possibilities for bodily actions by focusing on spatiality, unifying the architecture of the foreground with the background. The concept of spatiality merges space and movement of the body, and therefore it can support or suppress the actions. These actions are subjectively performed based on perceived spatial opportunities through haptic perception. The thesis is intended to explore possibilities embedded within haptic space to create a richer architectural experience. It will explore the spatial interconnections between haptic perception, somatosensory system, vision and consequently bodily movements. 



\section{Acknowledgments}

I would like to thank and express my gratitude to my thesis supervisor, Marco Polo, for his expertise, patience, support and motivation during the course of this thesis project. You have not only guided me throughout the research and design process, but also encouraged me to believe in myself and gave me the power to express my ideas with confidence. It has been a pleasure working with you and learning from your knowledge and experience that without a doubt aid in the development of my professional character and advance my future career as an architect.

I would also like to thank my thesis committee members Garth Norbraten and Leila Farah, who challenged and encouraged me throughout the process. This thesis work would have not been possible without their input and assistance.

Finally, I would like to thank my family and friends for their understanding, support and encouragement throughout this intense year. I appreciate every smile you have put on my face during the hard times. 
Table of Contents

Author's Declaration $\quad$ iii

Abstract

Acknowledgments $\quad$ vii

List of Figures $\quad x$

01 Introduction 1

02 Science of the Senses 11

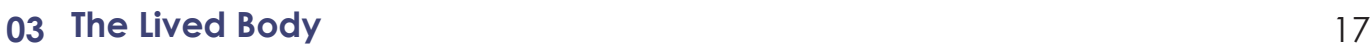

04 The Analogy of Dance 23

05 Haptic Perception 29

$\begin{array}{ll}\text { Kinesthesia } & 31\end{array}$

$\begin{array}{ll}\text { Proprioception } & 32\end{array}$

$\begin{array}{ll}\text { Vestibular Sense } & 32\end{array}$

$\begin{array}{ll}\text { Thermoception } & 32\end{array}$

$\begin{array}{ll}\text { Nociception } & 33\end{array}$ 
$\begin{array}{ll}\text { Attractions and Aversions } & 37\end{array}$

$\begin{array}{ll}\text { Parallactic Space } & 60\end{array}$

$\begin{array}{ll}\text { Perilous Space } & 70\end{array}$

$\begin{array}{ll}07 \text { The Library of Spatial Binaries } & 77\end{array}$

08 A Haptic Space: An Experiential Machine 87

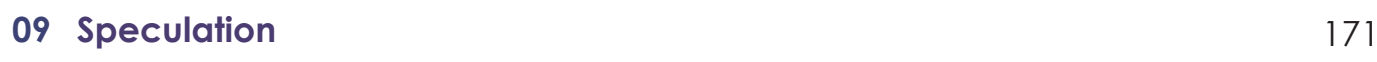

Appendices

$\begin{array}{ll}\text { Appendix A - Experiential Section } & 177\end{array}$

$\begin{array}{ll}\text { Appendix B - Experiential Movie } & 185\end{array}$

$\begin{array}{ll}\text { Appendix C - Haptic Tool Kit } & 191\end{array}$

$\begin{array}{ll}\text { Glossary of Terms } & 200\end{array}$

$\begin{array}{ll}\text { Works Cited } & 202\end{array}$

$\begin{array}{ll}\text { Works considered } & 207\end{array}$ 


\section{List of Figures}

Figure 1: Afrum, Pale Pink by James Turrell

Source: http://www.smartshanghai.com/articles/activities/these-are-the-three-exhibitions-tosee-during-cny.

Figure 2: Church of the Light by Tadao Ando

Source: http://www.interactiongreen.com/church-light-tadao-ando/.

Figure 3: Floating Cube Courtyard by 314 Architecture Studio

Source: https://thearchitectureclub.com/architecture/a-store-framed-by-an-optical-illusion-ofa-floating-cube-courtyard.

Figure 4: Classification of the Senses

Edited By: Nona Arezehgar

Source: http://www.psy.gla.ac.uk/ steve/best/senses.html.

Figure 5: Rituals of Movement in Phillips Exeter Academy Library by Lovis Kahn Edited by: Nona Arezehgar

Sources: http://www.designcurial.com/news/louis-kahn---six-most-important-buildings-4323752/. http://motionographer.com/2009/08/16/alex-roman-thethirdtheseventh/.

http://www.wordsinspace.net/shannon-archive-2017/wp-content/uploads/2010/05/NNJ_v12n3_ Mattern_onlinefirst.pdf

Figure 6: Two Means of Circulation in Villa Savoye

Source: https://www.khanacademy.org/humanities/ap-art-history/later-europe-and-americas/ modernity-ap/a/corbusier-savoye.

Figure 7: The Body's Movement in Space

Source: https://www.vice.com/en_uk/article/d74zey/can-robots-dance.

Figure 8 \& 9: Dance for Architecture - Tesseracts of Time

Source: https://divisare.com/projects/303047-steven-holl-architects-tesseracts-of-time-adance-for-architecture?utm_campaign=journal\&utm_content=title-project-id-303047\&utm_ medium=email\&utm_source=journal-id-5.

Figure 10: Exploring Spatial Boundary through Body's Extremity in "Pas De Deux" by Norman McLaren

Edited by: Nona Arezehgar

Source: https://www.youtube.com/watch?v=WopqmACy5XI.

Figure 11: Mapping the Relationships between the Somatosensory System and 30 Haptic Perception Created by: Nona Arezehgar

Figures 12 \& 13: Repetitive Elements Exaggerating the Sense of Movement Created by: Nona Arezehgar 
Figures 14-16: The Three Research Concepts

Figure 17: Play of Light, Animating Space 
Figure 24: Analysis of Spatial Qualities in Chapel of St. Ignatius

Sources: https://seattle.curbed.com/2018/1/30/16947838/amazon-spheres-seattle-architecturephotos

http://hockhua.com/amazon-spheres-indoor-rainforest/ 
Figure 27: Analysis of Spatial Qualities in Bioscleave House

Sources: https://www.elledecor.com/it/best-of/a26471849/madeline-gins-arakawa-bioscleavehouse-new-york-for-sale/ https://www.archdaily.com/903925/touch-it-smell-it-feel-it-architecture-for-thesenses/5bc46634f197cc9le100012f-touch-it-smell-it-feel-it-architecture-for-the-senses-image https://www.aestheticsofjoy.com/2016/04/a-tokyo-apartment-complex-designed-to-reverseaging/ http://www.reversibledestiny.org/news/shusaku-arakawa-trans-japan-cis-japan https://thefunambulist.net/architectural-projects/interviews-architectures-of-joy-a-conversationbetween-two-puzzle-creatures-part-b https://www.nytimes.com/slideshow/2019/08/20/t-magazine/inside-the-bioscleave-houselifespan-extending-villa.html https://www.cretechiotnyc.com/the-house-of-our-dreams-bioscleave-house-is-for-sale-in-easthampton-new-york/

Figure 28: Analysis of Spatial Qualities in Rotman School of Management Edited by: Nona Arezehgar Photographs by author

Figure 29: Parallax Effect Created by: Nona Arezehgar

Figure 30: Parallax Effect in the Frontal Plane Created by: Nona Arezehgar

Figure 31: Parallax Effect in the Horizontal Plane Created by: Nona Arezehgar

Figure 32: Parallax Effect in the Vertical Plane Created by Nona Arezehgar

Figure 33: Analysis of spatial Qualities and Parallax Effect in Villa Savoye Created by: Nona Arezehgar

Sources: http://www.0425.info/villa-savoye-interior-ramp-65b6b9e36f2503879f218a.html. https://www.aminka.xyz/ https://T.co/stinn lwoSW Pic.twitter.com/k41GhFlrZH. https://twitter.com/mgbarahona/status/777067420892721152.

https://www.khanacademy.org/humanities/ap-art-history/later-europe-and-americas/modernityap/a/corbusier-savoye.

http://www.pedrokok.com/villa-savoye-in-poissy-france/.

https://www.pinterest.ca/pin/469289223646044683/?|p=true.

Figure 34: Analysis of Spatial Qualities and Parallax Effect in Kiasma Museum of 68 Contemporary Art

Created by: Nona Arezehgar

Sources: https://commons.wikimedia.org/wiki/File:Kiasma_\%27pasta_stairs\%27_seen_from_ ground_floor,_2011.jpg

https://hellosinki.wordpress.com/2010/08/22/kiasma/

https://www.pinterest.ca/ 
http://www.stevenholl.com/news/

https://larryspeck.com/photography/kiasma-contemporary-museum-of-art/

https://www.spacesxplaces.com/kiasma-museum-architecture-helsinki-steven-holl/

http://www.galinsky.com/buildings/kiasma/index.html

Figure 35-43: Uneven ground

Source: https://books.google.ca/books?id=sfx8DQAAQBAJ\&printsec=frontcover\&source=gbs_

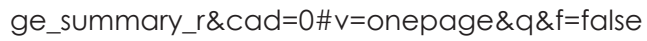

Figure 44: Wharton Esherick's Staircase

Source: https://books.google.ca/books?id=sfx8DQAAQBAJ\&printsec=frontcover\&source=gbs_ ge_summary_r\&cad=0\#v=onepage\&q\&f=false

Figure 45 \& 46: Fondazione Querini Stampalia's Irregular Stairs

Sources: https://books.google.ca/books?id=sfx8DQAAQBAJ\&printsec=frontcover\&source=gbs_ ge_summary_r\&cad $=0 \# v=0$ enepage \& $q \& f=$ false

https://stephenvaradyarchitraveller.com/2016/05/17/venice-querini-stampalia/querini-stampaliavenice-by-carlo-scarpa-58_stephen-varady-photo/

Figure 47 \& 48: Stepstones in Heian Shrine and Katsura Imperial Villa

Source: https://books.google.ca/books?id=sf×8DQAAQBAJ\&printsec=frontcover\&source=gbs_ ge_summary_r\&cad $=0 \# v=0 n e p a g e \& q \& f=$ false

Figure 49-52: The Splitting Effect by Gordon Matta-Clark

Sources: https://paddle8.com/work/gordon-matta-clark/87067-untitled-interior-from-splitting/. https://www.thepolisblog.org/2012/05/gordon-matta-clark-on-role-of-sculpture.html. http://www.agencespatiale.net/gordon-matta-clark-•-splitting-1974/.

https://www.pinterest.ca/pin/375558056419870152/?:p=true.

Figure 53: The Library of Spatial Binaries

Created by: Nona Arezehgar

Figure 54: Matrix A - Comparison of the Impact of Spatial Binaries on the Senses Created by: Nona Arezehgar

Figure 55: Matrix B - Analysis of the Concepts Based on Their Sensory Experience Created by: Nona Arezehgar

Figure 56: Spatial Binaries Applied to Floor Created by: Nona Arezehgar

Figure 57: Spatial Binaries Applied to Wall Created by: Nona Arezehgar

Figure 58: Spatial Binaries Applied to Roof and Column Created by: Nona Arezehgar 
Figure 59: Experiential Machine - Coexistence of Static and Kinetic Spaces

Figure 60: Massing Exploration to Achieve Dynamism and Different Spatial Conditions Created by: Nona Arezehgar

Figure 61: Exterior View During the Day

Created by: Nona Arezehgar

Figure 62: Exterior View During the Night

Created by: Nona Arezehgar

Figure 63: First Floor Plan

Created by: Nona Arezehgar

Figure 64: Scene A - View of the Inside through Openings, while on the Ramp

Created by: Nona Arezehgar

Figure 65: Second Floor Plan

Created by: Nona Arezehgar

Figure 66: Scene B - View of the Entrance to the Foyer

Figure 67: Sectional Perspective of the Machine

Figure 68: Third Floor Plan

Created by: Nona Arezehgar

Figure 69: Scene C - View of the Foyer with Drastic Light and Shadow Effect Created by: Nona Arezehgar

Figure 70: Scene D - Looking Up from the Foyer

Created by: Nona Arezehgar

Figure 71: Fourth Floor Plan

Figure 73: Scene E - Inside the Warm Brick Space, Looking towards the Window 106 Created by: Nona Arezehgar

Figure 74: Scene E - Inside the Warm Brick Space, during the Night 
Figure 75: Scene F - Inside the Warm Brick Space, Looking towards the Opening 108 Created by: Nona Arezehgar

Figure 76: Scene F - Inside the Warm Brick Space, during the Night

Figure 77: The Ascendant Space

Created by: Nona Arezehgar

Figure 78: Scene G - Looking up from the Ascendant Space, towards the

Figure 79: Scene G - Looking up from the Ascendant Space, during the Night 113 Created by: Nona Arezehgar

Figure 80: The Mirror Room

Created by: Nona Arezehgar

Figure 81: Scene H - The Visual Abstraction Created by Mirrored Surfaces

Figure 82: Fifth Floor Plan

Created by: Nona Arezehgar

Figure 83: The Flexible Space

Created by: Nona Arezehgar

Figure 84: Scene I - Inside the Flexible Space

Created by: Nona Arezehgar

Figure 85: Scene I - Inside the Flexible Space during the Night

Created by: Nona Arezehgar

Figure 86: Sixth Floor Plan

Created by: Nona Arezehgar

Figure 87: The Curved Wall

Created by: Nona Arezehgar

Figure 88: Scene J - The Curved Wall Interrupted by a Series of Wooden

Partitions, during the Day

Created by: Nona Arezehgar

Figure 89: Scene J - The Curved Wall Interrupted by a Series of Wooden Partitions, during the Night

Created by: Nona Arezehgar 
Figure 90: The Oblique Floor

Figure 92: Scene K - The Path to Get to the Curved Wall, during the Night

Figure 93: Scene L - Ascending the Ramp

Figure 94: The Glass Elevator

Figure 95: Seventh Floor Plan

Figure 96: The Wooden Partitions

Figure 97: Scene M - The Wooden Partitions, Looking Towards the Bottom of the Pool

Created by: Nona Arezehgar

Figure 98: Scene M - The Wooden Partitions, Looking Towards the Bottom of the Pool

Created by: Nona Arezehgar

Figure 99: Scene N- Descending the Ramp

Figure 103: Partitions as Horizontal Elements Created by: Nona Arezehgar 
Figure 105: Scene O - View of the Pool during the Day

Created by: Nona Arezehgar

Figure 106: Scene O - View of the Pool during the Night

Created by: Nona Arezehgar

Figure 107: Scene P - Inside the Pool during the Summer

Created by: Nona Arezehgar

Figure 108: Scene P - Inside the Pool during the Winter

Created by: Nona Arezehgar

Figure 109: Scene Q - The Abstraction Created by the Water during the Summer 142 Created by: Nona Arezehgar

Figure 110: Scene Q - The Abstraction Created by the Water during the Winter 143 Created by: Nona Arezehgar

Figure 111: Scene R - Looking up from the Pool, Seeing the Reflections in the Mirror 144 Created by: Nona Arezehgar

Figure 112: Scene R - Looking up from the Pool, Seeing the Reflections in the Mirror during the Night

Created by: Nona Arezehgar

Figure 113: Scene S - View from under the Water Distorting the Space Created by: Nona Arezehgar

Figure 114: Scene S - View from under the Water Distorting the Space during the Night

Created by: Nona Arezehgar

Figure 115: Tenth Floor Plan

Created by: Nona Arezehgar

Figure 116: The Unstable Floor Created by: Nona Arezehgar

Figure 117: Scene T - View of the Unstable Floor Created by: Nona Arezehgar

Figure 118: Scene U - Looking up from the Unstable Floor Created by: Nona Arezehgar

Figure 119: The Fur Room Created by: Nona Arezehgar 
Figure 121: Scene V - Inside the Fur Room, Looking Towards the Mirror, during 155 the Night

Created by: Nona Arezehgar

Figure 122: Scene W - Looking down to the Pool from the Fur Room 156 Created by: Nona Arezehgar

Figure 123: Eleventh Floor Plan Created by: Nona Arezehgar

Figure 124: The Room of Compression

Created by: Nona Arezehgar

Figure 125: Scene $X$ - Inside the Compressed Room, Feeling the Texture of Concrete 159 Created by: Nona Arezehgar

Figure 126: The Room of Expansion Created by: Nona Arezehgar

Figure 127: Scene Y - Play of Light Animating the Room of Expansion - 8 am Created by: Nona Arezehgar

Figure 128: Scene Y - Play of Light Animating the Room of Expansion - 10 am Created by: Nona Arezehgar

Figure 129: Scene Y - Play of Light Animating the Room of Expansion - 12 pm Created by: Nona Arezehgar

Figure 130: Twelfth Floor Plan Created by: Nona Arezehgar

Figure 131: The Stepstones on Water Created by: Nona Arezehgar

Figure 132: Scene Z - View of the Stepstones on Water Created by: Nona Arezehgar

Figure 133: Section 01

Created by: Nona Arezehgar

Figure 134: Section 02

Created by: Nona Arezehgar

Figure 135 -137: Physical Models of the Machine 


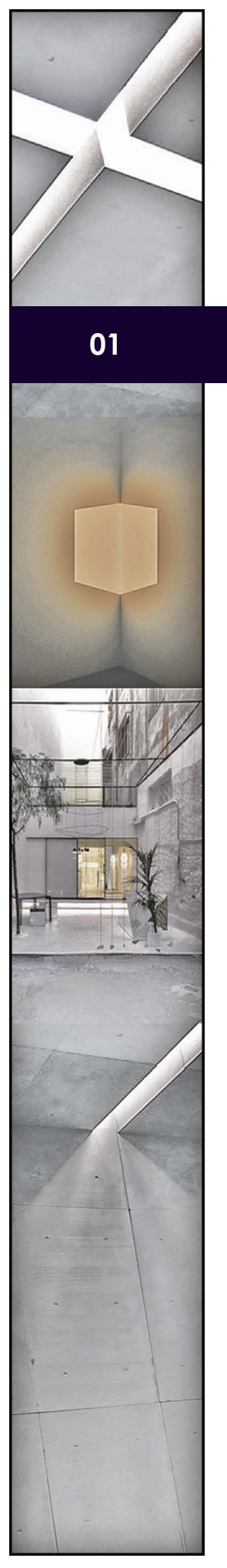




\section{Introduction}

The hegemony of vision and the suppression of other sensory realms has led to an architecture distanced from the human body. Even though this supremacy has been comprehensively critiqued, this paradigm is still predominant. Due to the remarkable range and variability of visual practices, many critics refer to architecture as being "dominated by vision." New technologies have facilitated vision to become the dominant sense in the modern world. Technical improvements related to vision have advanced at a far more rapid rate than any of the other senses and have therefore intensified its importance.'

The dominance of vision over other senses can be considered to have reached its highest point during the late 18th century. The Western tradition recognizes vision as a symbol of knowledge due to its power ${ }^{2}$ since it can receive the greatest amount of information from our surroundings; hence, anything not visible is deemed to be insignificant. This approach can be traced back to Renaissance philosophers, ranking vision at the top of the sensory hierarchy. Greek philosophers, such as Plato and Aristotle, both denoted vision as the noblest of the senses. They grouped this sense with intelligence and cognition, while other sensations were grouped with man's material being; ; therefore, the eye became the predominant organ of perception. Plato's myth of the cave is also significant in the development of this paradigm since it demonstrates how people chained to the wall of the cave, facing a blank wall, are fooled by "the visible world." the wall represent reality, and they are unable to see the source of truth behind

\footnotetext{
Jay, Martin. Downcast Eyes: The Denigration of Vision in Twentieth Century French Thought. 66. Lupton, Ellen, and Andrea Lipps. The Senses: Design Beyond Vision. 13.

Jay. 28.

Kavanagh, Donncha. "Ocularcentrism and Its Others: A Framework for Metatheoretical Analysis". 6.
} 
them. In Plato's theory, similar to the fire that cast shadows and fooled people, the human condition is always defined by the information received by the human senses, the visible world, which misrepresents reality; whereas the truth lies in the mind's eye, which he refers to as "the intelligible world." He refers to the senses as a bodily prison due to their limitations of range and focus, and therefore, he believes they distract humans from pursuing the truth. Socrates was one of the first people who considered "the body" as valuable and important for all human activity.

On the other hand, many critics have taken an "ocular-phobic" direction' by referring to visual experience as illusory; they believe it can manipulate the viewer to perceive reality deceitfully and alter perception. Martin Jay suggests that in the postmodern era, images could be "set completely adrift from their referents" and often "precede their referents," essentially turning reality into images.7 Most of the critiques have used the limitations of sight to build their arguments. One of these limitations is that only a small part of the light spectrum is visible to us. Also, "the blind spot" refers to a portion of the visual field that is unable to detect an image due to the absence of photoreceptors. There is also the limitation of frontality, our inability to see what is behind us. The restriction of frontality is part of Husserl's phenomenology; he believes that features that are not directly given to the senses are still "essential" to the experience and are comprehended through the mind. ${ }^{8}$ Martin Jay refers to these restrictions as "holes in vision." "These limitations have aided the anti-ocular-centric critique that started to develop in the 20th century.

Immanuel Kant divided cognition into two categories: intuitions and concepts. The capacity of humans to be impacted by objects is referred to as "intuitions." On the other hand, he believed our mind is continuously organizing experiences according to "concepts," which he referred to as the "understanding" of the surroundings. ${ }^{10}$ Therefore, to him, the knowledge of the world is through concepts, and bodily perception is merely an intuition. Kant's theory of cognition is a non-

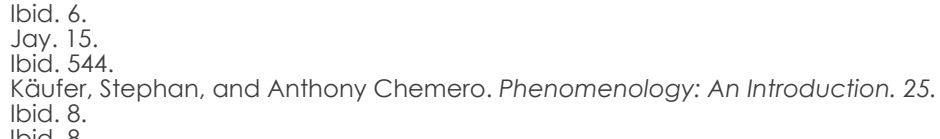


empirical approach to knowledge, and he believed that cognition must consist of a priori concepts and a priori intuitions." His "transcendental idealism" explains his view that objects are only intelligible to us from the human standpoint and depend on our minds; he argued that space and time do not exist independently from our minds and are solely features of our perception. ${ }^{12}$ After Kant, the theorists of this paradigm, mentioned below, toiled within his framework while rejecting various aspects of his philosophy.

Martin Heidegger rejected Kant's cognitivism and avoided the Cartesian dualism between the body and the mind; he approached the question of "being" by referring to Dasein, "da" means "there" and "sein" means "being." In his theory, the world is there for the lived body to engage in and make "skillful use" of space. For him, the primary way to experience the world is through the skills one uses to encounter a purposive engagement. ${ }^{13}$ Heidegger influenced Maurice MerleauPonty since his core example is "active involvement with tools and equipment in the course of accomplishing some purpose." 14

While Heidegger does not mention the body, Merleau-Ponty argues that "the way we are directed in the world, our intentionality, is a motor-intentionality grounded in our bodily abilities." 15 This motor-intentional knowledge of the world provides an infinite number of possibilities for engagement. ${ }^{16}$ While Heidegger refers to the lived body as the objective body, Merleau-Ponty believes that the lived body is "a vehicle of being in the world"17 and does not happen in space as an object; it has its spatiality. ${ }^{18}$ Merleau-Ponty criticizes both empiricists and intellectualists; empiricists assumed that sensations were produced by external stimuli and therefore considered to be at fault by Merleau-Ponty due to turning the subject into an object. On the other hand, empiricists assumed absolute subjectivity but gave power to cognition and neglected perception. ${ }^{19}$ In his opinion, the perceptual goal of bodily movement is not only to get information about the surroundings,

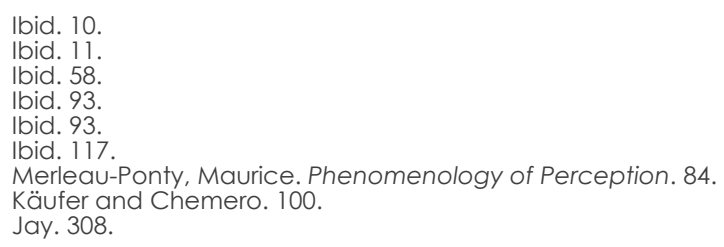


but also to open up opportunities for actions that we "can" take in the world. ${ }^{20}$ Even though Merleau-Ponty's critique carries much value in this debate, his sharp criticism against vision, "nothing is more difficult than knowing precisely what we see" 21 , is problematic; a better critique would be to question how one perceives its surroundings and how bodily perception affects what one sees. This can be related to Husserl's "essentials" of perception and the limitations of frontality. It is possible to see more than what meets the eye; we perceive objects in three-dimensions even though we are unable to see their backsides. In Merleau-Ponty's formulation, the importance of bodily perception in comprehending the surroundings as a totality was highlighted, and it established a foundation for the work of subsequent theorists and architects.

Although there are some similarities to Merleau-Ponty' ideas, James J. Gibson did not derive his ideas from other phenomenologists; rather they came from science and the addition of perceptual experience to traditions of psychology. ${ }^{22}$ Gibson asks: "How can one account for the richness of sight considering the poverty of the image within the eye?"23 Gibson criticizes the image within the eye for lacking depth, distance, and solidity. He also questions translating what we see into meaningful experience since the image received is reversed and inverted. ${ }^{24}$ Gibson is best known for his ecological approach: in contrast to the inferential approach that accounts for perceptual error due to lack of information in the environment for accurate perception, the ecological approach believes that perception is direct. ${ }^{25}$ He believes that the data existing in the environment is sufficient for perceiving the world and there is no need for interpretations; therefore, perception should merely be explained in terms of the direct contact of the body with the environment. ${ }^{26}$ For him, the purpose of perception is generating and controlling actions, through "affordances" that exist in our environment as opportunities for engagement. ${ }^{27}$

As part of the ongoing debate about the dominance of vision, Richard Shusterman,

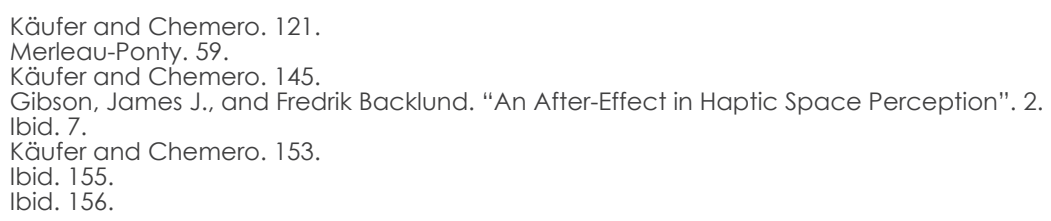


a contemporary philosopher, developed the theory of somaesthetics. His philosophy focuses on modern culture, where humans have moved away from the practicality of body awareness. ${ }^{28}$ By criticizing both the Kantian body-mind divide and phenomenologists' subject-object divide, he believes that the current state of the body expresses an ambiguous state. ${ }^{29}$ Through the body, one experiences both power and weakness; the body unifies us as humans but also differentiates us; it gives us our capacities of knowledge while also limiting it to its boundaries. As Shusterman mentions in Thinking Through the Body, there is a tendency to relate the body with the negative sides of this ambiguity while connecting the positives to cognition. Somaesthetics is a critical study of the use of one's body in experience, referring to physical being and somatic knowing and thus redirecting aesthetics to perceptions and consciousness. ${ }^{30}$ The term soma, meaning the body, and aesthetics, the Greek word for sensory perception, allowed Shusterman to designate embodiment without the problematic associations of the term "body" and "flesh." 31

As an opposite approach to Merleau-Ponty, who mentioned a universal embodied consciousness, Shusterman believes that somatic consciousness is shaped by culture and thus our bodies are diversified. ${ }^{32}$ In his theory, he introduces the idea of correcting the functional performance of the senses through improving somatic awareness as opposed to rejecting the body due to its deceptions. ${ }^{33}$ As an antagonist, he mentions the parsimonious economy of consciousness, and based on this economy, the limited concentration should be on the most important features of action - the end goal. However, he responds to this criticism by stating: "If we truly care about the ends, we must care about the means necessary to realize those ends." 34 Some of the somatic use habits are faulty and need corrections through somatic consciousness, which is identified by Shusterman as "somatic selfimprovement." 35 Even though Shusterman suggests that this somatic consciousness should no longer claim our primary attention after faulty habits are corrected,

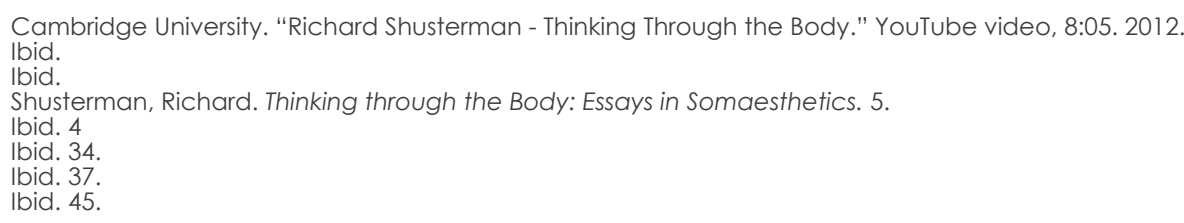


learning must never be concluded since there is always room for refinement as we experience new conditions of self throughout life. ${ }^{36}$ He explores the topic of somaesthetics in relation to different creative activities, such as architecture, photography, and the art of living. As part of his critique of architecture in relation to soma, he discusses the notion of "atmosphere" in providing a sense of place as an approach adopted by architects. ${ }^{37}$ The architects who best exemplify the emphasis of atmosphere in architecture are Alvar Aalto, Juhani Pallasmaa and Peter Zumthor.

The dominance of vision continues to play a role in both professional and academic discourse, and hence, the relationship between body and architecture became the topic of many architectural theories. The appreciation of the concept of spatiality and how it is experienced and perceived through the body has been overlooked. There is an immediate side to space which can be understood through the body. Therefore, creation of space is achieved through unifying the background, middle ground, and foreground views, and tying together the perspectives, visual experience, with the details, haptic perception.

The hegemony of vision and exclusion of other sensory realms has been a topic of concern in contemporary architectural discourse. The power of the eye over other senses has propelled architecture into an art of instant images for immediate persuasion. This critique has been observed by many architects who became interested in the phenomenological dimensions of human experience. Juhani Pallasmaa, Steven Holl, Alberto Pérez-Gómez and Peter Zumthor are some of the more prominent architects inspired by the phenomenological aspects of human experience in architecture. In The Eyes of the Skin: Architecture and the Senses, Pallasmaa relates what he describes as the inhumanity of contemporary architecture to the neglect of the body. ${ }^{38} \mathrm{Holl}$ believed that "an awareness of one's unique existence in space is essential in developing consciousness of perception", and therefore the importance of the body in perception became an inspiration in his work. ${ }^{39}$ Alberto Pérez-Gómez mentioned the dependency between "place"

\footnotetext{
$36 \quad$ Ibid. 205.

Cambridge University. 2012

Pallasmaa, Juhani. The Eyes of the Skin: Architecture and the Senses. 17.

Holl, Steven, Juhani Pallasmaa, and Alberto Pérez-Gómez. Questions of Perception: Phenomenology of Architecture. 40.
} 
and "movement," i.e., space and time, in experiencing reality. ${ }^{40}$ Therefore, the importance of experience through the body, while in movement, is emphasized in the process of perception.

As mentioned by Merleau-Ponty, the body has its subjective spatiality and is "a vehicle of being in the world." 41 The information in the world, the "affordances," are obtained through a combination of perceptual systems. Merleau-Ponty refers to this phenomenon as "synergic totality" 42 since these systems are interrelated and codependent. The visual perception of space is strongly interconnected with the haptic perception. Due to this strong visual-bodily linkage, heightening our attention to the bodily sensations in spatial perception, "we can render such perception not only more acute, penetrating, and critical but also sharpen our attentiveness and penetration of architecture's visual experience." ${ }^{43}$

This synesthesia can be further explained through the following concepts. When perception is faced with the limitations of sight, "holes in vision", the body tries to compensate using other senses to seek confirmation and understand the totality of space. The concept of spatiality, an overlooked concept in contemporary architecture, emphasizes this connection further. This concept merges architectural space and bodily movement. The creation of space is achieved through unifying the background, middle ground, and foreground and tying together the perspectives - visual perception - with the immediate details - haptic perception. According to Edward T. Hall's classification of the body's sensory system, distant receptors including the eyes examine distant objects while the immediate receptors are concerned with the immediate world and sense closeness and immediacy through skin, membranes and muscles. ${ }^{44}$ Therefore, as Gibson mentioned, a space that is sensed only through the distant receptors will lack depth and distance. Spatiality also has a direct impact on how bodies perceive and move through space; therefore, spatiality is not neutral, and it can "help or prevent the proper performance of the body." ${ }^{45}$ Even though kinesthesia, the sense of movement, is fundamental in bodily

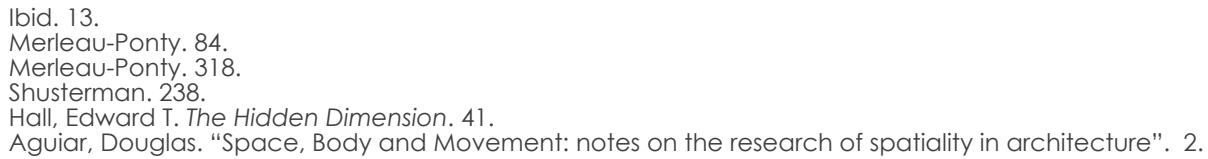


perception, it had been neglected in the traditional classification of the senses. Aside from kinesthesia, another way our body experiences movement is through vision.

The dominance of vision continues to play a role in both professional and academic discourse and hence, the relationship between the body and architecture has become the topic of many architectural theories. The fact that vision is the most developed sense in our bodies should not be overlooked; it has a superior capacity to process a surprising amount of information to the brain. ${ }^{46}$ The purpose of this critique is not to demonize visuality; it is to consider the rhizomatic nature of the haptic perception of space. Vision's interconnection with other bodily sensations is essential for us to perceive space as a totality and therefore notice more possibilities for actions and engagements. This interconnection offers no hierarchy in bodily sensations and allows for vision to be part of the experience and not the sole means of perception. A corporeal approach and the focus on the body allows us to not only appreciate the visual effects of architecture by perceiving depth and distance, but also the sensory effect of moving in space. ${ }^{47}$ Approaching corporeality results in haptic spaces that enhance or suppress our bodily experience of spatial qualities while sharpening our visual experience. A haptic space will introduce more possibilities for bodily actions by focusing on spatiality, while unifying the architecture of the foreground with the background. The thesis is intended to explore possibilities embedded within haptic space to create a richer architectural experience. It will explore the spatial interconnections between haptic perception, somatosensory senses, vision and consequently bodily movements.

$46 \quad$ Jay. 6.

Shusterman. 224 
Visual experience can manipulate the viewer to perceive reality deceitfully and alter perception. When perception is faced with the limitations of sight, the body tries to compensate using other senses to seek confirmation and understand the totality of our surroundings.

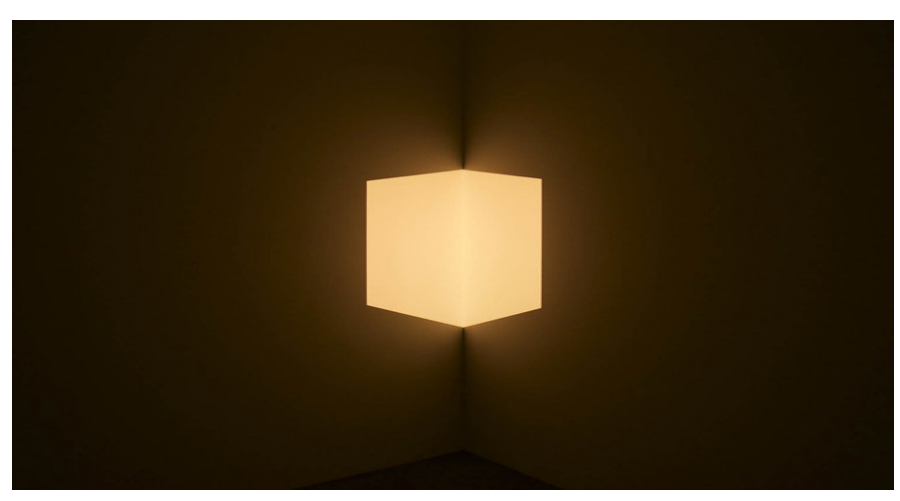

Figure 1: Afrum, Pale Pink by James Turrell - an optical illusion of a floating volume is created using a projector, casting basic geometries

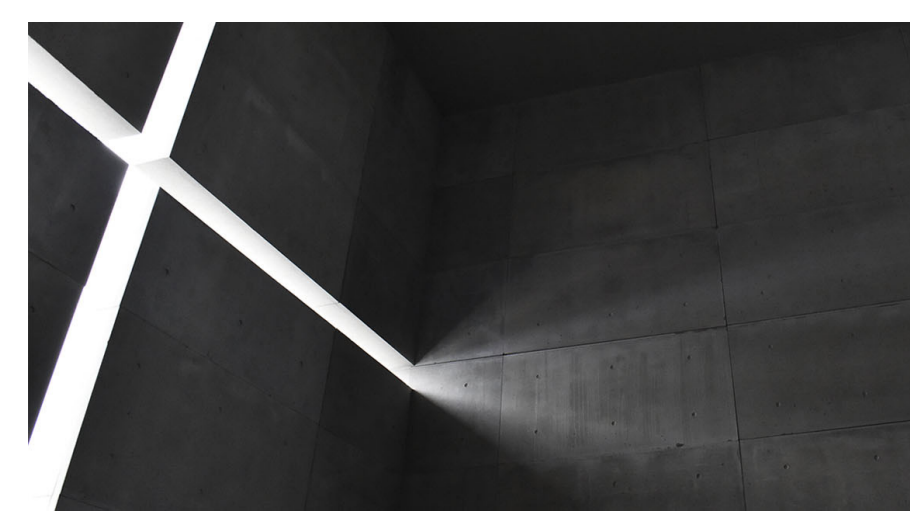

Figure 2: Church of the Light by Tadao Ando - the void of light has a stronger existence than the solid; it looks like the void exists while the solid does not

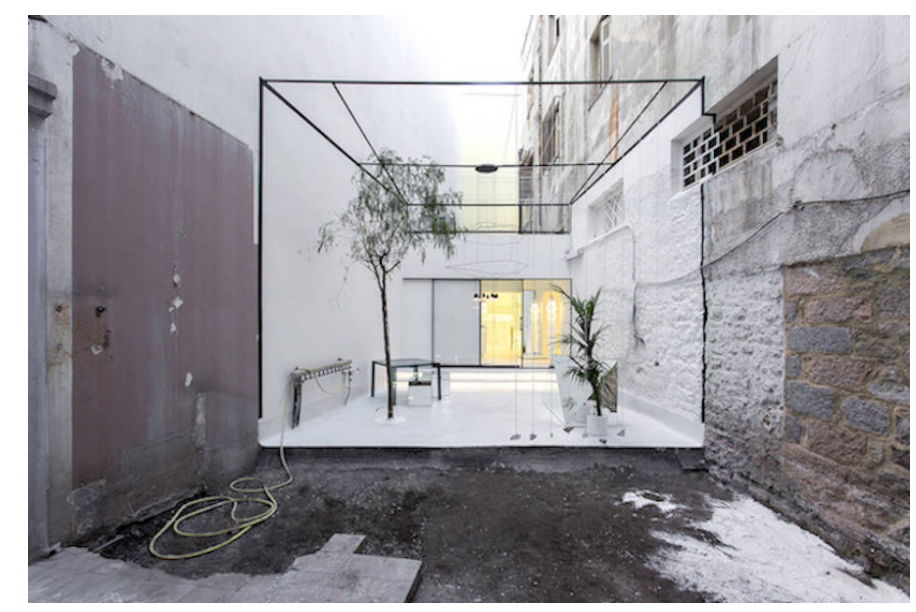

Figure 3: Floating Cube Courtyard by 314 Architecture Studio - an optical illusion of a floating courtyard deceives the viewer 
Sensory Modalities

Vision

\begin{tabular}{|l|}
\hline \\
\hline \\
\hline \\
\hline Auditory \\
\hline Smell \\
\hline
\end{tabular}

02

\begin{tabular}{|l|}
\hline \\
\hline \\
\hline Tactile \\
\hline \\
\hline \\
\hline Pain \\
\hline
\end{tabular}

Mechanoreception

Temperature

Interoception

\begin{tabular}{|l|}
\hline \\
\hline \\
\hline \\
\hline \\
\hline \\
\hline Exteroception \\
\hline Chemetoception \\
\hline \\
\hline
\end{tabular} 


\section{Science of the Senses}

The traditional classification of the senses has been rejected and considered to be a myth. Today, scientists have discovered more than nine senses; some are claiming there are more than twenty while some have found thirty-three senses.' Even though the number of scientifically proven senses continues to expand, the importance of these senses and specifically haptic senses is neglected in architecture, constituting missed opportunities.

There is no definite number as to how many senses humans have; rather, a wide range of senses can be understood to fall under three categories, introduced by Charles Scott Sherrington. ${ }^{2}$

1. Exteroception - What is happening in the surroundings of the body?

2. Proprioception - Where is the body located in space?

3. Interoception - What is happening inside the body?

Exteroceptors are in organs, such as the eyes, ears, mouth, and skin to provide information such as touch, pressure, light, sound and taste; interoceptors are inside the internal organs and provide data such as blood pressure and heartbeat; and proprioceptors offer information about "muscular and articular sources of movement." ${ }^{\prime 3}$ As the number of discovered senses increases, the boundaries between the senses become blurrier. What constitutes a sense and what distinguishes senses from one another is still up for debate. Only a few years ago, nociception was detached from the sense of touch and was categorized into three

Hiskey, Daven. "Humans Have a Lot More Than Five Senses."

Admin, lalab. "Proprioception Interaction: Upgrade Human Perception with Prothesis."

Ibid. 
parts: cutaneous (skin), somatic (bones and joints), and visceral (body organs). ${ }^{4}$ On the other hand, some of the senses are still not accepted by many scholars; for instance, magnetoception is known to be a strong sensation in birds and not humans, while recent experiments have demonstrated that humans have this sensation to some degree. ${ }^{5}$ The senses of intuition and time also remain debatable since there is not enough conclusive evidence to prove their existence. ${ }^{6}$ It can be concluded that perception of space is all about integration of the information across senses, across time, and space.

James Gibson was one of the first theorists who questioned the original classification of the senses into categories. He believed that perception has to do with the environment and proprioception with the body. To move, the body requires both the external information and bodily data; hence, the combination of perception and proprioception produces action. A body can be stimulated in two different ways; obtained and imposed stimulation. Based on Gibson, obtained stimulation comes with activity and when the internal organs or the movement of the body's extremities provide stimulation. Imposed stimulations are produced by triggers inside or outside of the body that do not relate to the person's actions. ${ }^{8}$ Therefore, he redetermined the categories into imposed perception, imposed proprioception, obtained perception, and obtained proprioception. Imposed perception arises from passive sense organs, and the stimulation is applied to them. Imposed proprioception refers to times when the organs are stimulated due to the movement of a passive individual. Obtained perception is when the sense organs are active to receive information, and obtained proprioception occurs when an active individual acts on motor systems of the body. ${ }^{9}$ This new categorization also can be related to the critique of Merleau-Ponty concerning empiricists and intellectualists; empiricists assumed that sensations were produced by external stimuli, and intellectualists gave power to cognition and neglected perception. ${ }^{10}$ Empiricists privileged imposed stimulations, and intellectualists privileged obtained stimulation.

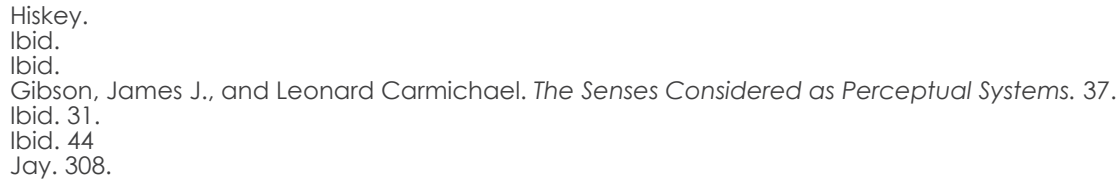


Gibson considered senses as active systems and categorized them to define modes of activity. His categories are: the basic orienting system, the auditory system, the haptic system, tasting and smelling system, and the visual system. He further elaborates on each of these systems. The visual system is activated by the variables of structure in ambient light. The taste-smell system is activated by the composition of the ingested medium through savouring and sniffing. The auditory system is activated by the vibration in the air, and the haptic system is activated by deformation of tissues, configurations of joints and muscles, resulting in contact with the earth, materials, and objects." Even though Gibson's theories are extremely valuable and set up a framework for the work of many other theorists and scientists, it is controversial to separate perception from proprioception since they are interconnected to produce spatial totality and consequently bodily movements and actions. 


\begin{tabular}{|c|c|c|c|}
\hline Sensory Modalities & & Accepted & Radical \\
\hline \multicolumn{4}{|l|}{ Vision } \\
\hline & Light & & \\
\hline & Colour & & \\
\hline & Red & & \\
\hline & Green & & \\
\hline & Blue & & \\
\hline \multicolumn{4}{|l|}{ Auditory } \\
\hline \multicolumn{4}{|l|}{ Smell } \\
\hline & 2000 or more receptor types & & \\
\hline \multicolumn{4}{|l|}{ Taste } \\
\hline & Sweet & & \\
\hline & Salt & & \\
\hline & Sour & & \\
\hline & Bitter & & \\
\hline & Umami & & \\
\hline \multicolumn{4}{|l|}{ Tactile } \\
\hline & Light touch & & \\
\hline & Pressure & & \\
\hline \multicolumn{4}{|l|}{ Pain } \\
\hline & Cutaneous & & \\
\hline & Somatic & & \\
\hline & Visceral & & \\
\hline \multicolumn{4}{|l|}{ Mechanoreception } \\
\hline & Vestibular & & \\
\hline & Rotational acceleration & & \\
\hline & Linear acceleration & & \\
\hline & Proprioception & & \\
\hline & Kinaesthesis & & \\
\hline & Muscle stretch & & \\
\hline & Muscle tension & & \\
\hline \multicolumn{4}{|l|}{ Temperature } \\
\hline & Heat & & \\
\hline & Cold & & \\
\hline \multicolumn{4}{|l|}{ Interoception } \\
\hline & Blood pressure & & \\
\hline & Arterial blood pressure & & \\
\hline & Central venous blood pressure & & \\
\hline & Head blood temperature & & \\
\hline & Blood oxygen content & & \\
\hline & Cerebrospinal fluid pH & & \\
\hline & Thirst & & \\
\hline & Hunger & & \\
\hline & Lung inflation & & \\
\hline & Bladder stretch & & \\
\hline & Full stomach & & \\
\hline \multicolumn{4}{|l|}{ Exteroception } \\
\hline \multicolumn{4}{|l|}{ Magnetoception } \\
\hline \multicolumn{4}{|l|}{ Chemoreception } \\
\hline & Intuition & & \\
\hline & Time & & \\
\hline
\end{tabular}

Figure 4: Classification of the Senses 



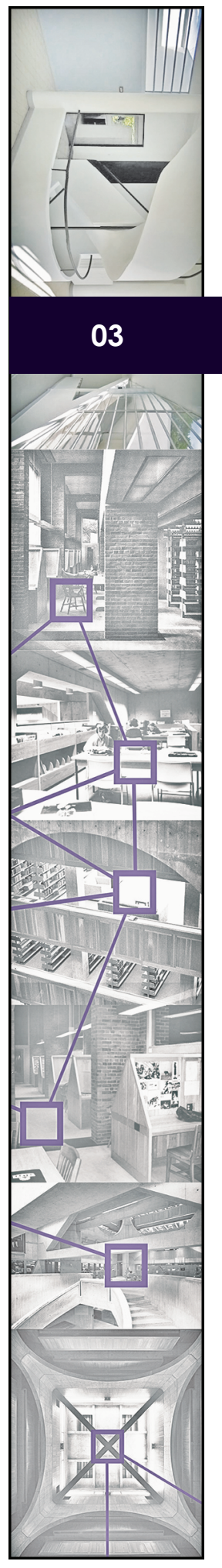




\section{The Lived Body}

"For a building to be motionless is the exception: our pleasure comes from moving about so as to make the building move in turn, while we enjoy all these combinations of its parts. As they vary, the column turns, depths recede, galleries glide: a thousand visions escape."

Valéry, The Method of Leonardo'

One inescapable truth about the lived body, and not simply as an object of contemplation, is its ability to move in the world, perceive spatial qualities, and be a "vehicle" for human choices. Therefore, it provides us with a perception that is informed through recollection and not just the instantaneous impact of external stimuli. ${ }^{2}$ As Steven Holl mentions, it is the "movement of the body as it crosses through overlapping perspectives formed within spaces [that provides] the elemental connection between ourselves and architecture." 3 The body is a subject since it extends beyond the boundaries of the skin to the surrounding world; it is alive; it can move, change, and act with intention. ${ }^{4}$ Even though the word "body" is controversial since it implies stability, it is constantly changing and adapting to its environment. ${ }^{5}$ Bodily movement allows one to perceive and understand the surroundings and therefore forces us to act upon "affordances"; through actions and potential actions, one further understands and engages with the world. The human body, the soma, will generate space through movement

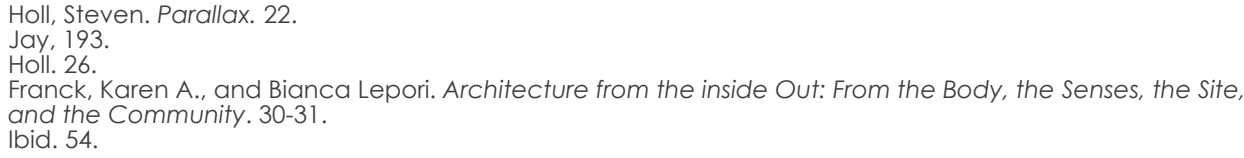


and gives it a particular shape. ${ }^{6}$ Architecture should not merely suggest movement within spaces, it choreographs it and encourages the body to move in a certain way. ${ }^{7}$ The patterns of actions and spatial relationships with the body can serve as an inspiration for the design of corporeal architecture.

Etienne-Jules Marey's works had an incalculable impact on the realization of movement in space. His approach was to record and capture a continuous movement in space through a series of static images on a single plate and from one point of view. ${ }^{8}$ The series of images can be understood as a critique of the static nature of photography for comprehending motion and moreover, a criticism towards understanding space from a single static point. Similarly, Eadweard Muybridge aimed to make time visible in space through capturing frames of a continuous movement. ${ }^{9}$

Gibson categorized bodily movements into two types; he believed some movements accomplish behaviour "in the usual meaning of the term," called performatory or executive, and some movements pick up information, called exploratory or investigative. ${ }^{10}$

Exploratory movements, intentional movement, help us to actively seek sensations. As Hugo Haring, a modern architect, believed "the spatial order of a building should be taken from the order of activities that the building is to house, an order that must be uncovered, not imposed." "I In this approach, spaces will be created to be appreciated on the move and in correspondence to bodily sensations. The intentional movement of the body, then, allows it to discover order and spatial rituals. These movements and rituals are carried out differently by different individuals, based on culture, tradition, and experience. In the works of architects like Alvar Aalto and Lovis Kahn, the purpose of architectural space is not its programmatic function, but to become inspired by human actions while focusing on the connectedness between everyday life and spatial qualities. "In this tradition,

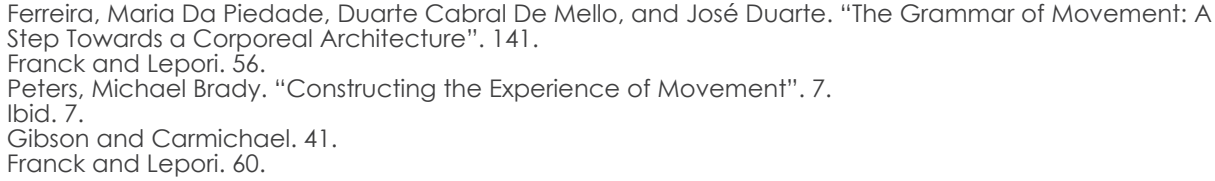


the body is treated as subject, not only as object. It is recognized as the necessary and animate condition for human life, as giving us access to the world."12

In the Library at Phillips Exeter Academy, Louis Kahn drew inspiration from analyzing the activities that were required in the space. Therefore, he focused on the ritual of reading in a library "as taking a book from the dark to the light" 13 to organize spaces. In this context, intentional movement is derived from the function of the building, whereas in some other cases this intention is solely the experience within spaces, similar to the Architectural Promenade.

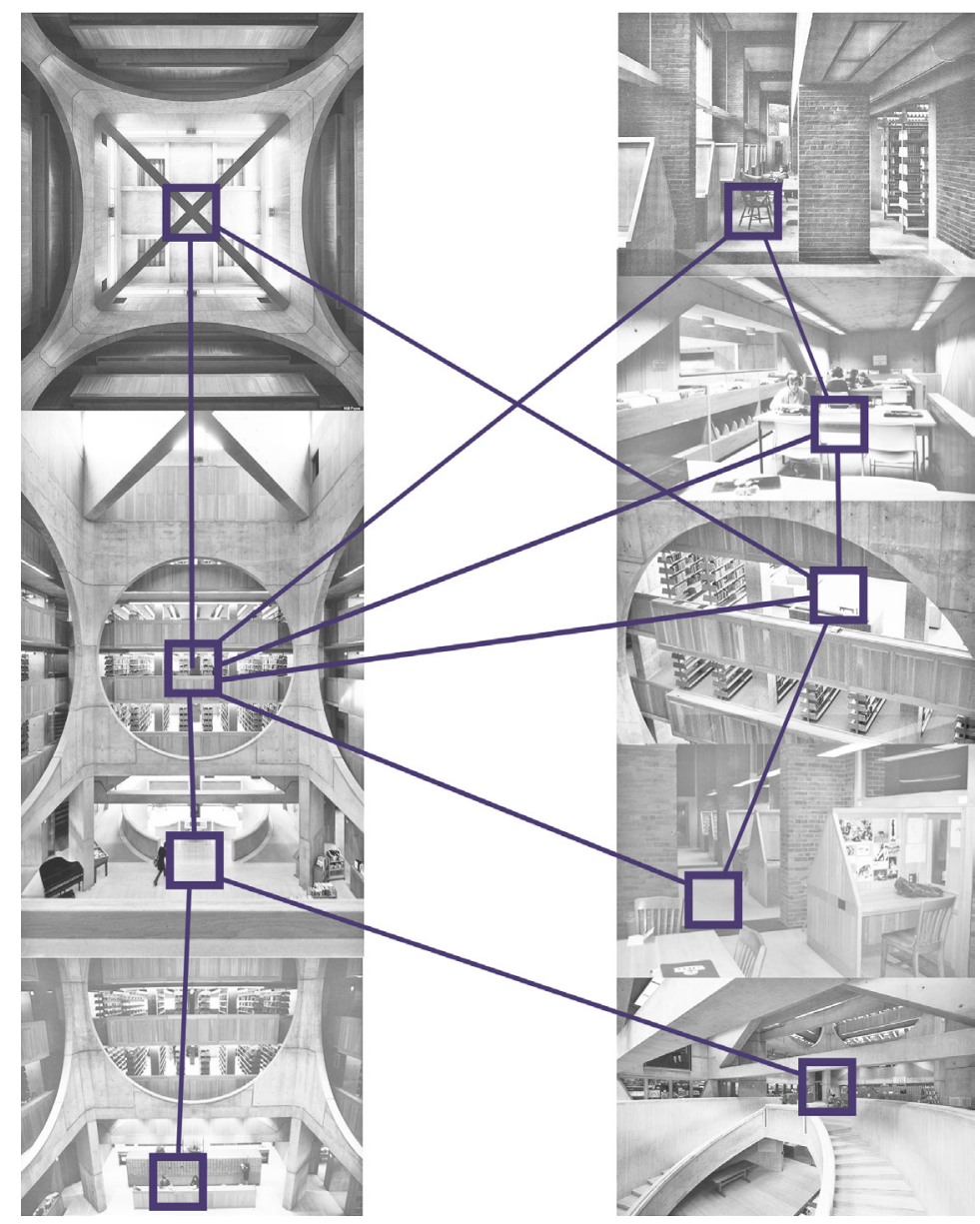

Figure 5: Rituals of Movement in Phillips Exeter Academy Library by Louis Kahn 
The Architectural Promenade was the inspiration behind many of Le Corbusier's efforts to develop space and movement. The Garden City Movement was one of Le Corbusier's motivations behind the Promenade. He was fascinated by this movement since it allowed access to nature while containing various and picturesque routes through spaces. ${ }^{14}$

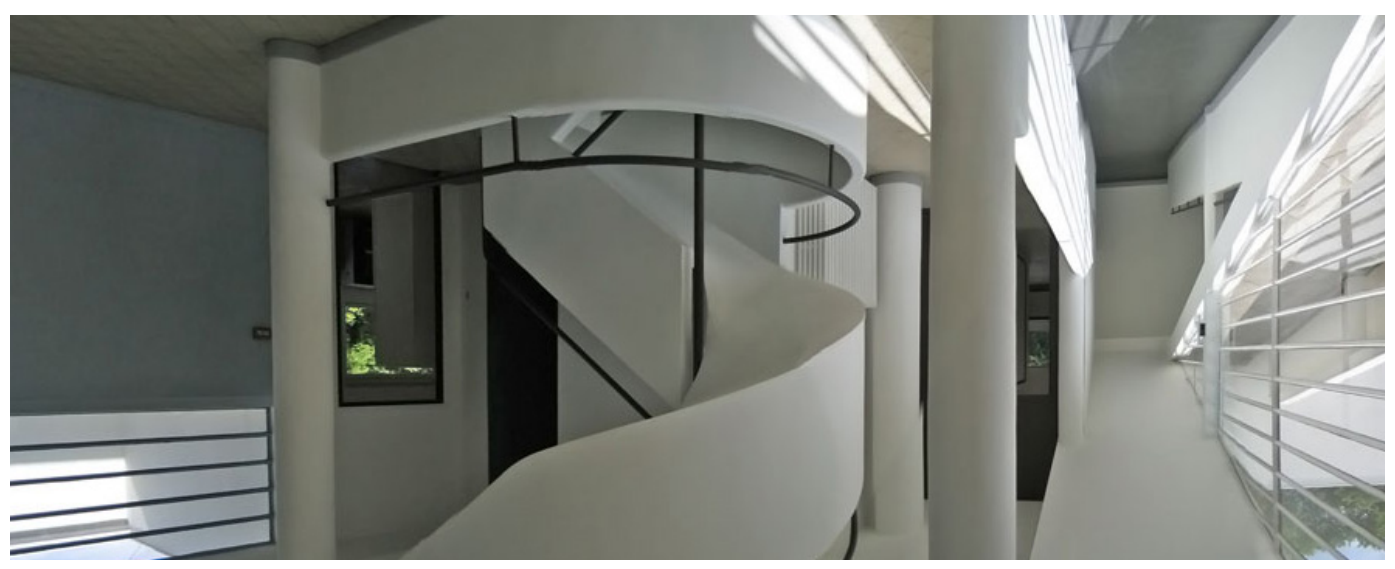

Figure 6: Two Means of Circulation in Villa Savoye

On the other hand, Le Corbusier was also interested in the work of Camillo Sitte, as he was creating curves and surprising pathways to encourage exploration. ${ }^{15}$ However, this approach contradicts his ideology about urban design as he states: "Winding streets are for donkeys, straight streets are for men..."16. In his strategy, he looked at the promenade in terms of frames with depth and therefore each frame became a stop in space, an event or a ritual. ${ }^{17}$ This approach allows the body to perceive spatial qualities to its full potential and discover rituals of space and movement through bodily sensations and actions.

Le Corbusier's narrative path for the Architectural Promenade was;

Introduction (threshold)

Disorientation (sensitizing)

Questioning (savoir habiter)

Reorientation (moving towards the center of gravity)

Culmination (state of liberation) ${ }^{18}$

Le Corbusier. The City of To-morrow and Its Planning. 222.

Samuel. 47

Ibid. 67. 
"The promenade continues. We climb up the ramp from the garden to the topmost level reaching the roof of the house, where the solarium is located. Arabic architecture has taught us an invaluable lesson. It favours walking; it is on foot that we can best see the unfolding of architectural arrangements..."19

Le Corbusier

Bernard Tschumi took another approach by removing the preconceived meaning given to a specific action to concentrate on its special effects and the movement of bodies. ${ }^{20}$ For example, the Manhattan transcripts try to disconnect space, movement, and events from each other to allow for independent comprehension of each and create new relationships along different axes. ${ }^{21}$ This consequently allows space to move away from objectifying bodies with deliberate actions and subjectifies them through their behaviour in different spatial qualities. In this case, the role of the body extends beyond a controlled order, space becomes action and action becomes space. The transcripts use a frame-by-frame approach, suggesting that spaces should be designed in a frame-to-frame manner, similar to cinema. ${ }^{22}$ Le Corbusier and Tschumi both utilized different techniques, the promenade and the transcripts, to create a journey to make spaces appreciated on the move and through rituals of movement.

In order to achieve choreographed rituals within space, circulation plays a vital role in creating connections between spaces and guiding people through rituals. As a part of the circulation, a pathway establishes the sequence and distribution of spaces and therefore organizes the choreography of the narrative. The entrance is the beginning of this ritual, and the degree of its separation or interconnection can be determined based on its punctuation and its relationship to the following space. Therefore, the pathways become the main structure of the ritual while giving order to the narrative. ${ }^{23}$ Similar to giving a speech, the user is carried through the sequence of spaces/sentences each made up of spatial qualities/words. ${ }^{24}$

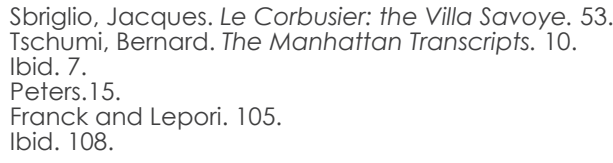




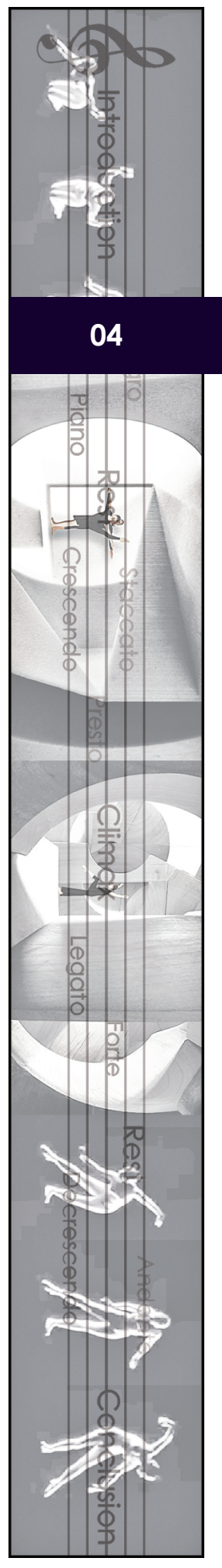




\section{The Analogy of Dance}

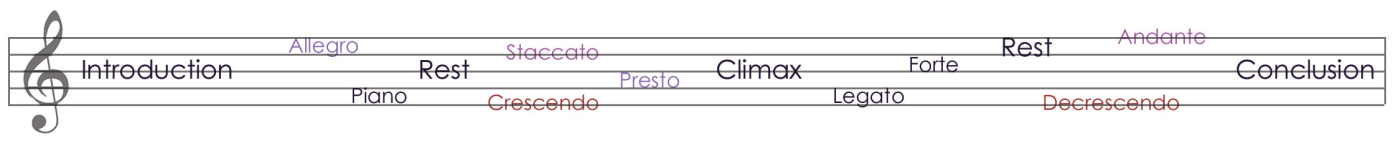

The body in space is a common characteristic between architecture and dance, as they both rely on the movement of the human body through space over time. Dance, aside from its visual component, is fundamentally related to kinesthesia and is appreciated not only through the eyes but also the entire body.' The body moves through a sequence of spaces, through spatial rituals of conflict and engagement, with a "phrased" function and purpose. ${ }^{2}$ The movement of the body becomes the source of interpretation and manifests the experience of spatial qualities in both architecture and dance. The person who choreographs a dance routine is not the originator; they are the facilitator to script the movement. The dancer gets to improvise the movement based on their interpretation in modern dance. The movement has an essential influence on how we experience space and consequently the impact it has on our body. Architecture allows the user to interpret and perceive spatial qualities over time by choreographing movement within the "haptic space."

Similar to dance, the journey through space has to have a beginning and an end; it has to have rises and falls, with a climax. ${ }^{3}$ It requires a strong dynamic, sometimes low tempo and sometimes a crescendo, sometimes tension and sometimes

Daly, Ann. Critical Gestures: Writings on Dance and Culture. 10

Humphrey, Doris, and Barbara Pollack. The Art of Making Dances. 67.

lbid. 69 


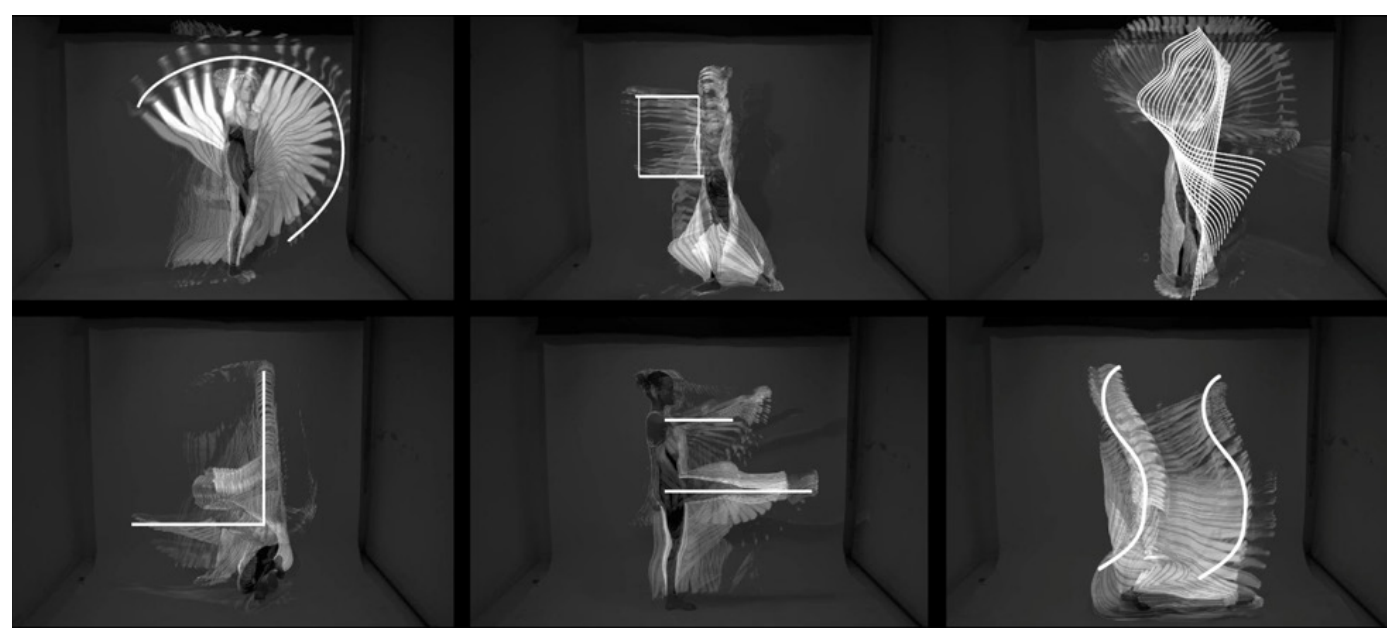

Figure 7: The Body's Movement in Space

relaxation. ${ }^{4}$ It also has to be considered that "too much sharp wears out the nervous system, and too much legato puts everybody to sleep."5 George Kupler, an American art historian, was obsessed with "the space between events"; the actuality and the pause when nothing is happening which is an occurrence in both dance and spatial sequence; the thresholds between sensations are achieved through transitions and are felt as we enter or leave sensory spaces; the change is either subtle or abrupt. ${ }^{6}$ A corporeal architecture will create haptic spaces that are naturally immersive and will induce and choreograph body movements in space utilizing their spatial qualities. It also allows the user to perceive the space, subjectively, over time by moving through it, while shaping his habitation through this movement. This type of architecture will have a greater impact on memory since it is more appealing to the body. 


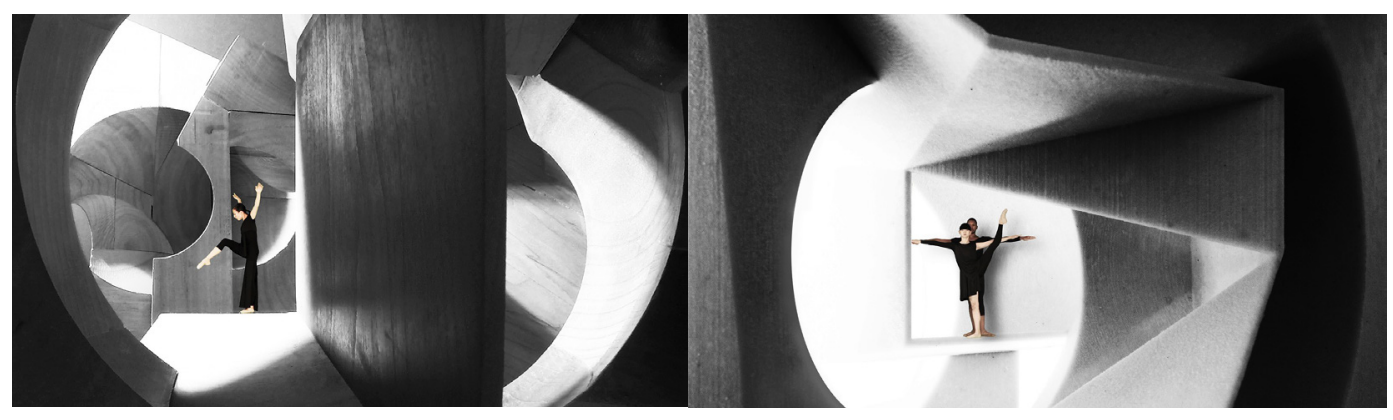

Figures 8 \& 9: Dance for architecture - Tesseracts of Time

Steven Holl is one of the few contemporary architects who is exploring the idea of experience through movement in architecture. His collaboration with the choreographer Jessica Lang in Tesseracts of Time celebrates the passion for space and time both in architecture and dance. ${ }^{8}$ However, Holl and Lang express the contrast between the two in terms of time, referring to architecture as one of the arts of longest duration, while dance can be a quick performance. In an interview with Archinect, Holl claims: "I feel that architecture-the movement of a body through space - that's the instrument of the measurement, space." In this approach, the movement of the extremity through the movement of the body can serve as a boundary for space. In this condition, the short duration of dance is in juxtaposition with the permanence of space.

Holl, Steven. "Steven Holl Architects." Tesseracts of Time - A Dance for Architecture. Lynch, Patrick. "Steven Holl and Jessica Lang's 'Tesseracts of Time' Explores the Relationship Between Architecture and Dance." 


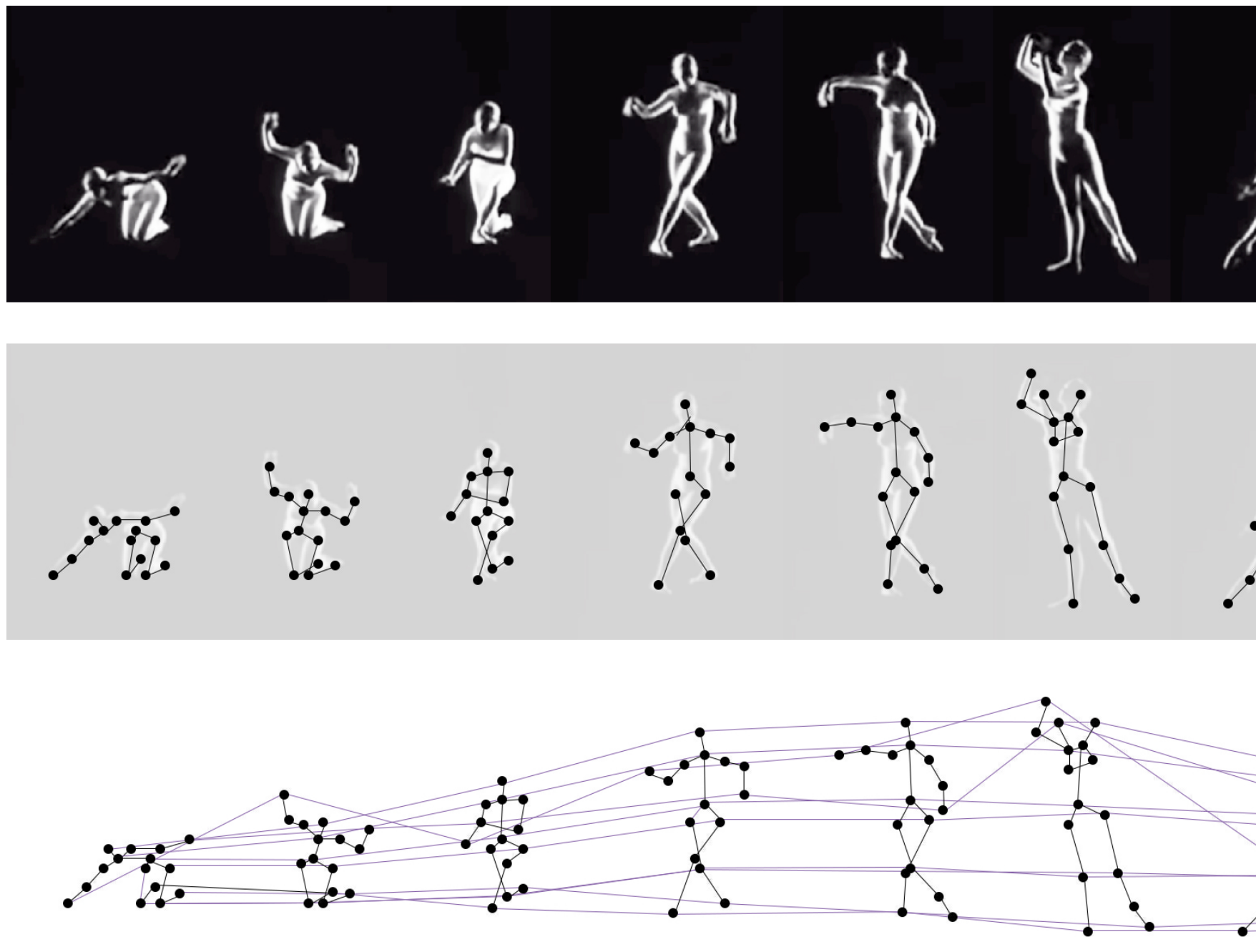




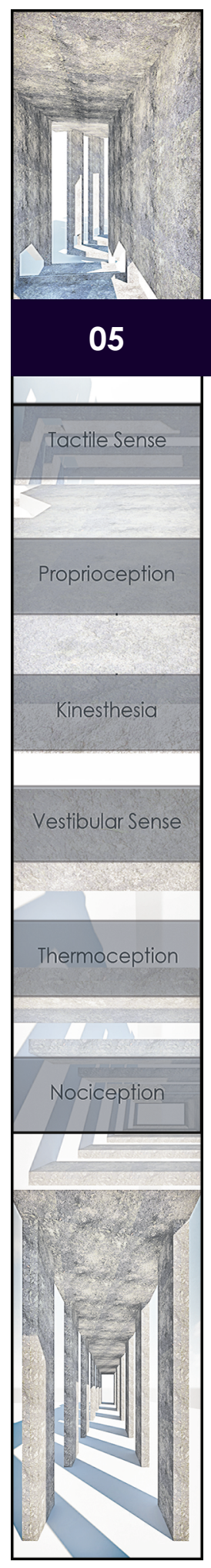




\section{Haptic Perception}

The haptic system, also known as the somatosensory system, is composed of receptors and processing centres to produce haptic perception. Haptic perception is not only about the two-dimensional act of touch; it extends to the three-dimensional exploration of space through proprioception, kinesthesia, the vestibular sense, thermoception (temperature), and nociception (pain).' Proprioception is the awareness of the position of one's body; kinesthesia refers to the sensation of movement or strain in joints of one's body. This information is communicated to the brain by sensors in muscles, tendons, and joints. The vestibular sense, located in the inner ear, grounds this understanding to the outside world by informing us about "our body's orientation relative to gravity and lets us know if we are being moved through space by an outside force or being propelled by our own muscles." 2 Therefore, the vestibular sense interacts with the information provided by proprioception and kinesthesia. Further investigations have added thermoception (sense of temperature) and nociception (sense of pain) to these haptic systems. ${ }^{3}$

The embodied perception of space, haptic spatial perception, is a result of all these senses working together in this complex system and is achieved through active exploration by a moving subject. "Proprioception and particularly kinesthesia seem important for the appreciation of architecture as an environment through which we move and orient our bodies, maintaining a dynamic equilibrium."4 Proprioception

lbid. 87

Shusterman. 226. 
is hugely dependent on kinesthesia since the proprioceptive sense is achieved through moving the body. On the other hand, kinesthesia is experienced through proprioceptors that keep one informed of the actions taken by the muscles and feedback from the surroundings, which enables one to move his or her body. Moreover, proprioception cannot be understood without exteroception since we are aware of our bodies through the interoceptive and exteroceptive stimuli. There is a strong interrelationship between thermoception, tactile sense, and nociception since they all get information from exteroceptors that are located in the skin. ${ }^{5}$

Haptic space enhances and motivates haptic spatial perception, by prioritizing the concept of spatiality as the main means of spatial articulation and therefore enhances our bodily experience of spatial qualities through engagement and interaction.

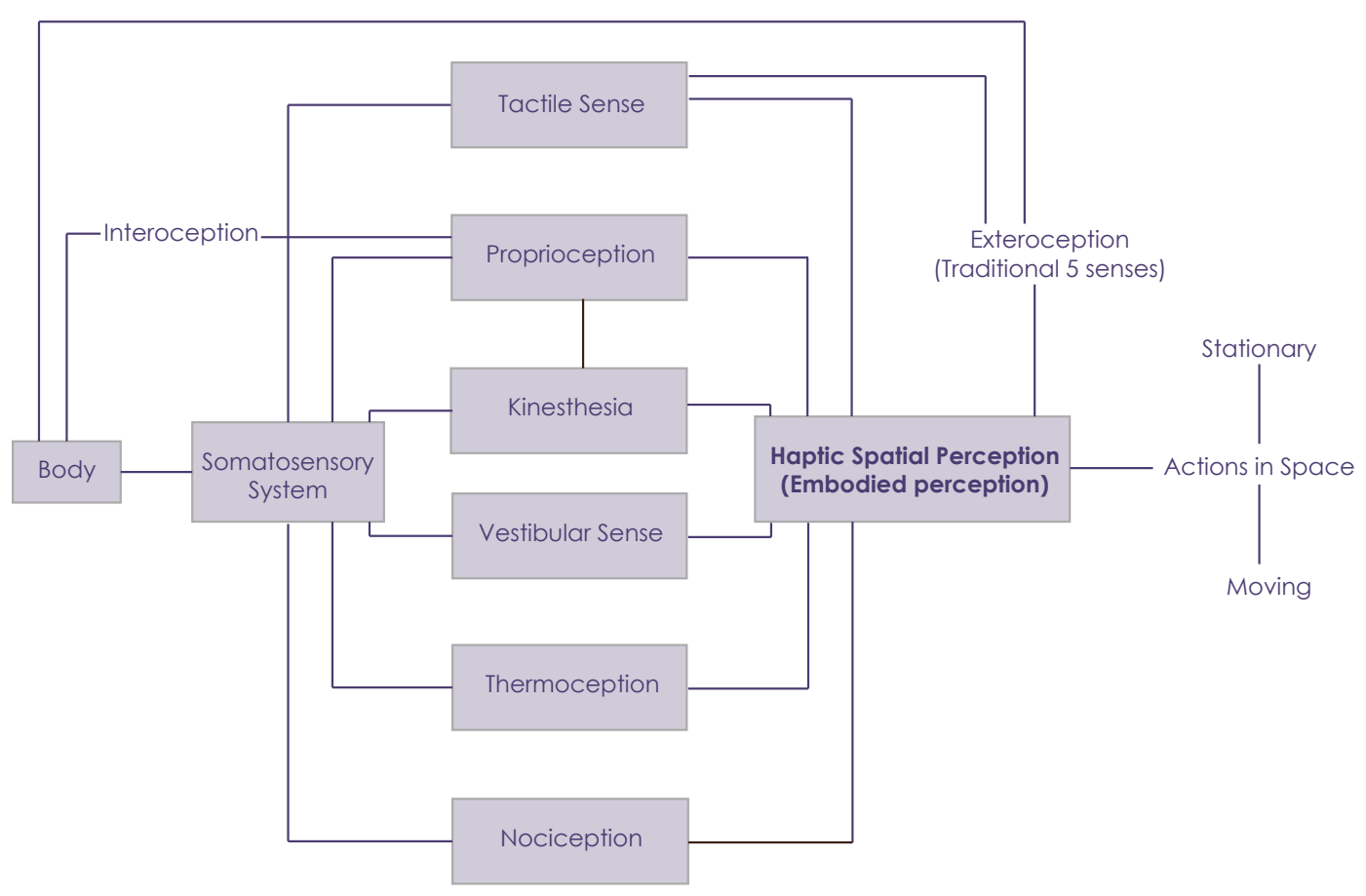



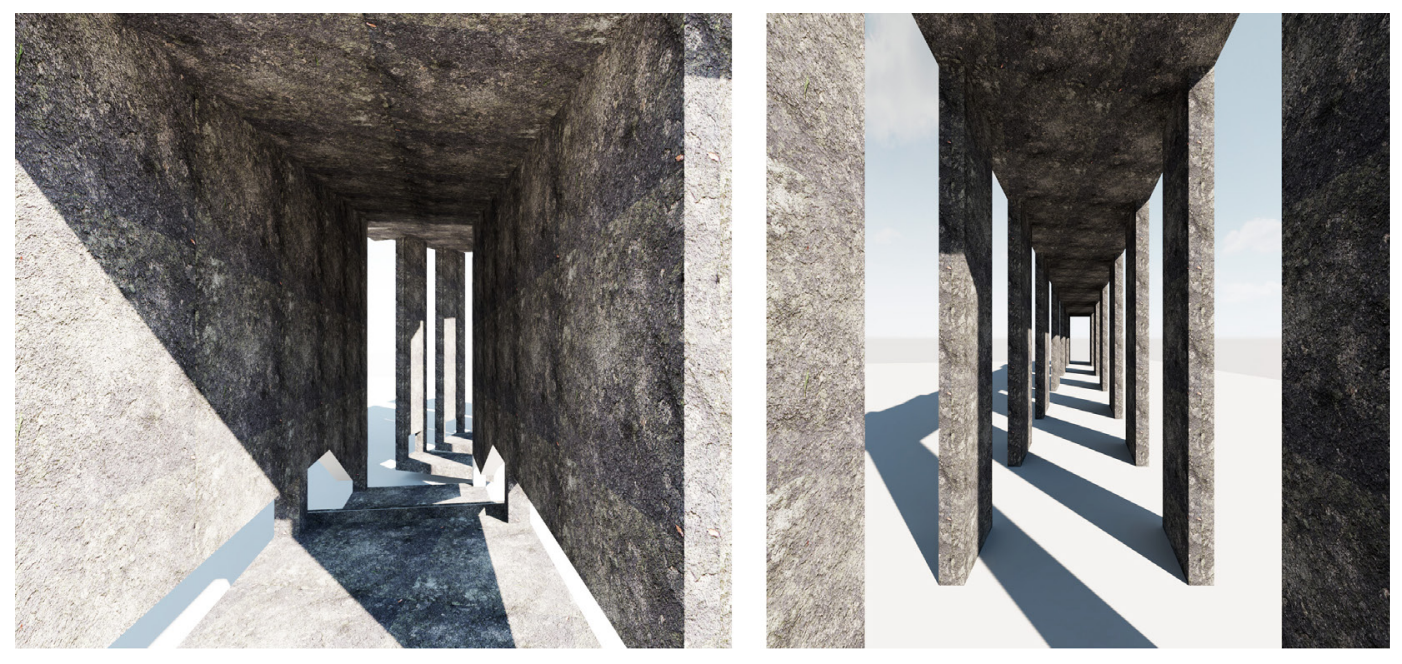

Figures 12 \& 13: Repetitive Elements Exaggerating the Sense of Movement

\section{Kinesthesia}

Haptic space has a strong connection with the eyes. "We experience places differently if we can visually see the forward progression of the path the body is traveling so that we can take the route in larger conceptual leaps and understand the choices available."6 The somatosensory system also is strongly impacted by visual perception, since vision is a fundamental way that our body experiences movement. The retina has three parts: the macula providing central vision; the fovea providing fine detail of colour and pattern; and the peripheral retina being sensitive to movement.? Through kinesthetic movement as one moves through space, the body receives messages from its surroundings, integrating information from the sense of movement and vision to stabilize perception. The visual field consequently expands and contracts as one moves through space, providing visual cues. ${ }^{8}$ Due to all these parts working simultaneously and differently, the perception of space differs for each individual and people define their personal and social distances differently. The interplay between vision and kinesthesia is also evident where repetitive and regularly spaced elements, such as trees or pillars, can exaggerate the sense of movement; therefore, this visual perception causes drivers to slow down when entering a tree-lined road. Increasing the number of

Erwine. 104.

Nussbaumer, Linda L. Human Factors in the Built Environment. 128.

T.Hall. 68. 
visual impacts slows people down and reducing them encourages them to speed up. In other words, crowding can be reduced by cutting down on the movement in the peripheral field of vision, and it can be increased by maximizing it.?

\section{Proprioception}

The word "touch" often refers to the sense of proprioception and many other sensory systems such as pain and temperature. Some theorists have even concluded that proprioception is a different version of the sense of touch that includes the sense of kinesthesia and the sense of joint position. ${ }^{10}$ This latter sense, the "forgotten sense," allows us to position ourselves and formulate our actions in space. The sense of where body parts are in relation to one another, without the need to use our eyes or hands, is transmitted through our proprioceptive sense. The body and its movement are embodied in proprioception since actions are not possible without the sense of proprioception. Physiologists describe proprioception as the perception of the position of the body, especially in movement." The kinesthetic sense receives information from both the exteroceptors (the external data) and proprioceptors (the internal data) to produce actions. The body reacts to the exteroceptors, "attractions and aversions", to create kinesthesia while proprioception executes the movement.

\section{Vestibular Sense - sense of balance and orientation}

The vestibular sense is responsible for balance and spatial orientation; it allows us to keep our bodies upright when jumping or changing positions. The feeling of dizziness after spinning in circles for a short time is due to the detection of movement by the vestibular sense. Any spatial quality that requires movement of the body is impacting the vestibular sense to a low degree, while any spatial quality that challenges movement and balance impacts it to a higher degree.

\section{Thermoception}

The body feels different temperatures and movements of air when it moves

lbid. 72.

Brown, David. "The Forgotten Sense - Proprioception". 22.

Admin. "Proprioception Interaction: Upgrade Human Perception with Prothesis." 
through architectural space. Temperature also has a great impact on how a body experiences crowding; ${ }^{12}$ cooler temperature makes crowded spaces more tolerable. Therefore, thermoception has a significant influence on how people define their "personal distance." People tend to move when the heat of a crowd increases and people's thermal spheres overlap. In addition, the radiant heat of materials aid in navigation and how people move in space. As Edward T. Hall mentioned: "a brick wall on the north side of a given street was identified as a landmark to the blind because it radiated heat over the total width of the sidewalk." 13

\section{Nociception}

Pain is the conscious experience of a feeling of unpleasantness that can manifest as a result of nociception, both physically and mentally. Therefore, any spatial quality that is exaggerated to the extreme can present an unpleasant experience and therefore be considered as painful. For instance, a room with an extremely uneven floor or a hallway that is too narrow to move through are examples of a painful experience.

$12 \quad$ T.Hall. 57. 


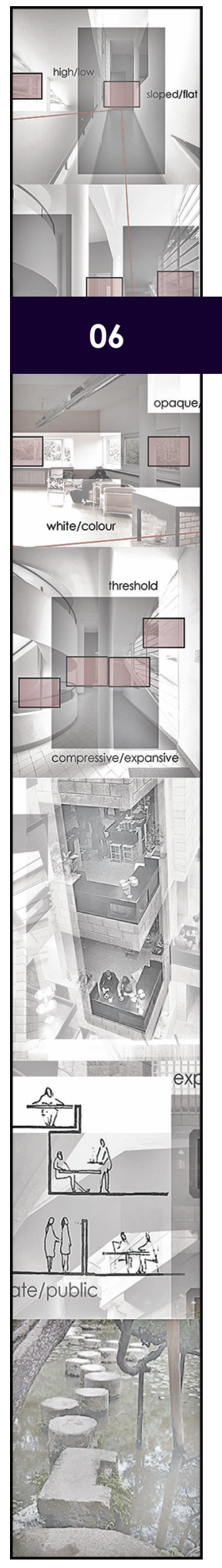




\section{Spatial Qualities}

The concept of spatiality can support or diminish the power of the body to act in space. These actions are subjectively determined based on spatial opportunities which are understood through haptic perception; these opportunities have an impact on our bodily decision to move or not to move. "The concept of field acknowledges [the] autonomous existence of the material world, of its qualities, which are not the result of passive accidents, but of active, interrelating forces." Therefore there is no isolation since everything is a part of this interrelating field. Our personal field resonates with the fields of spaces around us. The kind of atmosphere that is created by these fields in a space choreographs the movement and actions of bodies. "In memorable experience of architecture, space matter and time fuse into one single dimension, into the basic substance of being that penetrates the consciousness." 2 Carlo Lodoli indicates that the role of the architect is to demonstrate through tangible signs the intangible that operates in the tangible. ${ }^{3}$ The tangibility of materials in space can create spatial perceptions that become an intangible entity for each individual.

The body in space interacts with the spatial qualities and makes decisions for its actions based on the way it perceives the totality of space. It can decide to stay stationary or decide to move; while moving, it can discover and encounter new opportunities in space. The following concepts -- attractions and aversions, parallactic space, and perilous space -- are used to explore possibilities embedded within haptic space and discover the interconnections between haptic perception, somatosensory senses, vision and consequently bodily movements.

Franck and Lepori. 88

Holl et al. 37.

Frascari, Marco. Monsters of Architecture: Anthropomorphism in Architectural Theory. 33. 
Body in Space $-\begin{gathered}\text { Body-Space } \\ \text { Interactions }\end{gathered}-$ Decision - making $-\begin{gathered}\text { Bodily Movements } \\ \text { (Actions) }\end{gathered}$

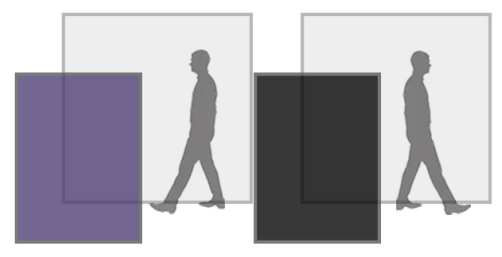

Attractions and Aversions

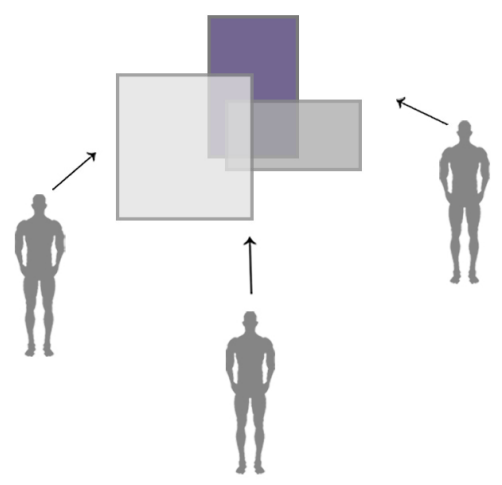

Parallactic Space - parallax

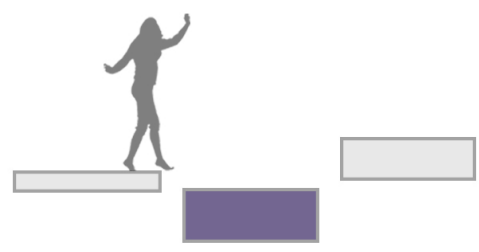

Perilous Space - taking risks

Figures 14-16: The Three Research Concepts

Followed by an introduction to each concept, analysis was conducted through a series of case studies to identify the spatial qualities related to each concept. Through this study, spatial qualities that impact the bodily senses and enhance the experience of space were selected and then categorized into the three concepts of attractions and aversions, parallactic space, and perilous space. 


\section{Attractions and Aversions}

These spatial events, aside from creating a rich experience, can create attraction or aversion based on one's perception of them; we do not just act in space, we act upon it. "The phenomenon of attraction or aversion depends on both the characteristics of the sensory phenomena and the internal conditions of the perceiver. This dependence of perception on interior conditions is known as alliesthesia." " These attractions and aversions in space choreograph the movement of people through exploratory kinesthetic movement.

One element that can strongly impact spatial qualities and act as an attraction or aversion is light. Light can bring many different spatial qualities to an experience such as brightness and darkness, reflection and glare, privacy and exposure, and many others. The most important quality it introduces to space is the passage of time, animating the space. These qualities can give character to space and their changing, either gradually or suddenly, can create an attraction and force our body to move forward, or create an aversion by evoking mystery and danger. ${ }^{5}$ The eyes are attracted to areas that are bright, high in contrast, and with strong patterns. Too little contrast and light makes an area uninteresting, while too much of it creates a distraction. ${ }^{6}$
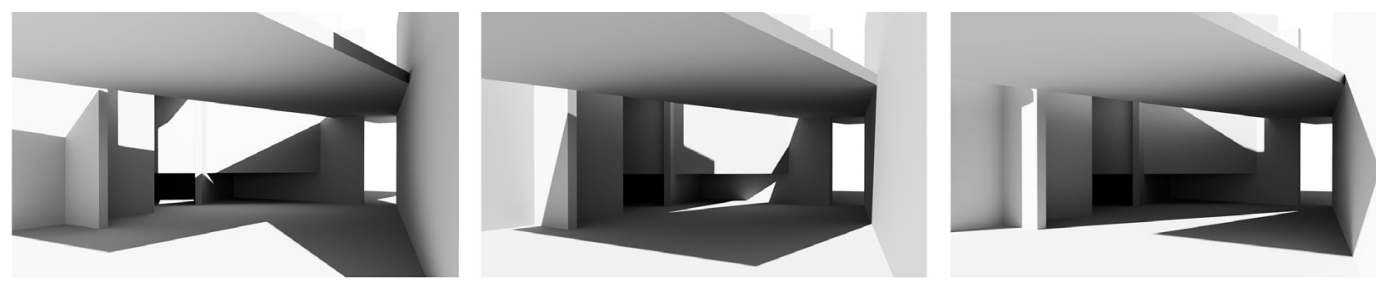

Figure 17: Play of light, animating space 
The ability of light and shadow to create space has always fascinated humanity. It can provide an opportunity for designers to create smaller spaces within a larger space, without using physical walls. ${ }^{8}$ It can also be utilized to either emphasize or dematerialize form and materials. When it is evenly illuminated, it can reinforce the form of a space, and when it does not follow the spatial layout, it can dematerialize the structure of the space. ${ }^{9}$ These characteristics can either attract or repel bodily sensations. It is also essential in creating spatial hierarchies, as well as directing movement. Since people are phototropic, they tend to move toward areas with more light since light adds a directionality to the spatial experience. ${ }^{10}$ On the other hand, darkness gives texture to the light-space, from small-scale pockets of shadows on materials and larger scale negative spaces."

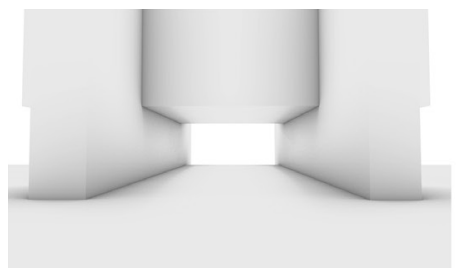

Form - straight parallel lines

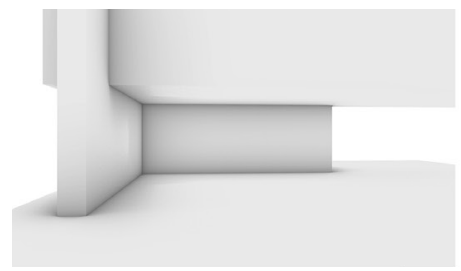

Form - straight perpendicular lines

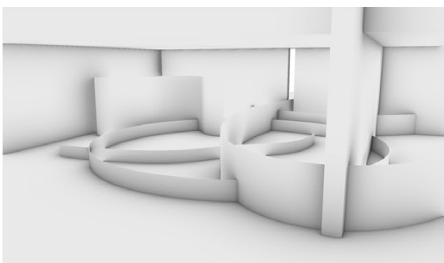

Form - curved lines

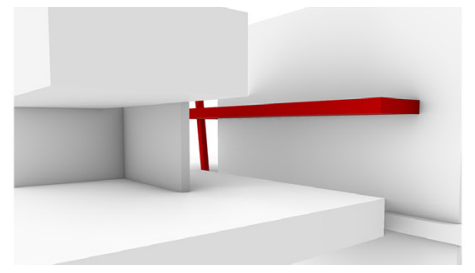

Colour

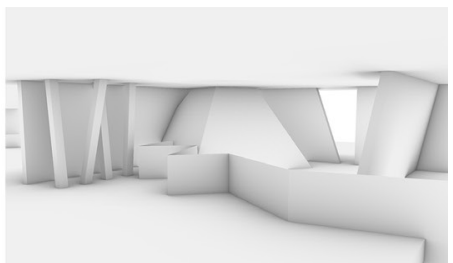

Form - angular lines

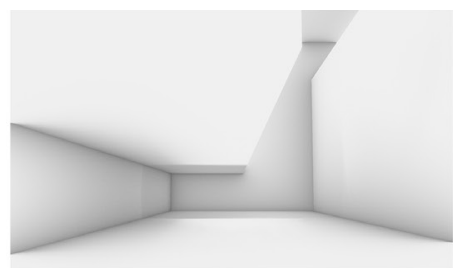

Scale

Figure 18: Examples of Spatial Qualities

lbid. 67.

lbid. 53

lbid. 63

lbid. 65

Ibid. 65. 
Architecture unifies foreground, middle ground, and background to connect visual experience with spatial details. ${ }^{12}$ In today's architecture, tactile space perception has been dulled since buildings have shifted more towards synthetics and materials have lost their texture and essence. ${ }^{13}$ This sensibility can enhance nearness and intimacy. Through haptic perception, one can comprehend tangible properties such as geometric qualities, dimension, form, scale and proportions/composition; surface qualities, such as texture and colour; and material qualities, such as smell, temperature. reflectivity, acoustics, and weight. Haptic perception puts "our body in contact with the materials as they change in texture, form, and density." 14 These variations in texture invite us to engage with surfaces or move away from them; they can be a signal to transition between spaces or direct the pattern of movement through space. There exist intangible qualities of the environment that impact the haptic perception of space when exposed through openings, inside/outside relationships and proxemics. These qualities include light, humidity, temperature, smell and noise. The effect of all these spatial qualities in activating bodily sensations is exaggerated when they come in binaries.

Holl et al. 41.

Ibid.91

Erwine. 91. 
Case Study 1

Calgary Public Library - Snøhetta - 2018 - Calgary, Canada ${ }^{15}$

The curved geometry of the interior of this library creates a dynamic space that attracts people to the circulation spaces. The contrast between the warm wood circulation areas and the cool stone flooring used in program areas create a unique spatial condition. The expansive atrium, in relation to the compressive entrance and the interior pathways, create a contrasting journey and allow for overlook into different areas of the building. 


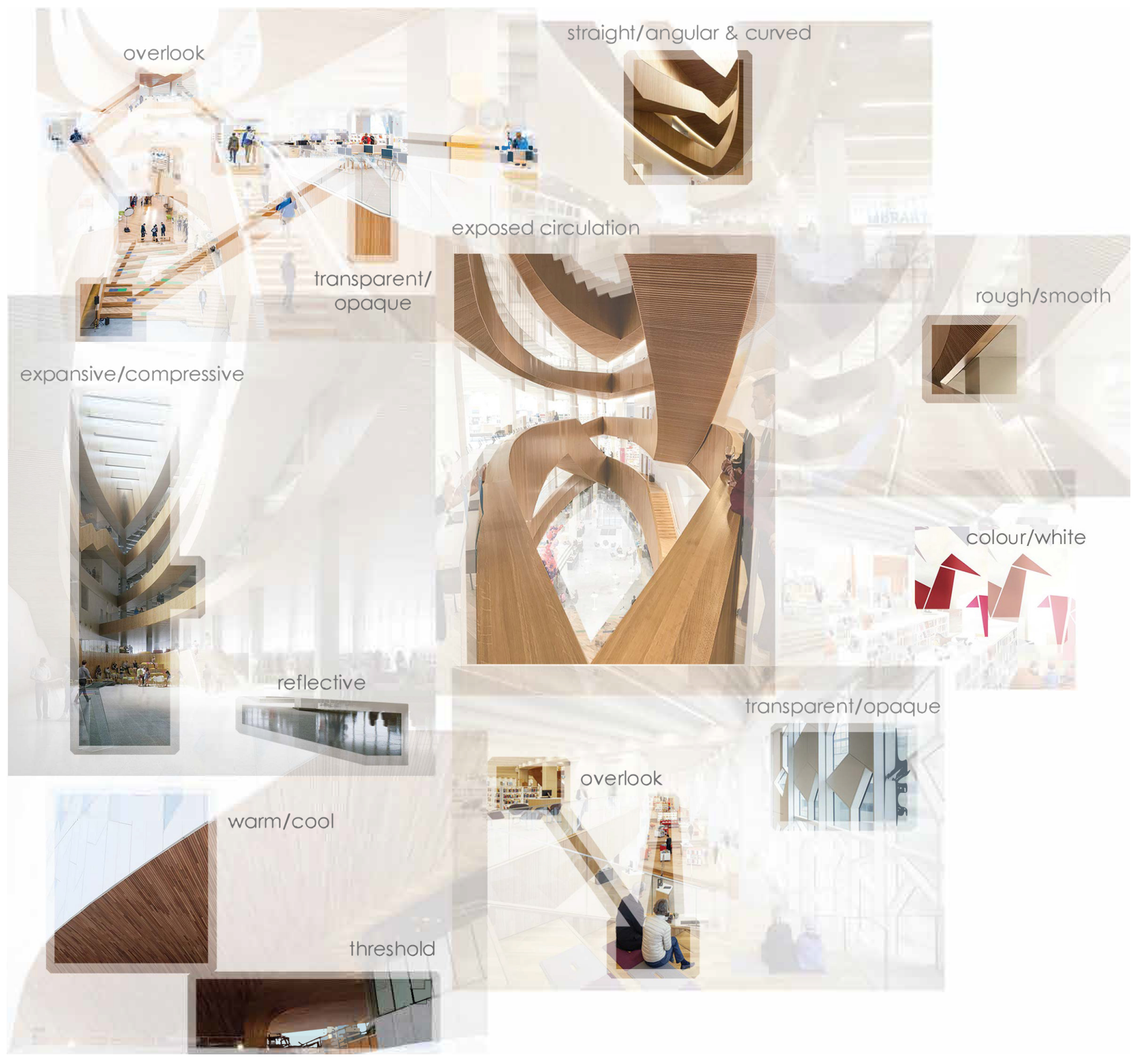

Figure 19: Analysis of Spatial Qualities in Calgary Public Library 
Case Study 2

New Halifax Central Library / Schmidt Hammer Lassen Architects + Fowler Bauld \& Mitchell - 2014 - Halifax, Canada ${ }^{16}$

The central atrium in this library contains an exposed central staircase that instead of providing a continuous movement throughout the building, interrupts movement by changing direction at every level. The use of a complex structure for the staircase allows for an overlap of its sections, consequently maximizing overlook into different areas. The skylight on top of the atrium animates the space throughout the day by creating light and dark spaces. 


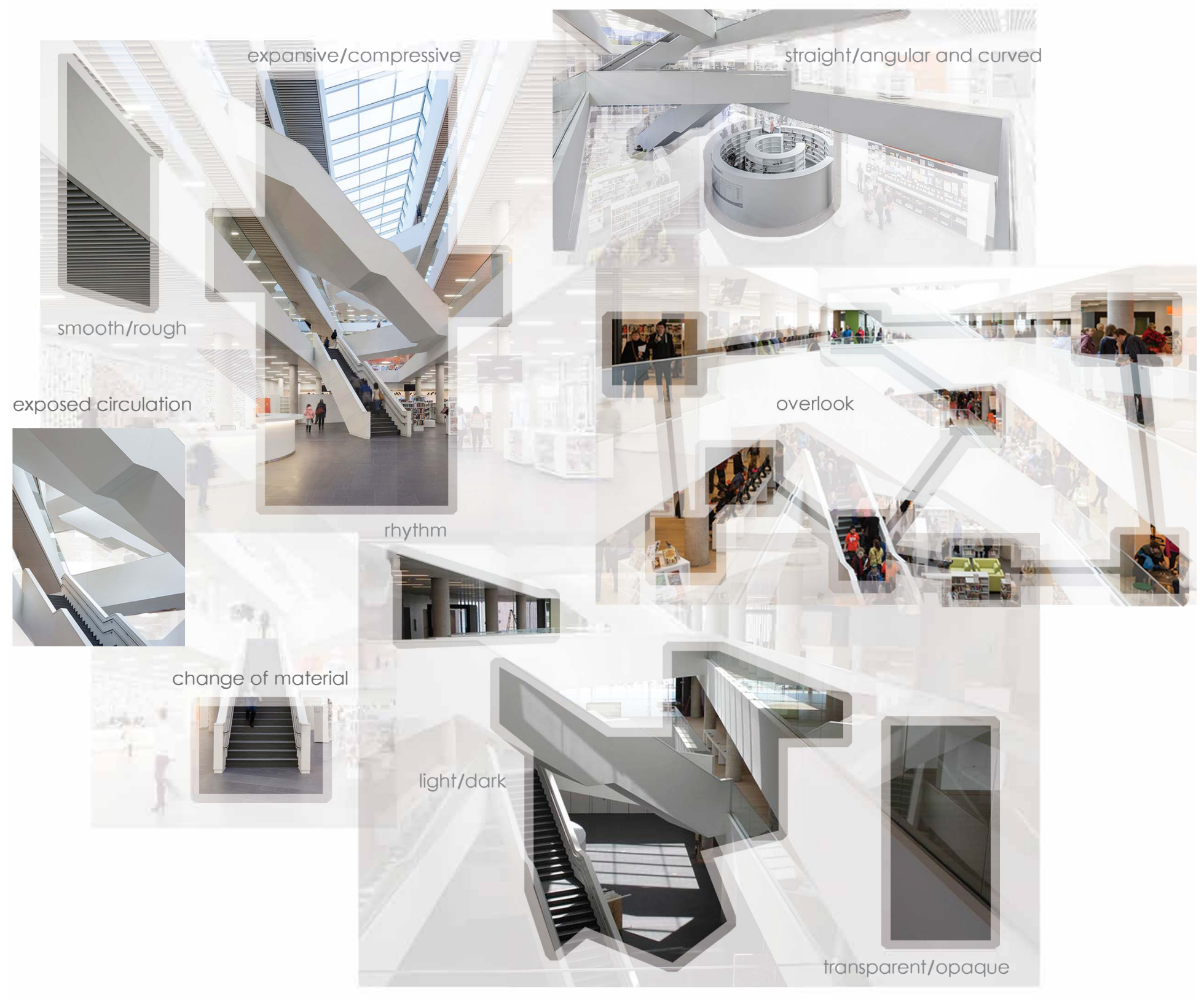

Figure 20: Analysis of Spatial Qualities in New Halifax Central Library 
Case Study 3

Phillips Exeter Academy Library - Louis Kahn - 1972 - Exeter, United States ${ }^{17}$

The rhythm of columns on all sides of the structure conceals the entrance and, therefore, creates a sense of ambiguity. Compared with the previous projects, this library hides the main circulation stairs in the corners and makes the visitors wander. The expansive central space allows for visual connection to different areas, while not providing an obvious way to get to them. The atrium space soaks in natural light during the day due to the clerestory at the top of the atrium, exaggerated by the expansiveness of the space. The use of wood and brick for more private spaces, contrasts with the concrete by creating a sense of warmth for visitors. 


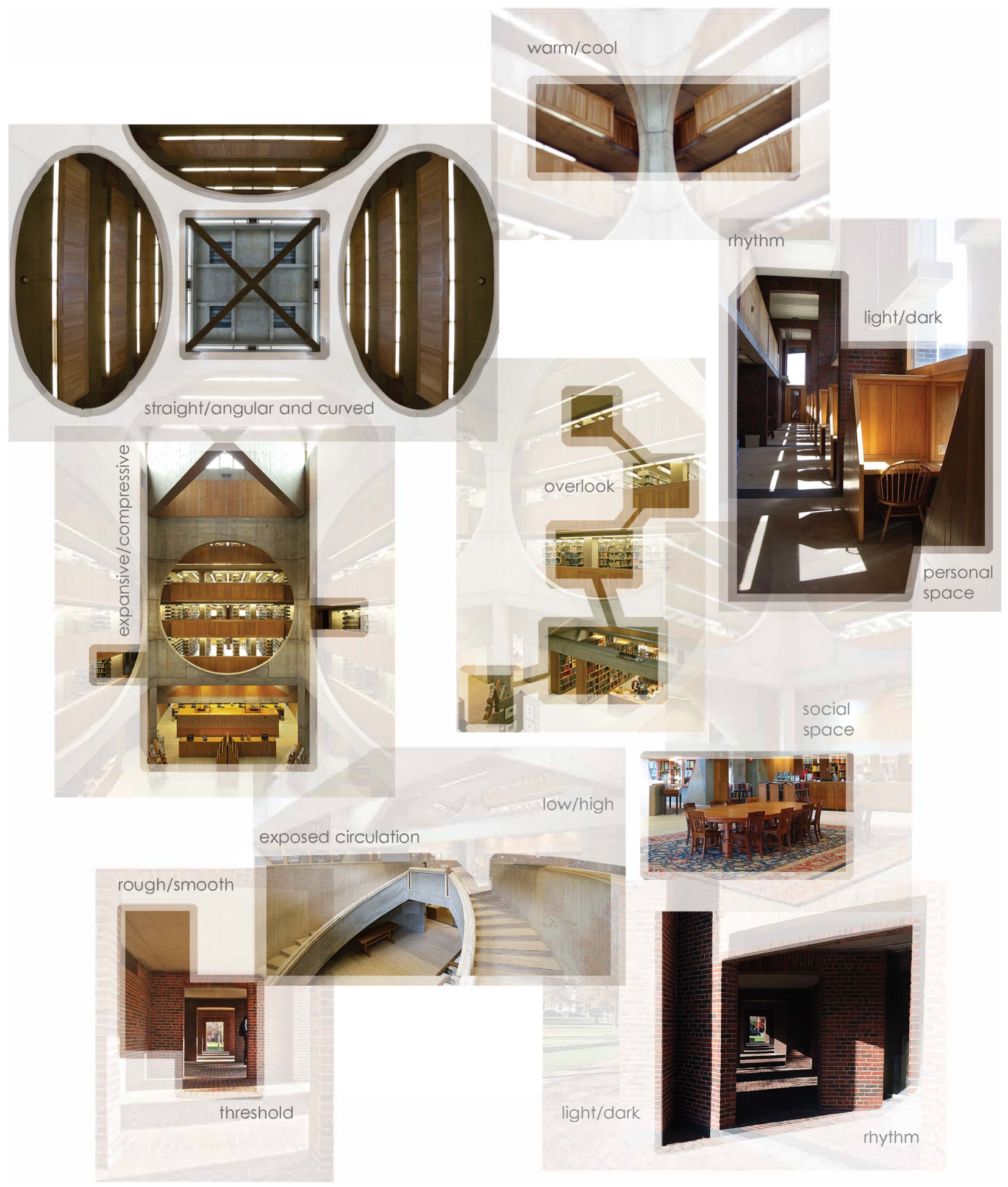

Figure 21: Analysis of Spatial Qualities in Phillips Exeter Academy Library 
Case Study 4

Toronto Reference Library - Raymond Moriyama - 1977 - Toronto, Canada ${ }^{18}$

The Toronto Reference Library provides visitors with two very diverse experiences. The first is a faster means of circulation via a glass elevator that provides views from different levels to the expansive atrium. The other experience is through an interrupted staircase with a switchback pattern of movement, offering a slower transition in space. This experience is punctuated with constant change between the narrow paths of the staircase and wider pathways between stairs. It also constantly disorients the body by forcing a change of direction at every landing. Red, used for flooring of circulation spaces, contrasts the white used on vertical surfaces; this contrast is considered to be an important feature of this project and gives it a unique character. The change in materiality of the flooring also creates contrast while on the move; the soft feeling of carpet for the program areas versus the harder feeling of the staircases strongly impacts the experience. 


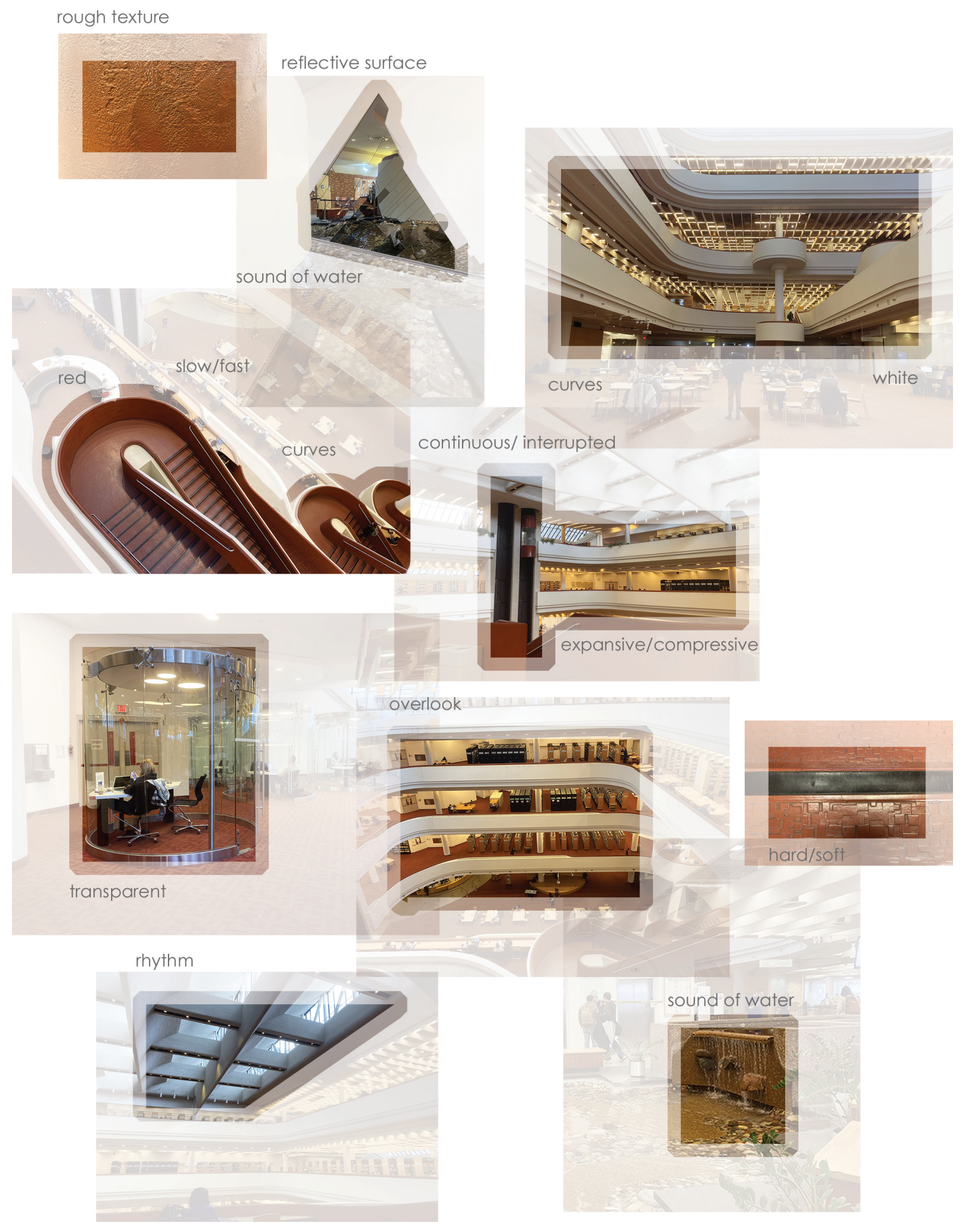

Figure 22: Analysis of Spatial Qualities in Toronto Reference Library 
Case Study 5

The Therme Vals - Peter Zumthor - 1996 - Vals, Switzerland ${ }^{19}$

Peter Zumthor used attractions and aversions in Therme Vals to guide people through space. This project by Zumthor engages bodily sensations to create a corporeal experience within the space. This "playground for the senses" reflects the bodily experience of spatial qualities, especially materiality and light, to provide opportunities for interaction. The spatial experience of the building starts from the arrival by a gentle slope leading people down to the locker rooms. There are many transitional spaces that allow visitors to experience and see different spaces at the same time. Each volume of space explores a different sense, using elements such as colour, scale, temperature, smell, and the water itself. The experience at night is drastically different since most of the lighting emerges from the water. Zumthor introduced contrasts in the formal elements of the project in terms of how the skin feels the environment, such as the hard feeling of rocks, the softness of water, and varying temperatures. For instance, the fire bath, a compressed space, is adjacent to the outdoor bath, an expansive space, so the body feels the contrast between compressed and expanded. From the other side, the fire bath is adjacent to the ice bath, where the body senses the drastic temperature difference. ${ }^{20}$ 


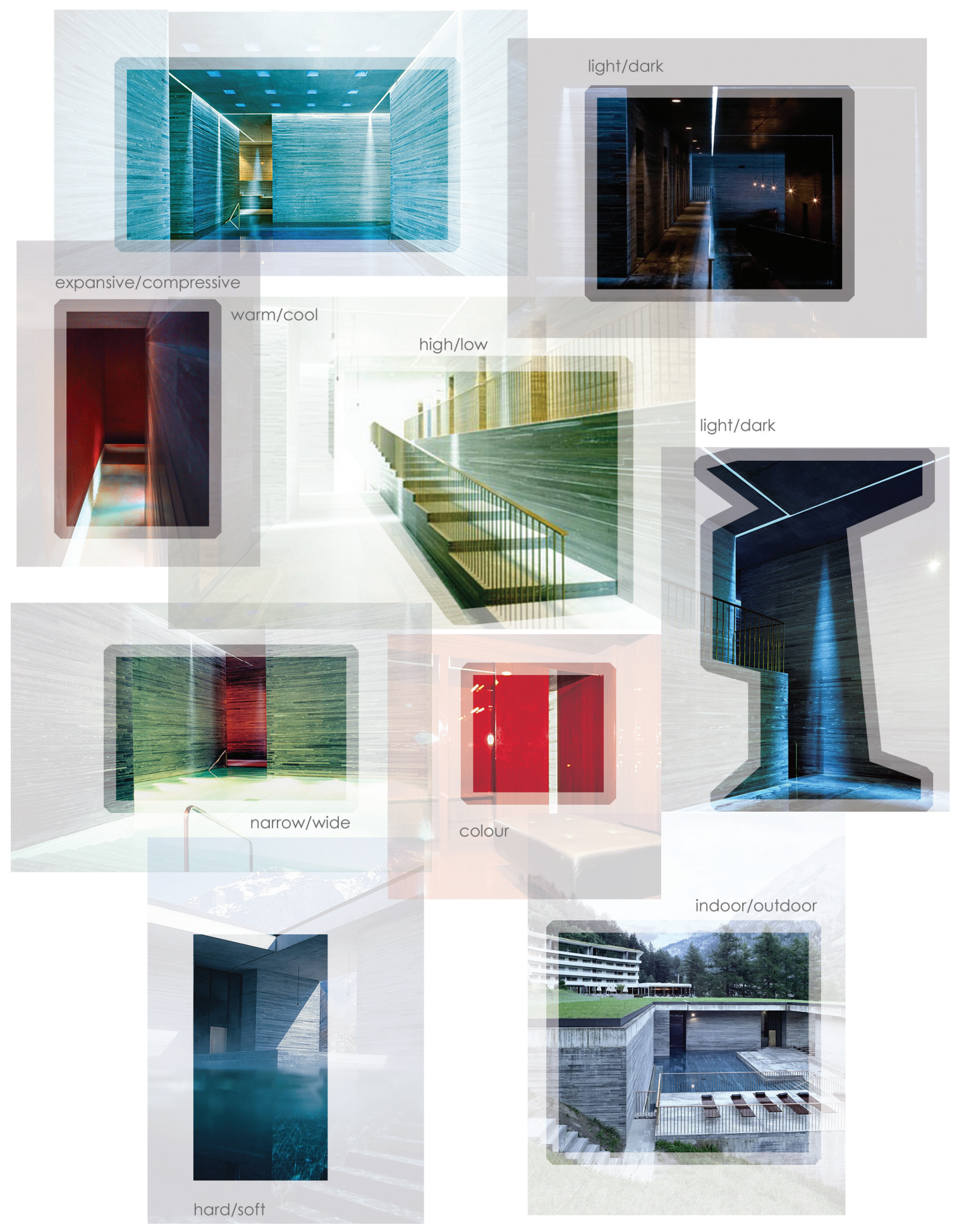

Figure 23: Analysis of Spatial Qualities in Therme Vals 
Case Study 6

Chapel of St. Ignatius - Steven Holl - 1997 - Seattle, United States ${ }^{21}$

In the chapel of St. Ignatius, at the University of Seattle, each volume of the building offers different qualities of light, corresponding to a part of the Jesuit Catholic religion. The central concept was "seven bottles of light in a stone box," referring to the tilt-up method of construction. ${ }^{22}$ The rectangular part is referred to as the stone box while the skylights are the seven bottles of light. Light projecting into each area defines a physical and spiritual condition. Most of the interior light sources are arranged in juxtaposition with their complementary colour. The result of this play of light is a glowing interior that changes the visual mood during the day. Other significant features of this chapel are the use of unique materials such as the honey onyx tabernacle, a tree branch, and beeswax-coated walls and a sanctuary lantern with leaf and feather imprints. Each vessel of light corresponds to the function of the space it projects into. As one moves through the spaces, the experience created by the projected light changes from one condition to another and therefore heightens sensitivity of the experience. ${ }^{23}$

Minner, Kelly. "AD Classics: Chapel of St. Ignatius / Steven Holl Architects."

Ibid.

Seattle University. "Seattle University." Virtual Tour - Chapel of St. Ignatius. 


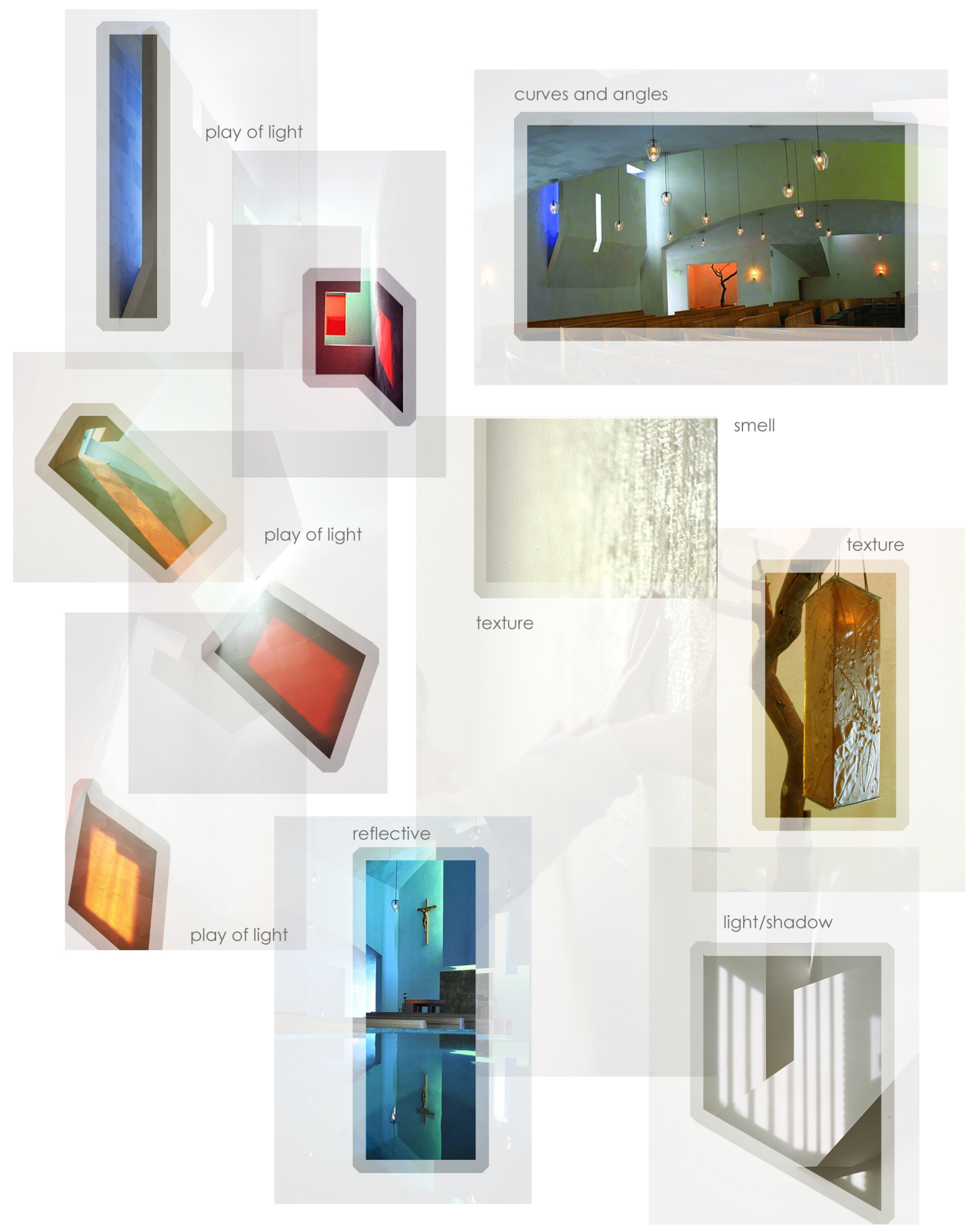

Figure 24: Analysis of Spatial Qualities in Chapel of St. Ignatius 
Case Study 7

Centraal Beheer - Herman Hertzberger - 1972, Apeldoorn, Netherlands²4

Centraal Beheer was designed to be an office building with 1000 articulated single units in sixty cubes, connected by over-passes..$^{25}$ Repetition of a single spatial unit allowed for an independent structure that is flexible to be interpreted based on need, making a contrast between fixed units and flexible programs. The more public spaces are designed to allow for visual connection, using shorter walls and transparency, while the private spaces use higher walls and opaque surfaces to minimize interactions. The expansive central space allows for visual connection to the more compressed spaces around it. The main staircase is not a central feature of the project and is hidden; this was done to emphasize the rhythm of the units.

$24 \quad$ AHH. "Centraal Beheer Offices, Apeldoorn." 


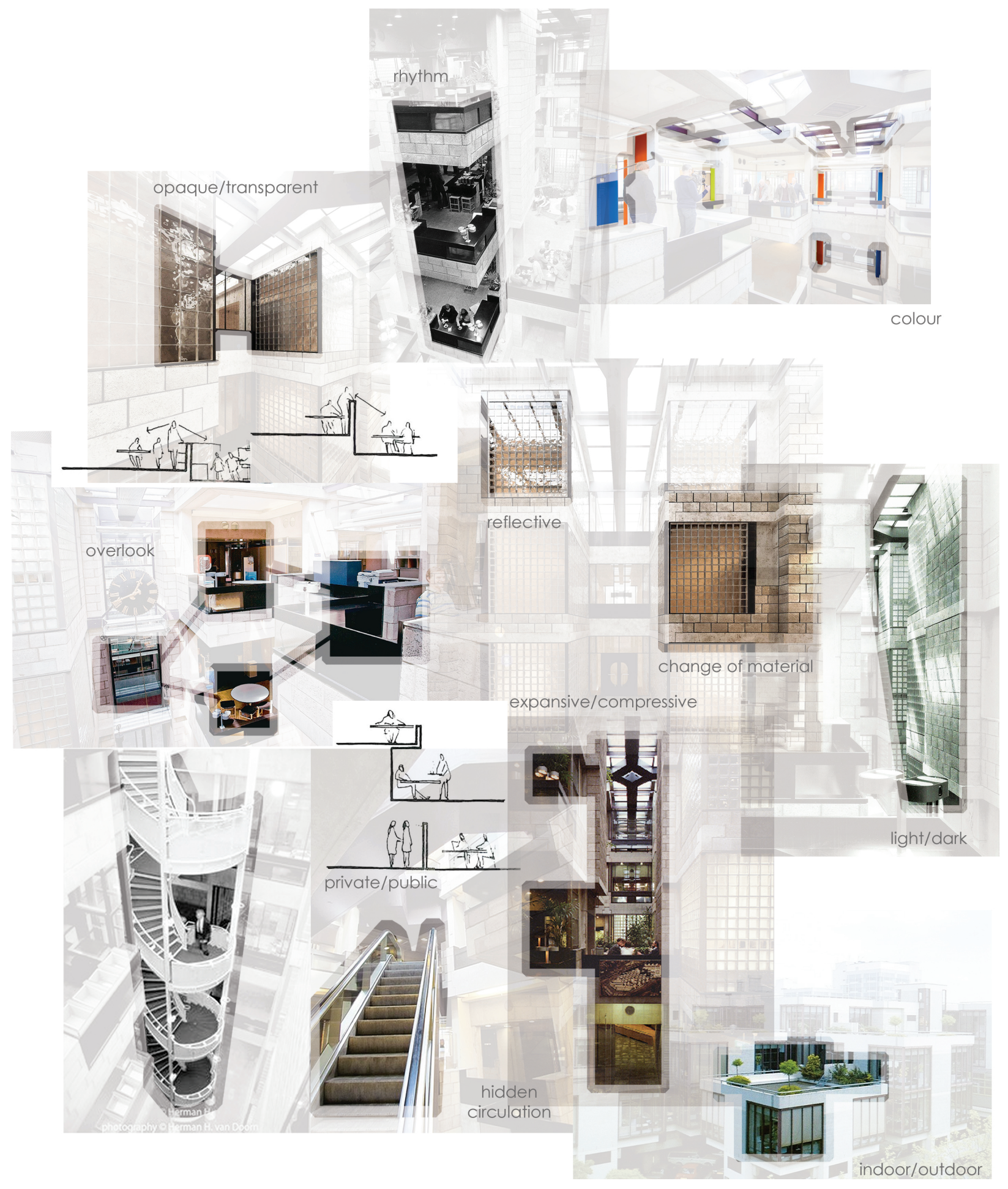

Figure 25: Analysis of spatial qualities in Central Beheer 
Case Study 8

Amazon Spheres - NBBJ - 2018 - Seattle, United States²6

The Amazon Spheres, a glass-enclosed workplace, are the new Amazon headquarters filled with diverse plants and trees. ${ }^{27}$ The main purpose of this project is to blur the boundary between inside and outside by designing an atmosphere that is equally beneficial for both people and nature. The juxtaposition of office spaces, commonly indoors, and green spaces, habitually outdoors, creates a sense of ambiguity between inside and outside. There are many changes in the floor height creating a feeling of compression on the higher levels and an expansive feeling on the lower levels. The transparency of the façade and its spherical quality also aid in blurring the indoor-outdoor divide.

26 Tapia, Daniel. "Amazon Spheres / NBBJ."

Ibid. 


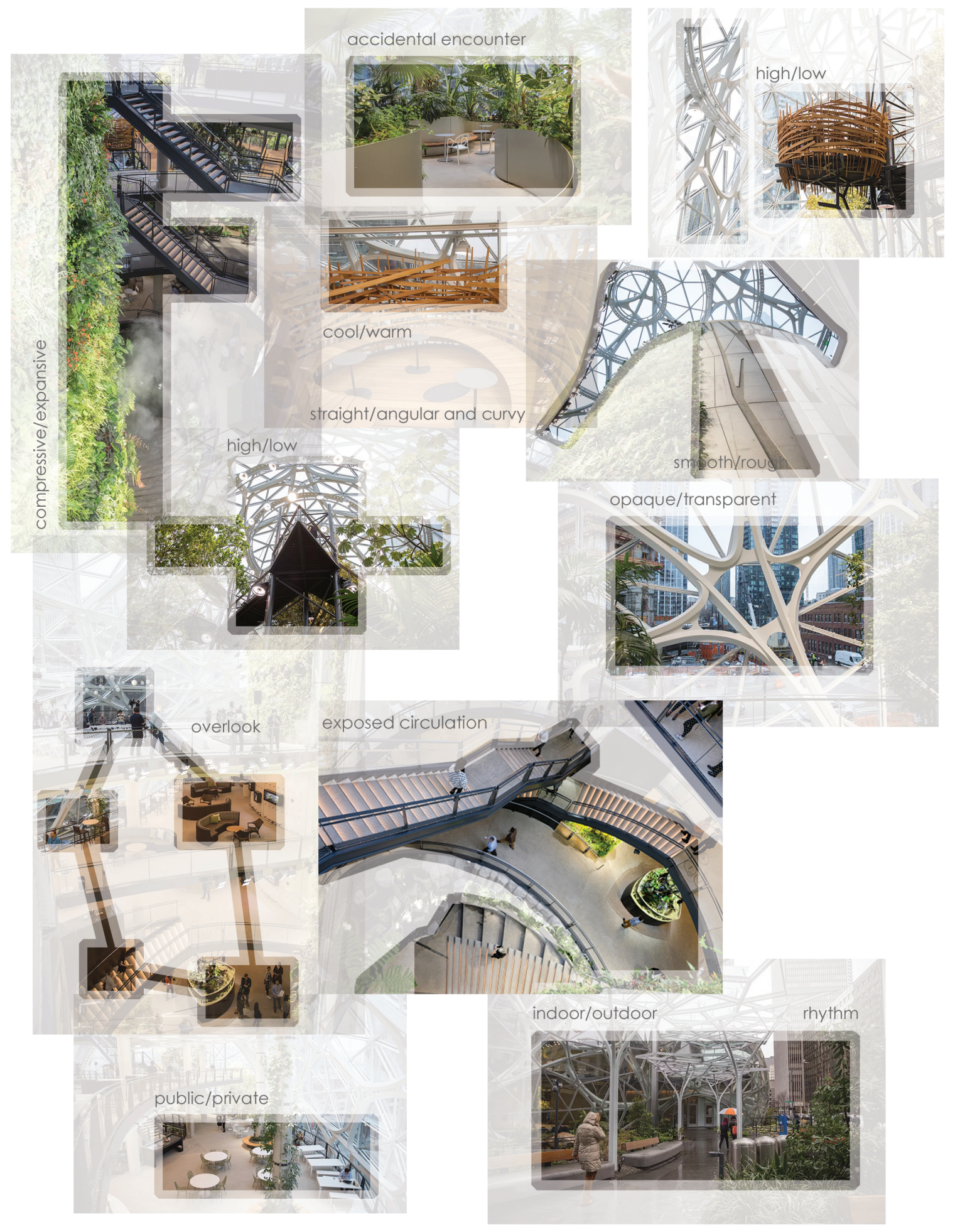

Figure 26: Analysis of Spatial Qualities in Amazon Spheres 
Case Study 9

Bioscleave House - Arakawa + Gins - 2008 - East Hampton, New York ${ }^{28}$

In order to reverse aging, Arakawa and Gins designed a house that promotes physical activity. They believe that heightening body awareness and challenging the senses are helpful in the process of aging. ${ }^{29}$ The main architectural elements of this house are sloped and uneven floors, random and complicated composition, bright and bold colours, and out of scale elements including the unreachable windows and encapsulated rooms. The randomness and arrhythmic quality of the space create a sense of discomfort, described as nociception in somatosensory terminology.

28 Mather, Lindsey. "The House of Our Dreams is for Sale in East Hampton, New York."

lbid. 


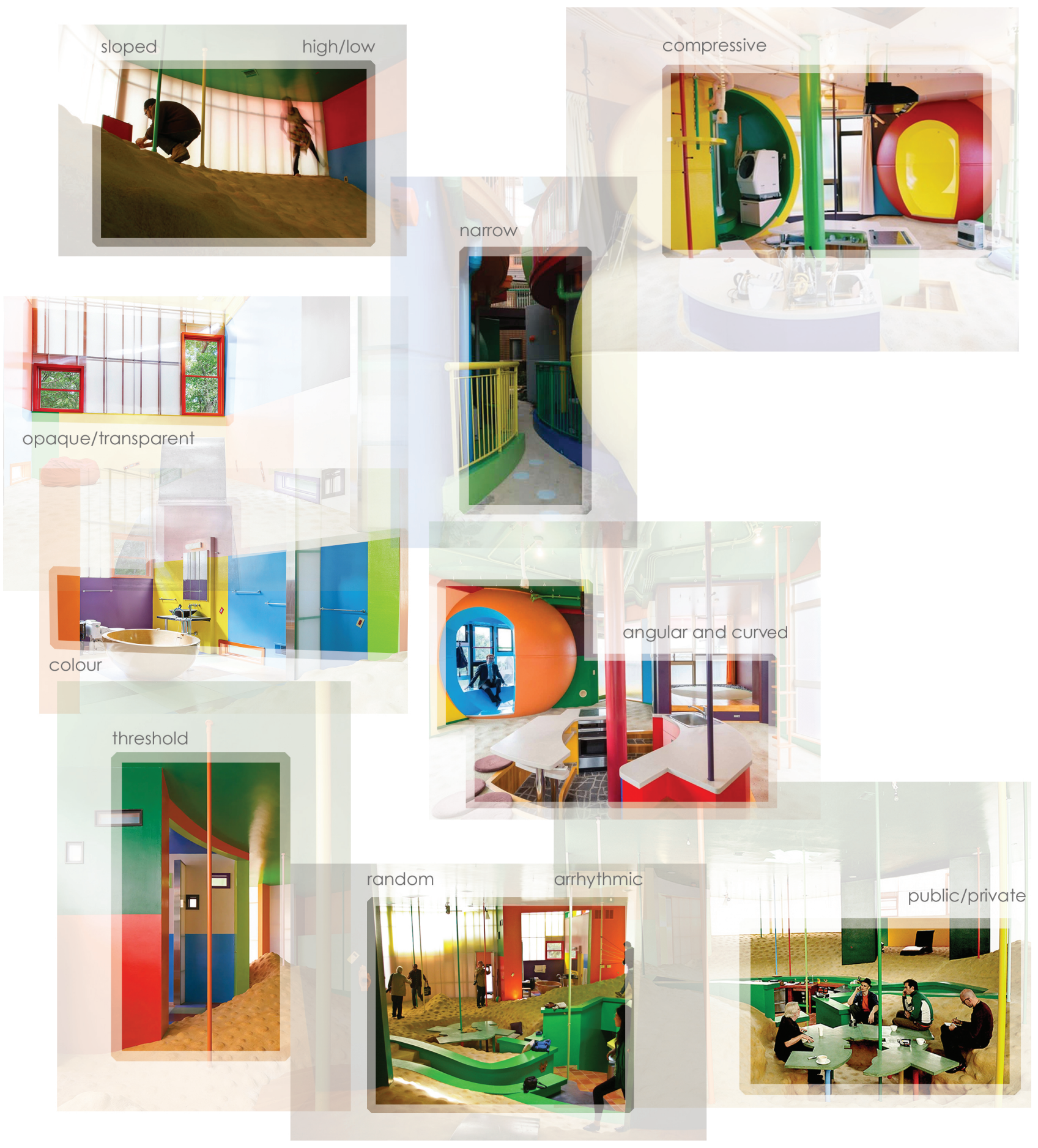

Figure 27: Analysis of spatial qualities in Bioscleave House 
Case Study 10

The Joseph L. Rotman School of Management - KPMB - 2012 - Toronto, Canada ${ }^{30}$

The primary spatial quality in this expansion to the school of business at the University of Toronto is the juxtaposition of black and white versus bright pink. The atmosphere of the building is very neutral and dark in some areas due to the use of black and white for all the program spaces. Once one enters the triangular staircase, the bright pink of the handrails grabs the attention and creates a vibrant sensation. Since the staircase is the only element in the building with this bright colour, it acts as an attraction to invite people to explore the building. 


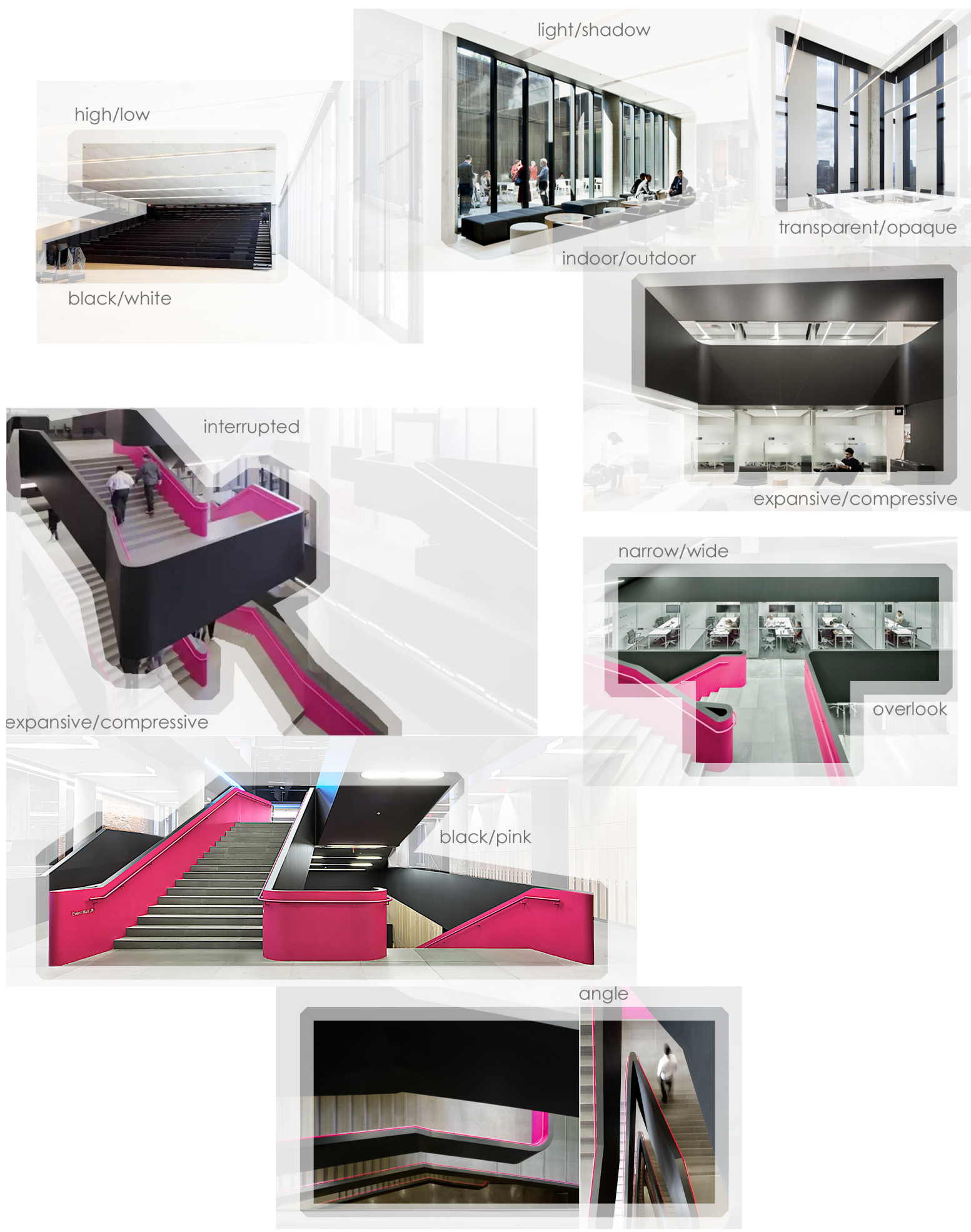

Figure 28: Analysis of Spatial Qualities in Rotman School of Management 


\section{Parallactic Space}

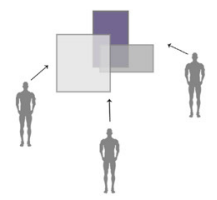

Peter Collins referred to the concept of parallax as an element in architectural composition that focuses on the connection between kinesthesia and vision. ${ }^{31} \mathrm{~A}$ shift in the position of a body does not only change the optical axis, but also the background and consequently the relationship between objects in space. Steven Holl referred to this phenomenon as the "apparent horizon", that is formed based on the movement of the body through space determining its own interpretation of space..$^{32}$

A

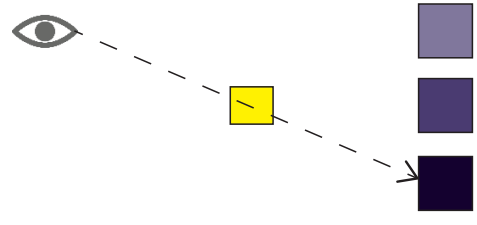

B
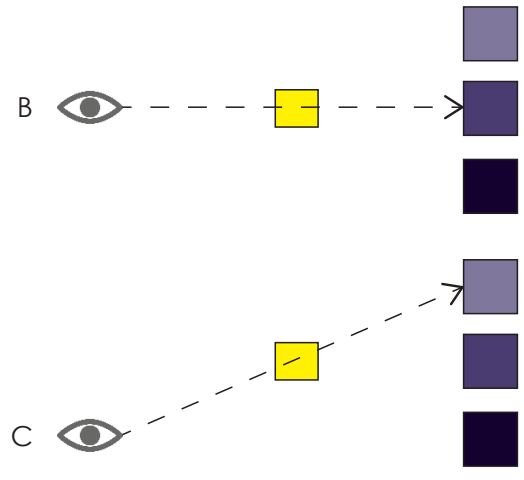

Figure 29: Parallax Effect

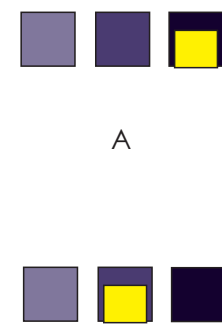

B

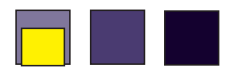

c

The effect of parallax is caused by a change of depth from different perspectives while experiencing space, considering the location and movement of the viewer. This approach criticizes the notion of static space that is seen from a single vantage point; it focuses on the determinate relationship between motion and spatial background. ${ }^{33}$

\begin{tabular}{ll}
\hline \hline & \\
31 & Peters. 9. \\
32 & Holl. 26. \\
33 & ibid. 26.
\end{tabular}




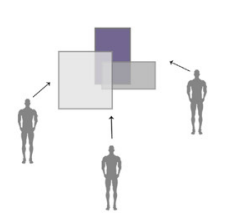

The parallax effect may be applied to space to achieve dynamism by constantly changing the subject-object relationship through motion. The centre of perspective resides in the mobile visitor, so the body continually redefines its relationship with its environment.

Holl believes that the movement of the body as it goes through the overlap of perspectives in space is the elemental connection between body and space. ${ }^{34}$ "The turn and twist of the body engaging a long and then a short perspective, an up-and-down movement, an open-and-closed or dark-and-light rhythm of geometries - these are the core of the spatial score of architecture." ${ }^{35}$ The impact of parallax is exaggerated, and the experience is multiplied when the axis of movement moves from horizontal to oblique or vertical. Therefore, spatial elements that allow for circulation, including ramps, staircases, elevators, and escalators, are the transitional spaces that allow parallax to create a multi-sensory experience. 


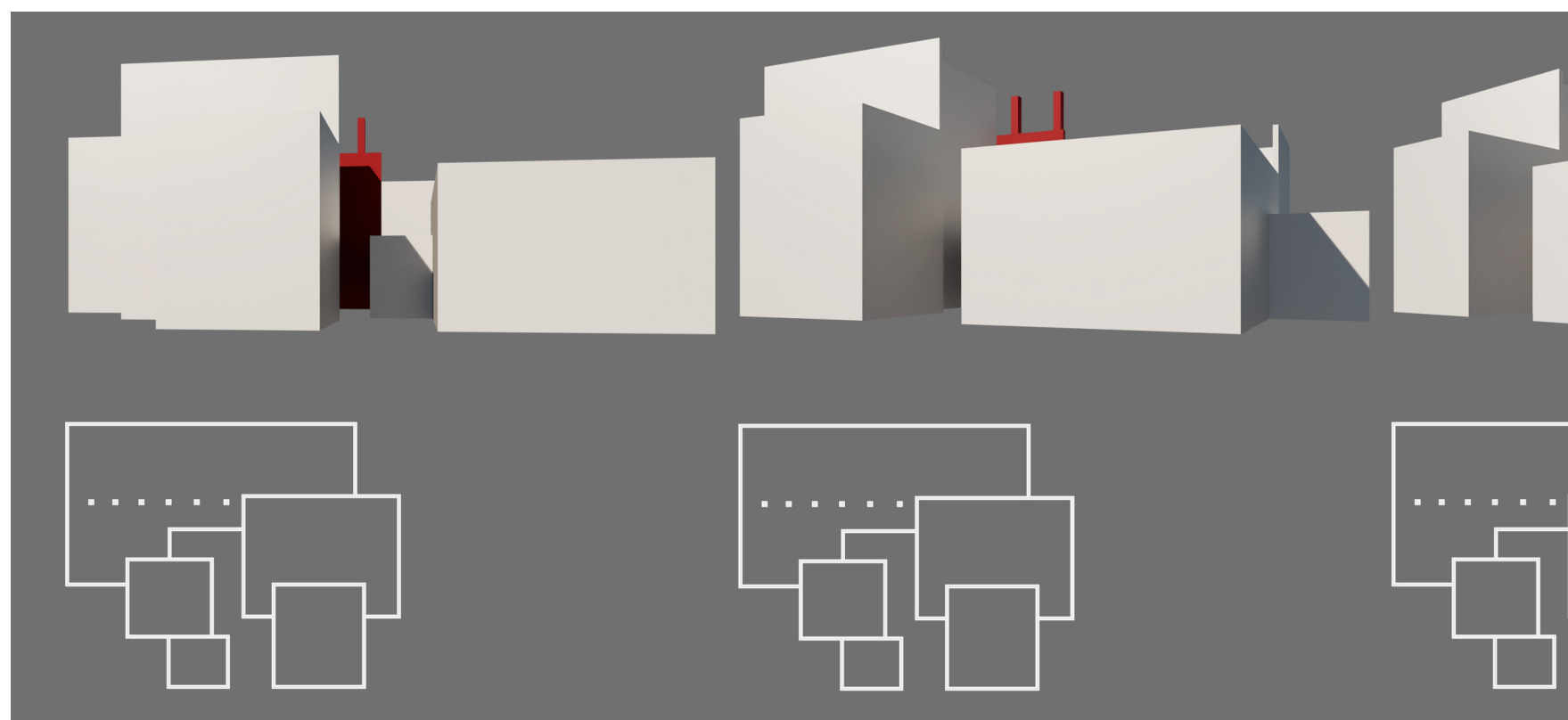

Figure 30: Parallax Effect in the Frontal Plane
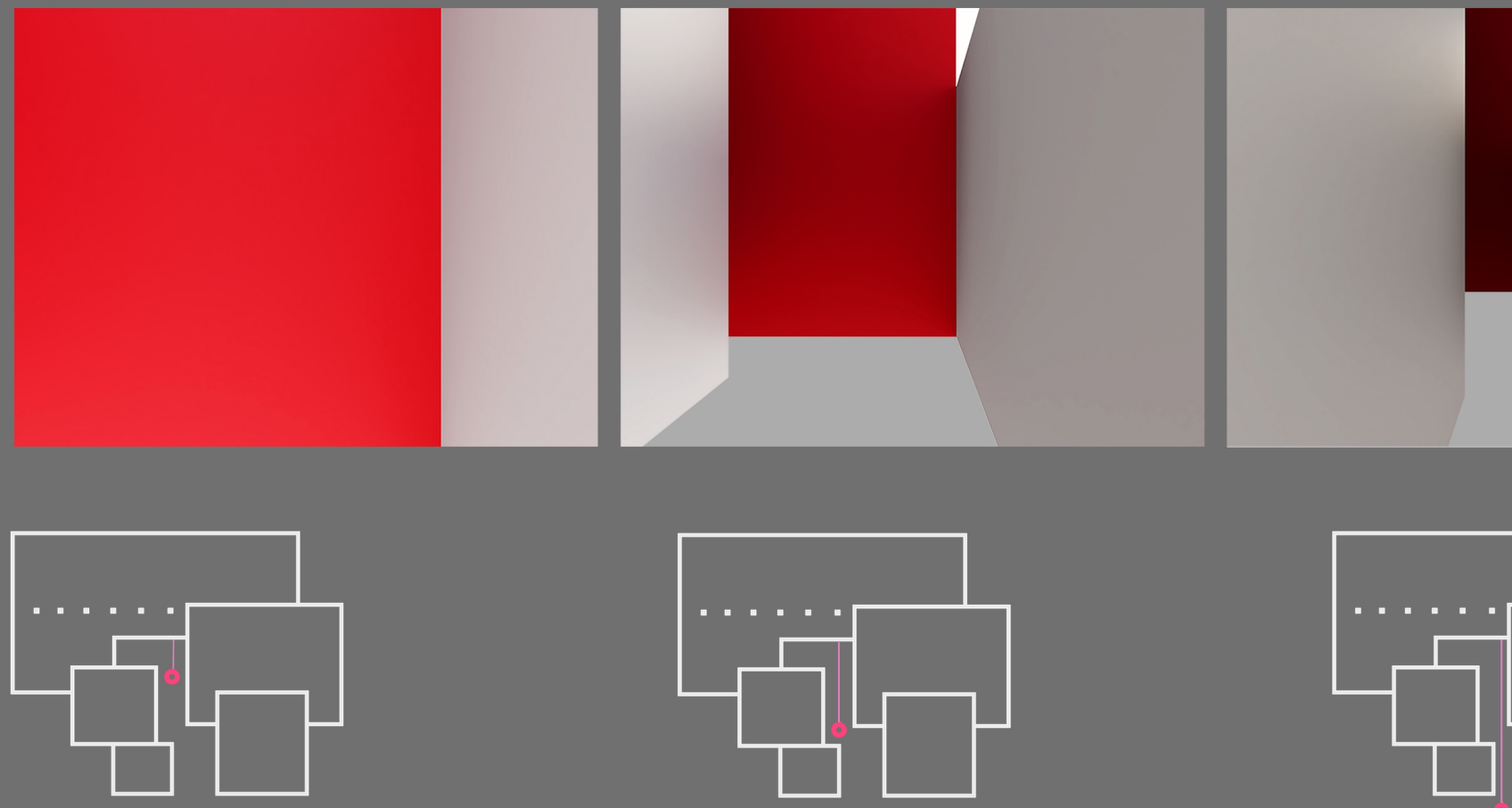


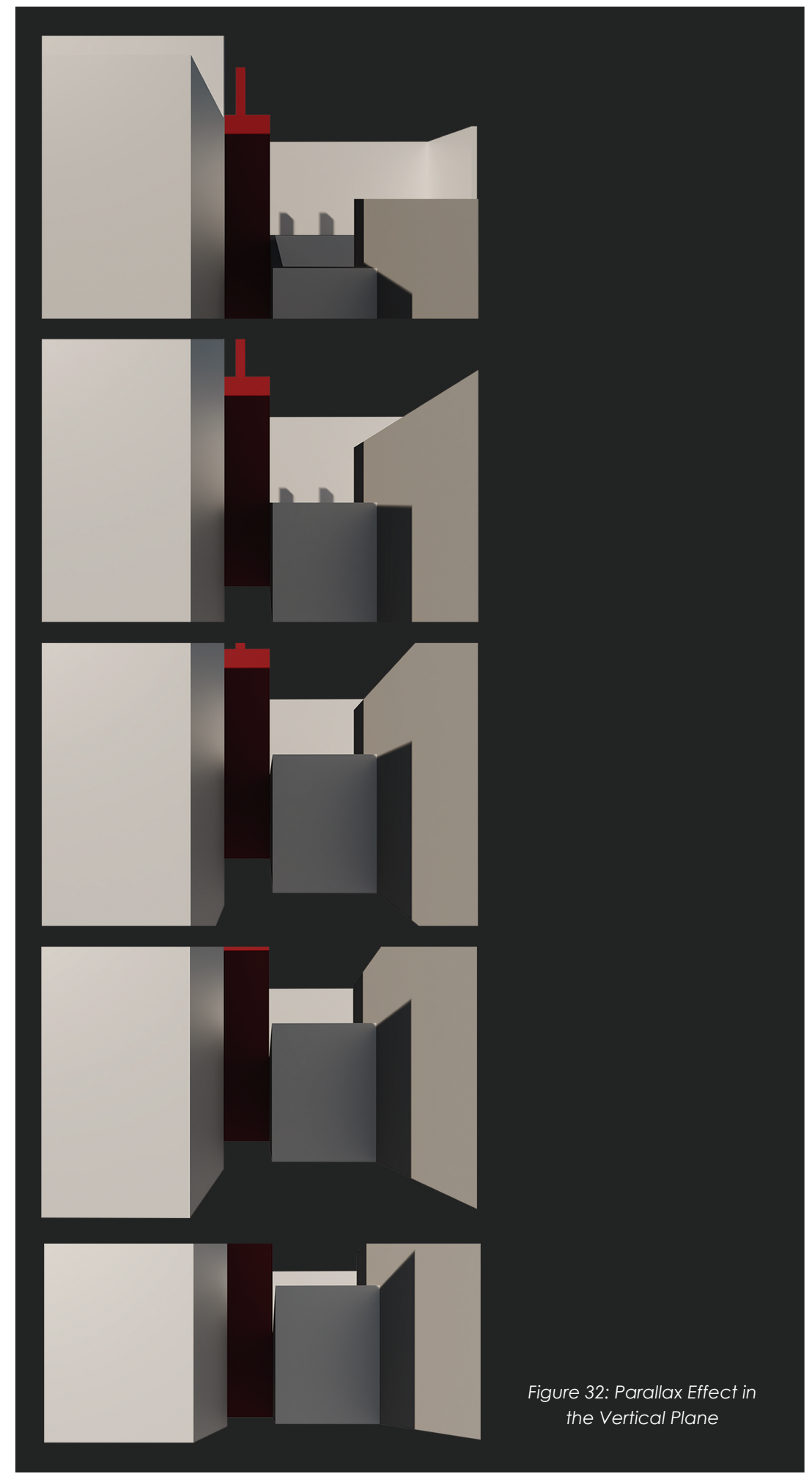


Case Study 11

Villa Savoye - Le Corbusier - 1929 - Poissy, France 36

In Villa Savoye, circulation is a significant part of the design and is used to portray the progression through states of human existence. Le Corbusier created two different forms of vertical circulation, the ramp and the spiral staircase, and each engages the body at a very different pace and rhythm of movement. ${ }^{37}$ The ramp provides a continuous movement that allows for the overlap of perspectives, while the staircase offers an interrupted movement that connects and disconnects the body constantly. Villa Savoye can only be experienced as a summation, and not from one viewpoint, allowing for a simultaneous perception of multiple layers.

Case Study 12

Kiasma Museum of Contemporary Art - Steven Holl - 1998 - Helsinki, Finland ${ }^{38}$

In this museum, the curves are used to turn and hide the vanishing point, overemphasize the sense of movement, and provoke a sense of curiosity. The movement in space is impacted by the ambiguous space that is hidden behind the curves. The spatial curve in addition to the ramp allows for the overlap of perspectives, the ability to see activities of multiple spaces at the same time. The criss-crossing effect happens where a cross passage is a point of intersection for multiple vertical ribbons of concrete stairs, providing visitors with multiple options for movement. ${ }^{39}$

Kroll, Andrew. "AD Classics: Villa Savoye / Le Corbusier."

Erwine. 103

Fiederer, Luke. "AD Classics: Kiasma Museum of Contemporary Art / Steven Holl Architects."

Holl. 51. 


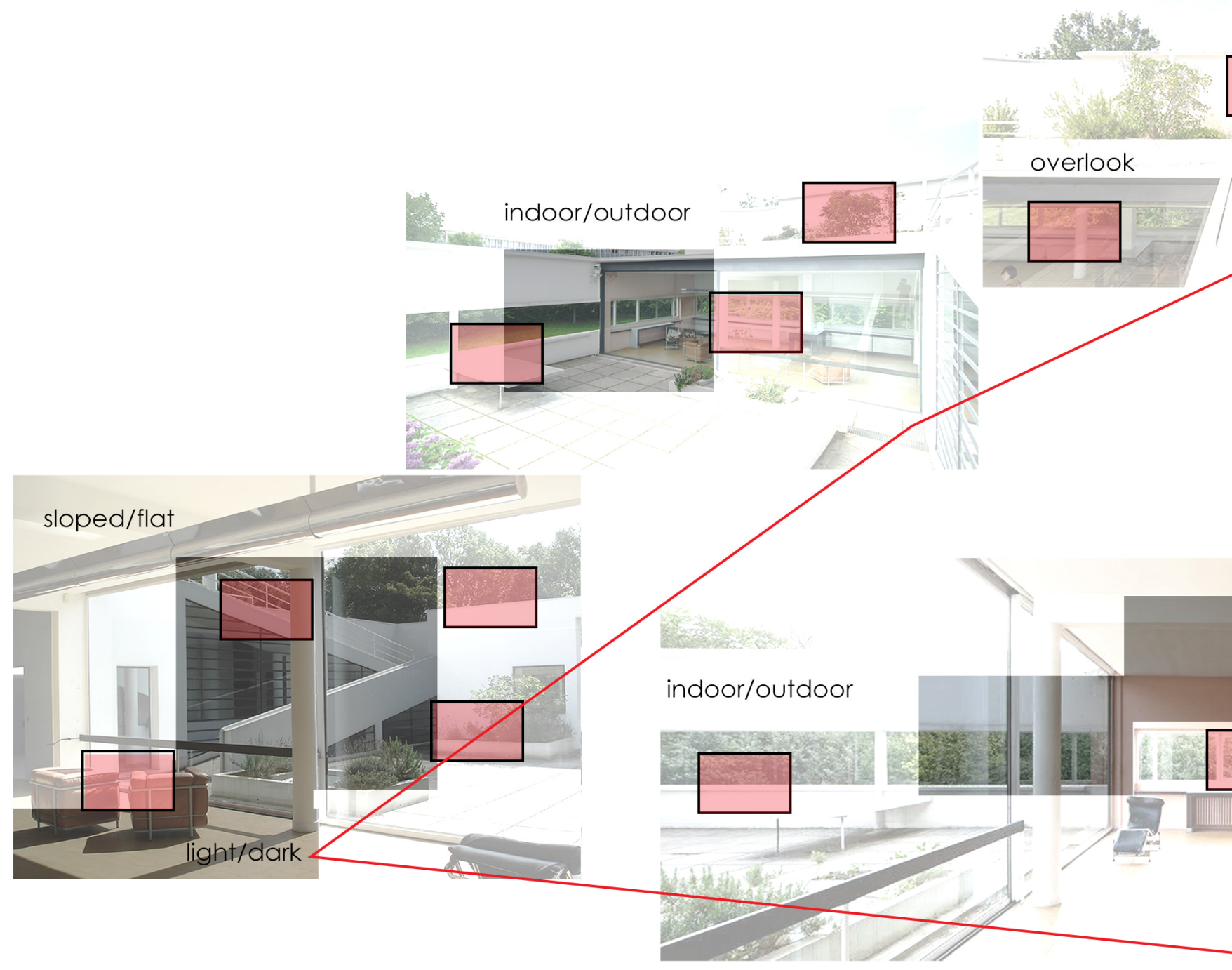

Figure 33: Analysis of Spatial Qualities and parallax effect in Villa Savoye 


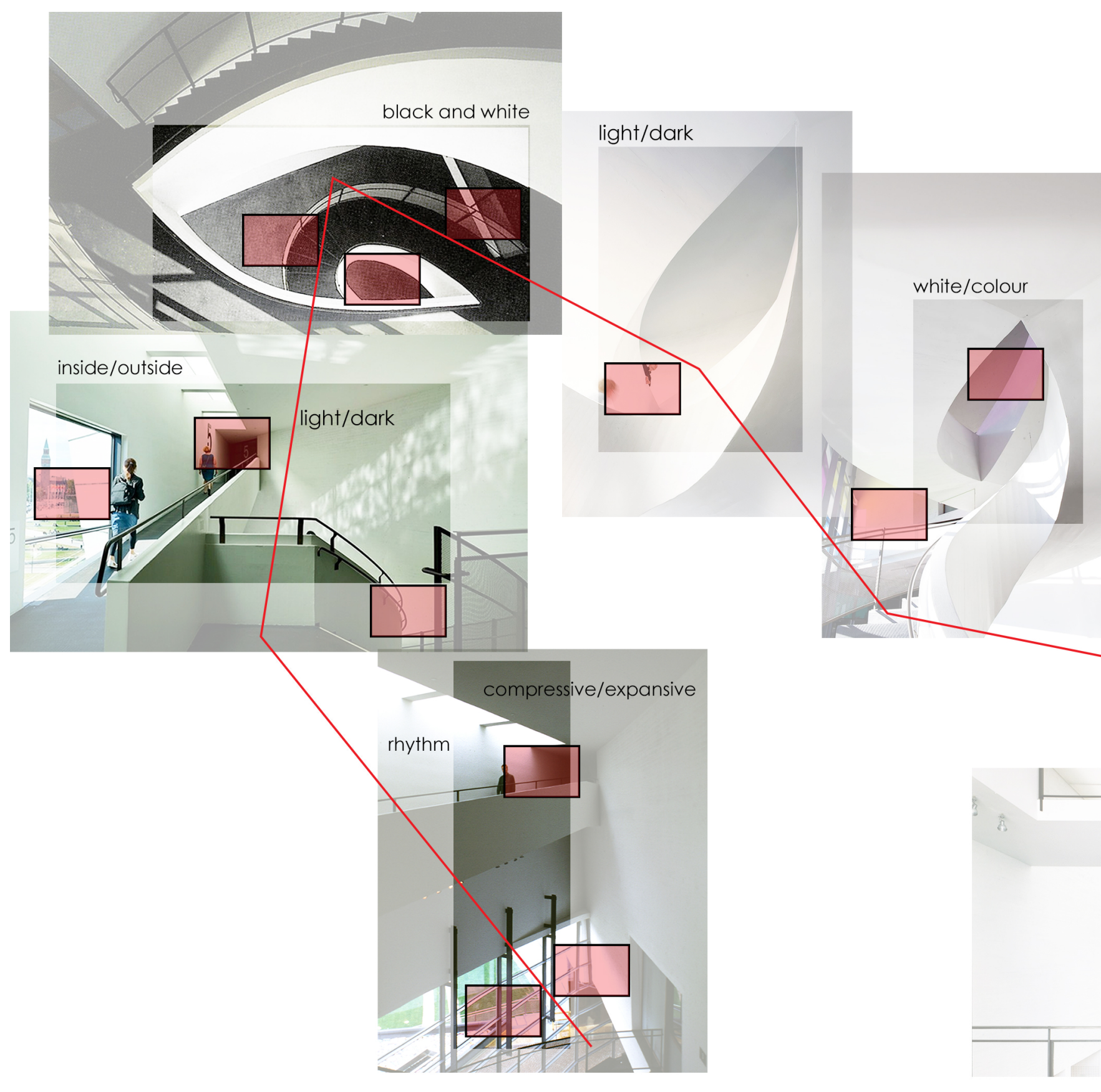

Figure 34: Analysis of Spatial Qualities and Parallax in Kiasma Museum of Contemporary Art 
Perilous Space

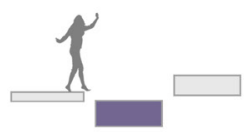

In every space there are opportunities embedded within or denied; these opportunities can deny the subject the chance to decide our own actions or they can provide possibilities for people to perform a subjective action. In this case, architecture acts as "a domain of human deliberation"40 where bodies can freely, but with vitality, engage with it. It can take people out of their habitual patterns of perception and movement and give them the ability to adjust to changing situations and threats. To do so requires modification of the pre-conceived notion of space. Instead of envisioning the experience ahead of time, "accidental opportunities"4l are introduced in more flexible and less defined spaces. Spatial qualities activate bodily senses; the more exaggerated these qualities are, the more intense the experience will be. One way to exaggerate these qualities is to go against the routines of movement in space. This allows for taking risks, encountering accidental opportunities, while enhancing the activation of the bodily senses.

"The floor is not only the ground of our world but also the springboard of our motion." 42 A flat surface does not provide a chance to interact with its surface; it does not allow tripping or falling, but at the same time, it does not allow the body to feel awake and alive during movement.
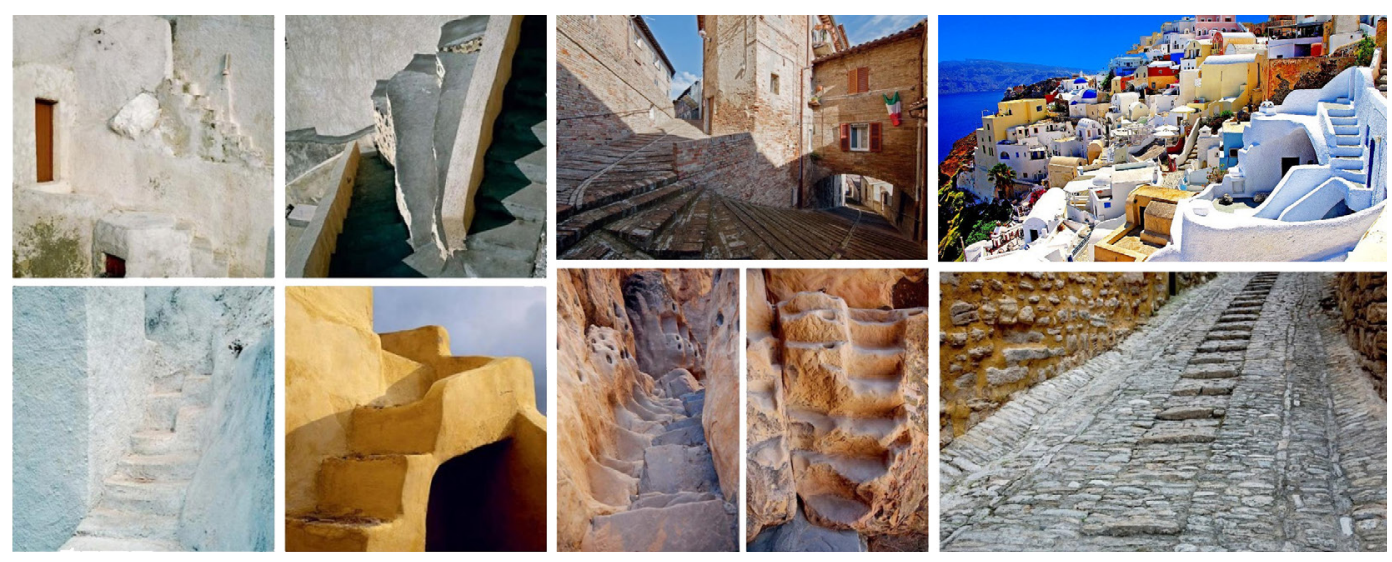

Figures 35-43: Uneven Ground

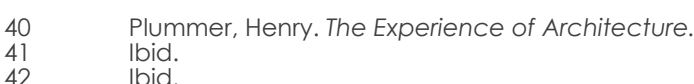




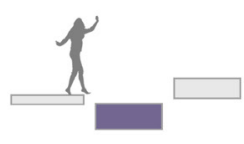

"The levelled floor gradually drills the human body into a kind of robotic motion." 43 The aim is not to go against practicality, but to provide risks for human existence and to eliminate routine motions to keep inhabitants awake and involved. To walk on uneven ground, torso, limbs, and the full anatomy of the legs are all used to stretch and compress as the body tries to land securely on the next platform. ${ }^{44}$

For cultures obsessed with time, comfort, and accessibility for all, quick movement with no distractions is necessary. Some architects have shown small concentrations of daring movement in combination with flat surfaces. Wharton Esherick, a furnituremaker, designed a unique staircase of red oak for his house. In this staircase, no two treads are identical and "the cantilevered blocks of wood twist about an equally twisting vertical post, echoing the torsion experienced in the climber's own torso." 45

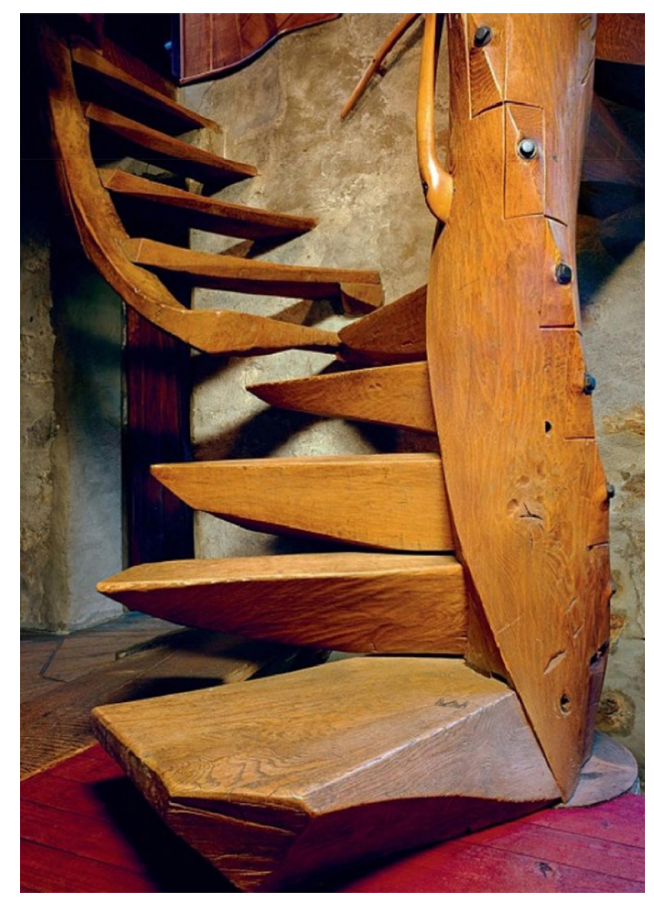

Figure 44: Wharton Esherick's Staircase 


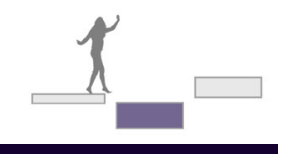

Case Study 13

Fondazione Querini Stampalia - Carlo Scarpa - 1963 - Venice, Italy ${ }^{46}$

Carlo Scarpa was also interested in disrupting habitual movements on horizontal planes, as can be seen in the new floors of the renovated Fondazione Querini Stampalia in Venice. These uneven steps require the visitors to watch their steps and focus entirely on how the foot touches the marble. The displacements of the floor in Scarpa's works originated from his admiration for Japanese architecture. ${ }^{47}$
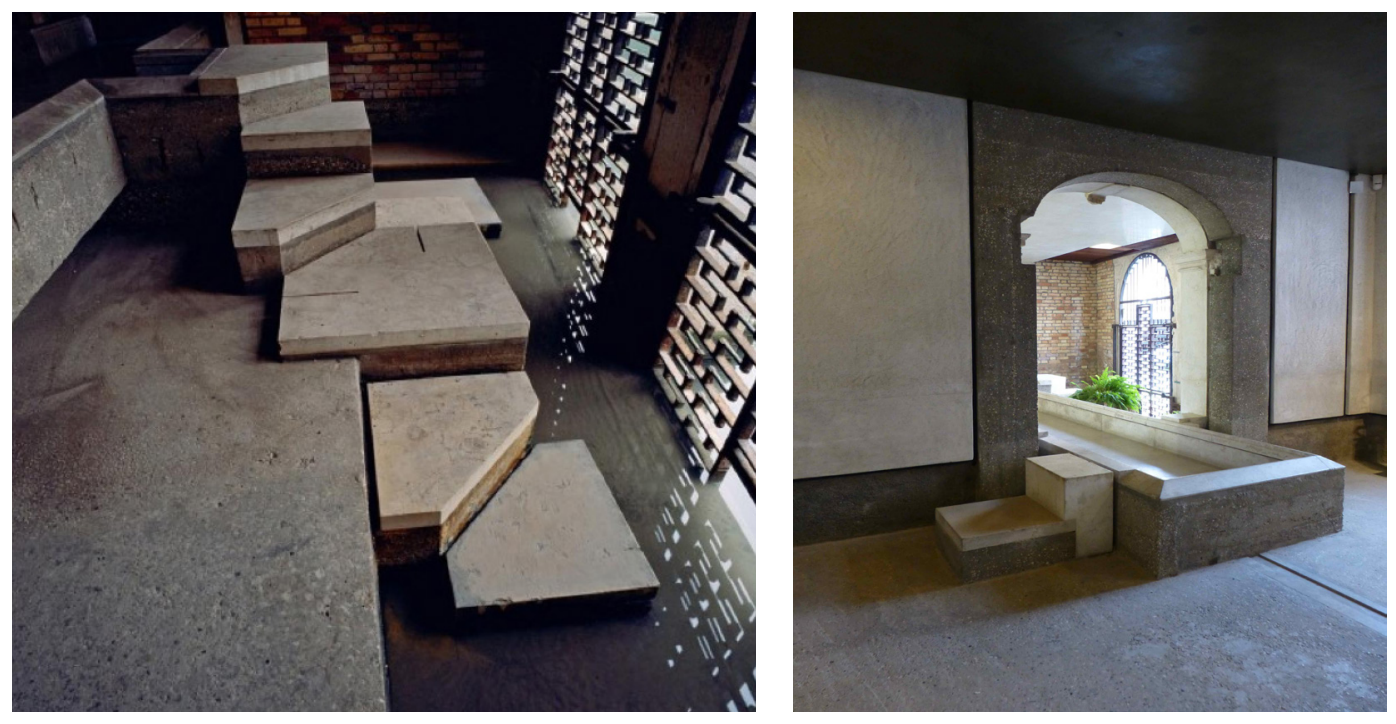

Figures 45 \& 46: Fondazione Querini Stampalia's Irregular Stairs

$\begin{array}{ll}46 & \text { Onniboni, Luca. "Museum Querini Stampalia Foundation by Carlo Scarpa." } \\ 47 & \text { Plummer. }\end{array}$ 


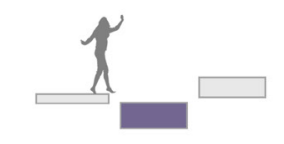

Case Study 14

Japanese Gardens

Heian Jingu Shrine - Itō Chūta -1896 - Kyoto, Japan ${ }^{48}$

Katsura Imperial Villa - Kobori Enshu - 1663 - Kyoto, Japan ${ }^{49}$

The early designers of Japanese gardens have focused on extending the visual space through haptic involvement of the body. The visitor is involved in both the visual and haptic experience since one is forced to engage both the eyes and other muscular sensations to experience and move through the garden. ${ }^{50}$ One is forced to pause and watch one's step to keep their balance, walking on the stepstones in a pool. On the other hand, to fully perceive the space visually, the body has to move through all the existing pathways. The intense connection between vision and the somatosensory system of the body is due to the kinetically indeterminate parts of these gardens. These gardens stimulate the body's equilibrium and proprioception sense while walking on the stepstones surrounded by water or crossing bridges with no handrails. The unexpected experiences, a risk in movement, are threatening to the body's balance and hence slow down motion and magnify actions in space.
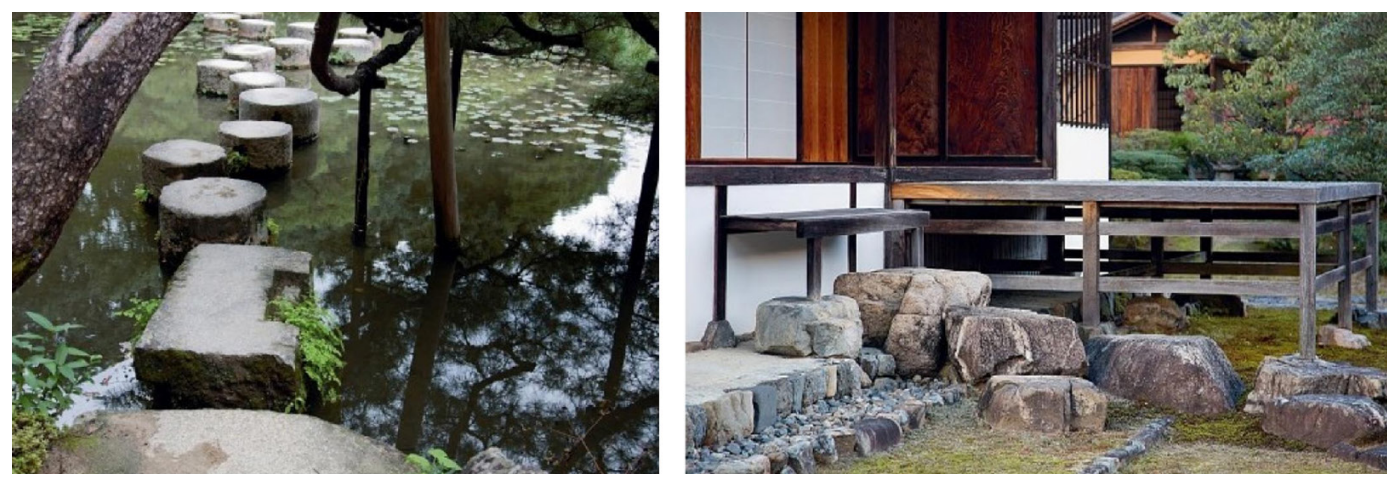

Figures 47 \& 48: Stepstones in Heian Shrine and Katsura Imperial Villa

Orientalarchitecture. "Heian Jingu Shrine, Kyoto, Japan."

Orientalarchitecture. "Katsura Imperial Villa, Kyoto, Japan."

T.Hall. 51. 


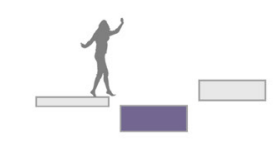

Case Study 15

Architectural Deconstruction - Gordon Matta-Clark

In his projects of architectural deconstruction, Gordon Matta-Clark interrupted the habitual circulation by introducing voids - cuts through buildings. These voids have a complicated presence since they change people's expectations of space with respect to circulation and shifting of light. This quality adds to the dynamism of space and reduces the static quality of the building. In this instance, people improvise their movement in space based on an open-ended opportunity provided by an unordinary condition.
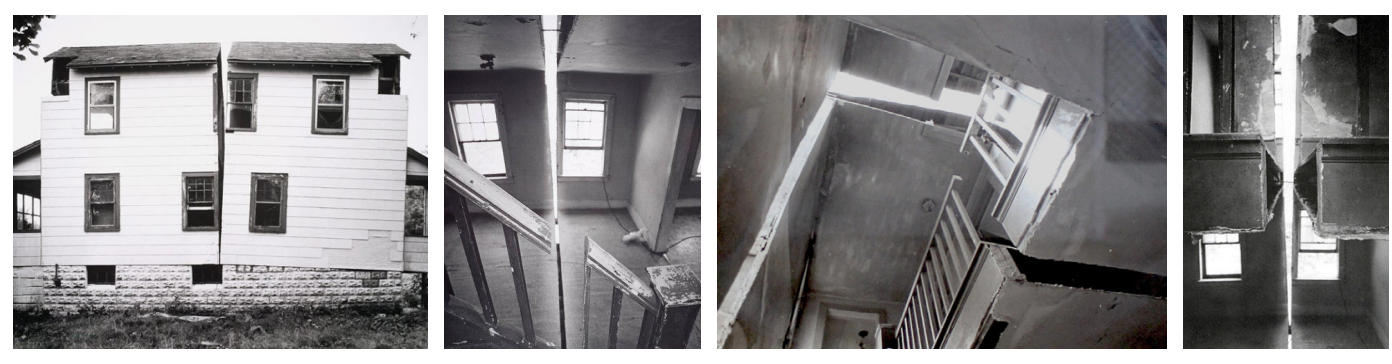

Figures 49-52: The splitting effect by Gordon Matta-Clark 



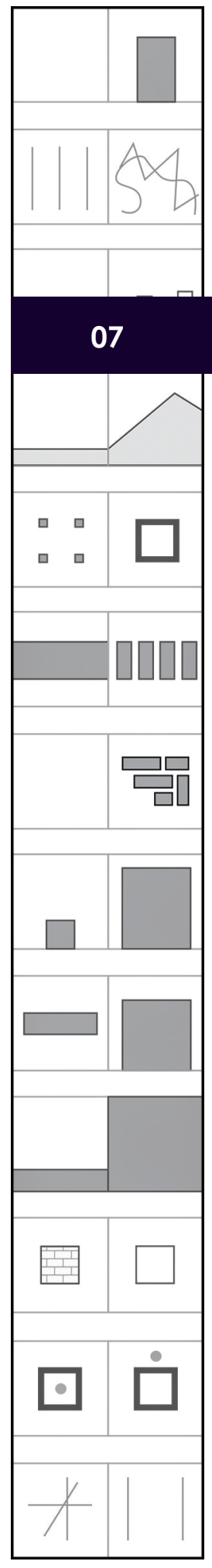




\section{The Library of Spatial Binaries}

Based on the analysis, the contrasting spatial qualities that can be used in haptic space to enhance the bodily sensation of space are summarized in the Library of Spatial Binaries. This library will mostly focus on the spatial binaries and qualities that impact the somatosensory system.

\section{Geometric Qualities - Form}

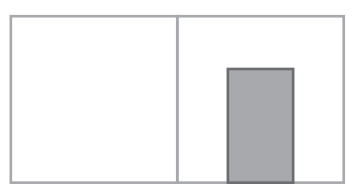

solid / threshold

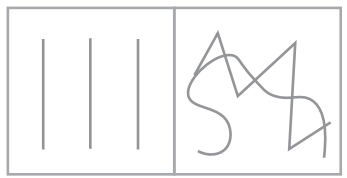

straight / angular and curved

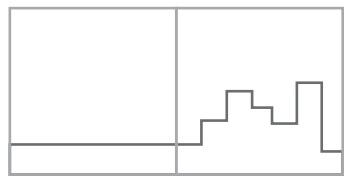

even / uneven

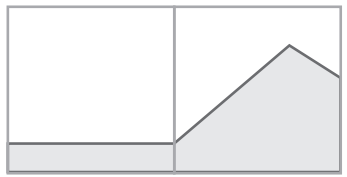

flat / sloped

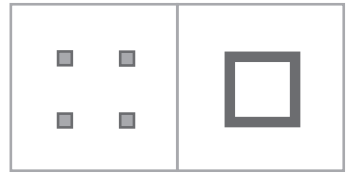

flexible / rigid 


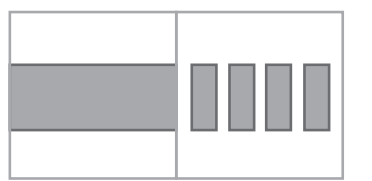

continuous / interrupted

(legato/staccato)

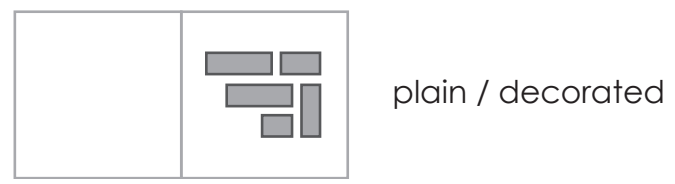

\section{Geometric Qualities - Proportion/Composition}
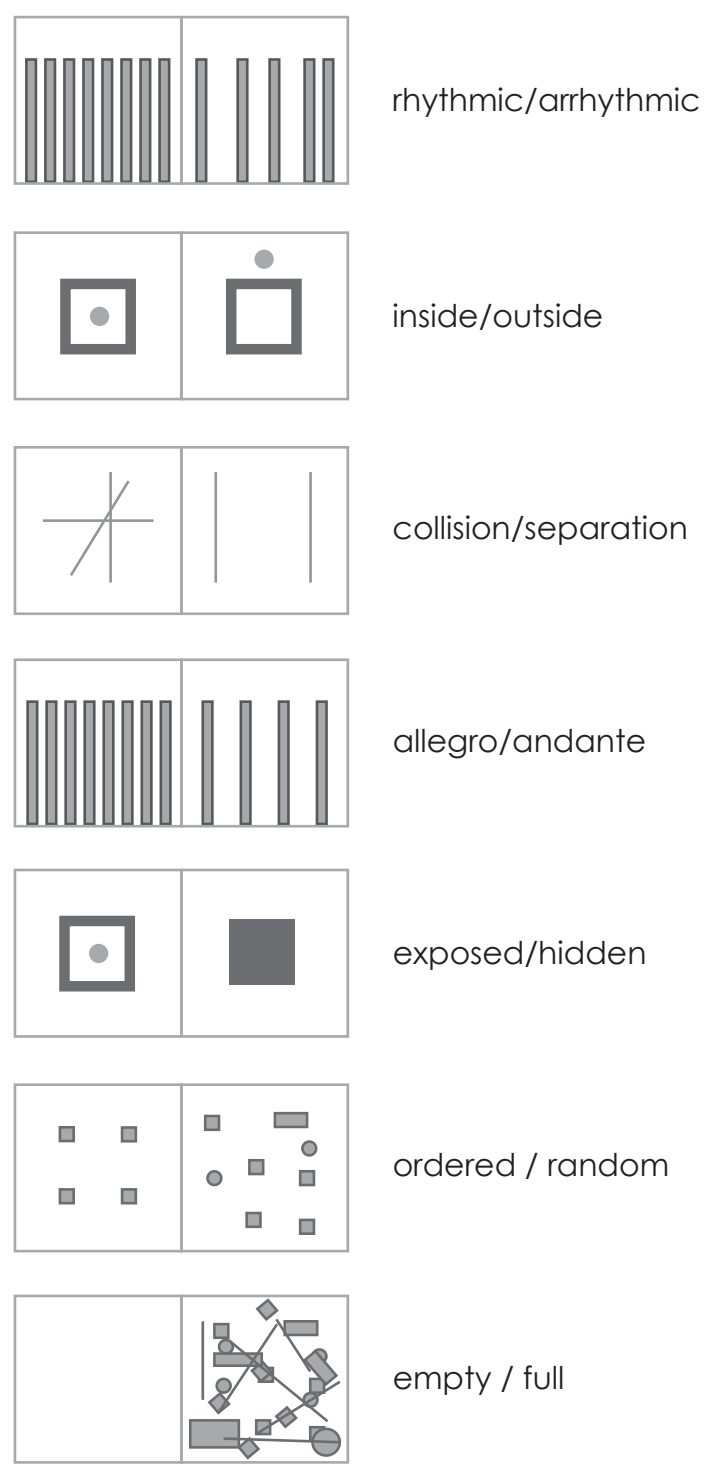
Geometric Qualities - Scale

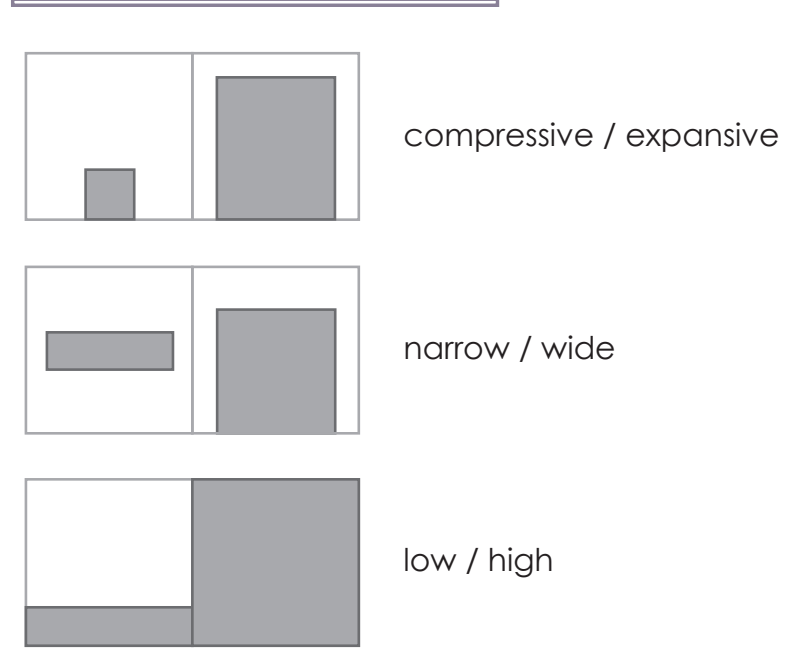

Surface Qualities

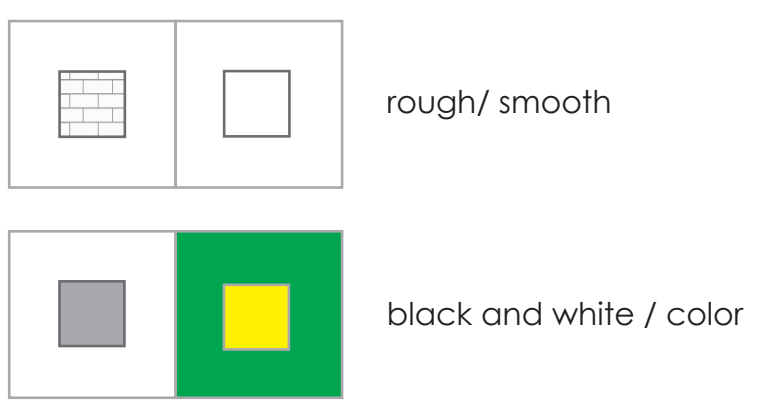

Material Qualities
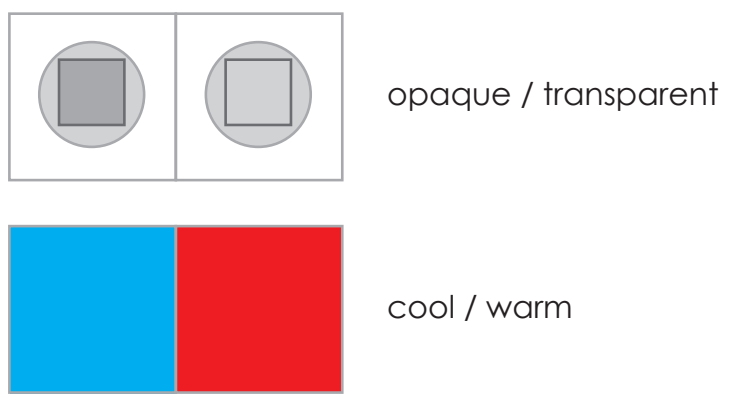

cool / warm

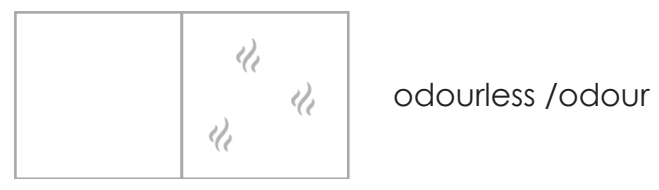




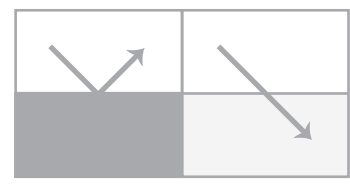

reflective / transmissive

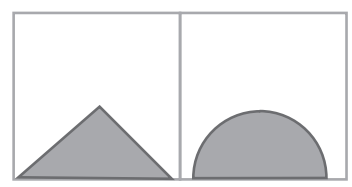

hard/soft

\section{Environmental Qualities}

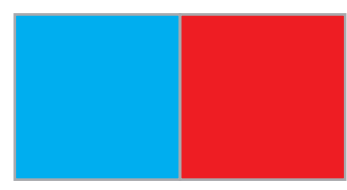

cool / warm

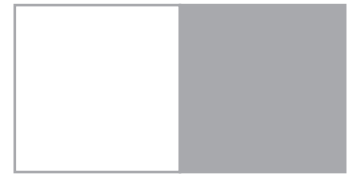

light / shadow

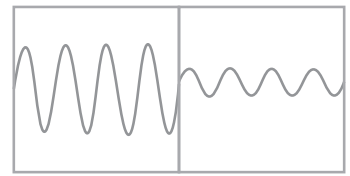

loud / quiet

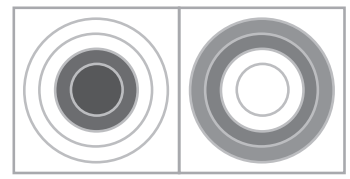

intimate and personal

space/social and public space

Figure 53: The library of Spatial Binaries 
These spatial binaries can be applied to space to enhance the architectural experience and provide more spatial opportunities for interaction. The effect of these qualities is exaggerated when they come in binaries, next to their contrasting quality. Frank Lloyd Wright uses this concept in many of his works, where two contrasting spatial conditions happen in sequence to exaggerate the experience. In many of his buildings, private spaces have low ceilings, narrow widths and less light and therefore seem to be compressive and intimate, whereas more public rooms are usually expansive with bright light and large spatial scale. The binary of a compressive space followed by an expansive space creates a dynamic experience.

The following matrix compares the impact of these spatial binaries on vision and somatosensory senses. It can be concluded that vision is the primary sense that we use to perceive space, followed by kinesthesia and proprioception. The binaries that fall under geometric qualities of space are considered to impact more senses simultaneously.

The three concepts of attractions and aversions, parallactic space, and perilous space that emerged from the analysis of spatial qualities were then analyzed based on the impact of their relevant spatial qualities on the bodily senses. The numerical values given in Matrix $B$, are the sum of the impacted senses of all spatial binaries under each concept. These calculations were based on Matrix A on page 74-75. For instance, perilous space has nine spatial binaries. The first spatial binary is insideoutside; this concept impacts vision, kinesthesia, and thermoception. The second spatial binary is flat-sloped and it impacts vision, kinesthesia, proprioception and balance. Using the same strategy, a total for each sense was determined and therefore the senses were ranked under each concept. The result shows that vision and kinesthesia are common factors in all these concepts. Aside from these two senses, attractions and aversions mostly impact thermoception, parallactic space mostly impacts proprioception, and perilous space mostly impacts the vestibular sense.

$1 \quad$ Kwang-ho. "A Study on the Concept of Prospect in Frank Lloyd Wright's Works". 299. 


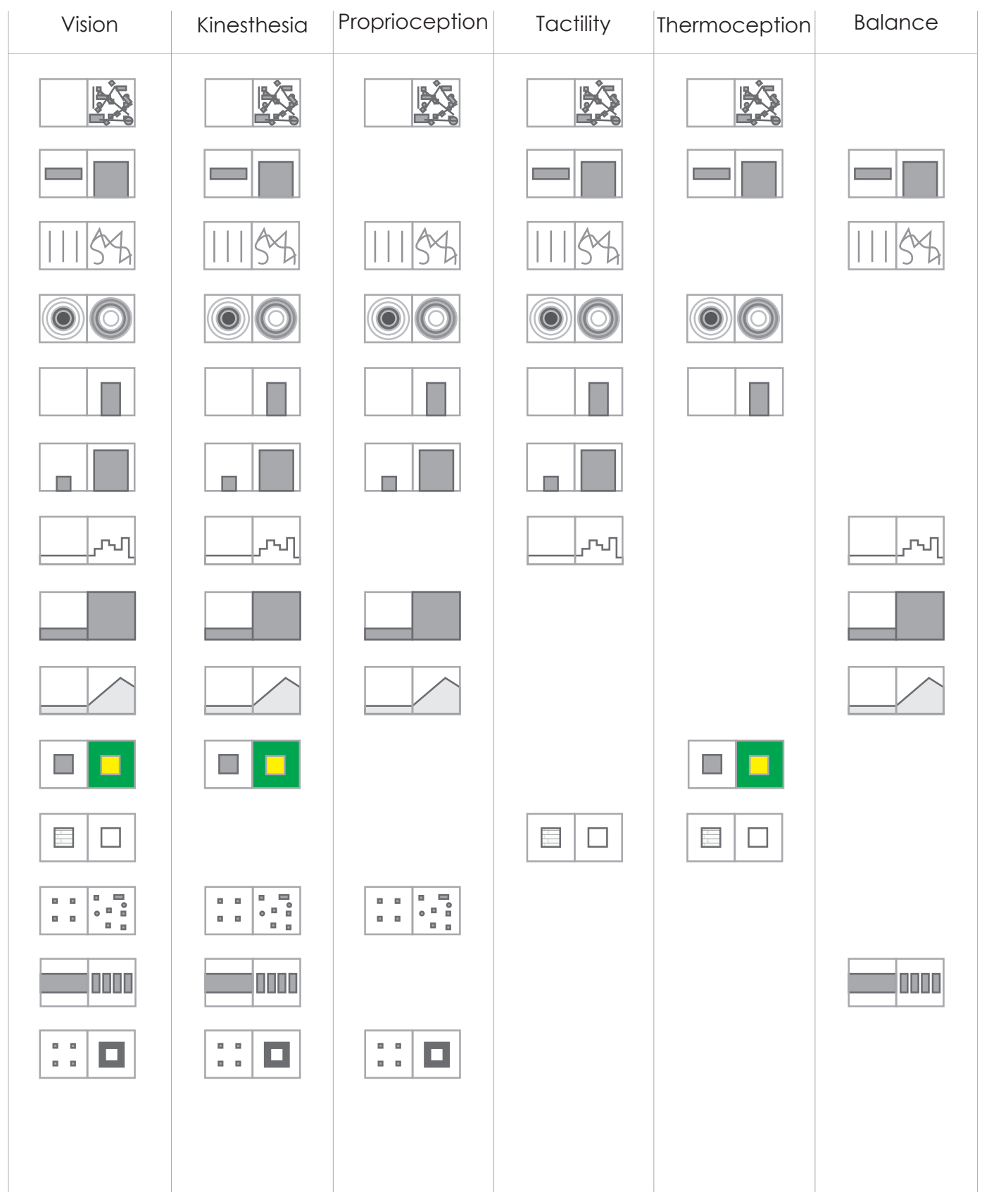




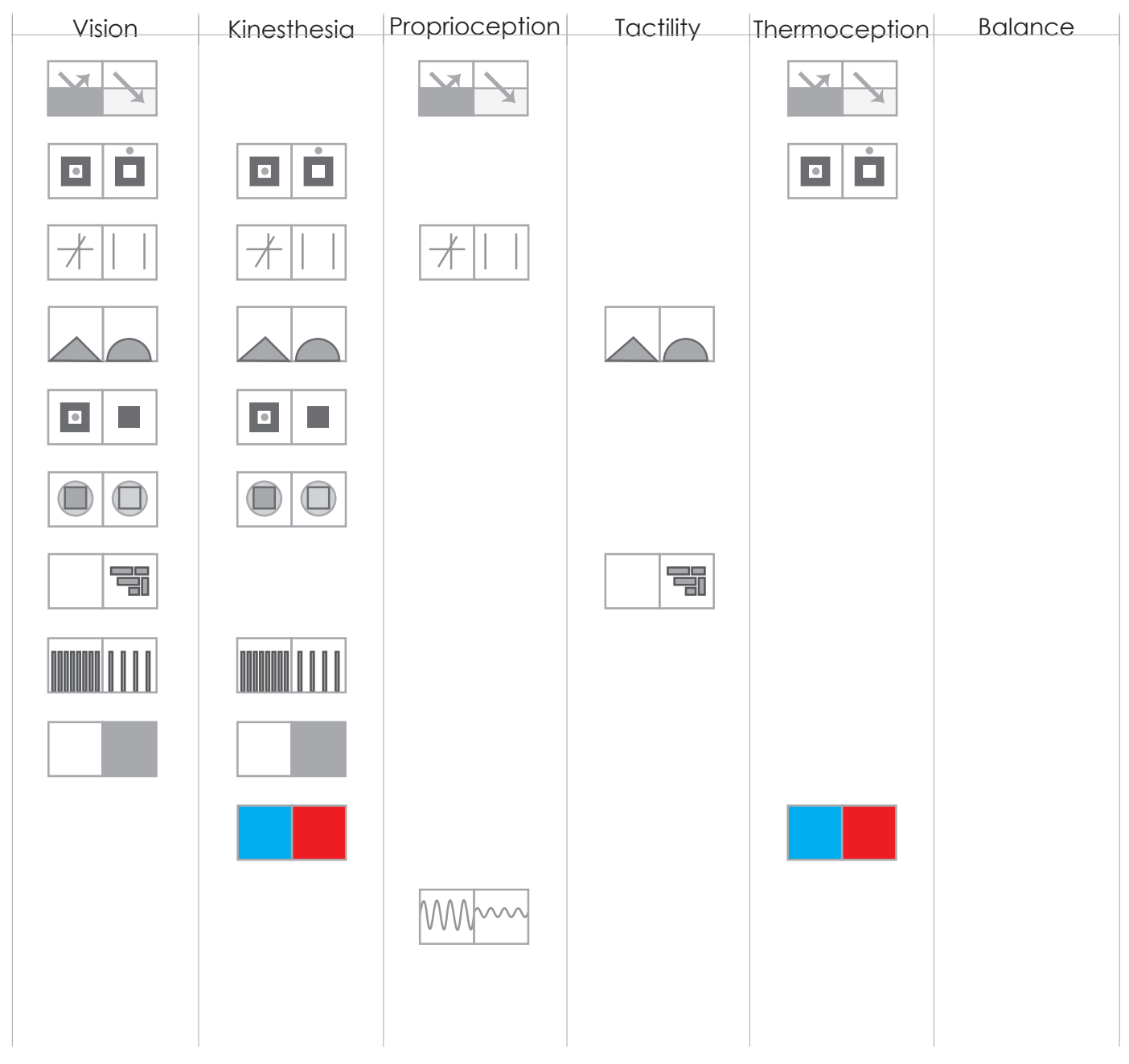

Figure 54: Matrix A - Comparison of the Impact of Spatial Binaries on the Senses 


\begin{tabular}{|l|}
\hline Concept 1 \\
- attractions and aversions \\
- navigation \\
- direction \\
- acceleration \\
- deceleration \\
\hline
\end{tabular}

Concept 2

-parallactic space

- overlook

- overlap

- parallax

-circulation
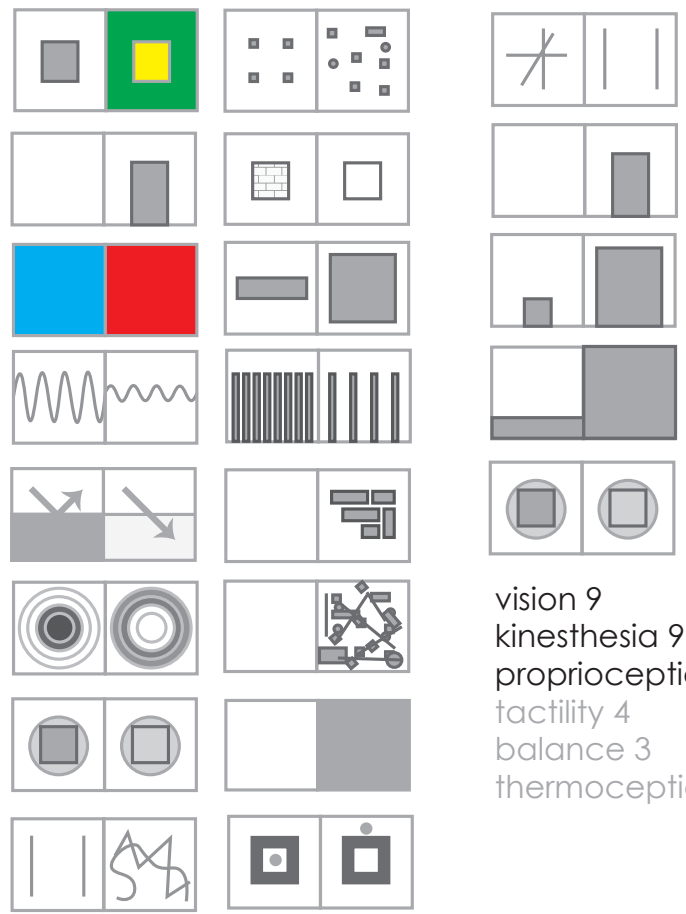
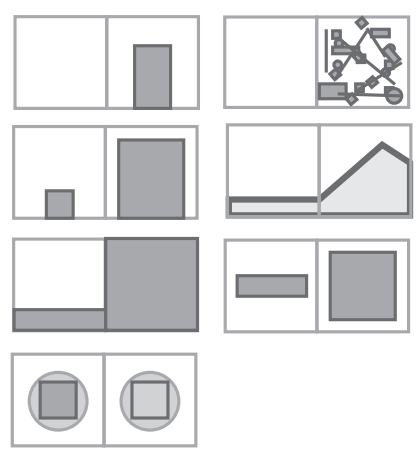

vision 9

kinesthesia 9

proprioception 8

tactility 4

balance 3

thermoception 1

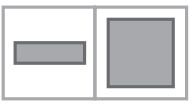

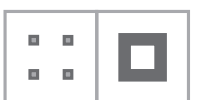

\section{Concept 3}

- perilous space

- unexpectedness

- accidental opportunities

- questioning boundaries

- ambiguity

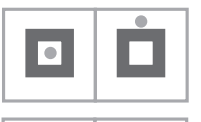

\section{-}
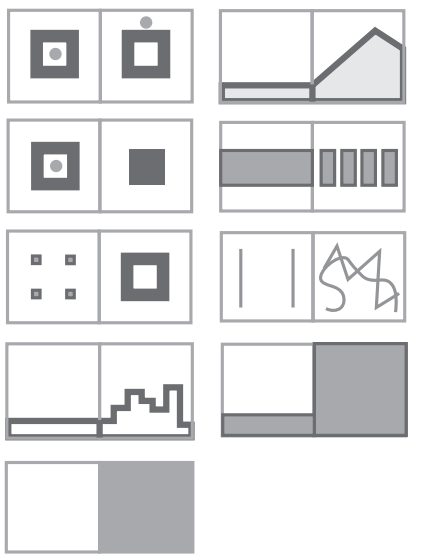

vision 9

kinesthesia 9

balance 5

proprioception 4

tactility 2

thermoception 1

vision 14

kinesthesia 12

thermoception 9

proprioception 7

tactility 6

Balance 2 



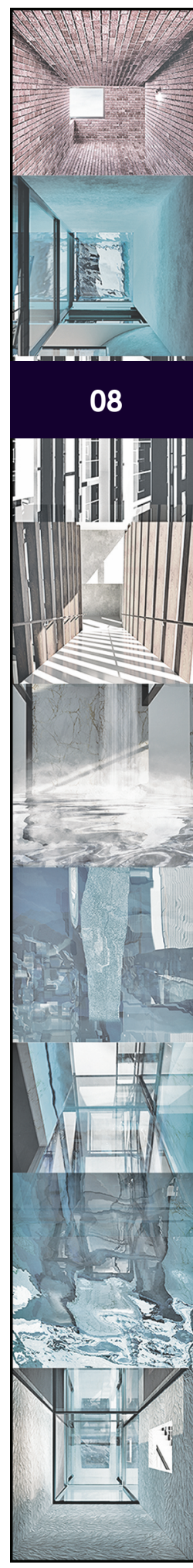




\section{A Haptic Space: An Experiential Machine}

The thesis project will focus on creating spatial opportunities that offer multiple

narratives for movement and numerous experiential opportunities in space as opposed to the typical homogenous single journey that exists in many buildings. This multiple experiential opportunity is made possible by providing parallactic and perilous qualities as well as attractions and aversions.

To do so, space is deconstructed into four architectural elements: floor, wall, roof, and structure. Then, the aforementioned spatial binaries are applied to each component; some result in ordinary conditions that can be encountered in everyday life while some result in uncommon bodily sensory experiences. These conditions are then applied to haptic space to create a multisensory experience. It is in the state of heightened awareness that the body encounters unexpected opportunities and experiences pleasure or fear. This somatic awareness can improve our bodily performance and habits by giving the body higher perceptual sensitivity and power for action. 


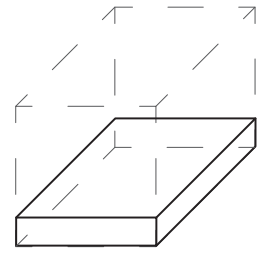

solid

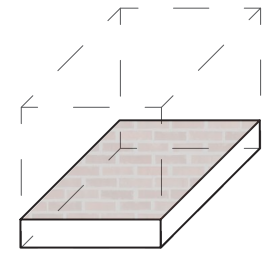

texture

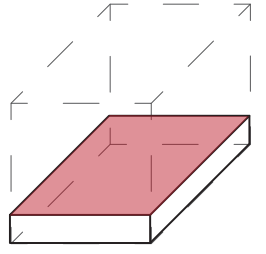

colour

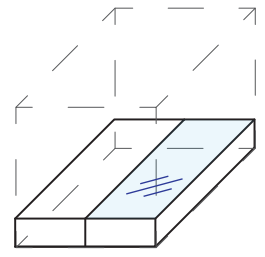

transparent

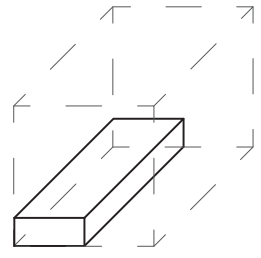

narrow

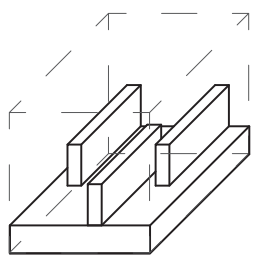

labyrinthic

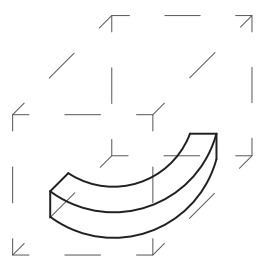

curvy

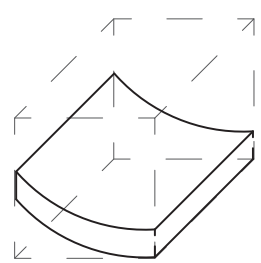

curved

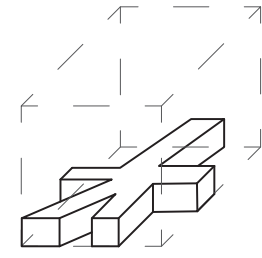

overlap

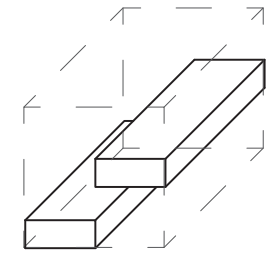

high/low

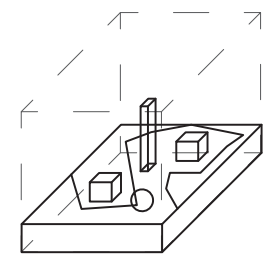

full

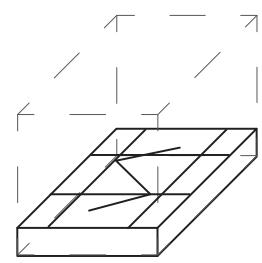

decorated

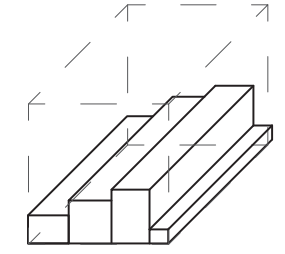

uneven

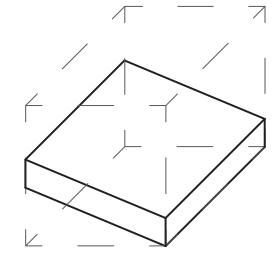

uphill

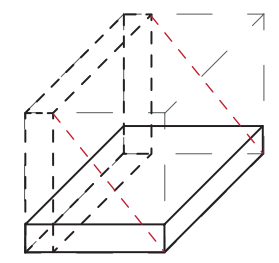

flexible

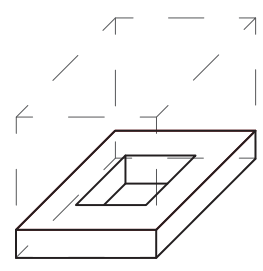

void

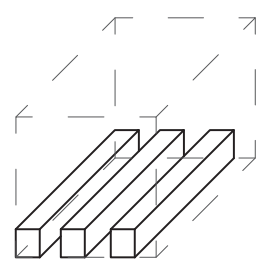

interrupted rhythmic

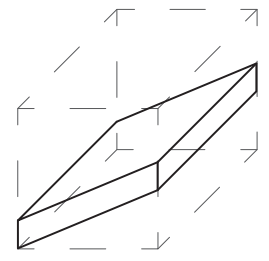

downhill
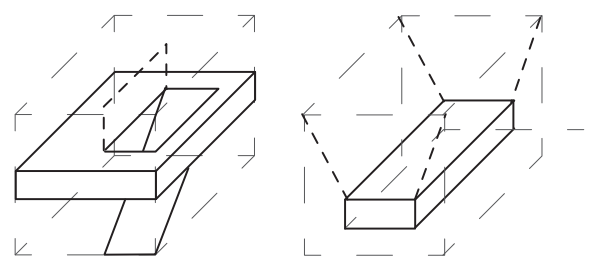

hidden

unstable 


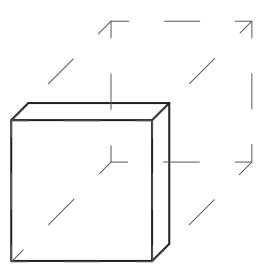

solid

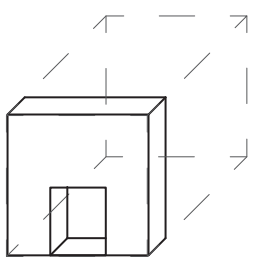

threshold

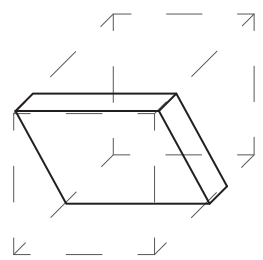

sloped

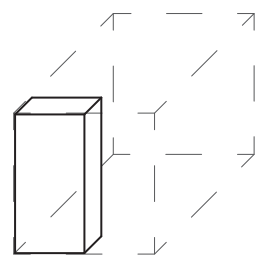

narrow

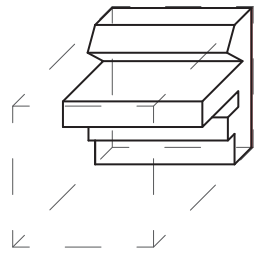

uneven

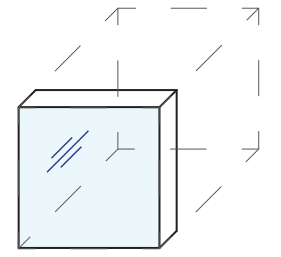

transparent

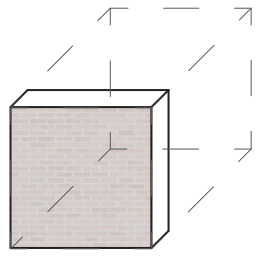

texture

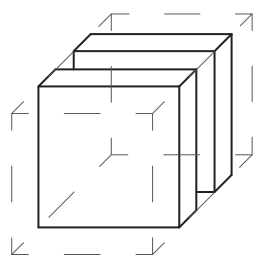

tall - narrow

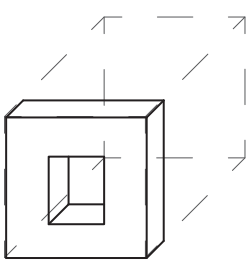

void

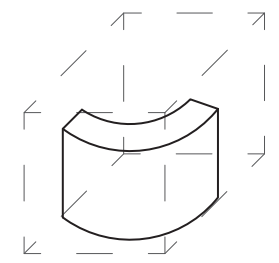

curved

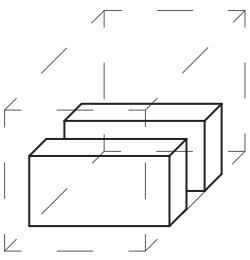

short -

compressed

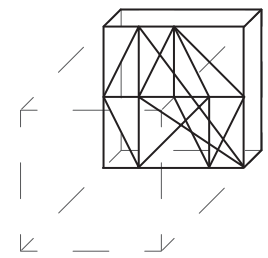

decorated

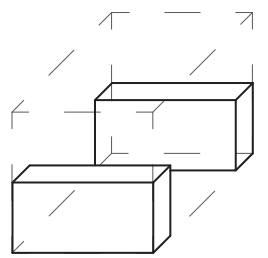

short - expansive

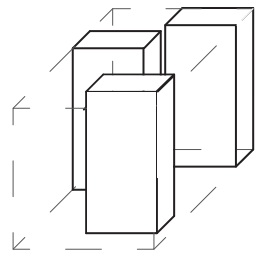

interrupted -

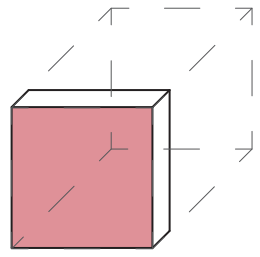

colour

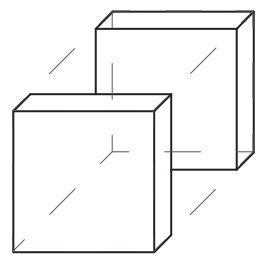

tall - wide

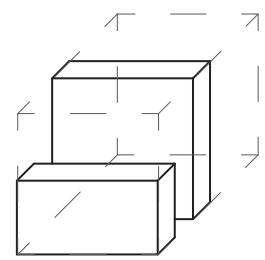

high/low

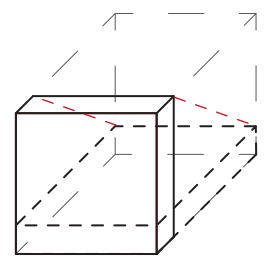

flexible arrhythmic

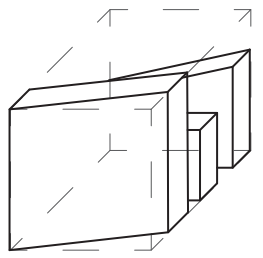

random 

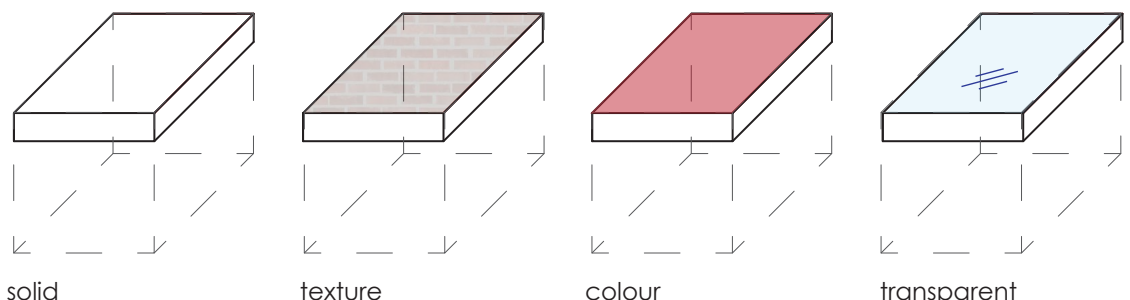

solid

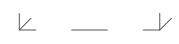

texture

k - $\downarrow$

colour

< - -

transparent
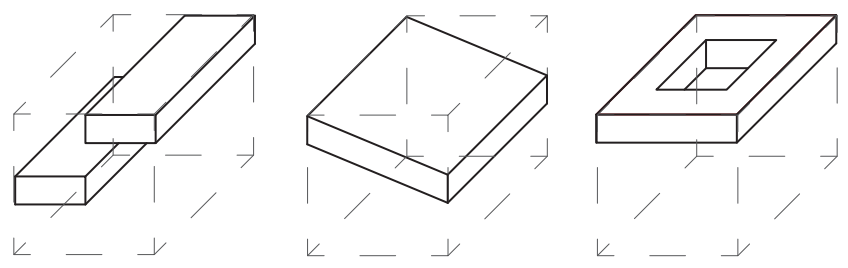

sloped

void
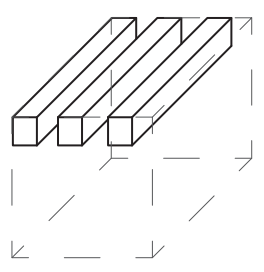

interrupted
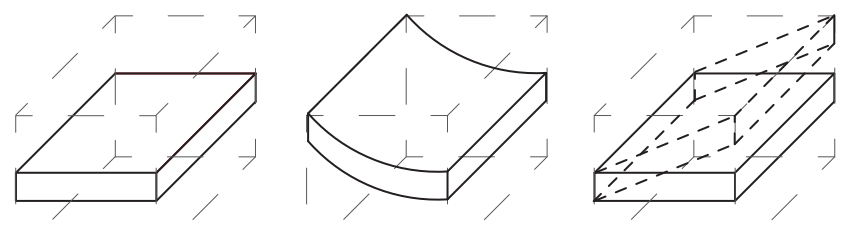

$k-\perp$

$k-\downarrow$

flexible

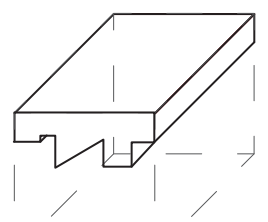

curved

< - -

compressed

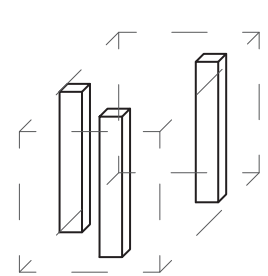

arrhythmic
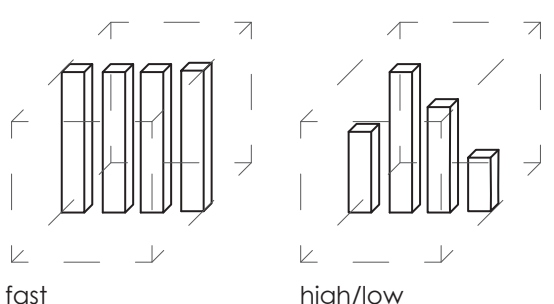

slow -

rhythmic

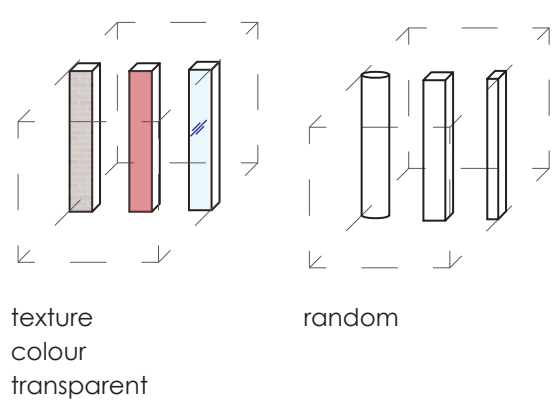

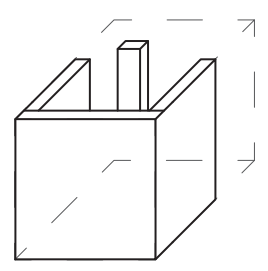

flexible

hidden 
The spatial experience can be categorized into static and kinetic; some experiences do not need movement to affect haptic and visual perception, whereas others do. Thus, the activities in spaces can be divided into static and transitional spaces. Haptic space becomes its own hybrid typology, allowing for static and kinetic perception to coexist by dedicating the use of static spaces to static perception and transitional spaces to kinetic perception, or the opposite depending on how the body understands space. In this case, when static and kinetic perception happen simultaneously, movement becomes a way to get to rest or rest becomes a way to get to move.

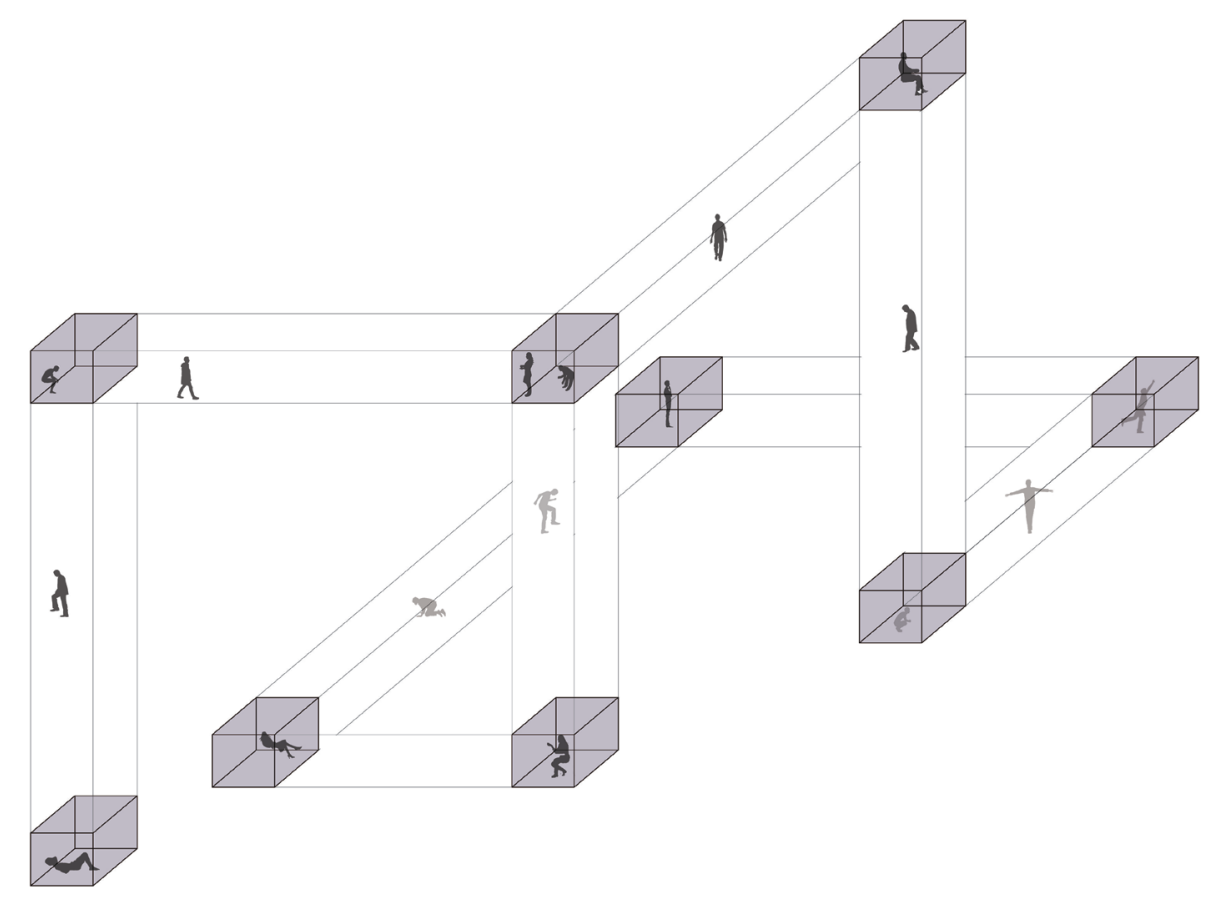

Figure 59: Experiential Machine-Coexistence of Static and Kinetic Spaces 

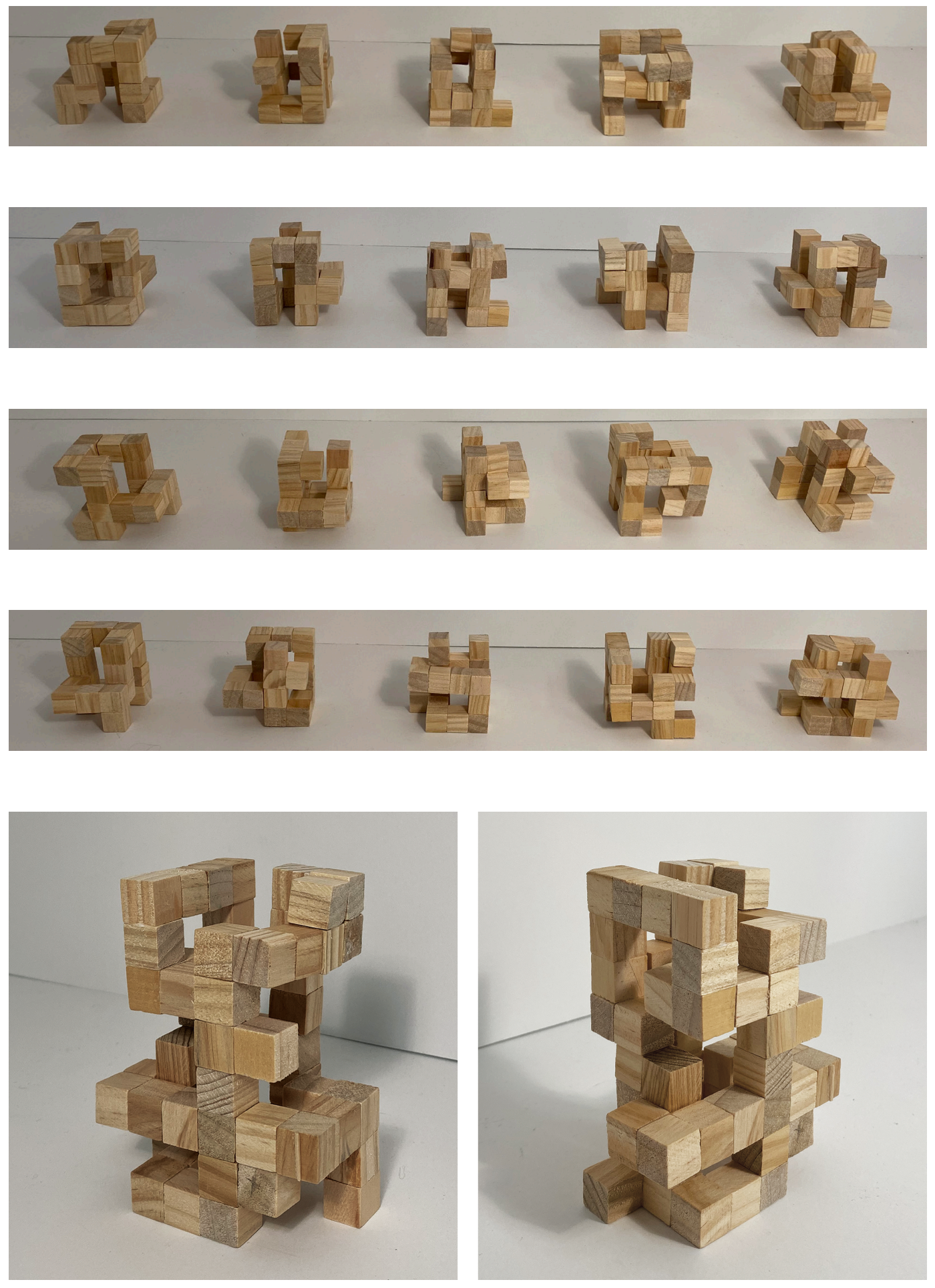

Figure 60: Massing Exploration to Achieve Dynamism and Different Spatial Conditions 
The proposed massing consists of a series of $3 \times 3 \times 3$ - metre cubes, which are placed around a $6 \times 6$ - metre core. The exploration of massing was based on achieving the maximum number of spatial opportunities within the form in terms of geometric qualities. The massing is composed of cubes that are considered to be static forms due to their equality of dimensions, while the complex overall massing depicts the dynamic nature of haptic perception. The core provides access to all spaces in an expeditious and conventional way, as well as maximizing visual connections between different spaces. On the other hand, the cubes provide as many spatial opportunities as possible, questioning conventional experiences and changing the architecture of distraction to an architecture of conscious awareness. The solid white exterior with a clear geometric definition contrasting the hapticity of the amorphous interior further emphasizes this dichotomy. This sharp contrast emerges as another binary to intensify the experience.

The cubes explore various spatial conditions to allow for attractions and aversions, parallactic space, and perilous space. Each space focuses on the interconnection between multiple somatosensory senses and vision. Similar to Matrix A (page 75), vision and kinesthesia are the leading senses that are affected in most of the proposed spaces, followed by proprioception, tactile sense, balance, and thermoception.

For the design project, the program and site have been suppressed to bracket out the external and multivalent forces in order to allow for the extreme exploration of the desired set of conditions. There are some parameters set for the site in order to achieve accurate lighting conditions; it is an abstract hypothetical urban site located in Toronto. All floor plans are oriented towards true north to obey the framework proposed for the design. 


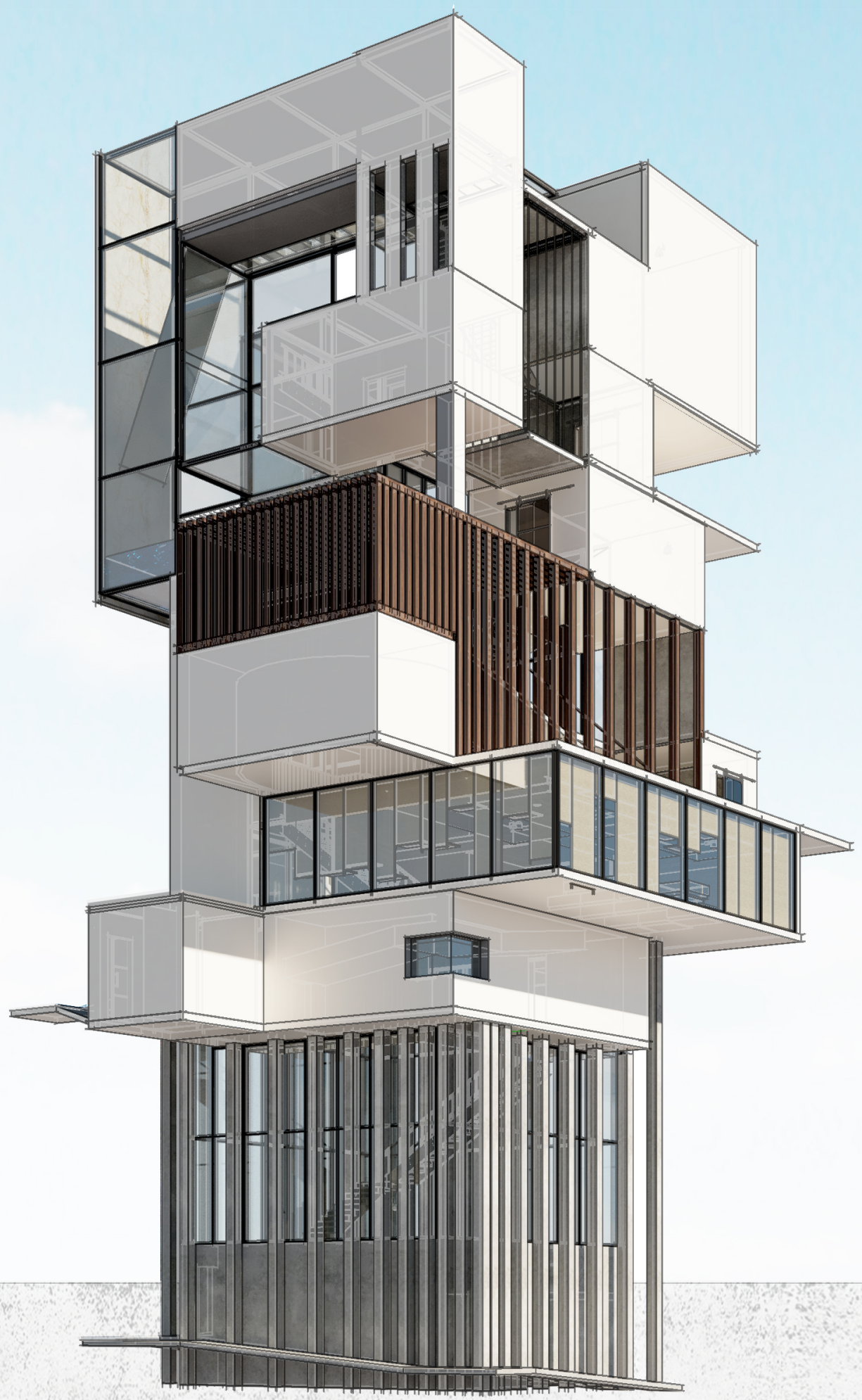




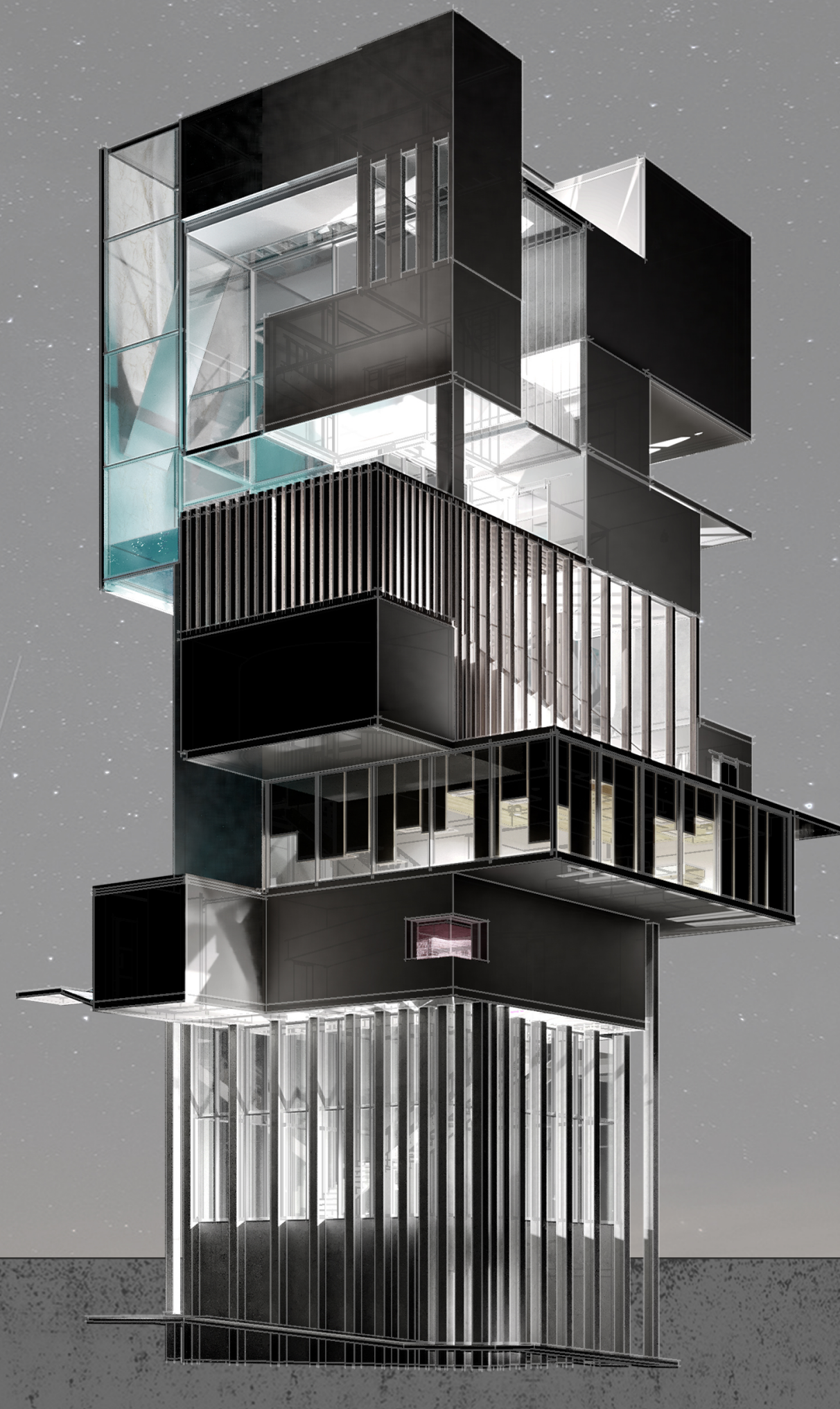



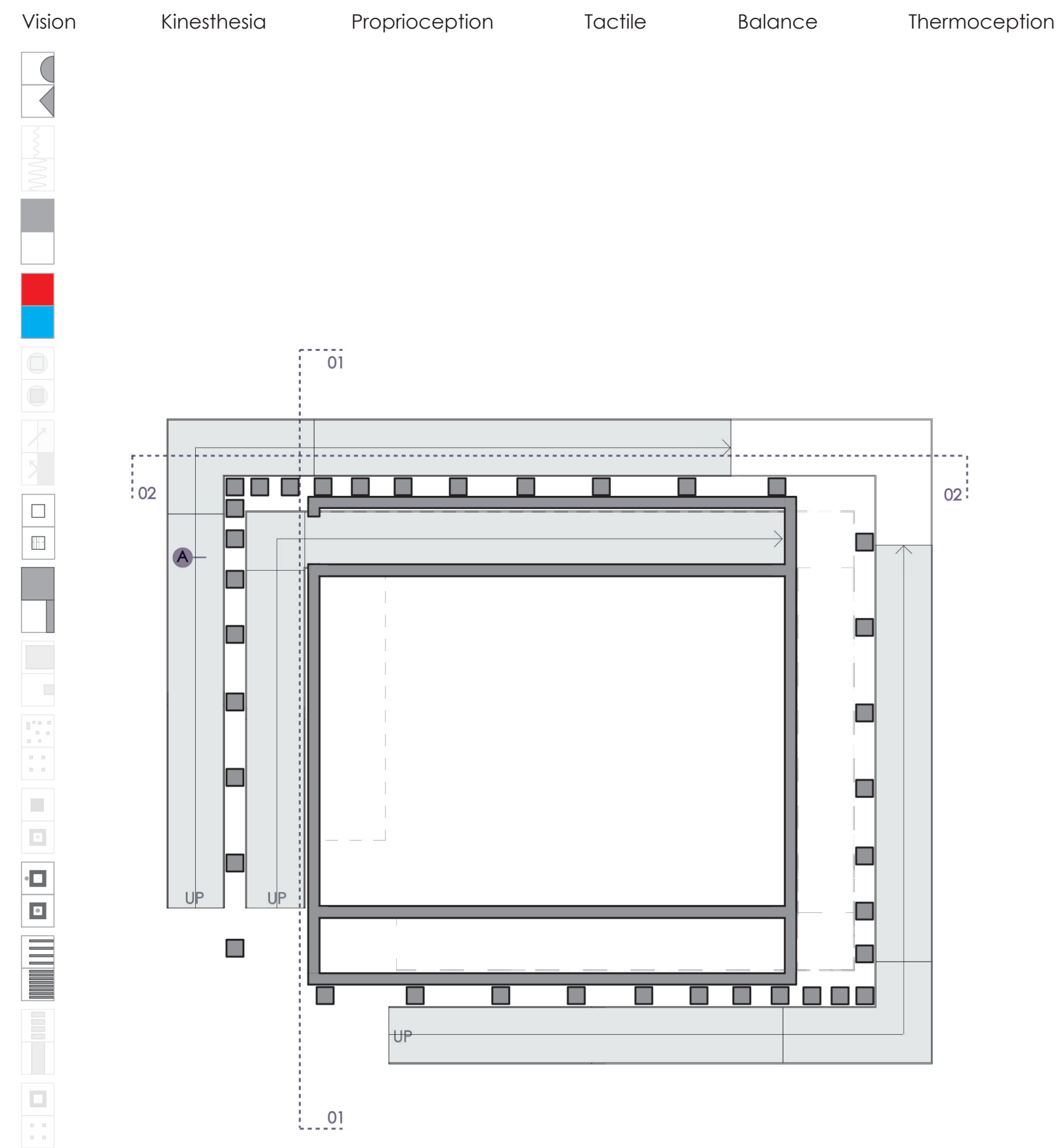

Figure 63: First Floor Plan 
Upon entering, the subject is faced with three options for movement. She pauses to make a decision, and then gradually ascends. As the eye see the interior through the openings, it is convinced that the body is moving in the right path. After a bit of walking, she finds herself descending again, reaching her initial location. Followed by a short pause, the second ramp is taken.

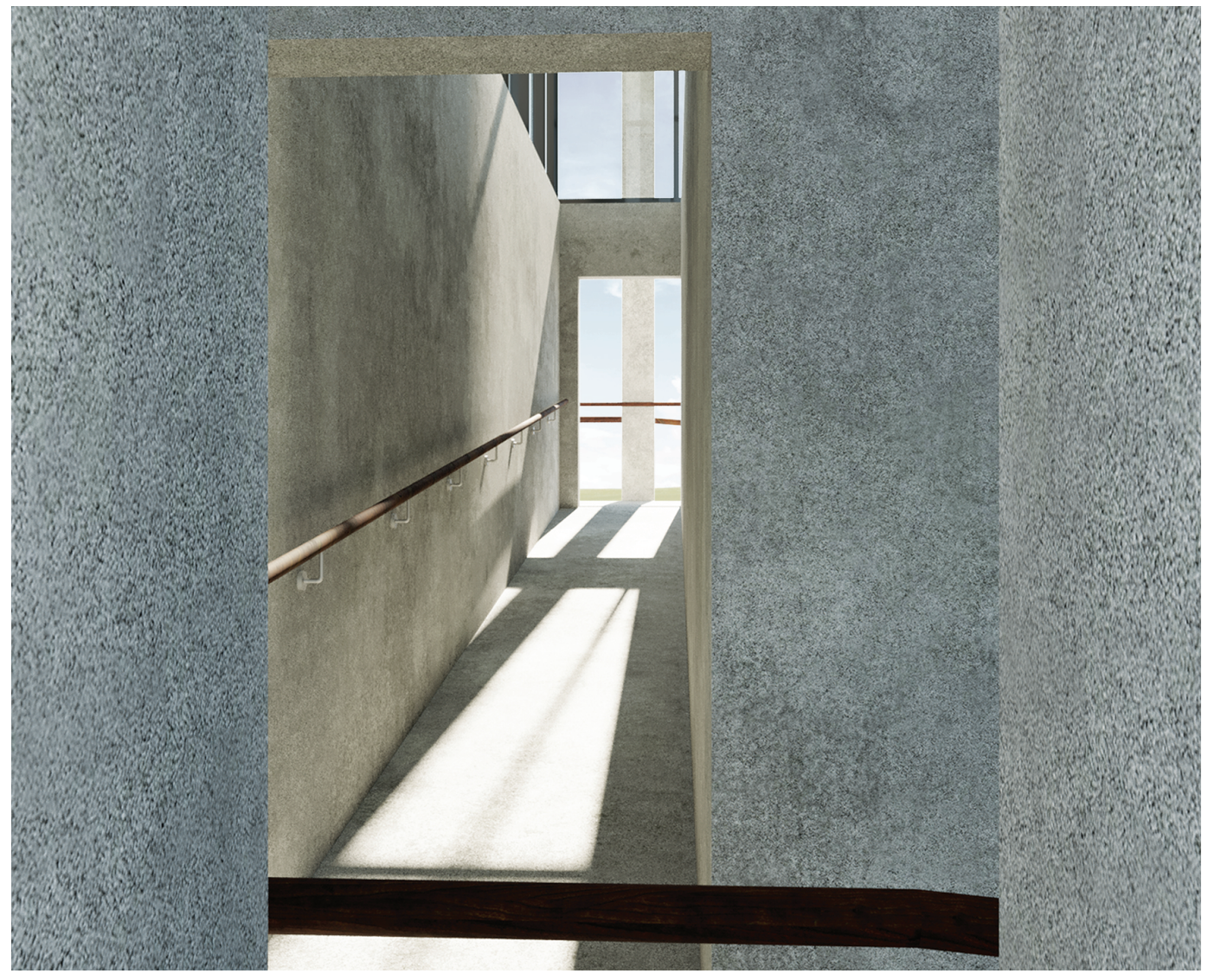

Figure 64: Scene A - View of the Inside through Openings, while on the Ramp 


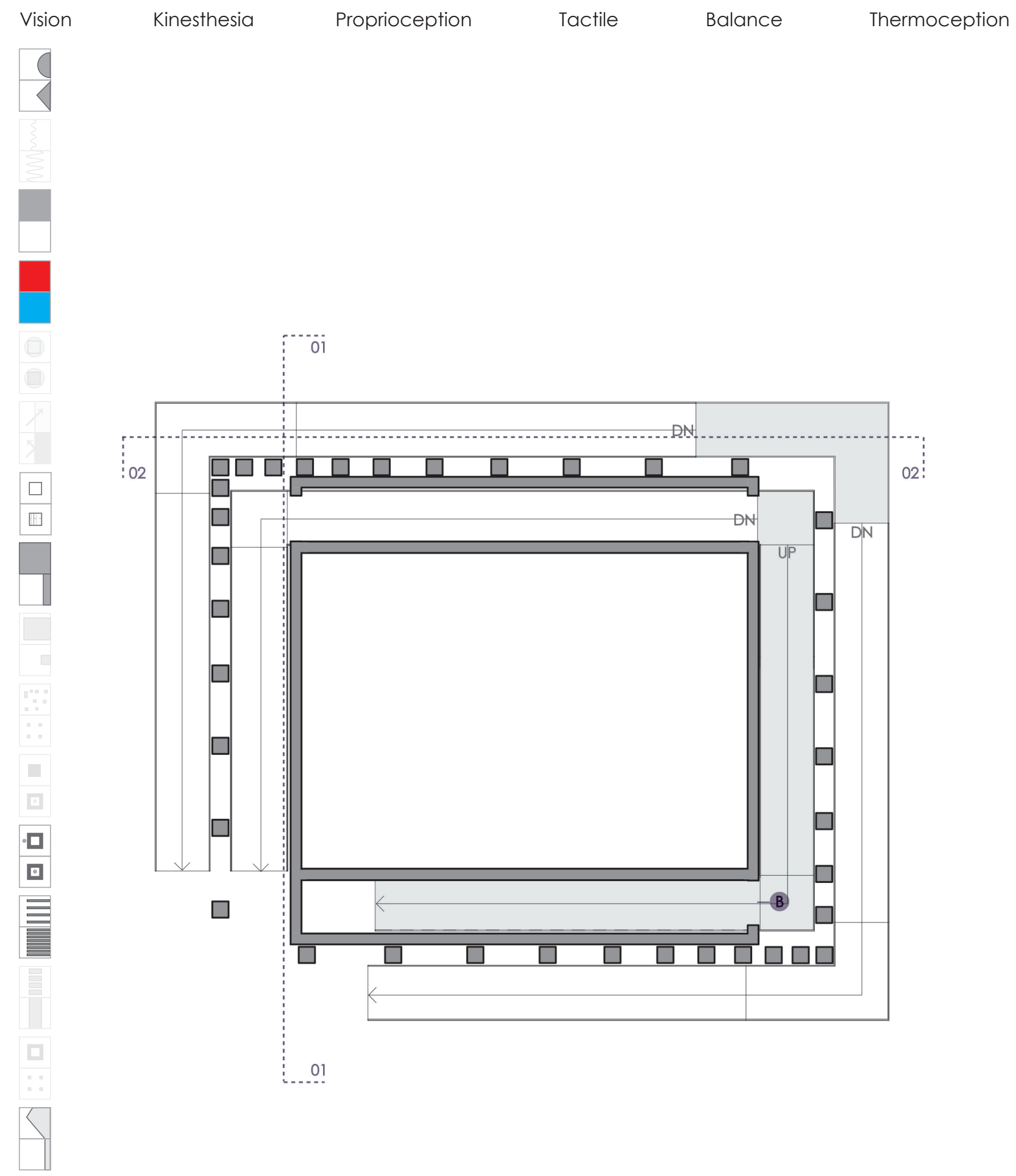

Figure 65: Second Floor Plan 
There is an ambiguous state between indoor and outdoor as the visitor slowly transitions between inside and outside. The exterior ramp becomes interior as it ascends. She finds herself inside the building but then is taken outside again. The constant change between inside and outside results in temperature fluctuations. The warmth, softness and circular geometry of the pine handrail, in contrast to the cold and hard texture of concrete, invites touch as the body tries to navigate in space.

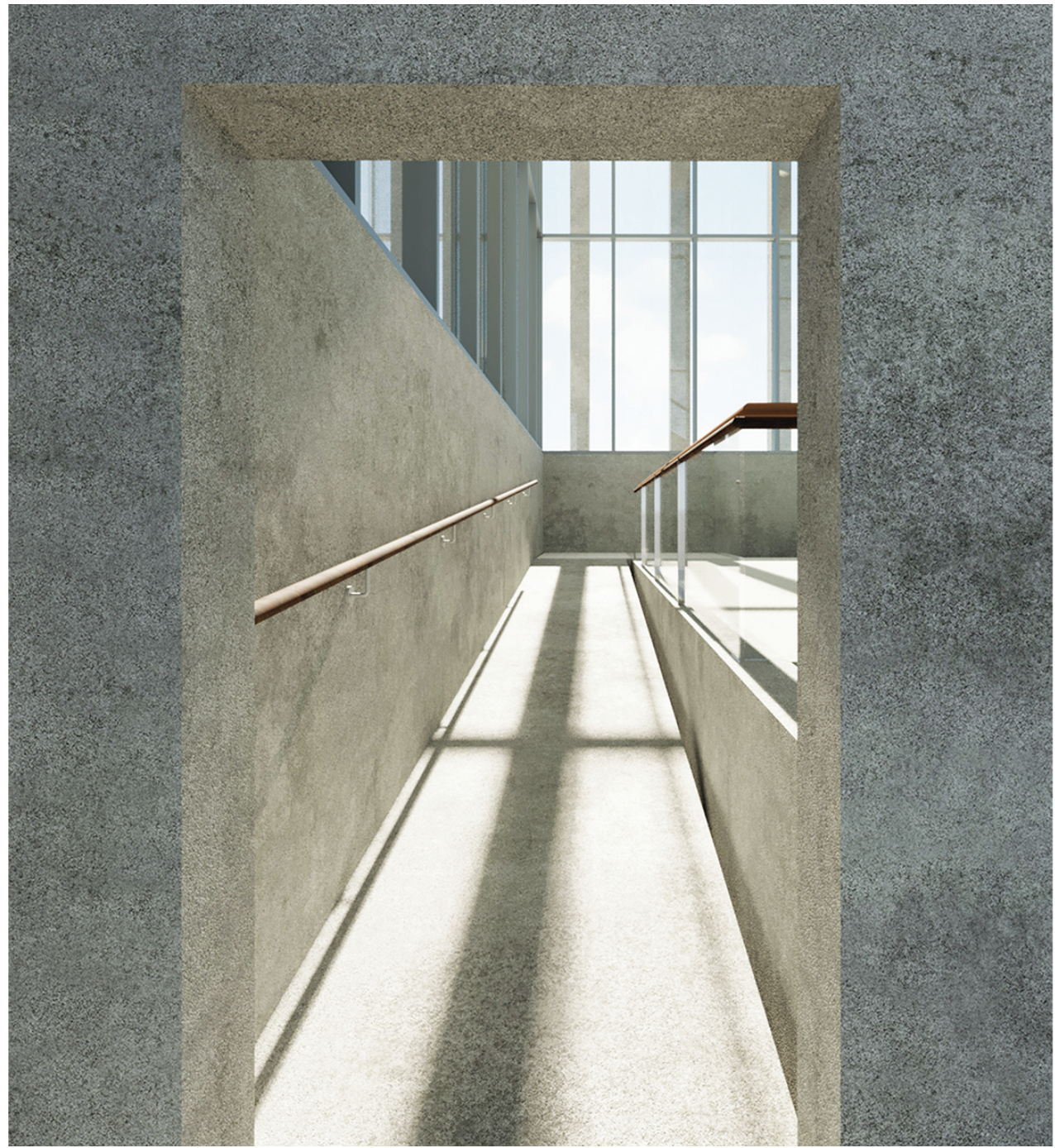

Figure 66: Scene B - View of the Entrance to the Foyer 


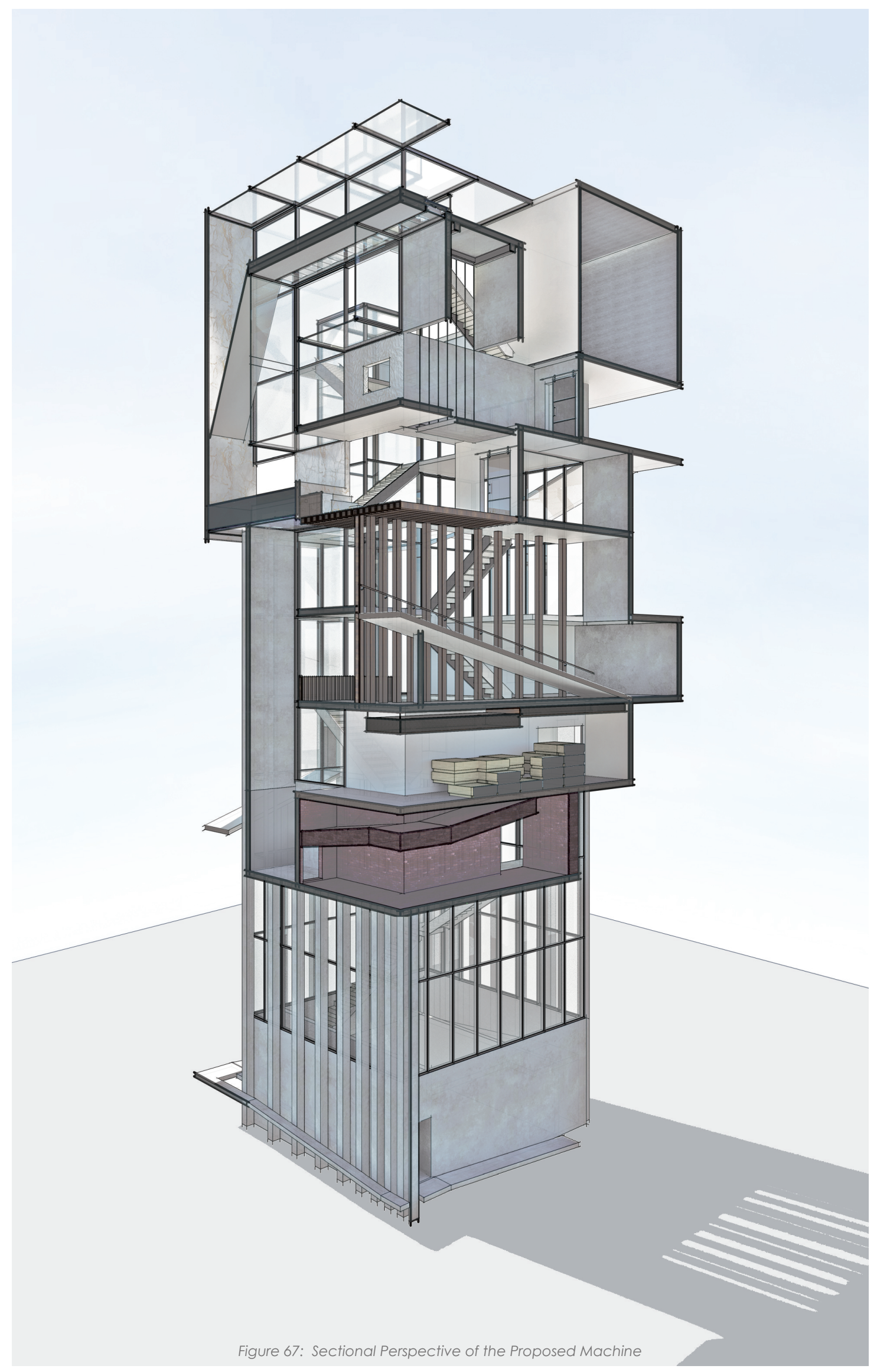


Vision

Kinesthesia

Proprioception

Tactile

Balance

(D)

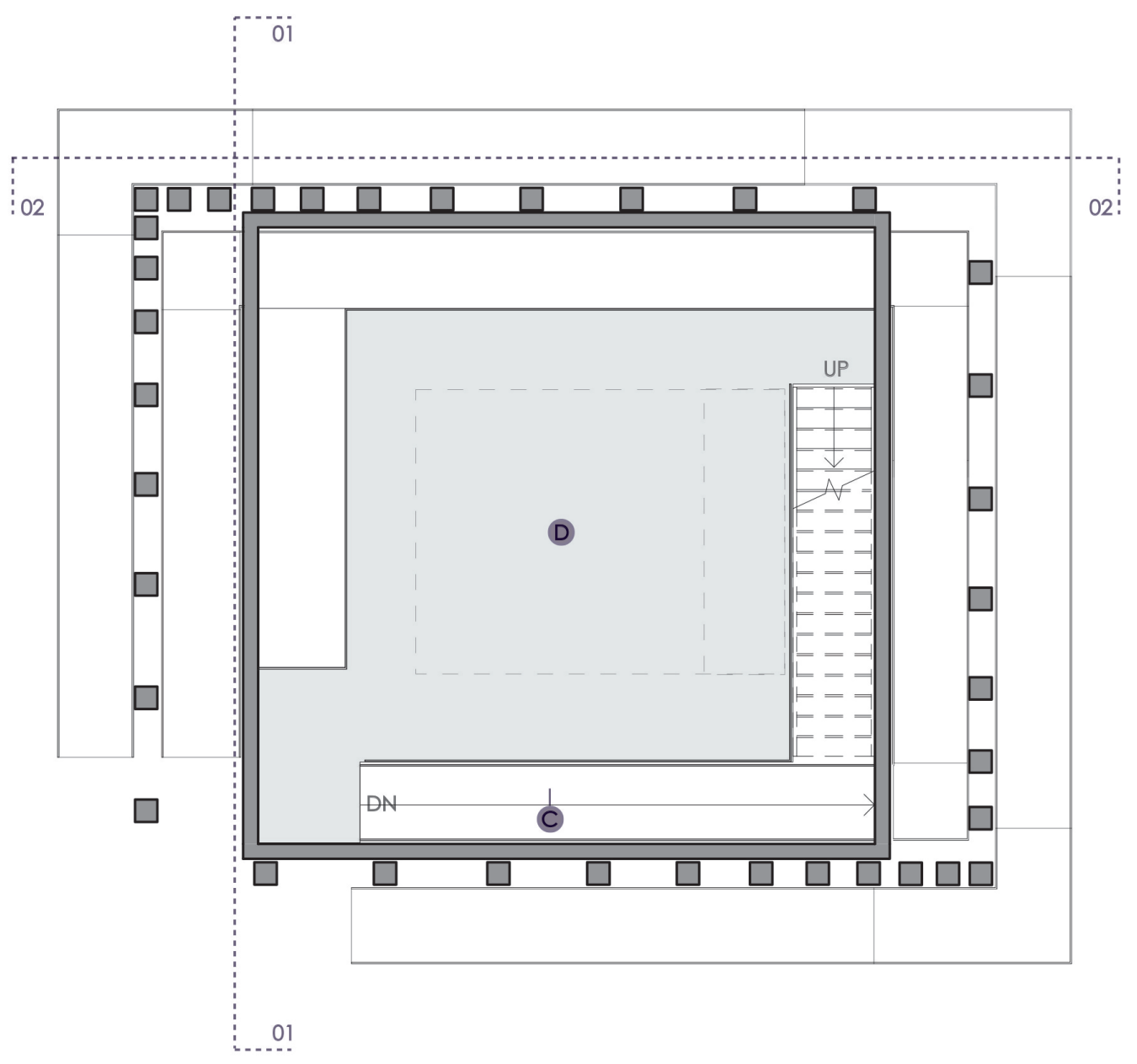

Figure 68: Third Floor Plan 
After the twists and turns, the ramp finally enters the building and leads to the large celebratory foyer. Looking around the foyer, she finds the next set of stairs in the corner.

On each level, the subject has the option of entering the staircase located in the core to get access to different levels in a fast and conventional way. However, there is also the option of entering the cubes and experiencing spaces with no knowledge of what comes next. The change in the materiality of the circulation spaces also encourages the exploration of the cubes. Soft carpet and wooden handrails with glass balusters are used for the circulation spaces, contrasting the harder feel of the metal staircases and stainless-steel handrails used on the stairs.

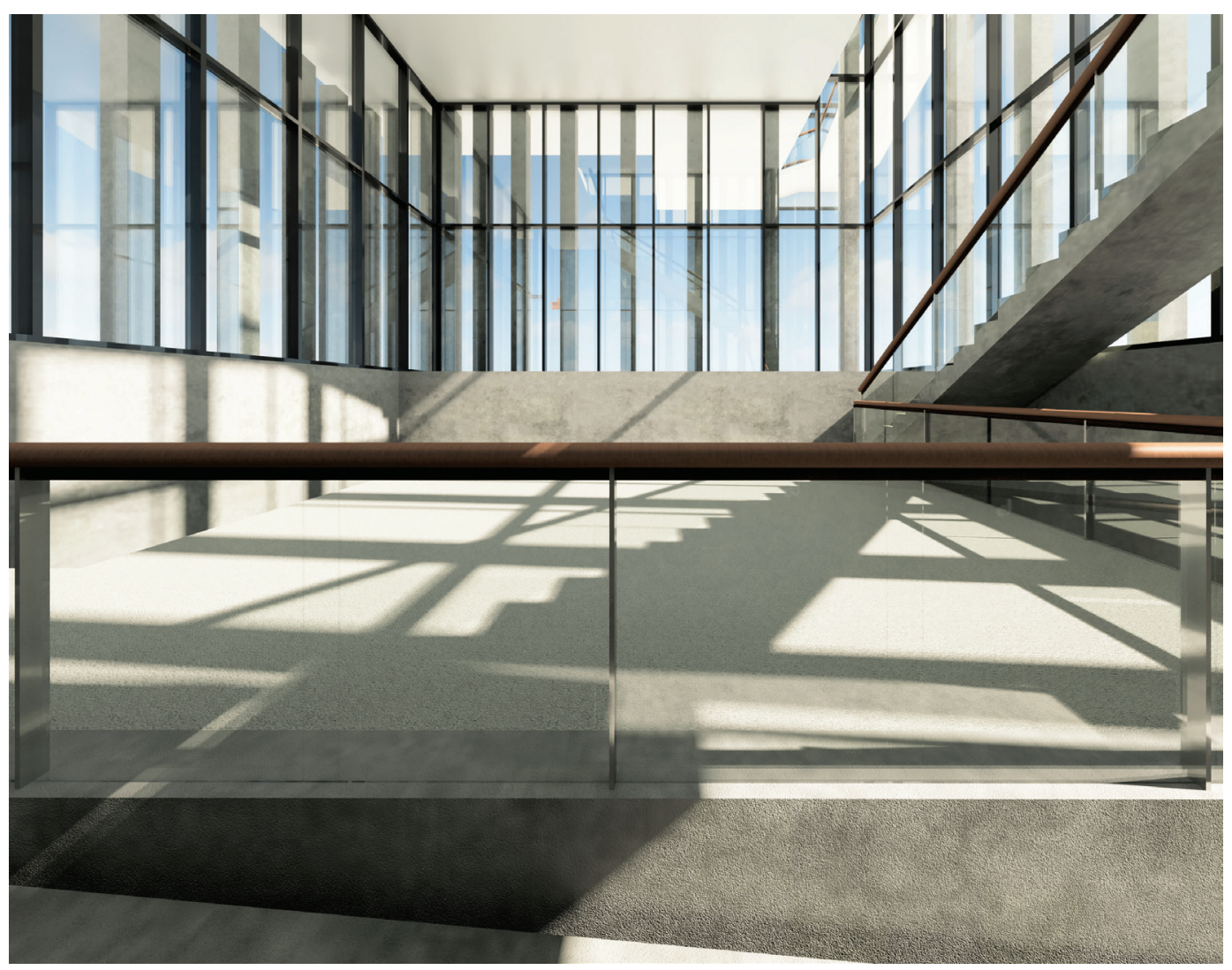

Figure 69: Scene C - View of the Foyer with Drastic Light and Shadow Effect 
The feeling of expansiveness motivates the eyes to look up to the sky. They interpret the repetition of stairs and landings as levels with similar layouts. Later, she decides to continue her journey.

This interrupted and slow movement, from the entrance to the foyer and then to the first level, requires a constant change of direction at every landing and, therefore, constantly disorients the body.

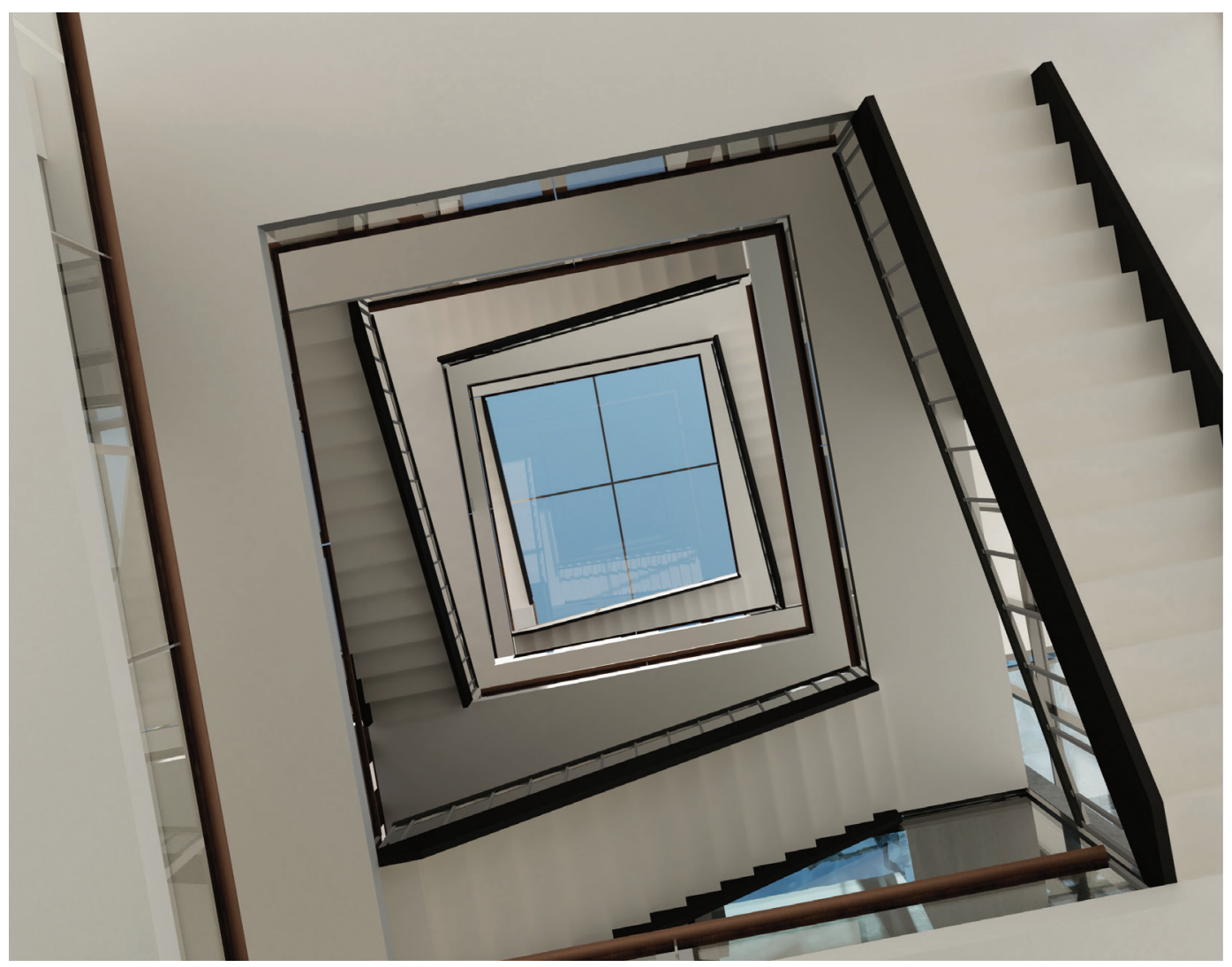

Figure 70: Scene D - Looking Up from the Foyer 
Vision

Kinesthesia

Proprioception

Tactile

Balance

Thermoception
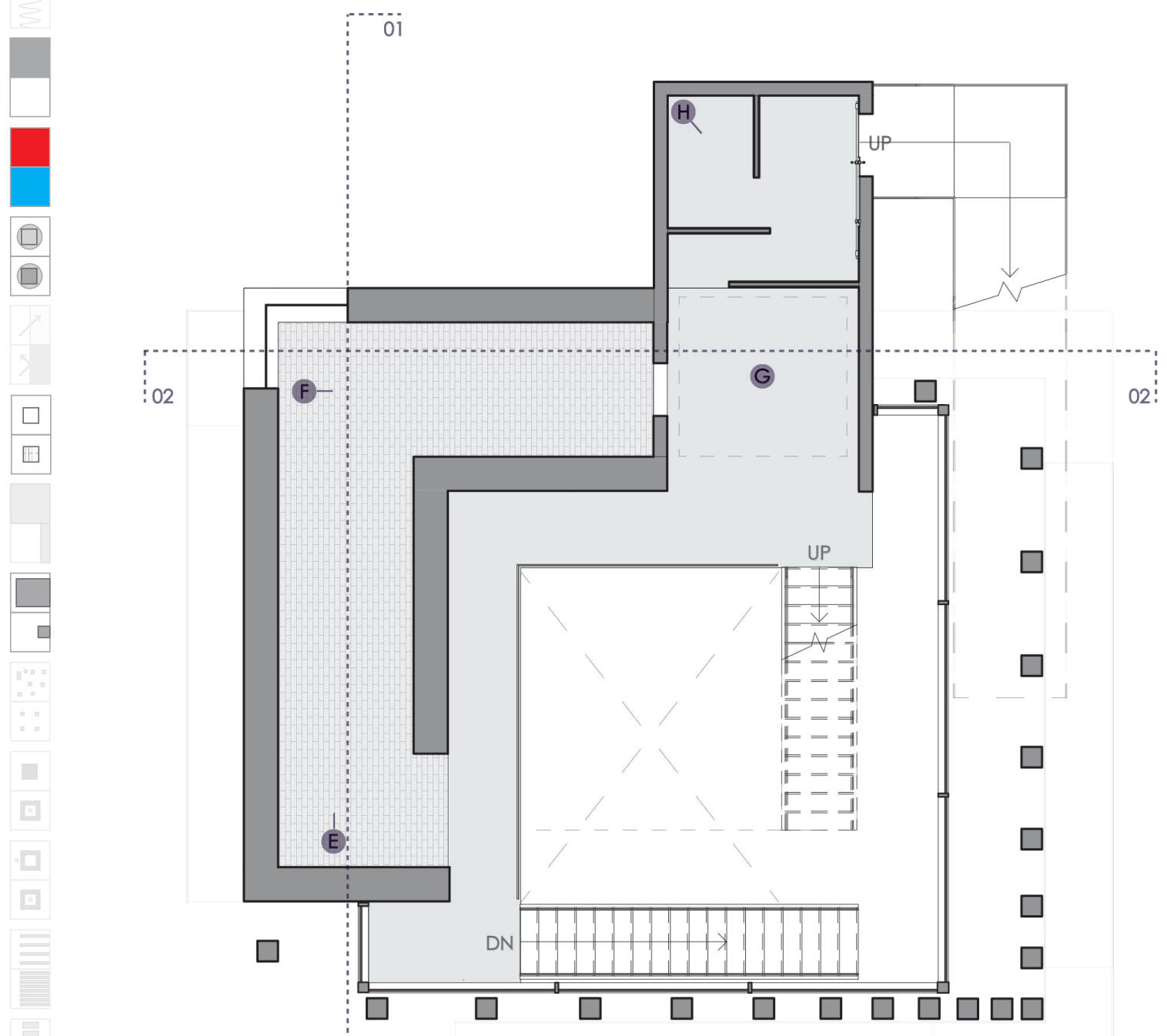

01

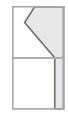

Figure 71: Fourth Floor Plan 
The Brick Room
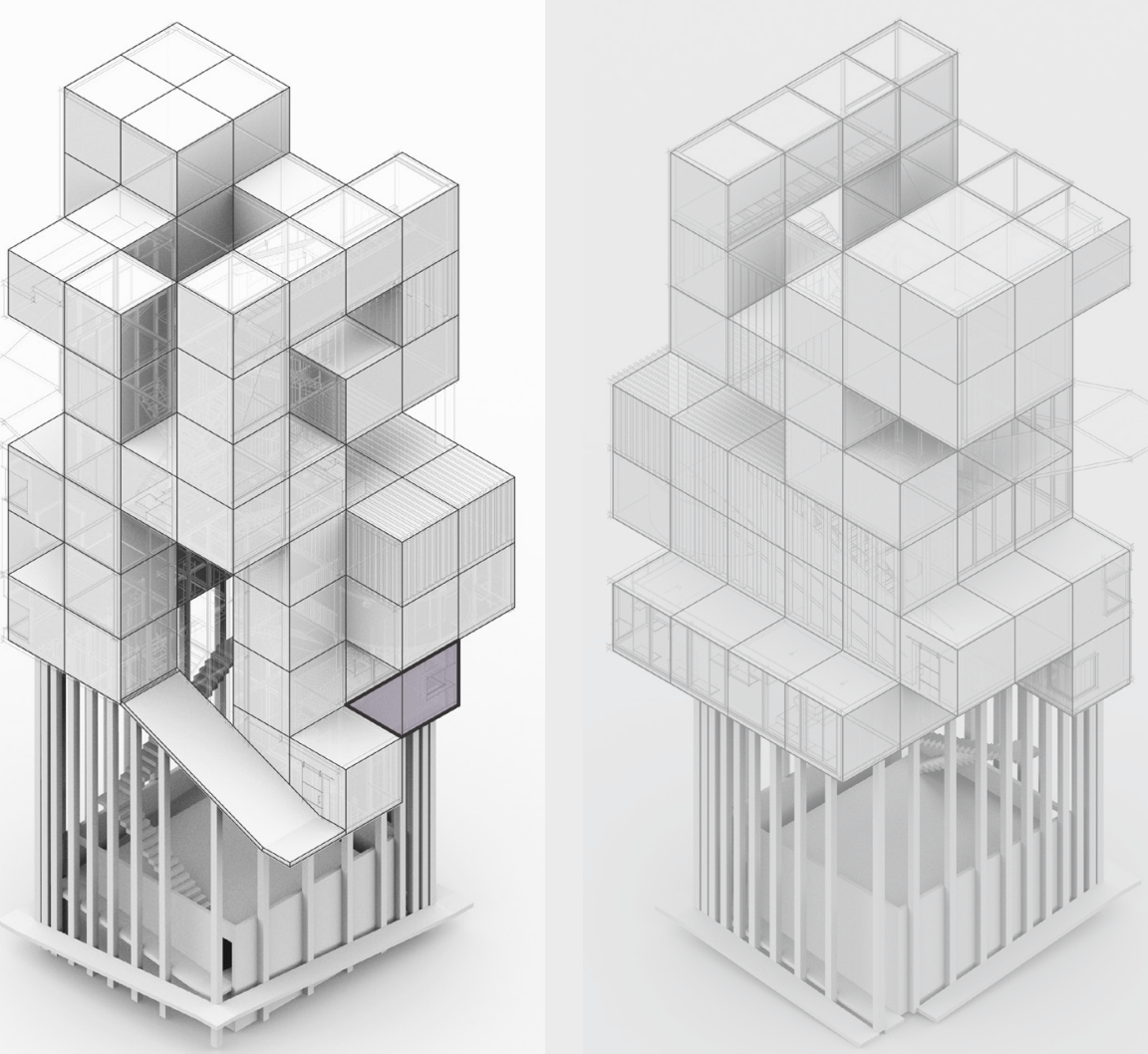

Figure 72: The Brick Room 
The visitor feels a transition between the cold and expansive atrium to the warm and compressed brick room. She senses the heat radiating from the thick brick surfaces, and suddenly feels warm. The hands reach out to feel the texture of the brick. The window creates a strong contrast by introducing an opening in a room with all solid surfaces.

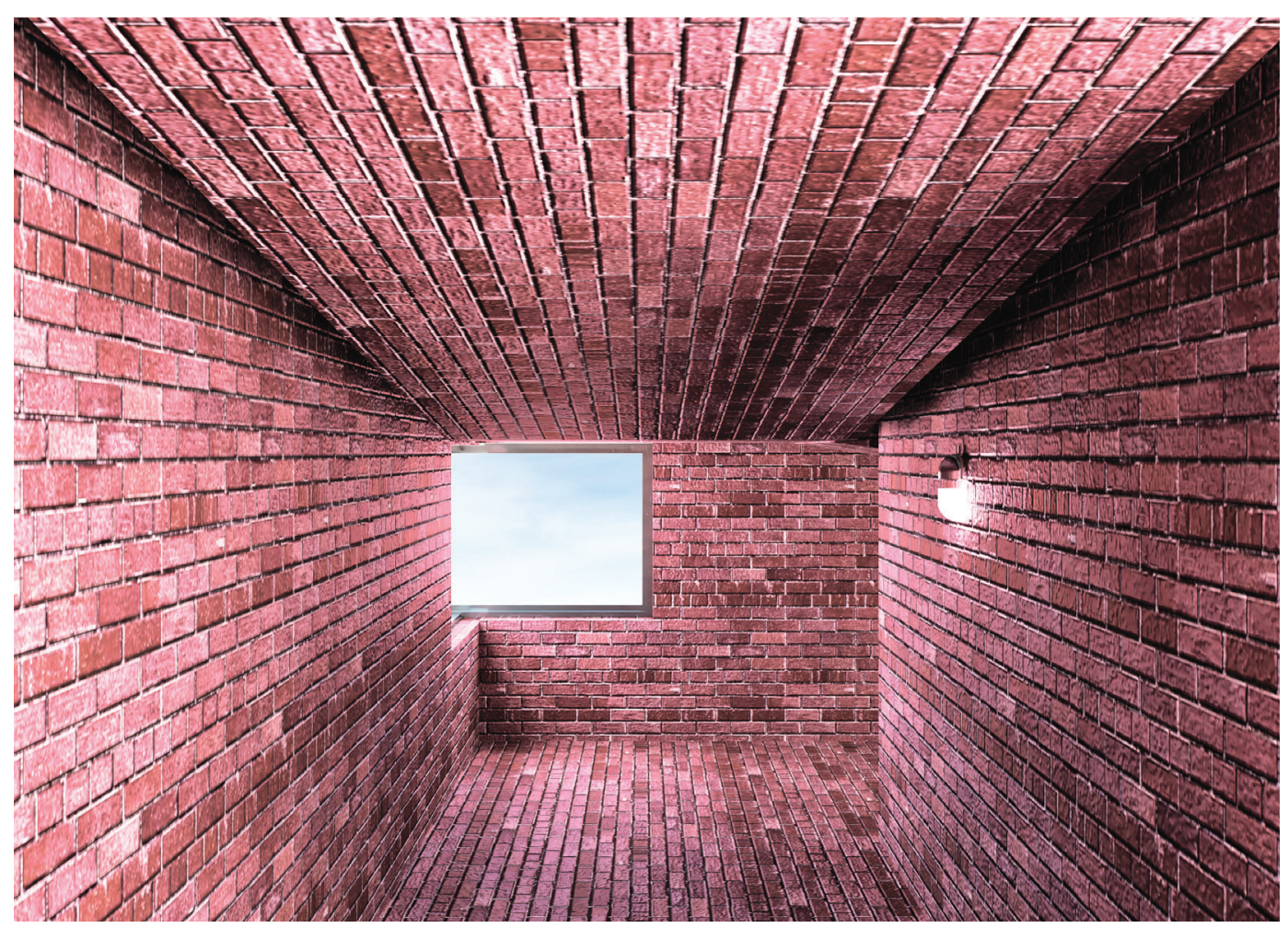

Figure 73: Scene E - Inside the Warm Brick Space, Looking towards the Window 


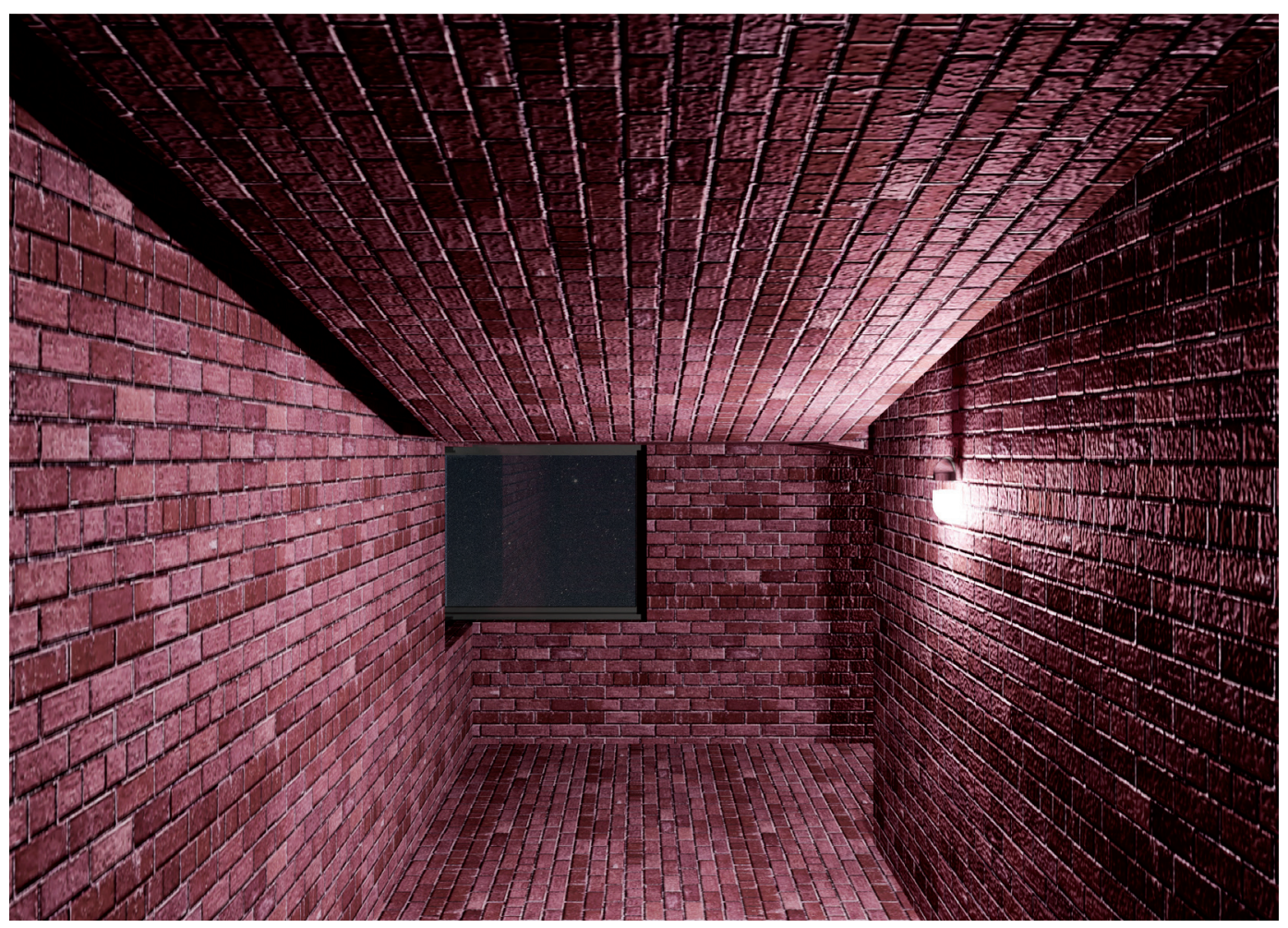

Figure 74: Scene E-Inside the Warm Brick Space, during the Night 
Looking through the next opening, the reflection of water on the floor acts as a visual attraction and invites the explorer to move towards it.

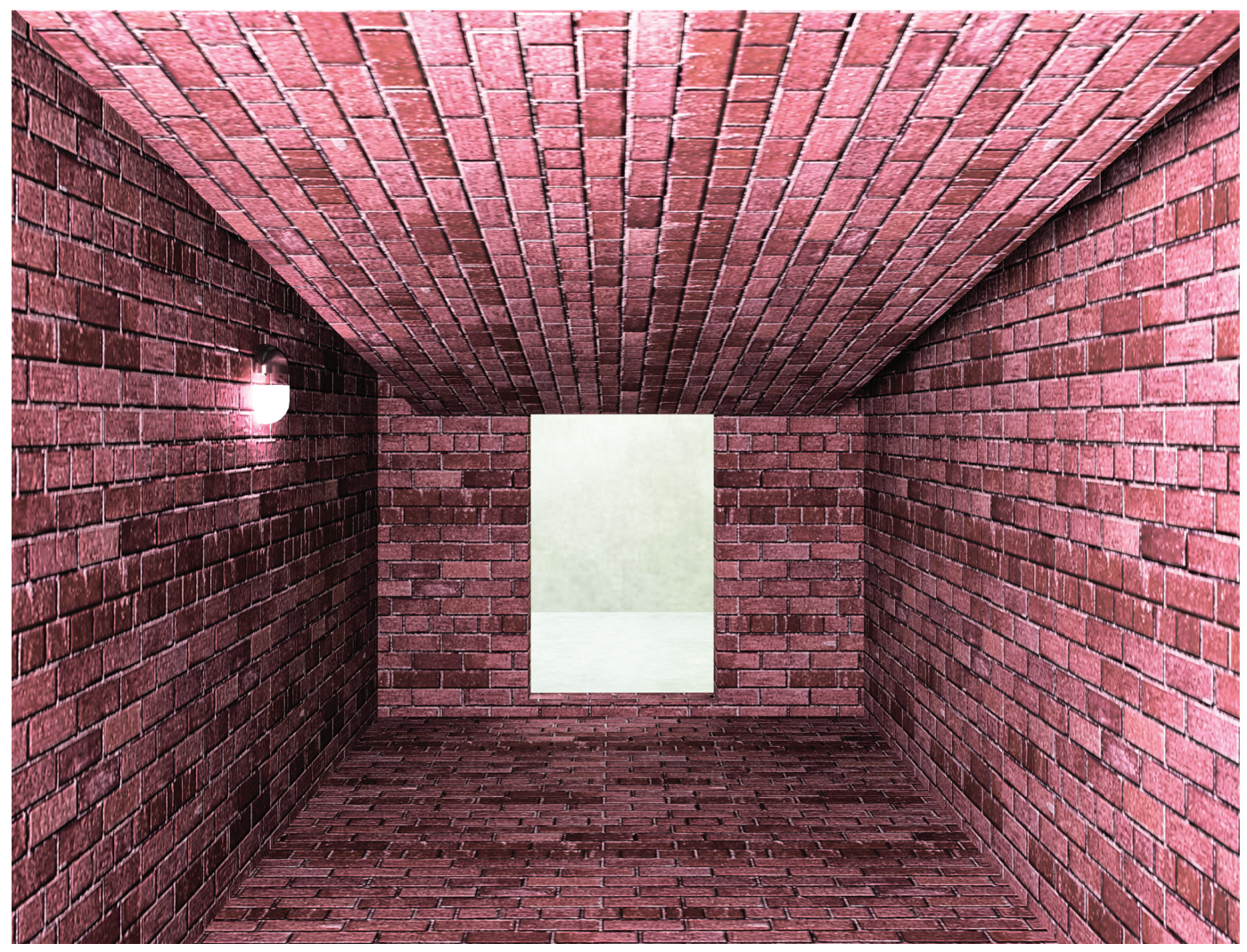

Figure 75: Scene F-Inside the Warm Brick Space, Looking towards the Opening 


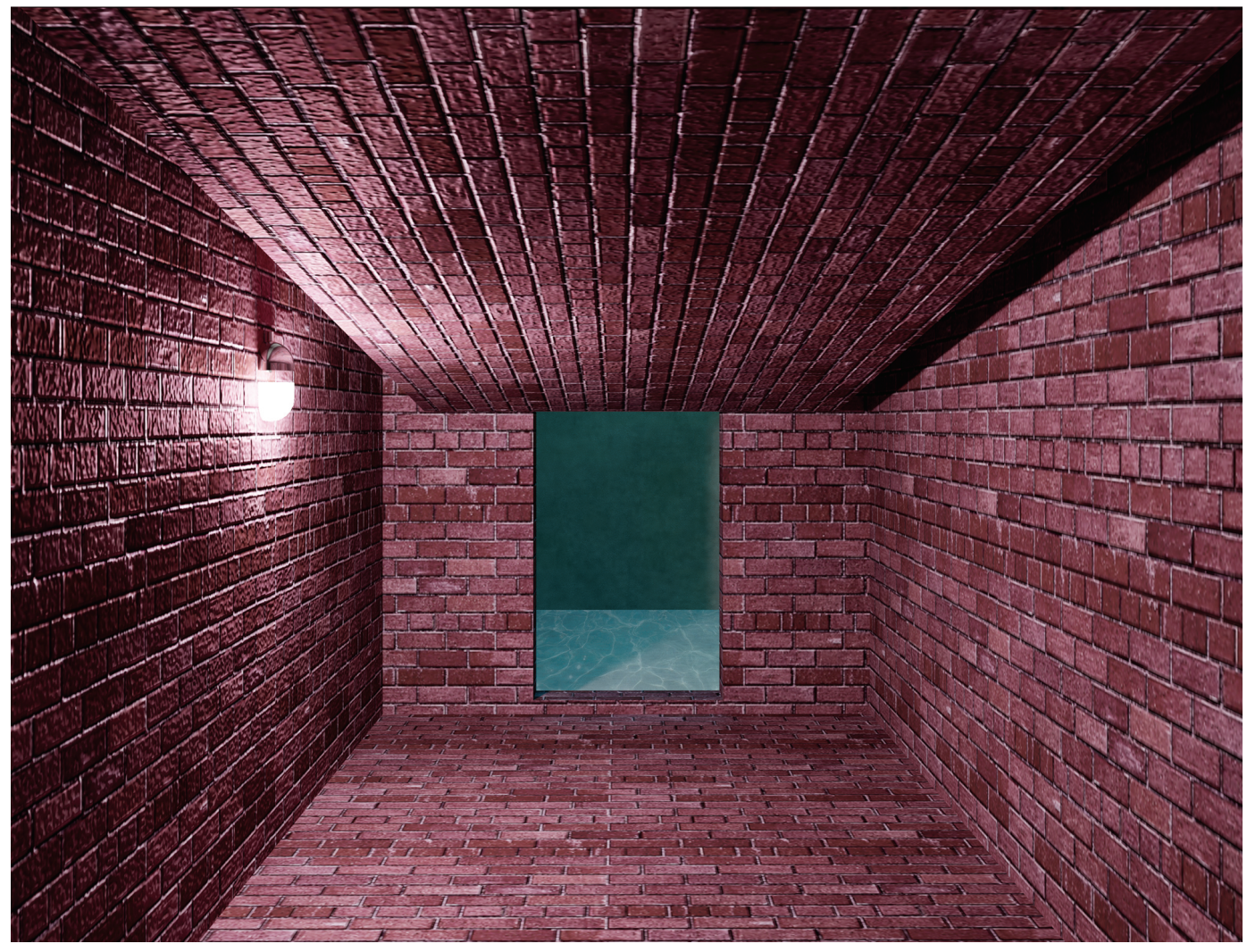

Figure 76: Scene F-Inside the Warm Brick Space, during the Night 

The Ascendant Space

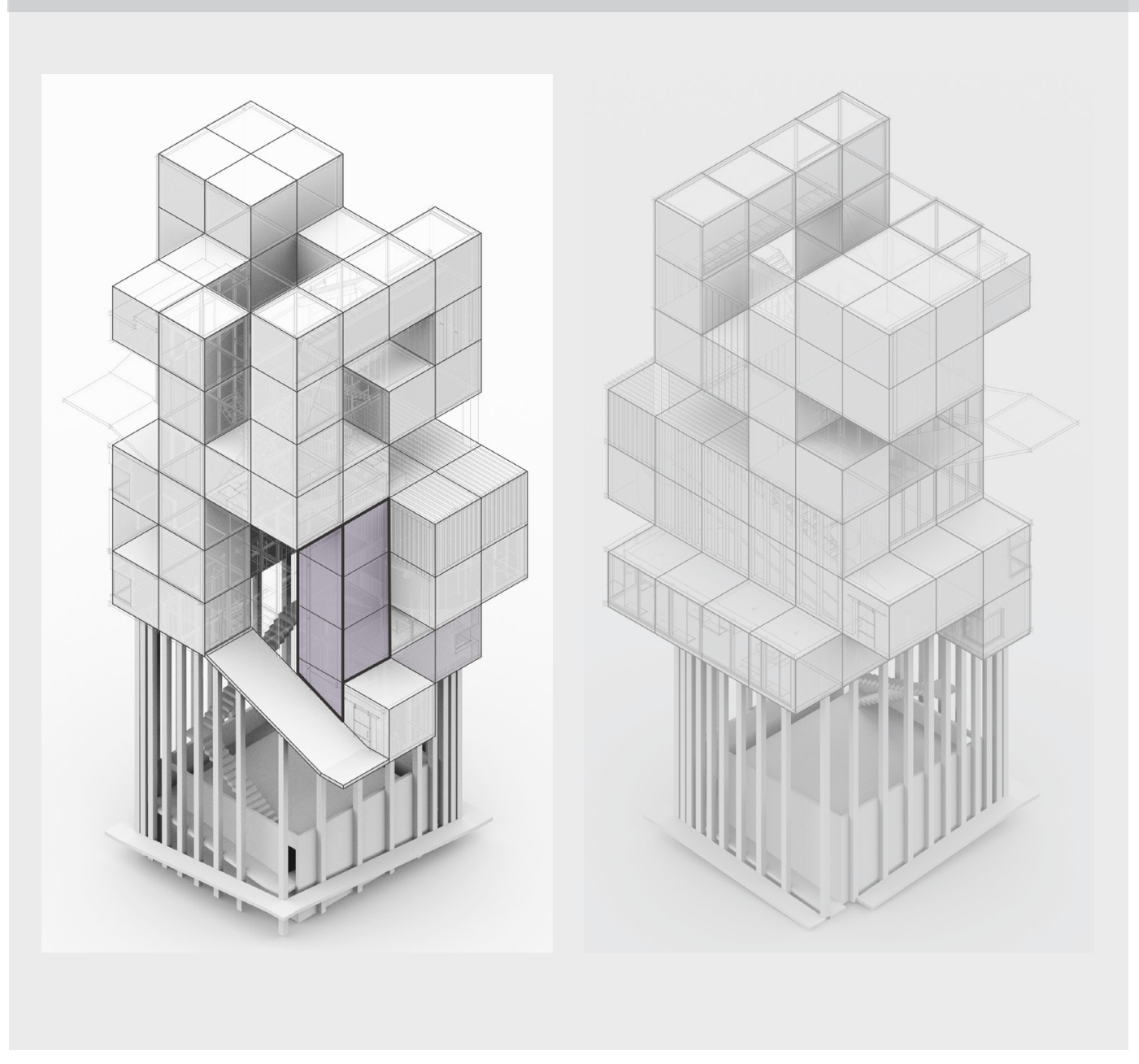

Figure 77: The Ascendant Space 
When leaving the brick room, the subject finds herself in another expansive space. However, this space seems more spacious since it was experienced directly following a very compressed room. Looking up, the eyes meet the water through a glass floor and become curious to navigate there.

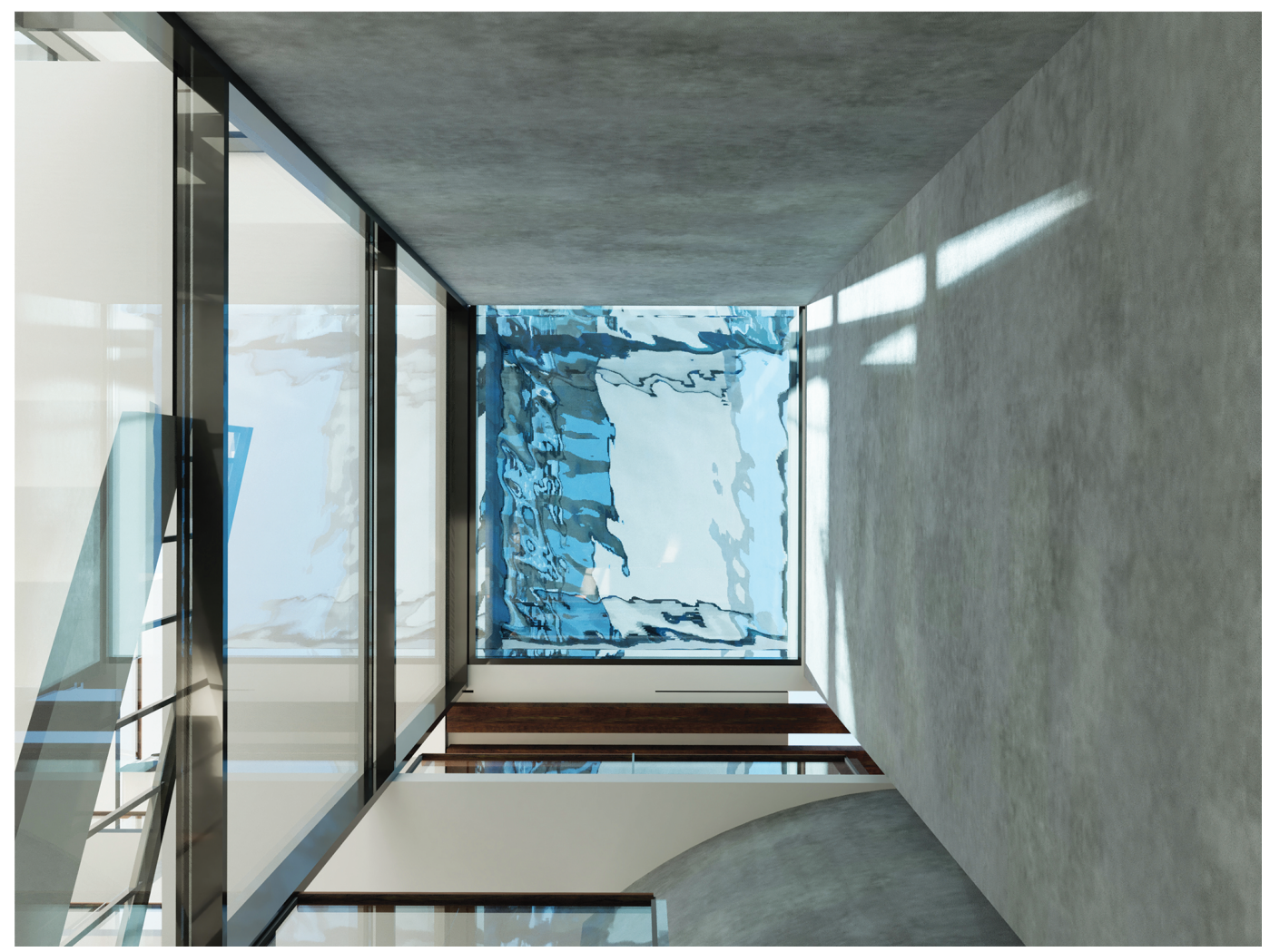

Figure 78: Scene G - Looking up from the Ascendant Space, towards the Glazed Flooring of the Pool 


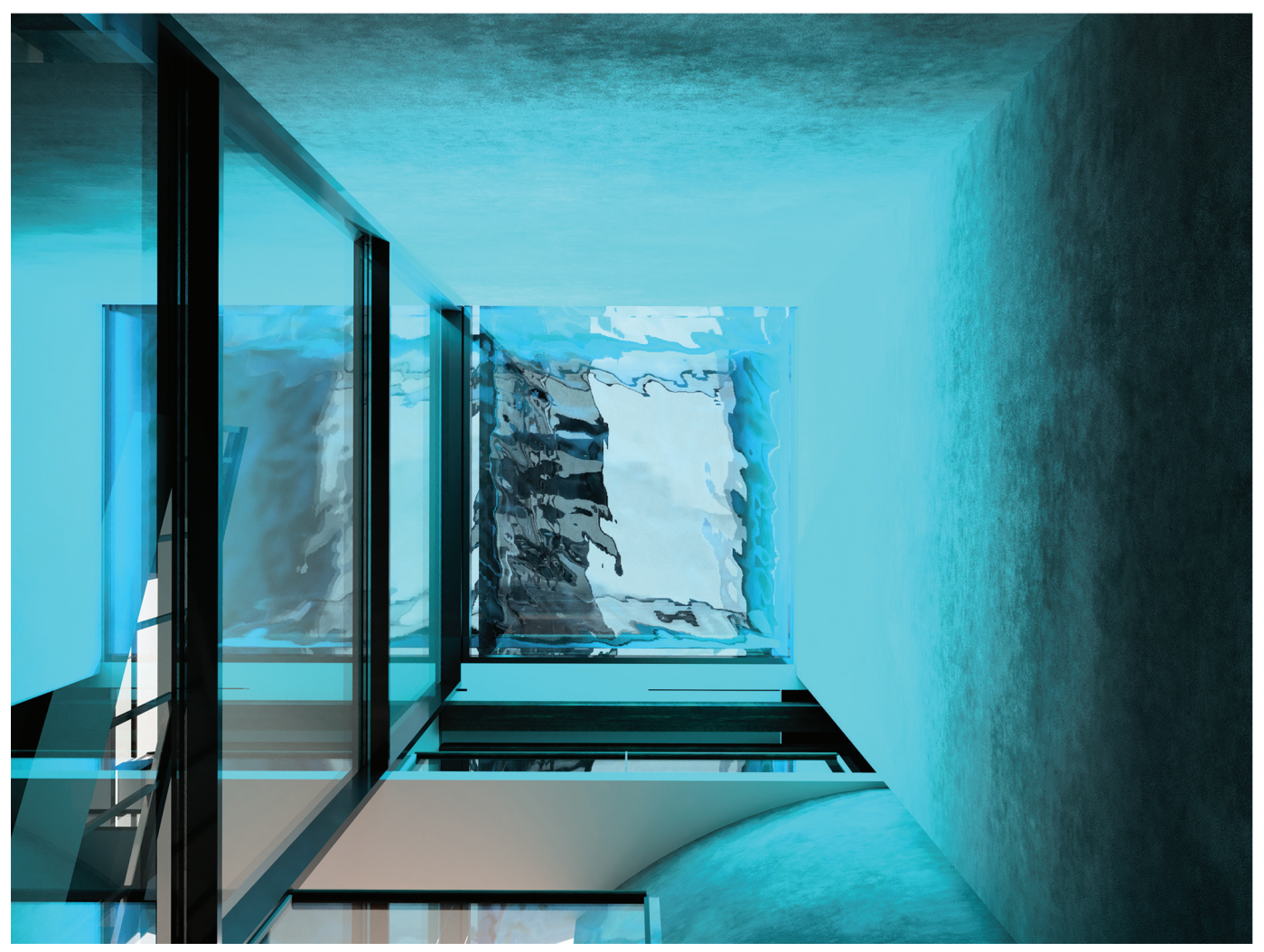

Figure 79: Scene G - Looking up from the Ascendant Space, during the Night 
The Mirror Room
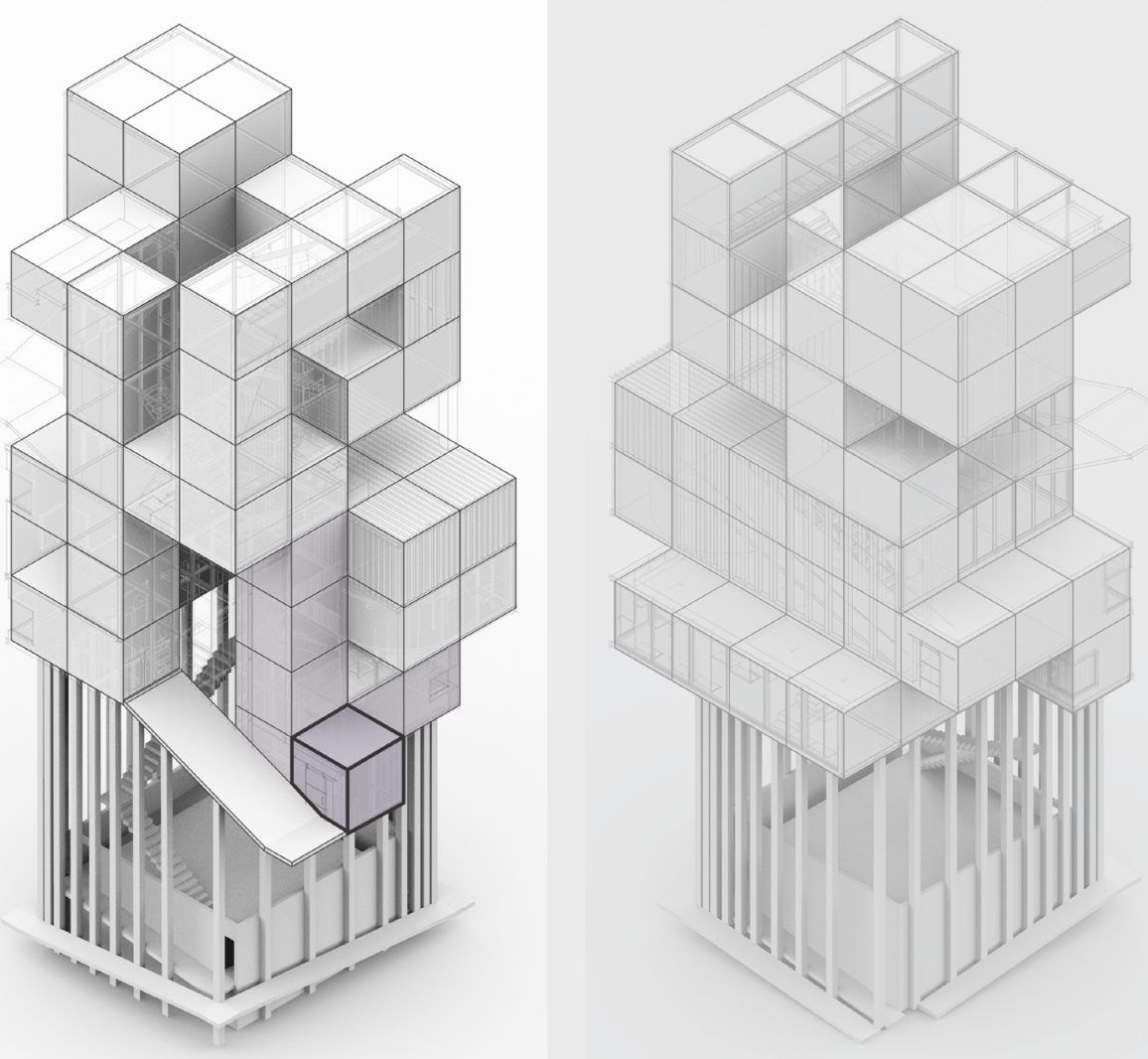

Figure 80: The Mirror Room 
With mirrored surfaces on all sides, the visual perception is expanded, and the visitor becomes extremely conscious of positioning herself and navigating through space. She raises the arms forward to find the way, and as her hands touch the mirrored walls, the feeling of expansiveness changes to one of compression.
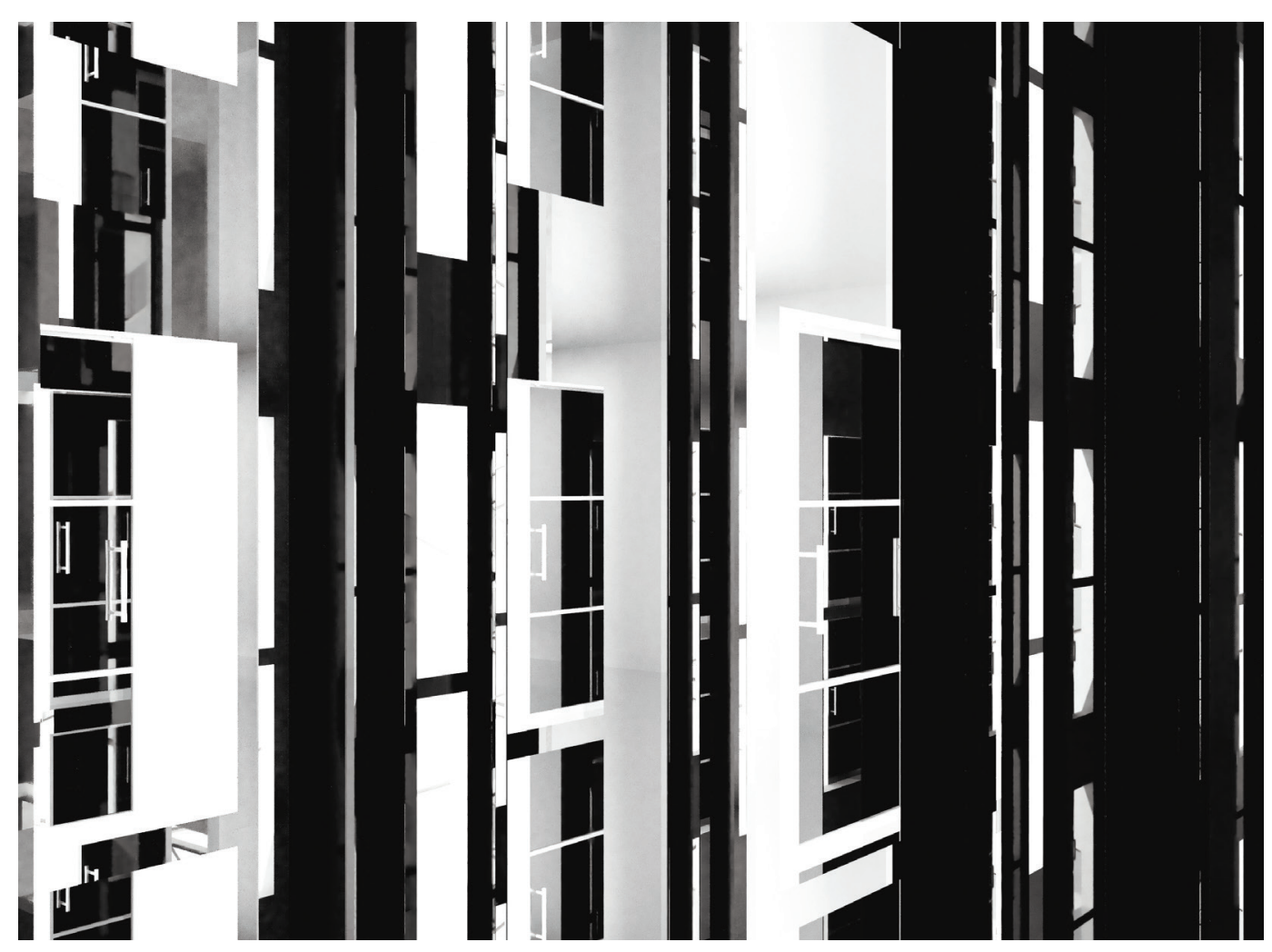

Figure 81: Scene $\mathrm{H}$ - the Visual Abstraction Created by Mirrored Surfaces 
Vision Kinesthesia Proprioception Tactile Bance Thermoception

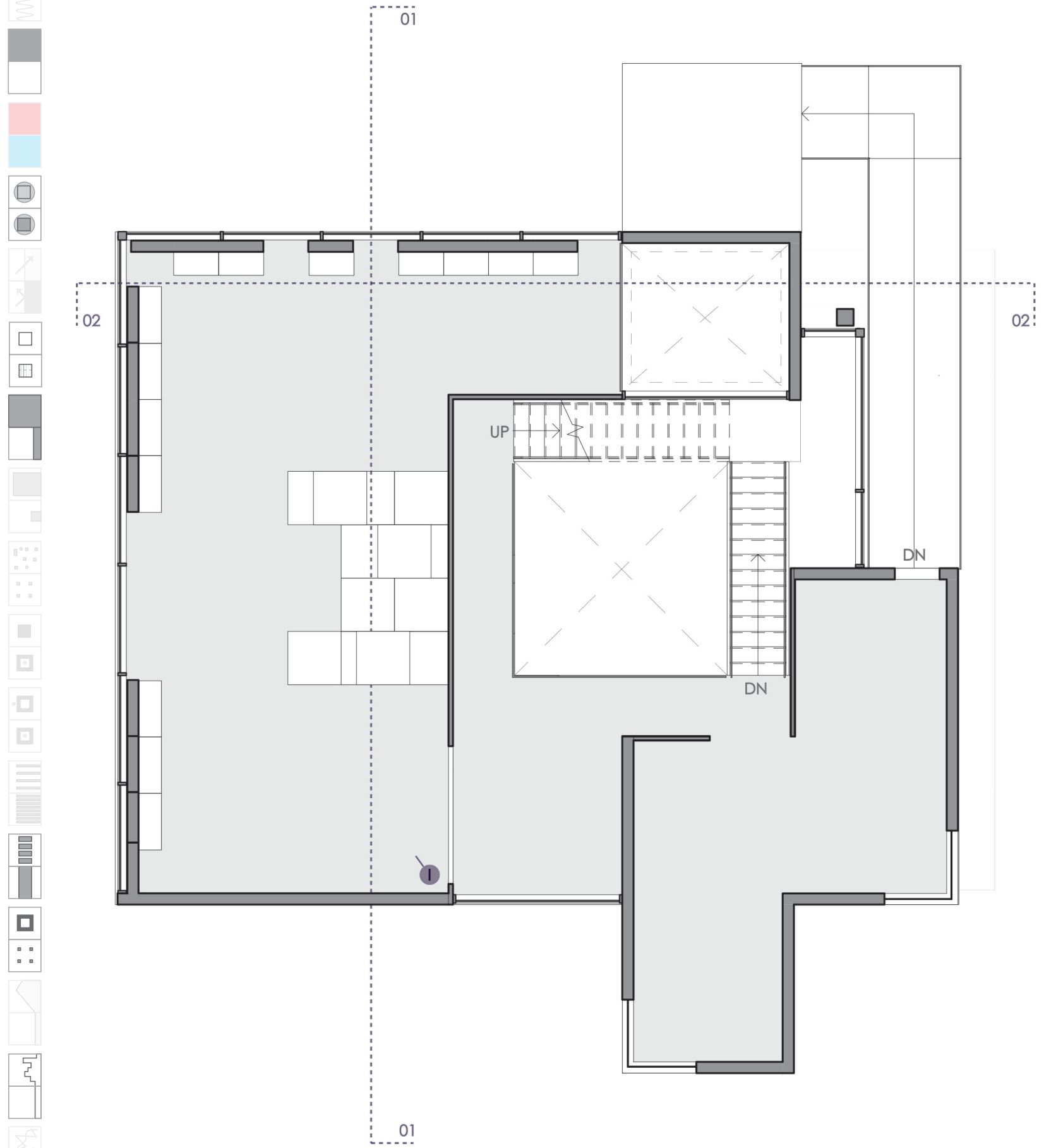

Figure 82: Fifth Floor Plan 


\section{The Flexible Space}
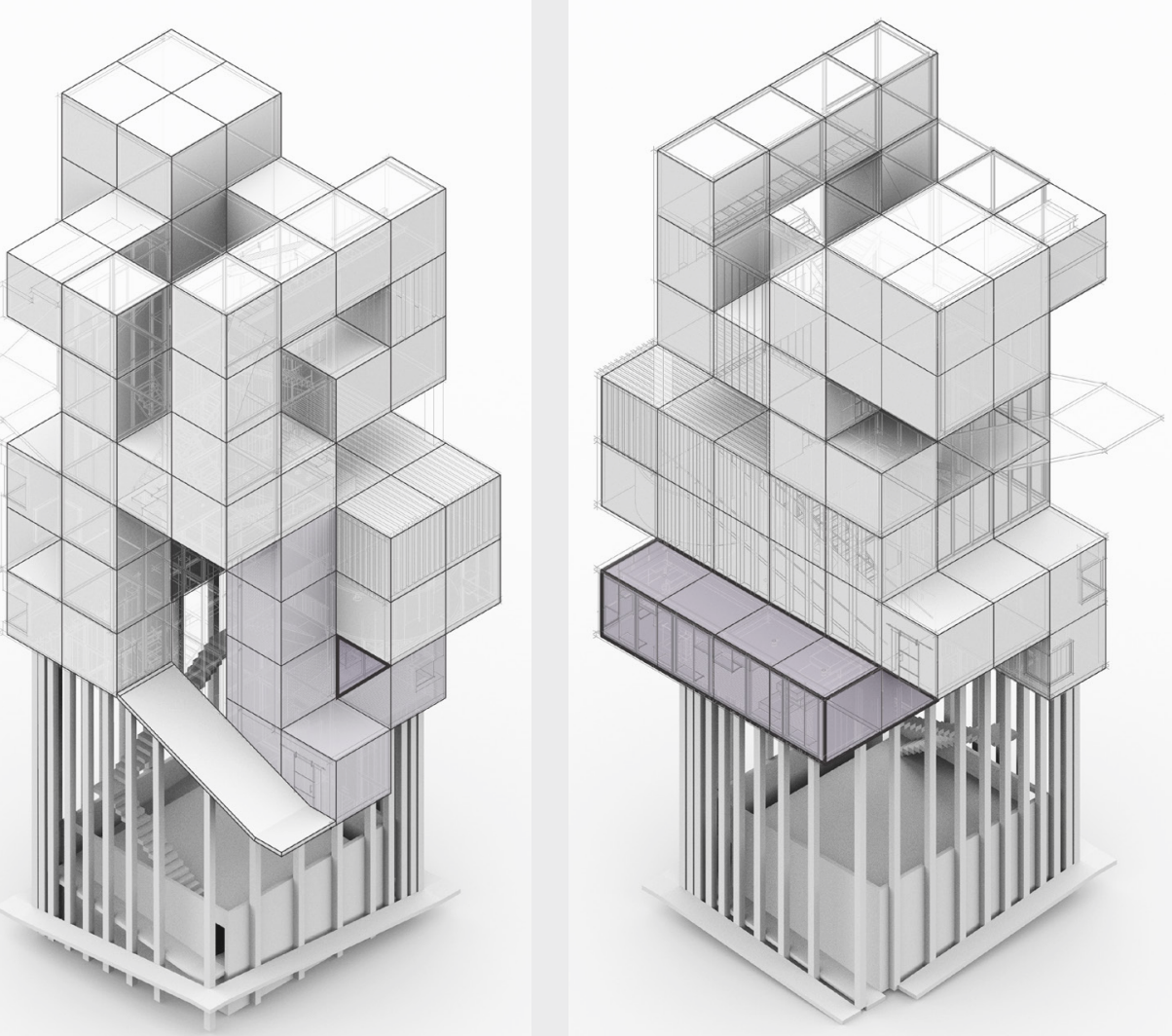

Figure 83: The Flexible Space 
Taking the exterior ramp, the body can reach the next level from the mirrored room. As the visitor enters the flexible space, she can interpret the room based on her need and comfort. This flexibility provokes a sense of ambiguity by questioning the boundaries.

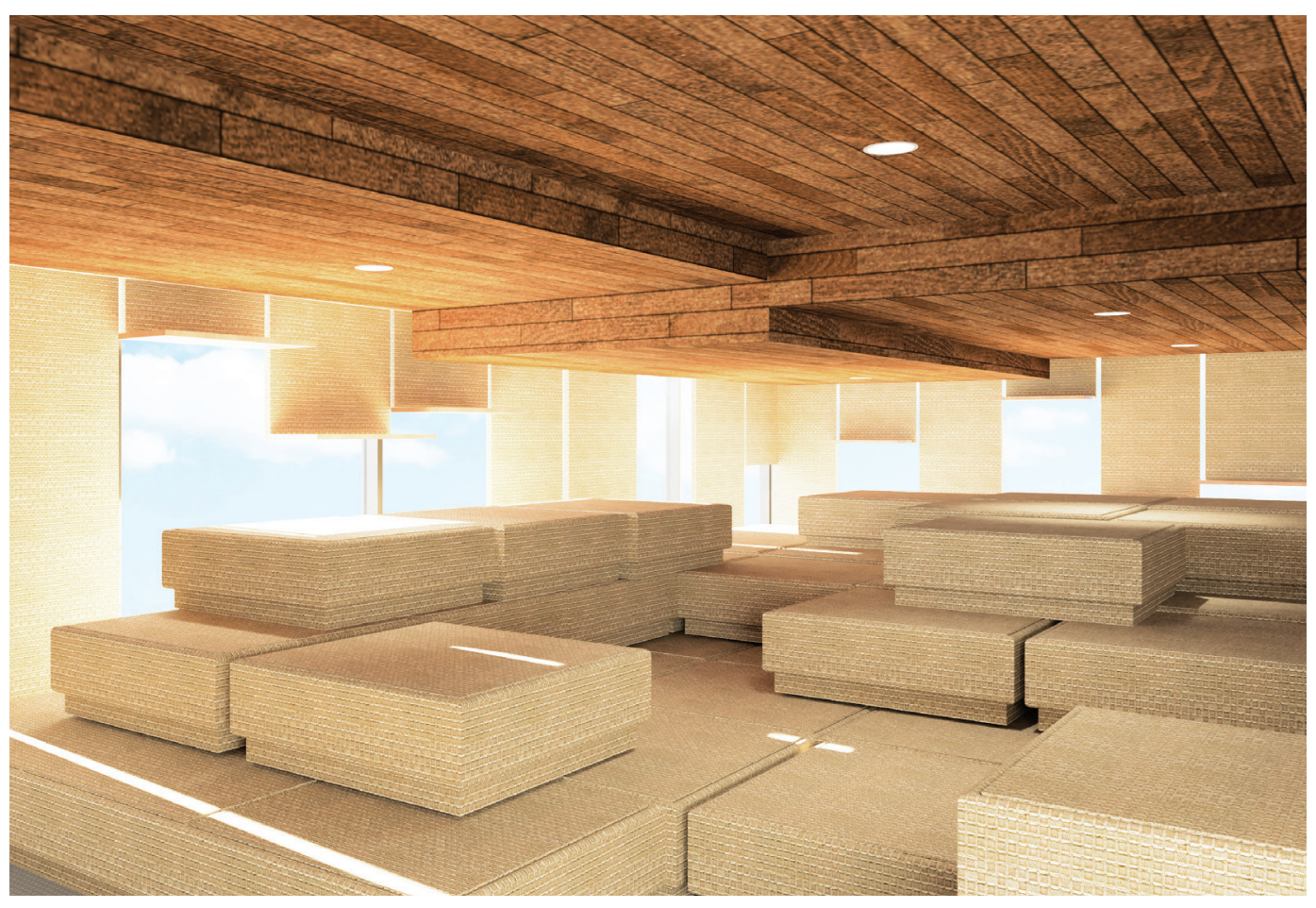

Figure 84: Scene I - Inside the Flexible Space 
The flexible façade can be used as a way to bring in light and provide views of the outside or can be used as soft sitting areas. The carpeted cubes can be interpreted as sitting surfaces, soft flooring to walk on, tables, or partitions.

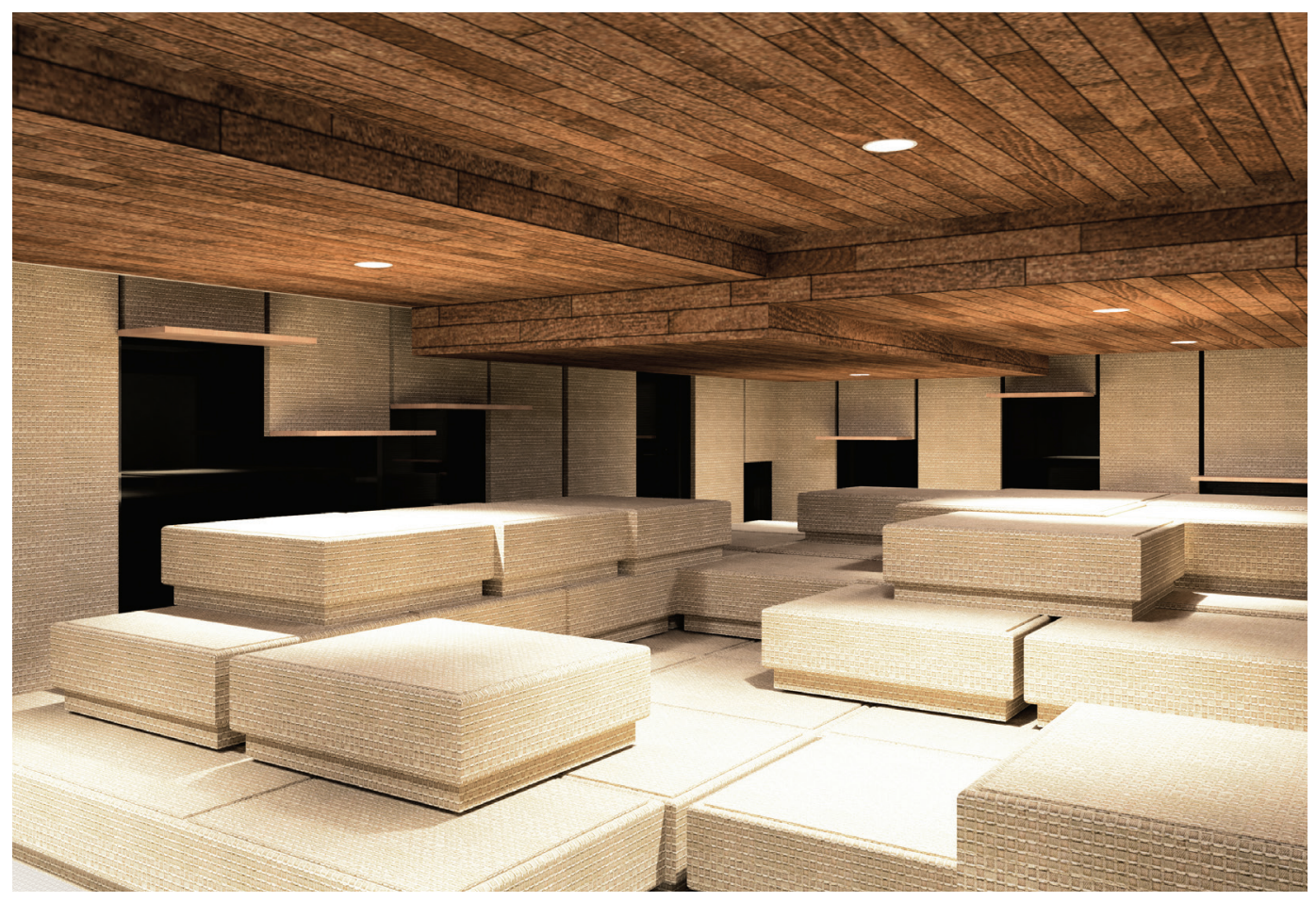

Figure 85: Scene I - Inside the Flexible Space during the Night 
Vision

Kinesthesia

Proprioception

Tactile

Balance

Thermoception

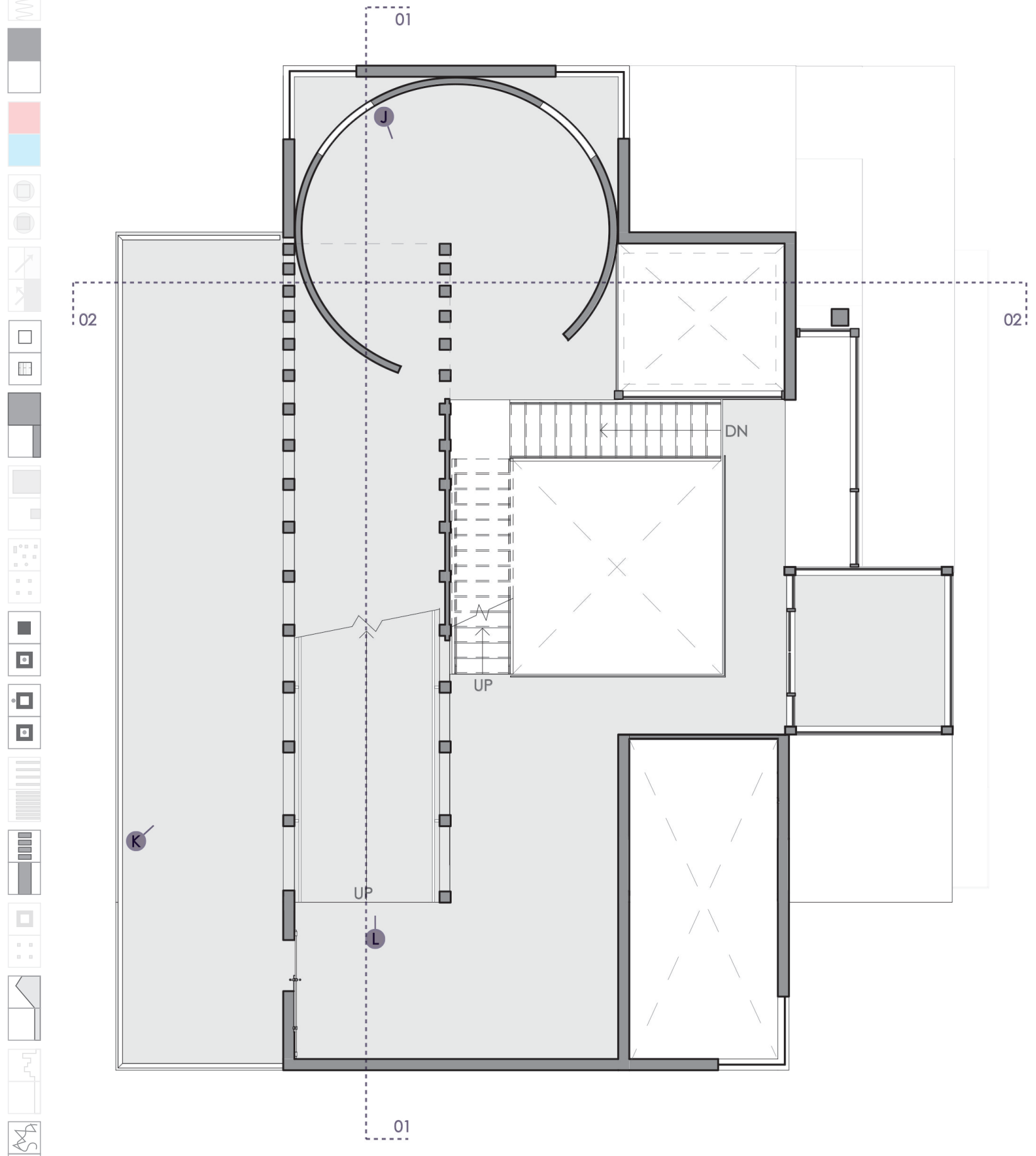

Figure 86: Sixth Floor Plan 
The Curved Wall
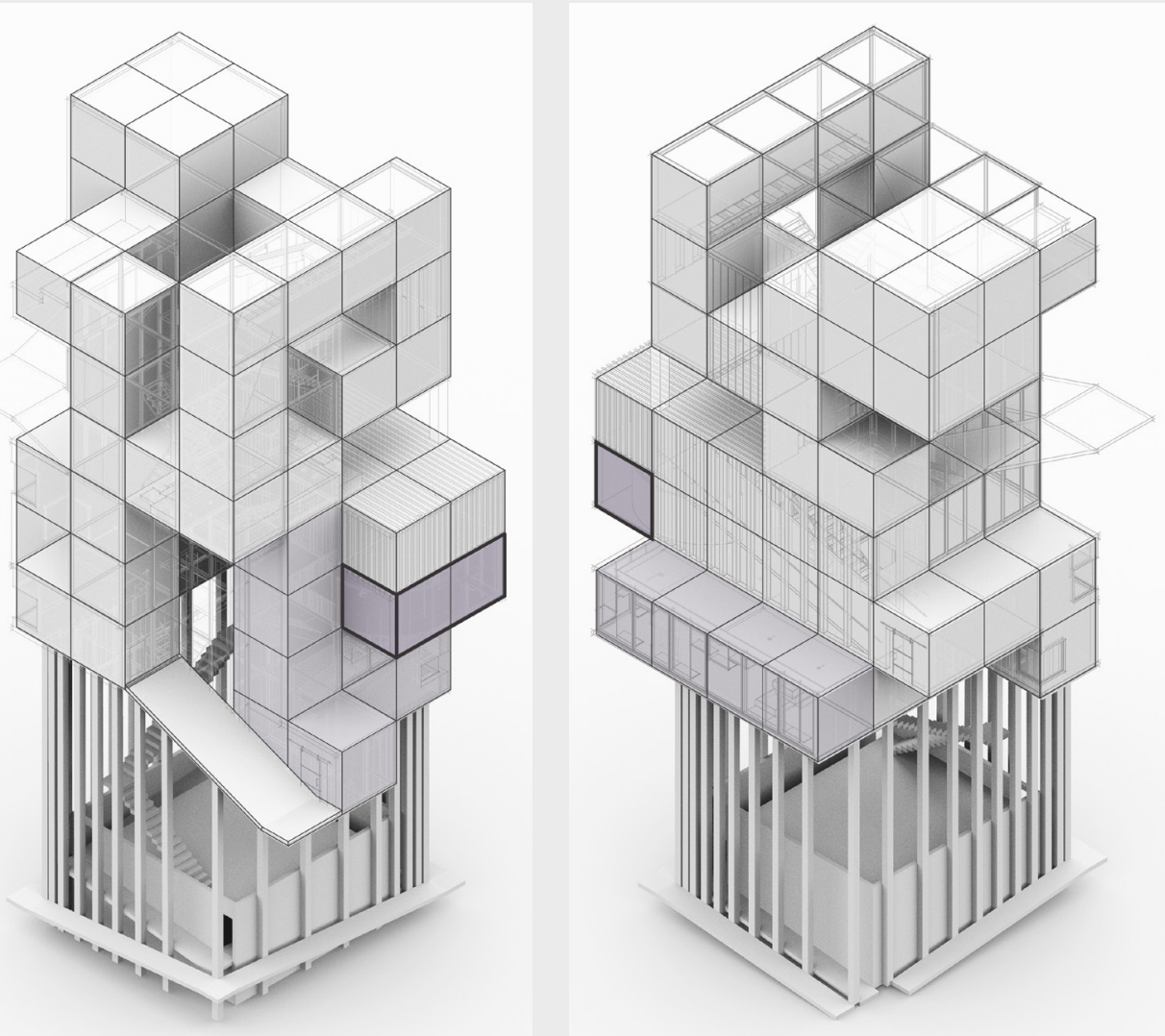

Figure 87: The Curved Wall 
As the subject reaches the next level, the curved wall interrupted by a series of columns grabs the attention. The explorer becomes curious enough to try to find her way there.

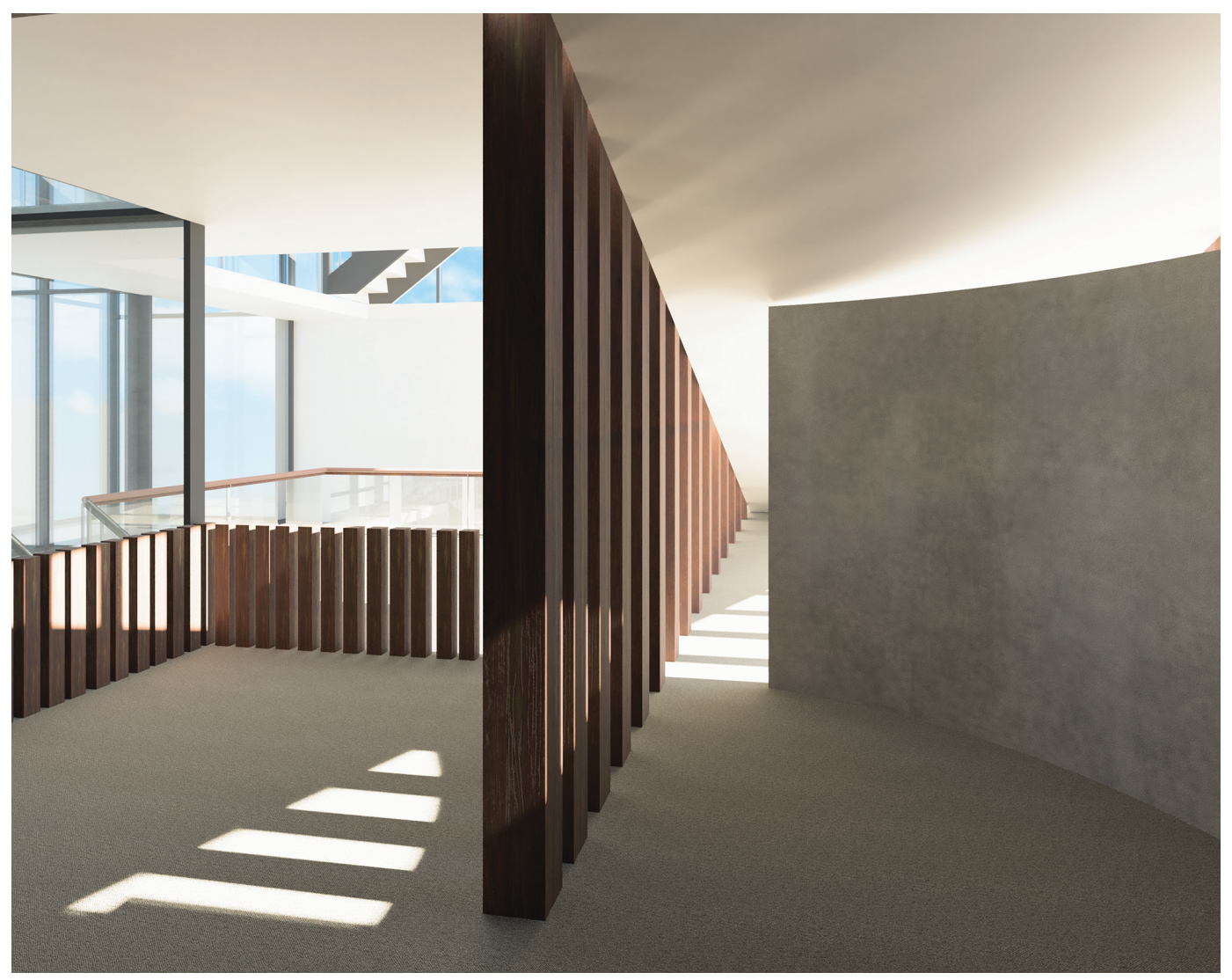

Figure 88: Scene J - The Curved Wall Interrupted by Wooden Partitions, during the Day 


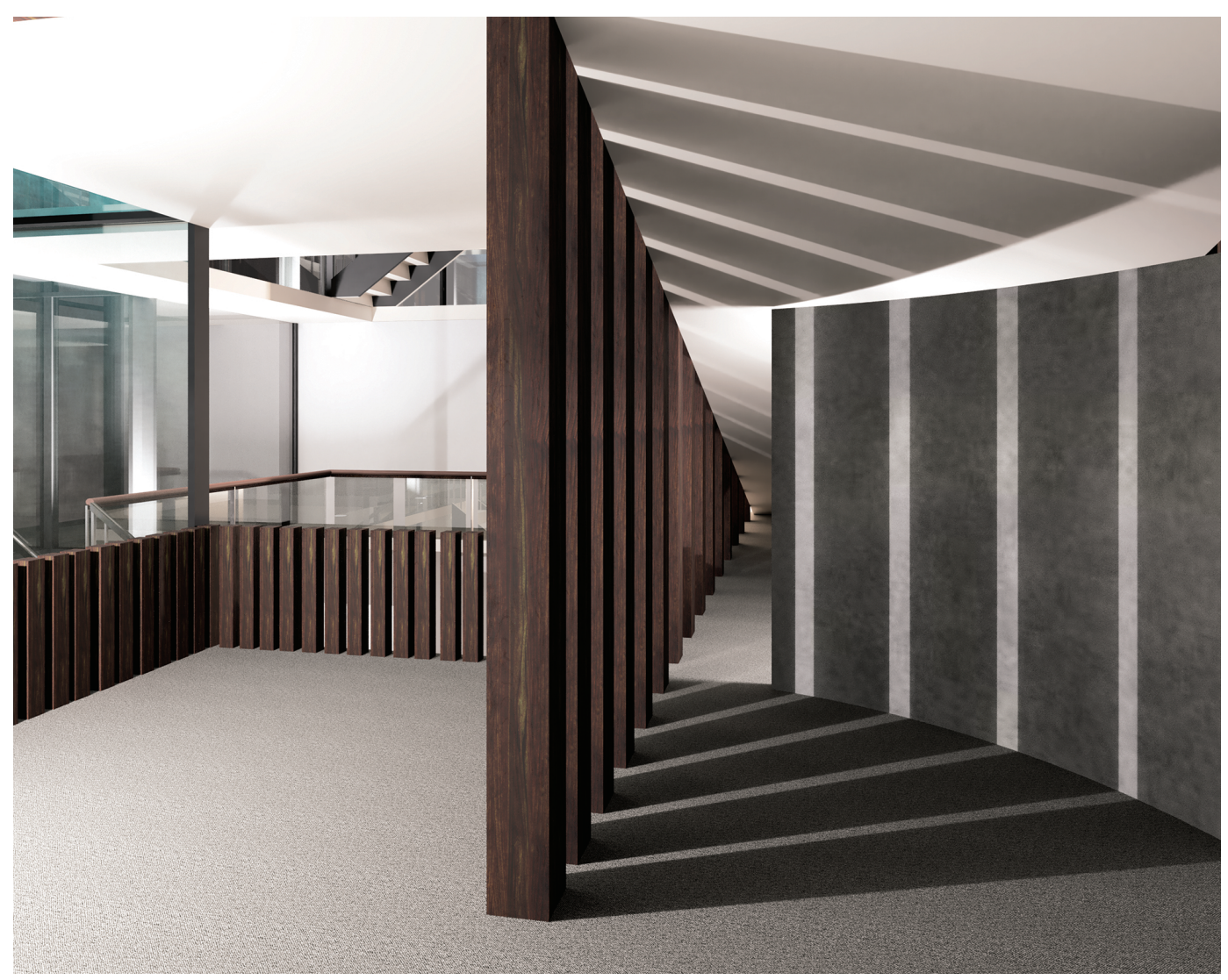

Figure 89: Scene J - The Curved Wall Interrupted by Wooden Partitions, during the Night 

The Oblique Floor
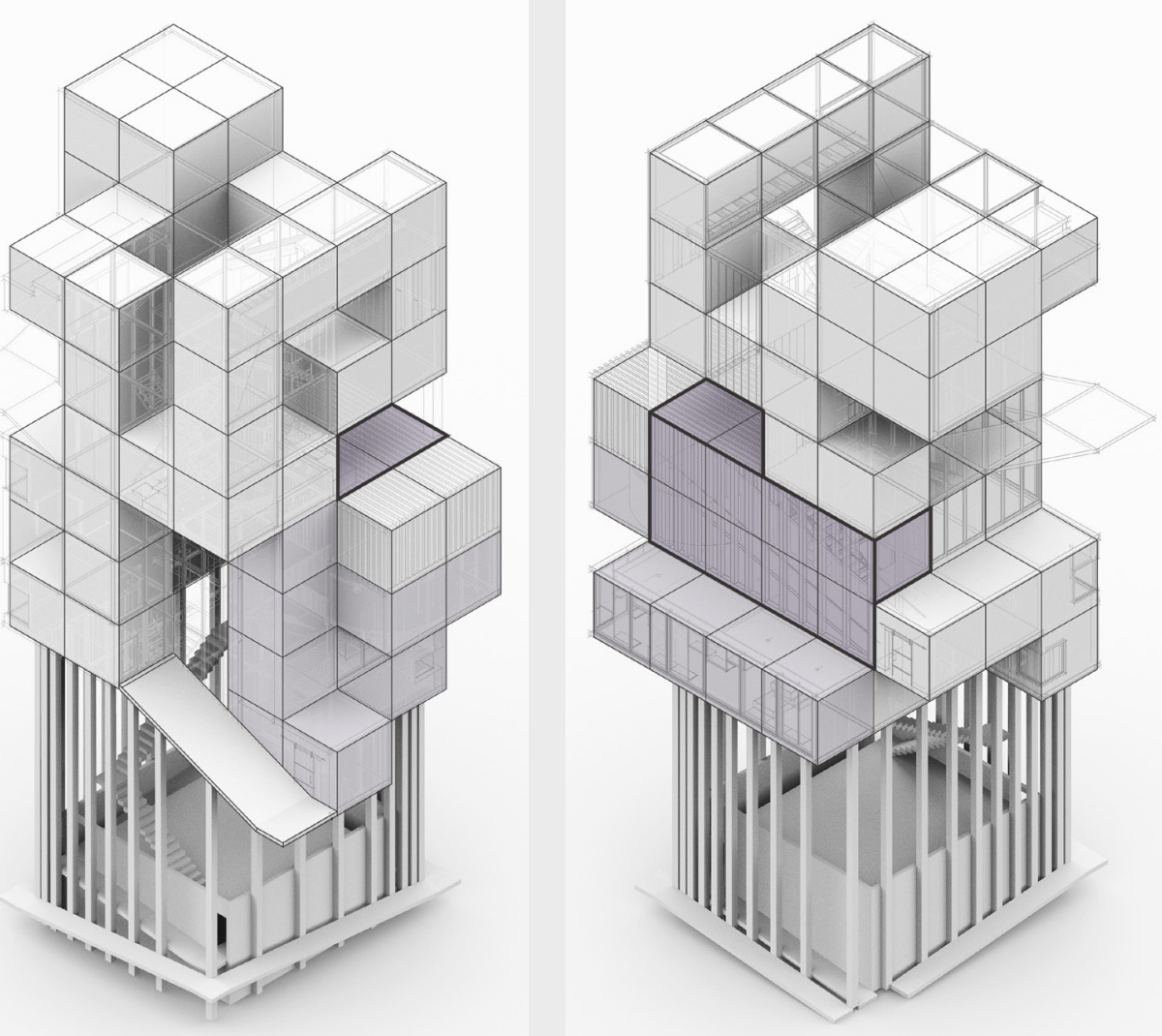

Figure 90: The Oblique Floor 
However, the path to get there is not easy; one can walk outside and walk back in from in between the columns or crawl under the ramp.

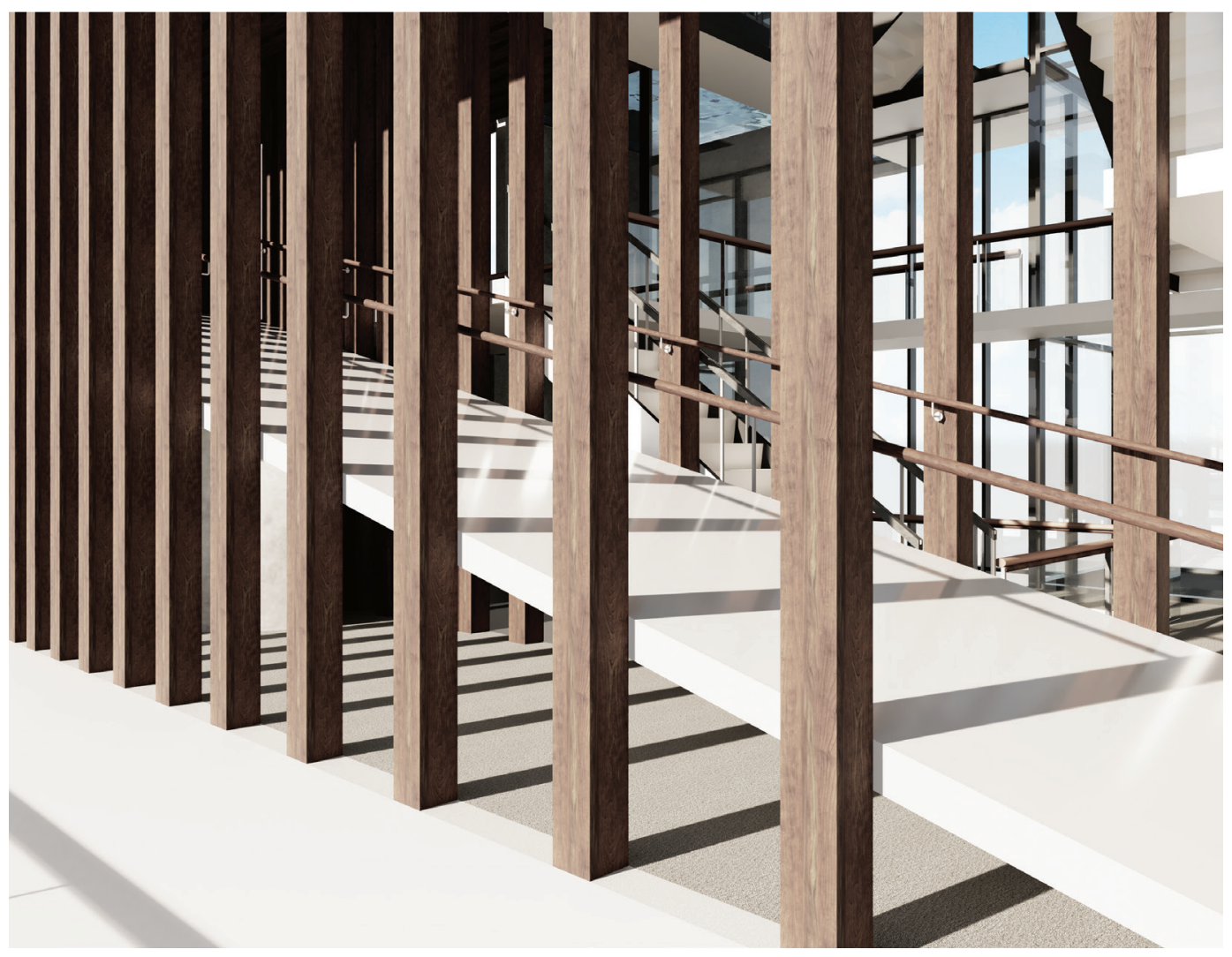

Figure 91: Scene K - The Path to Get to the Curved Wall, during the Day 


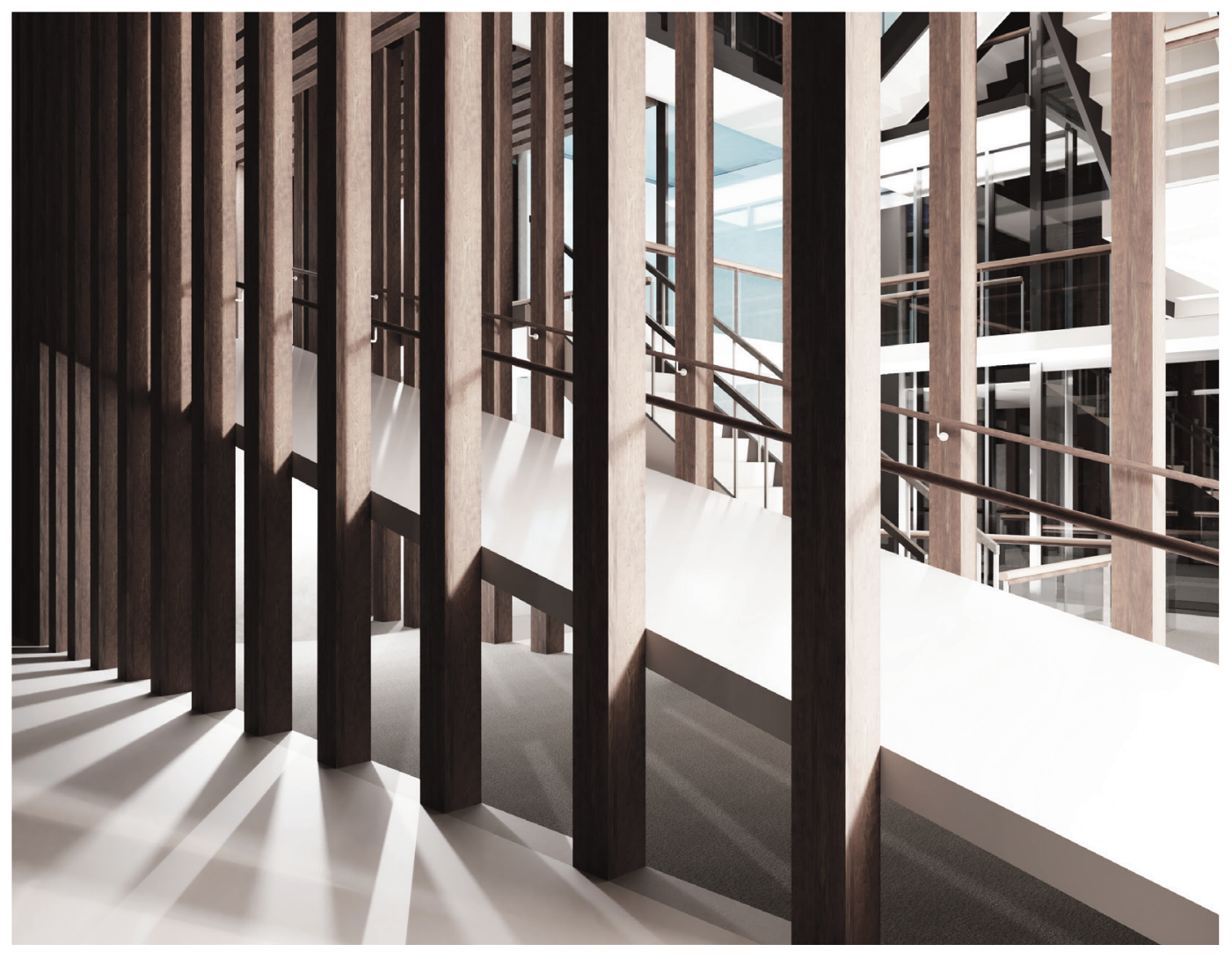

Figure 92: Scene K - The Path to Get to the Curved Wall, during the Night 
To move to the next level, she is faced with multiple options, each engaging the body at a very different rhythm of movement. The first one is a continuous and faster means of circulation through a glass elevator that provides a view to different spaces but does not have access to all of them. Another experience is through a ramp that reaches the following level. While ascending the ramp, the columns provide structural elements to grab onto for maintaining balance.

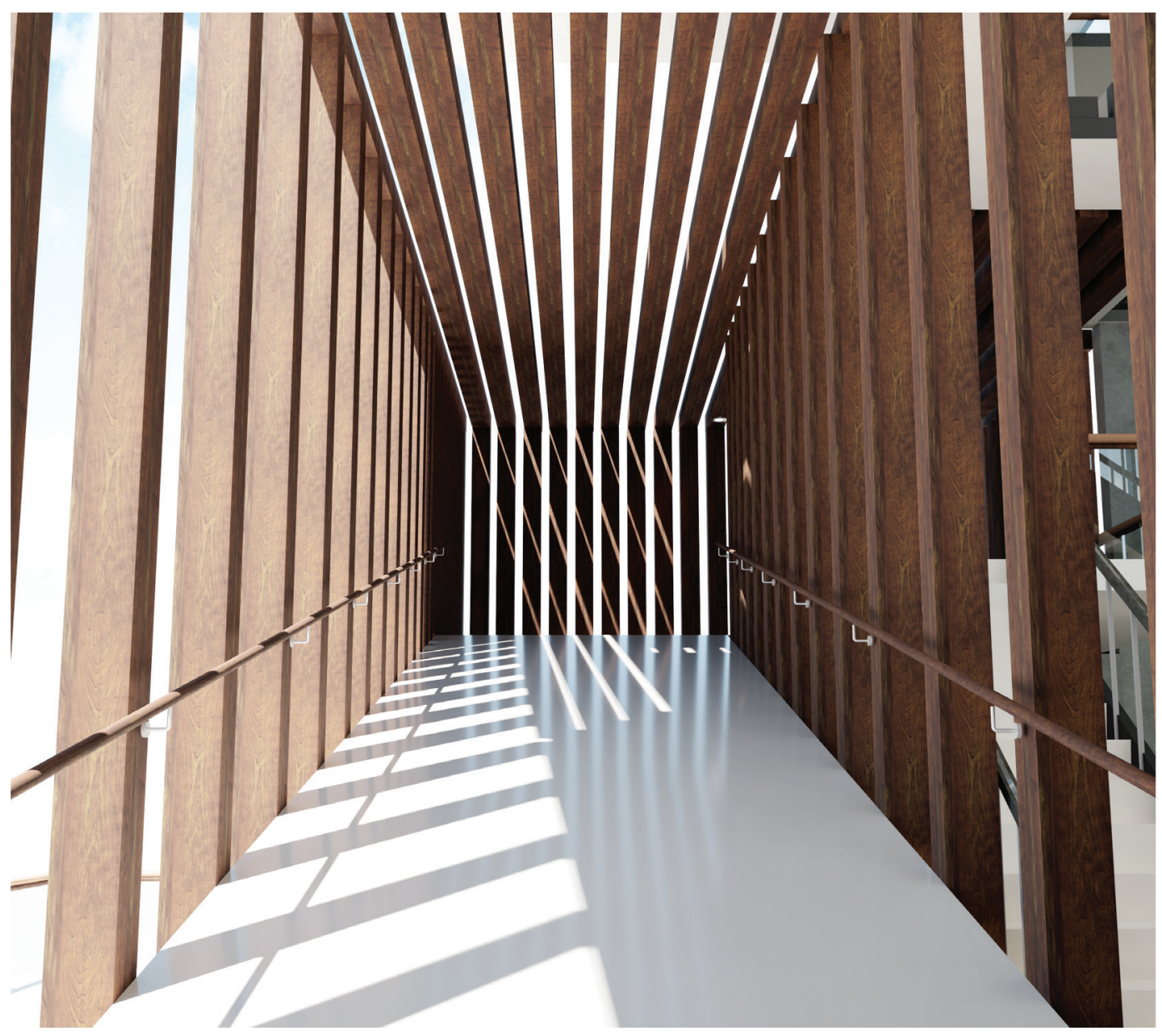

Figure 93: Scene L - Ascending the Ramp 
The Glass Elevator
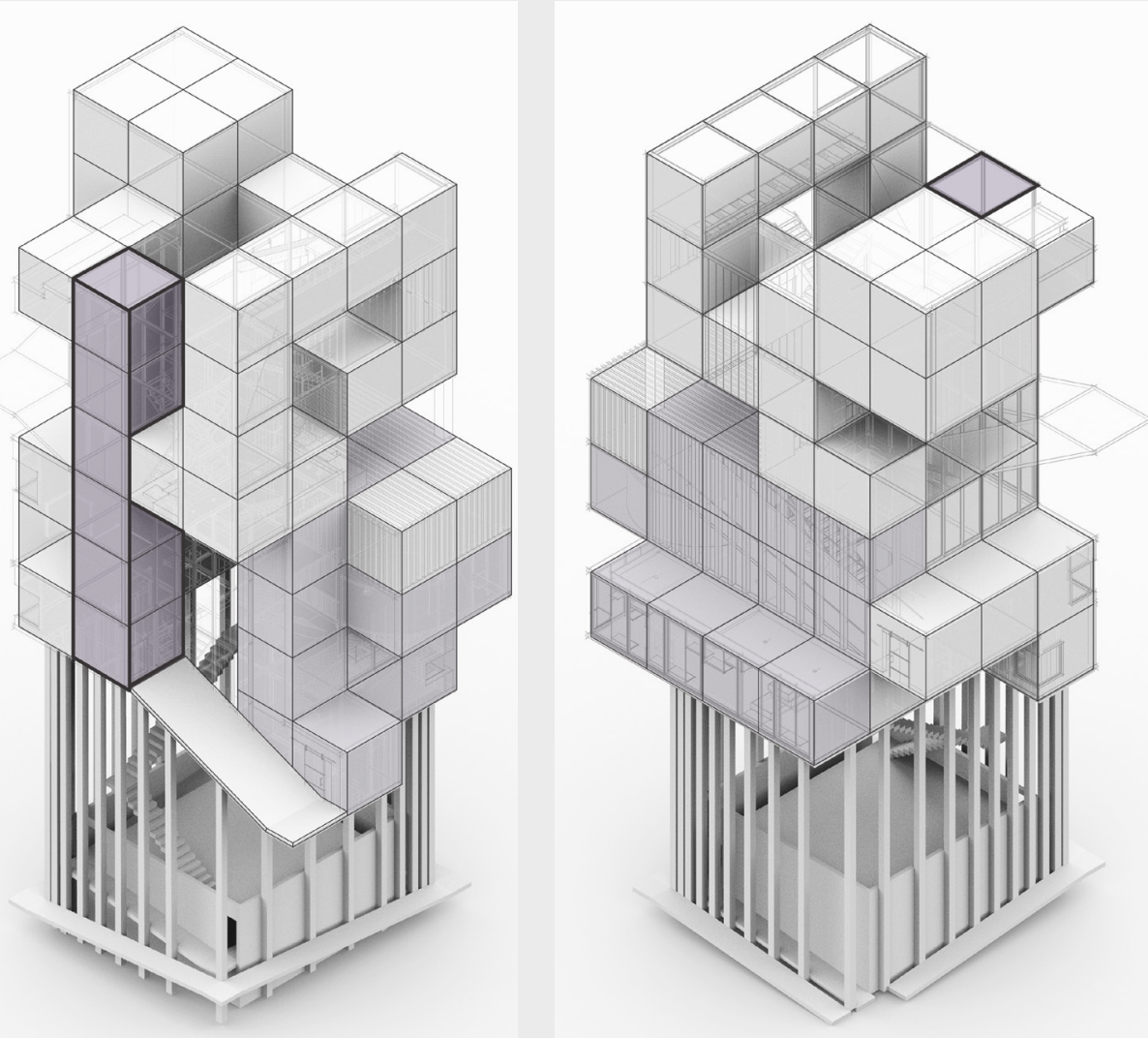

Figure 94: The Glass Elevator 
Vision

Kinesthesia

Tactile
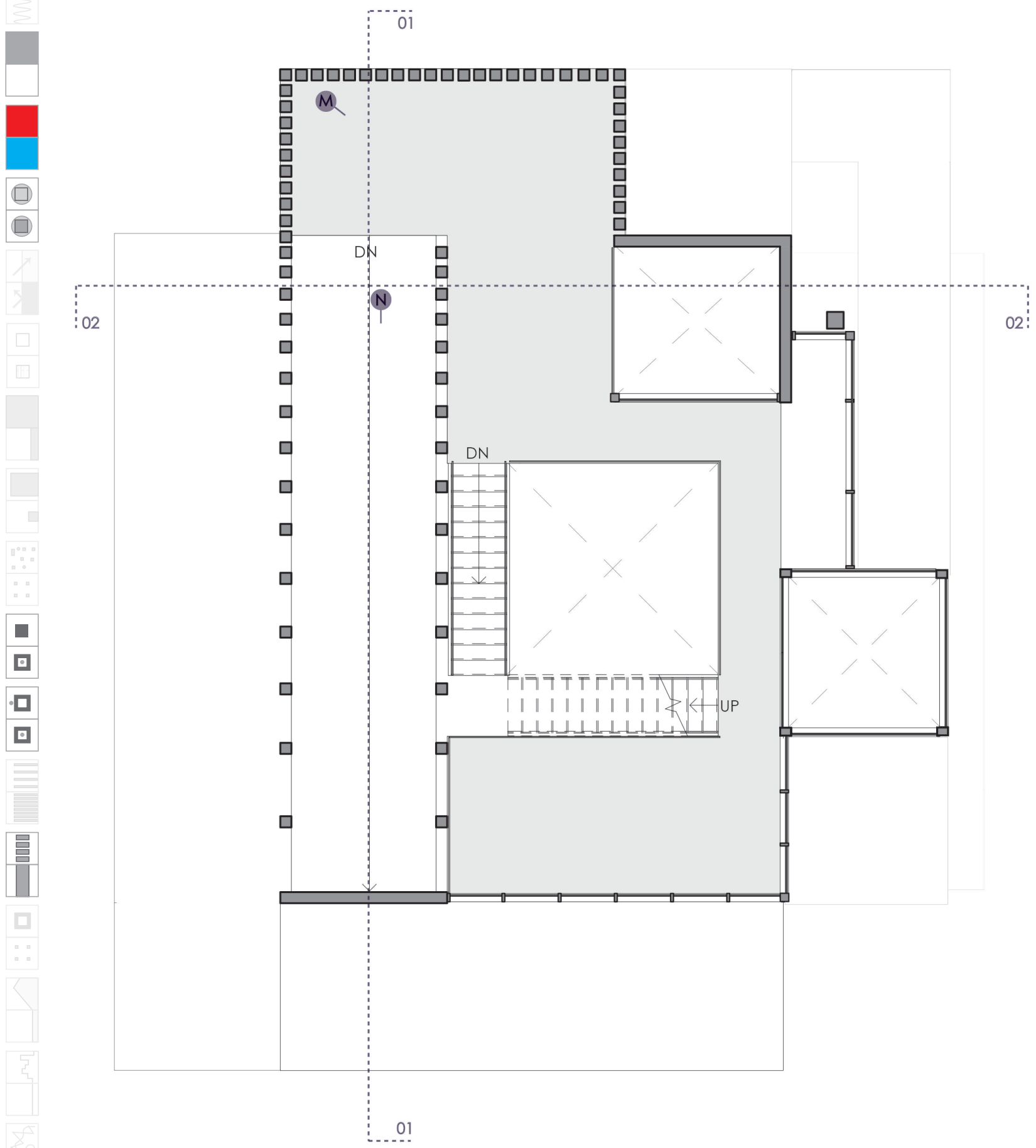

Figure 95: Seventh Floor Plan 
The Wooden Partitions
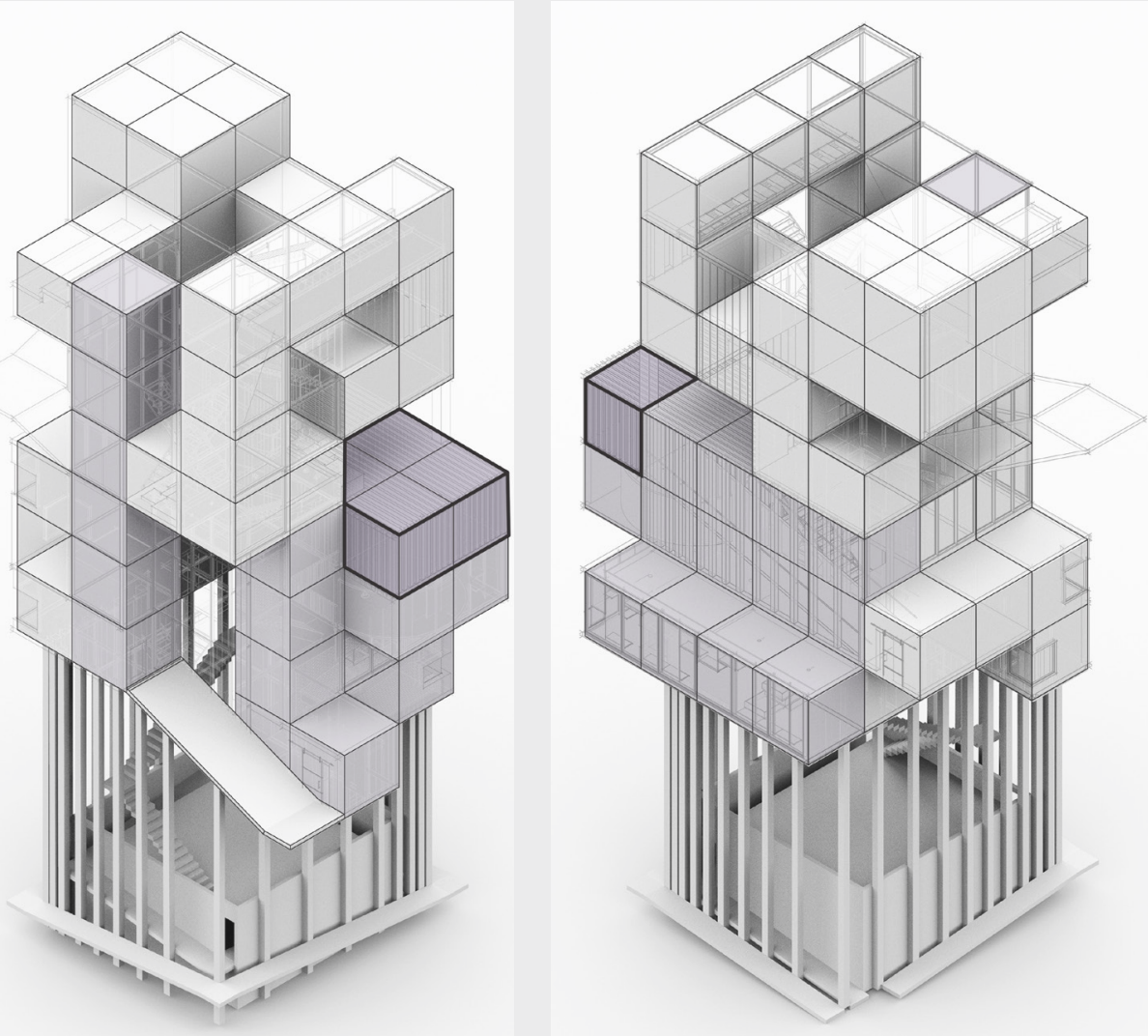

Figure 96: The Wooden Partitions 
The next level will be skipped if the elevator has been chosen as a way of ascending the building. The columns have now become partitions and set the boundary between inside and outside. These partitions intensify the experience by creating a light and shadow effect.

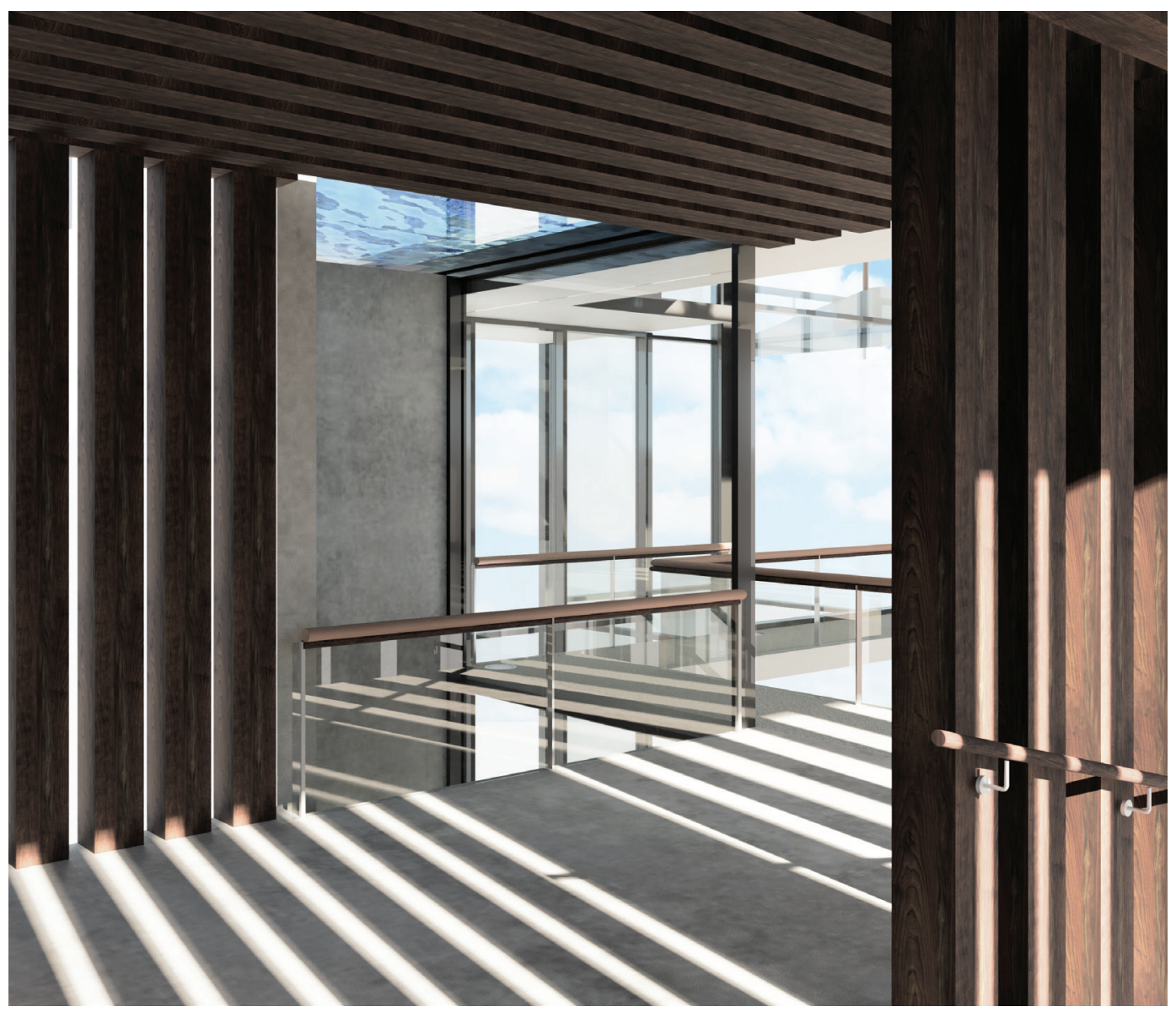

Figure 97: Scene M - The Wooden Partitions, Looking Towards the Bottom of the Pool 
As they are placed evenly and rhythmically, they suggest calmness and avert movement. Looking around, the glass floor of the next level provides a visual cue of the water. Moving forward, the bottom of the pool becomes visible.

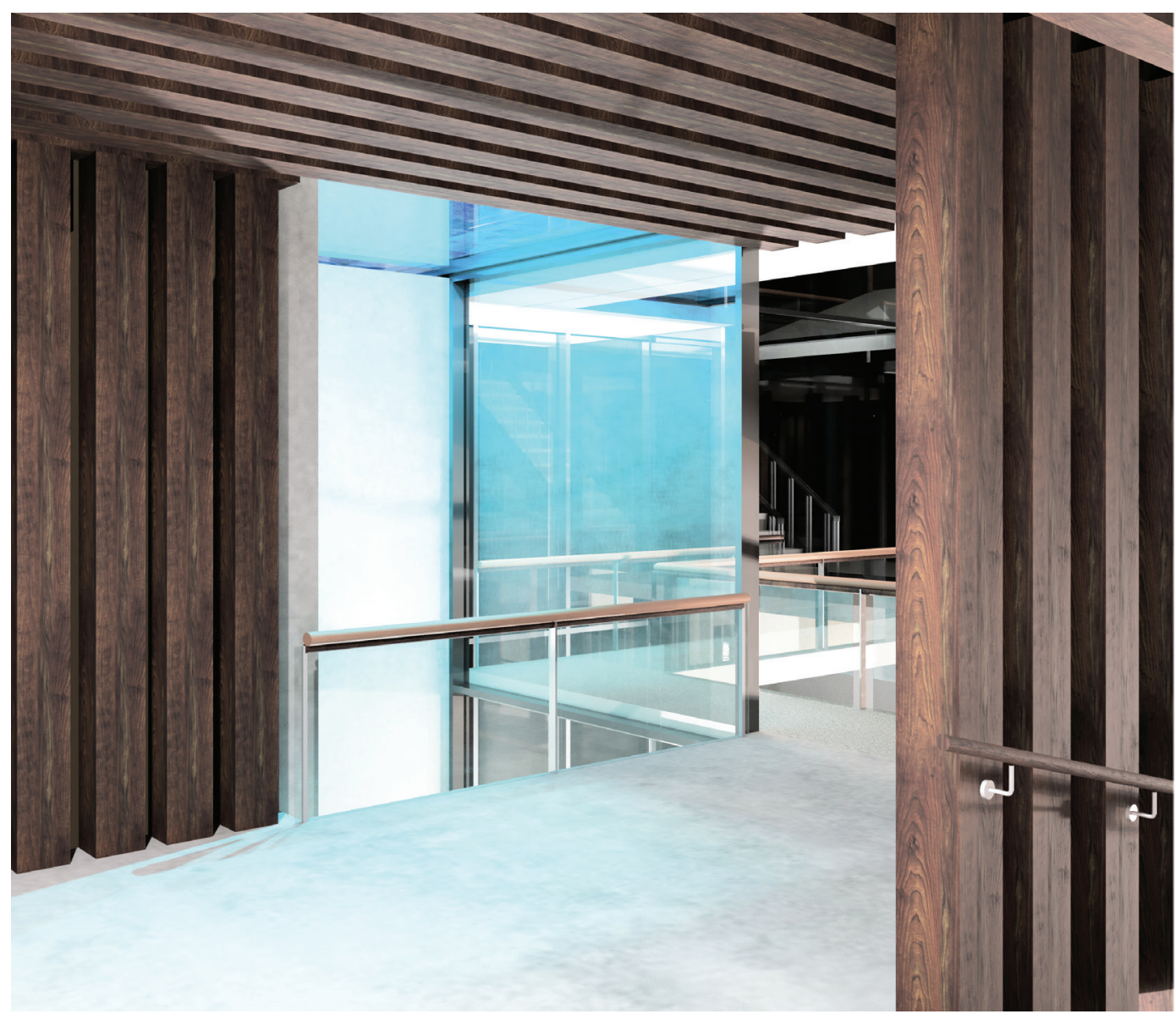

Figure 98: Scene M - The Wooden Partitions, Looking Towards the Bottom of the Pool 
On this level, the ramp or the climbing surface is now interpreted as a slide. When the visitor is descending on this surface, she senses a decrease in her speed of movement until realizing the change in the rhythm of columns. As these repetitive elements get farther apart, the body misinterprets its own speed of movement. In this case, the columns are now visual elements to exaggerate the sense of movement.

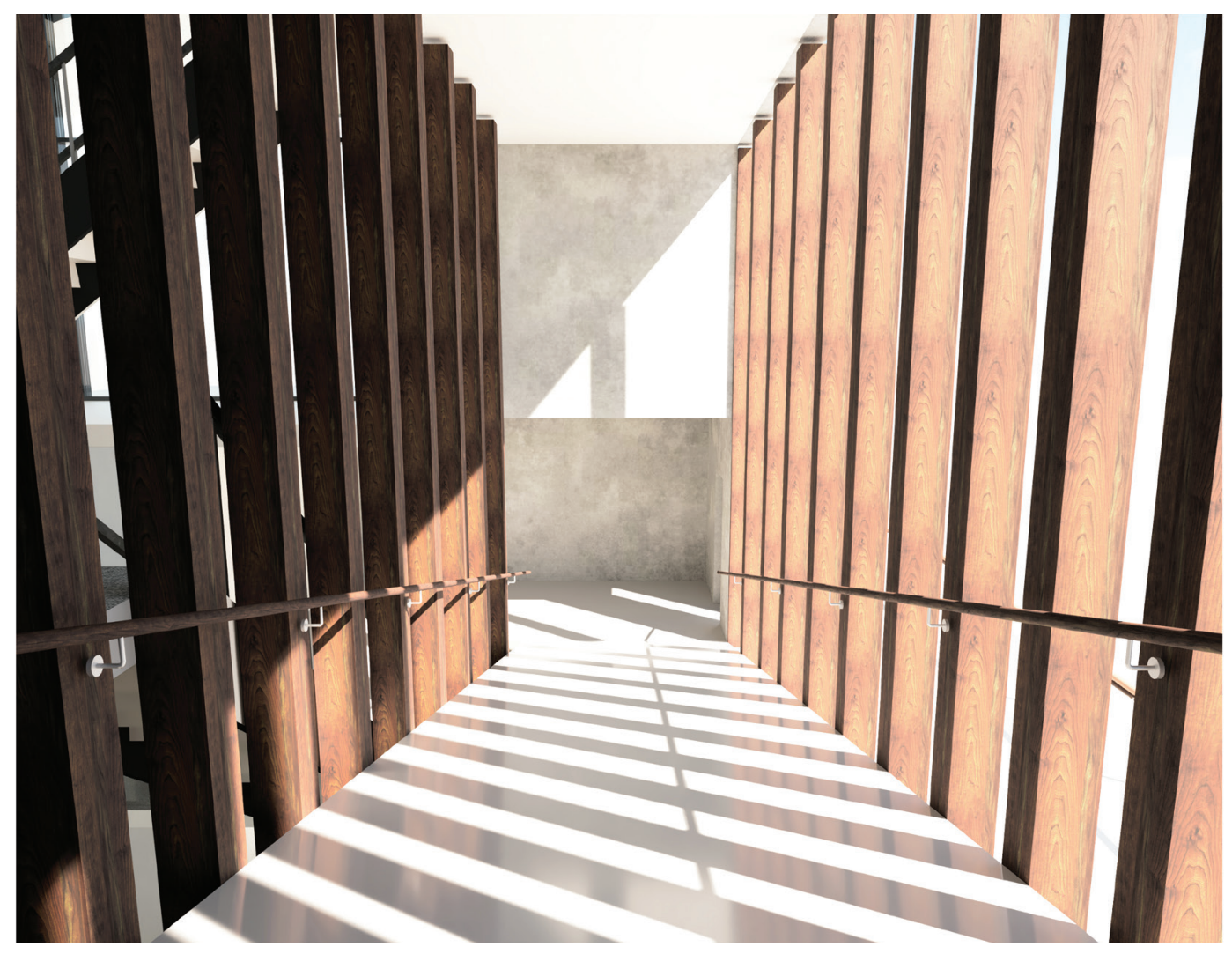

Figure 99: Scene N - Descending the Ramp 


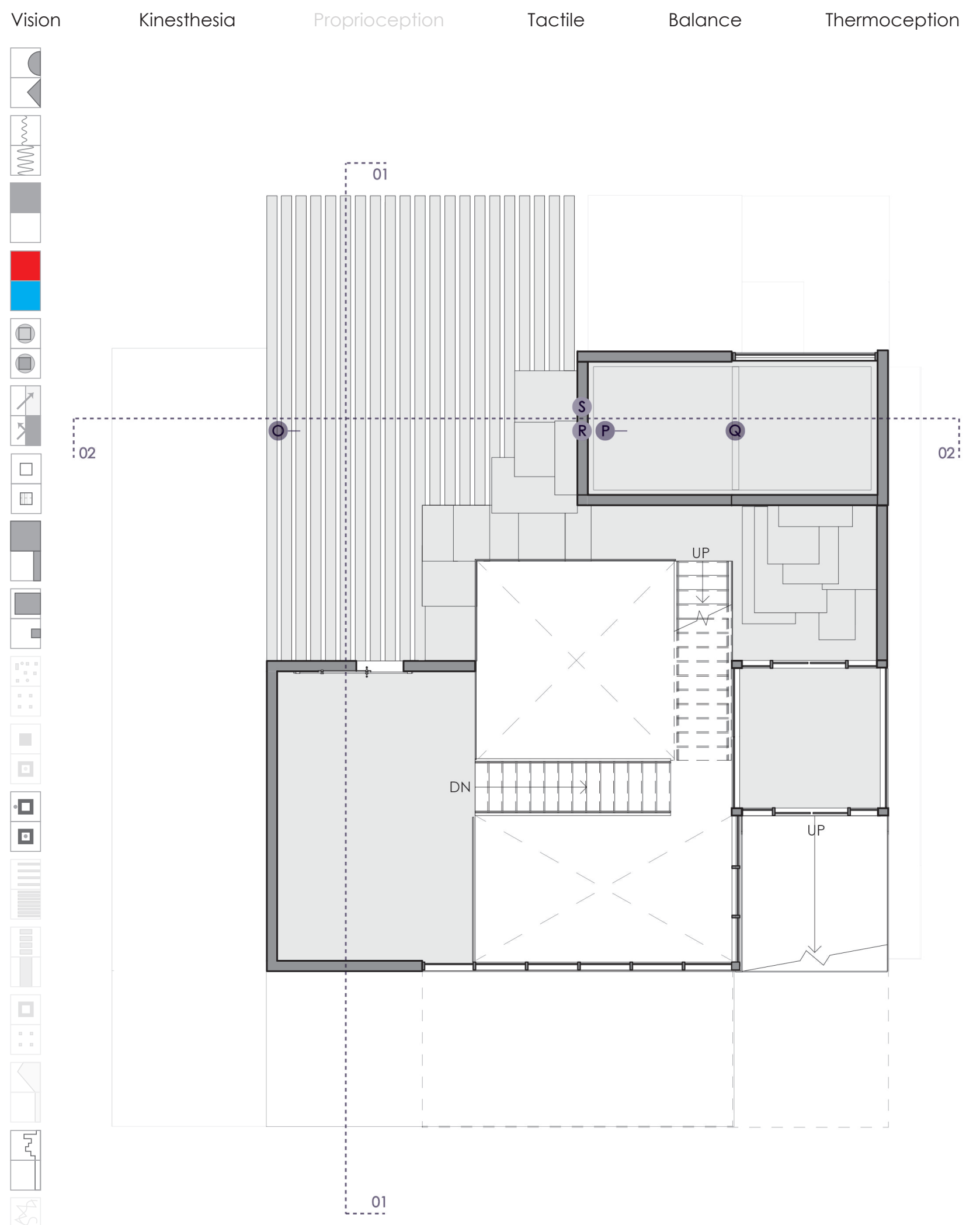

Figure 100: Eighth Floor Plan 
The same wooden elements have been interpreted as visual elements to exaggerate or suppress the sense of movement, structural elements to support movement, vertical elements to establish a boundary between inside and outside, and horizontal elements for the flooring of the next level.
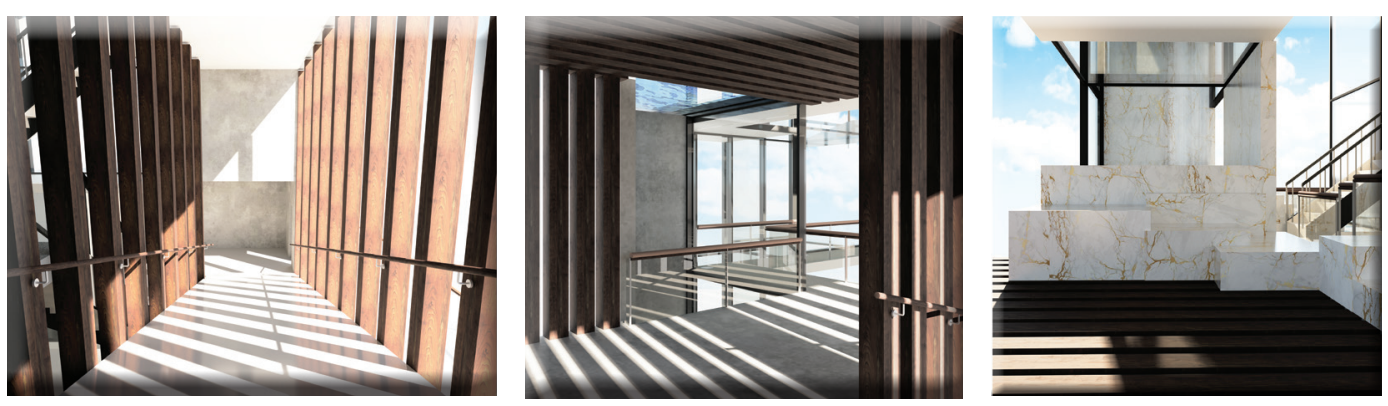

Figure 101: Partitions as Visual and Structural Elements

Figure 102: Partitions as Vertical Elements

Figure 103: Partitions as Horizontal Elements 
The Plunge Pool
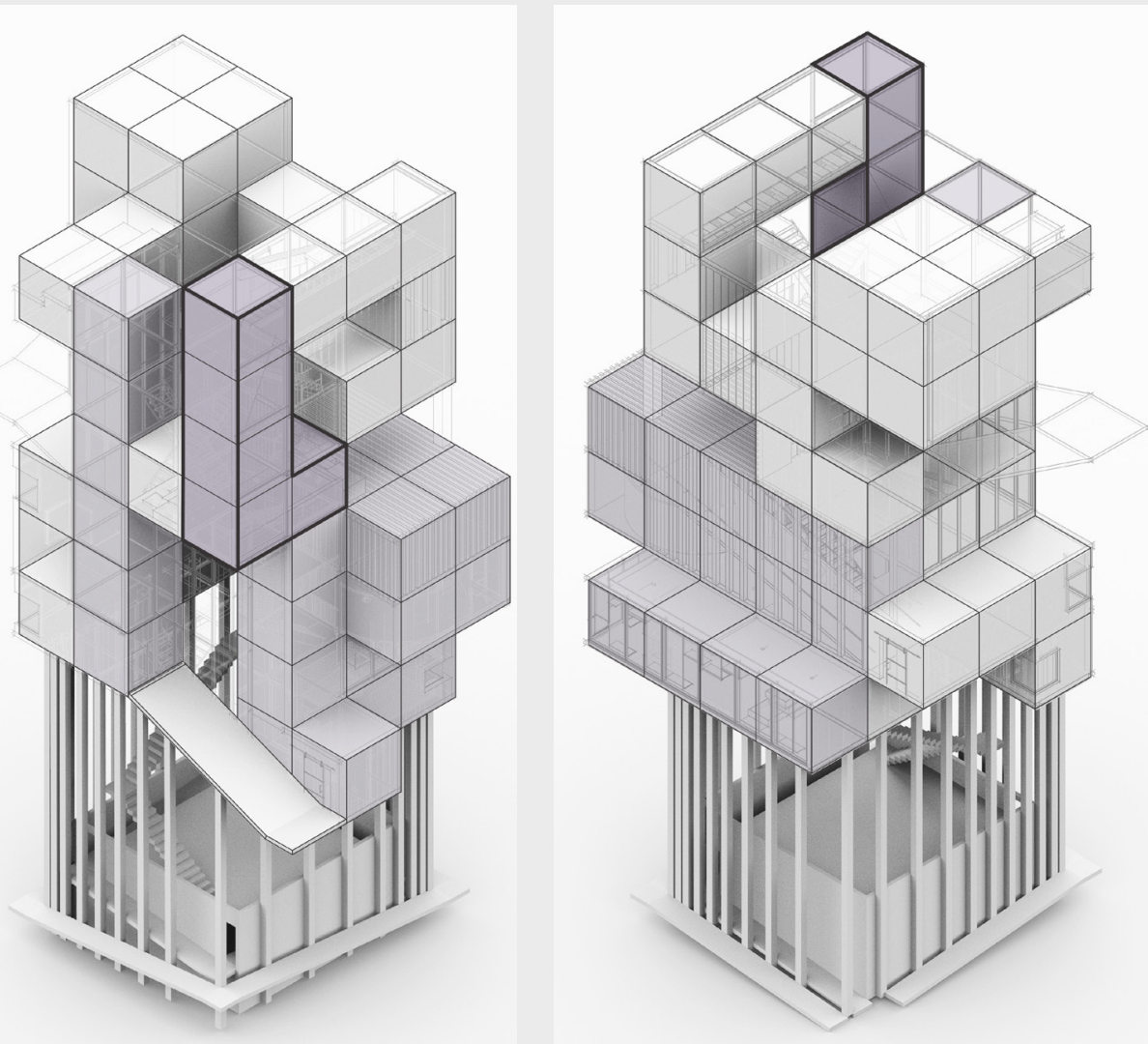

Figure 104: The Plunge Pool 
From both directions, the visitor has to move through a series of uneven steps, using the eyes and bodily sensations, to get to the pool. The floor is uneven and interrupted; nothing distracts the body from the conscious and careful movement of its feet on the steps. On one side, the subject places her bare foot on the wooden planks and feels the warmth of the sunlight. As the explorer continues to move with consciousness, she reaches the pool.

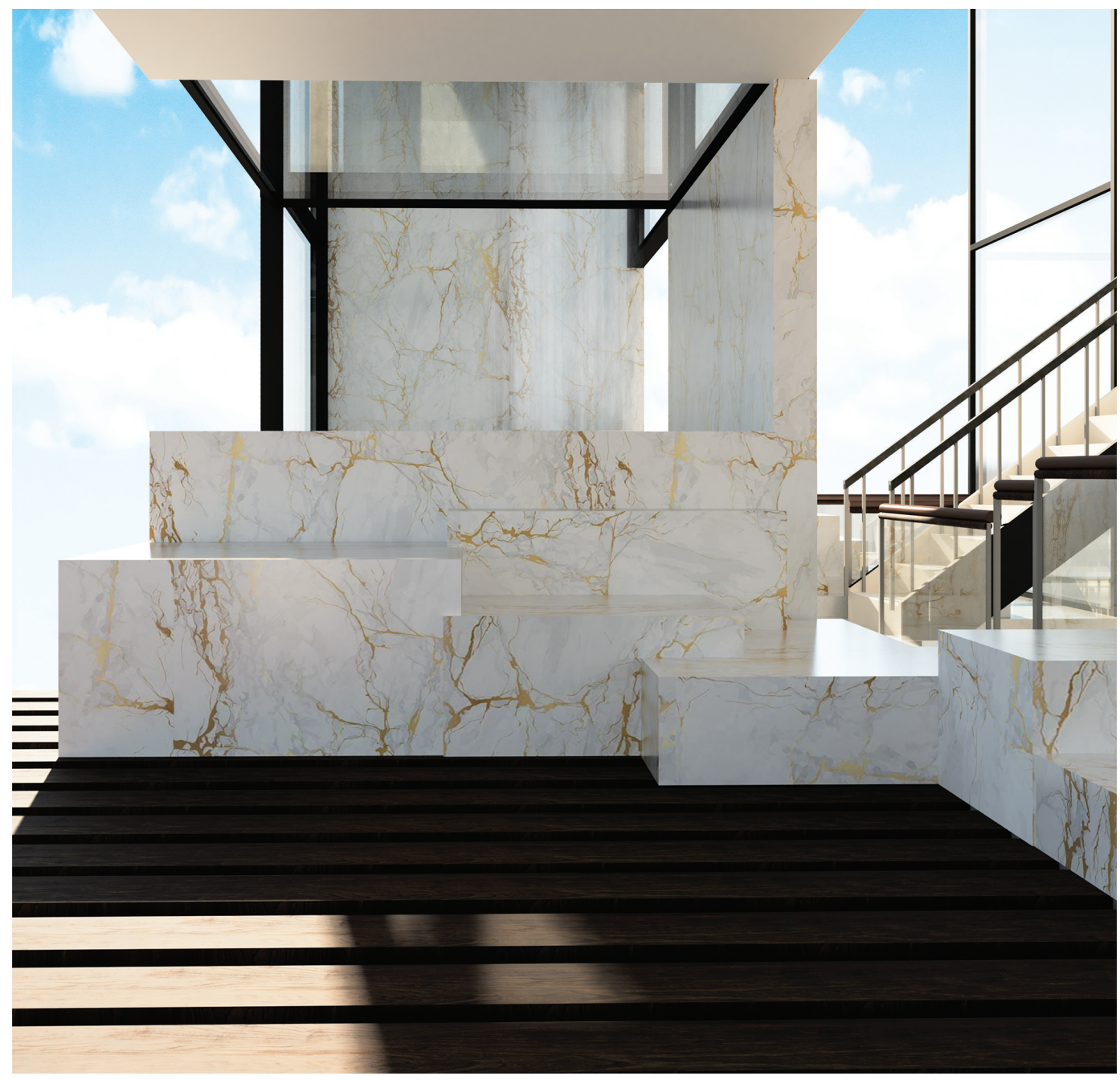

Figure 105: Scene $O$ - View of the Pool during the Day 


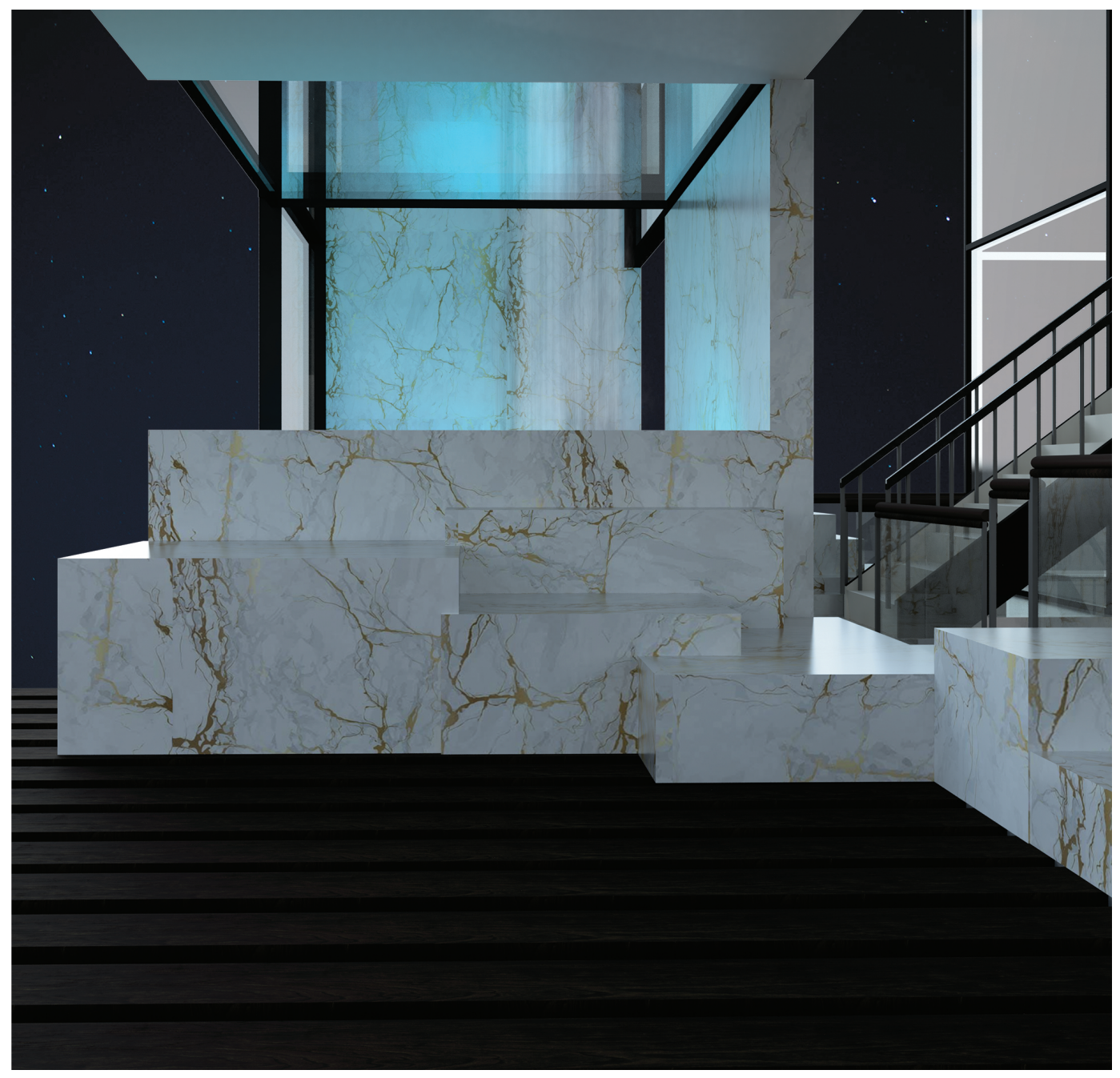

Figure 106: Scene O - View of the Pool during the Night 
There is tension between inside and outside as the low walls and transparent surfaces provide views to both the interior and exterior. The skin feels the spatial contrast that exists between the softness of the water and the textured feeling of marble.

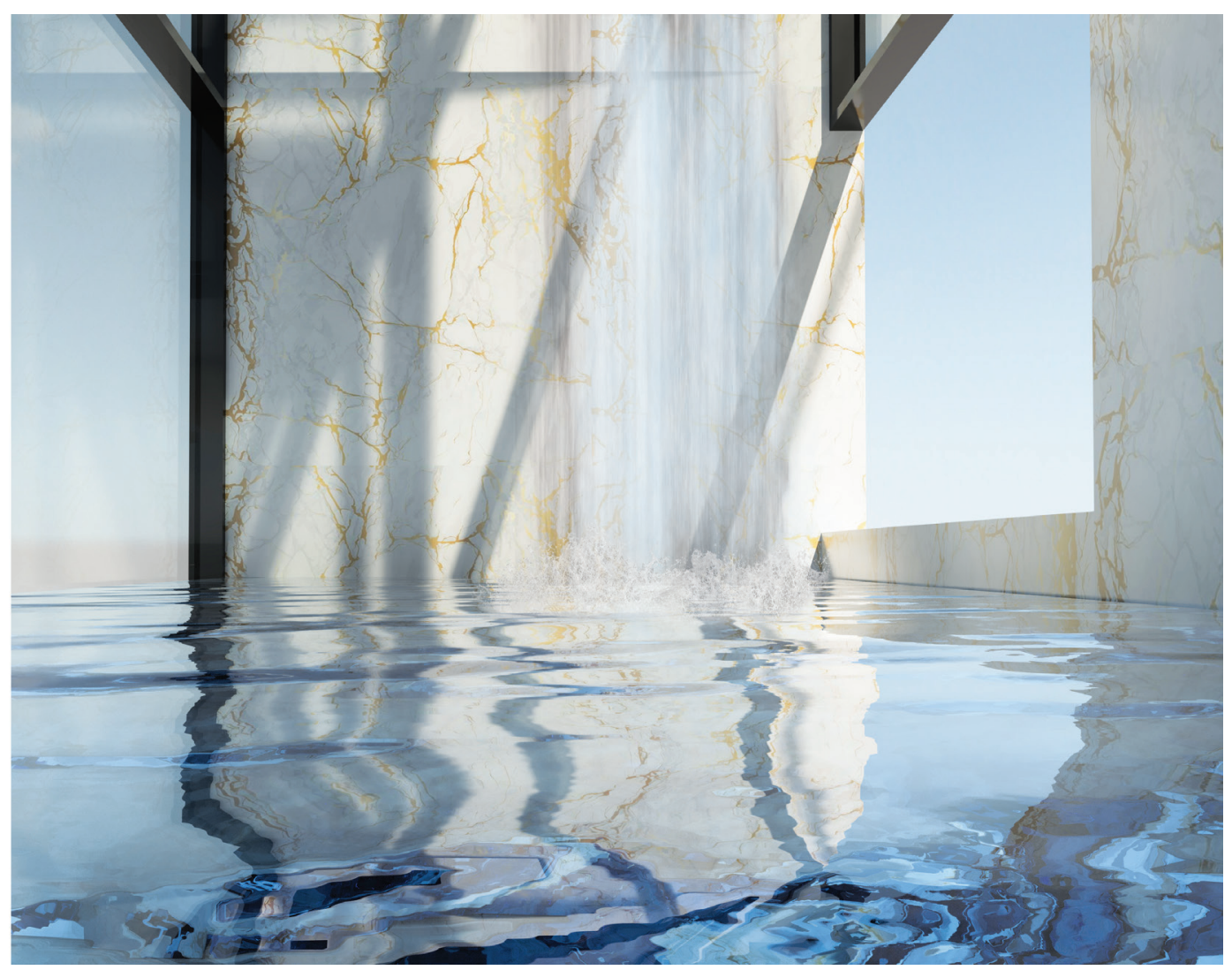

Figure 107: Scene P - inside the Pool during the Summer 
During the winter, the pool acts as a hot tub, and the drastic temperature difference between the cold weather and the hot water triggers the sense of thermoception.

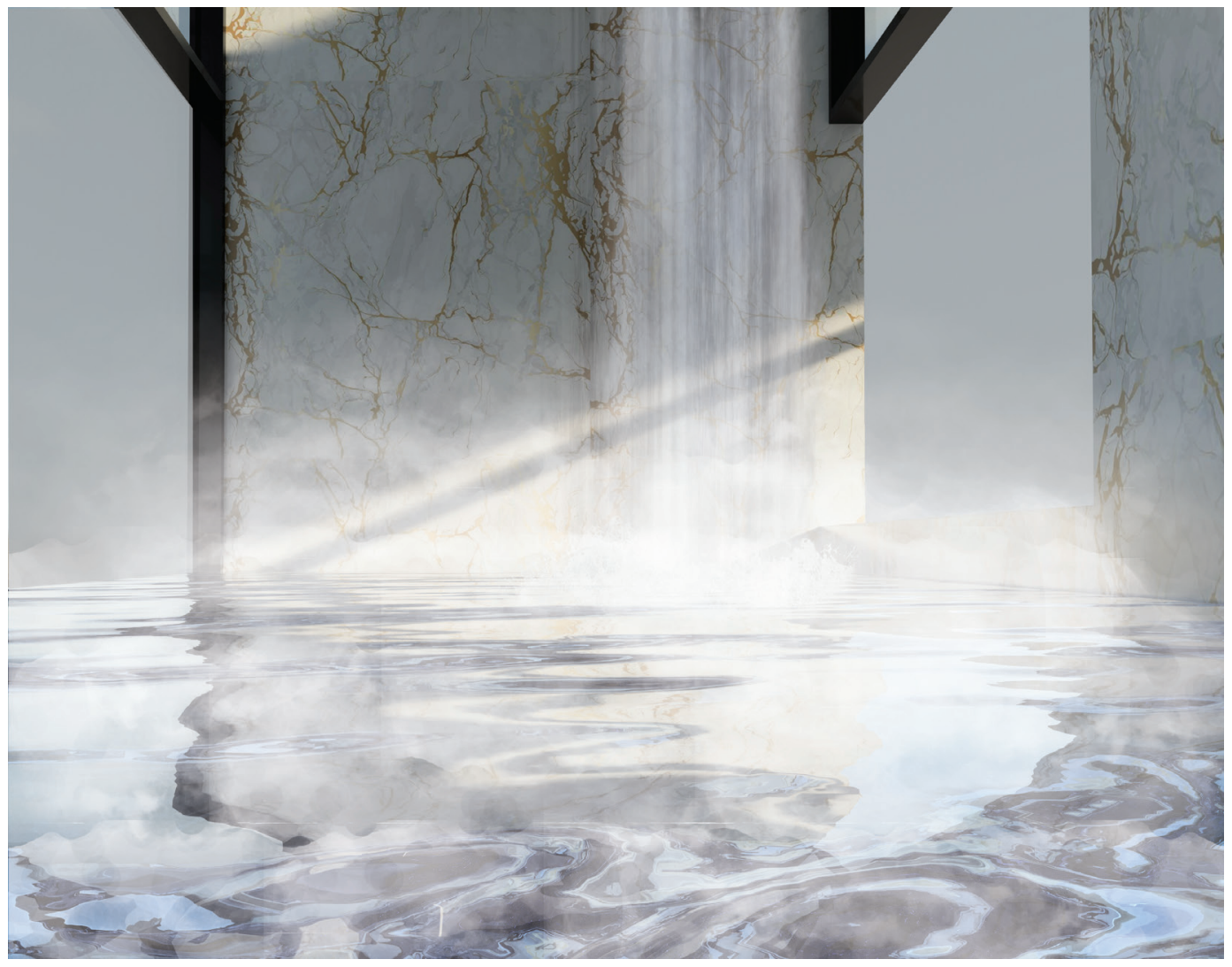

Figure 108: Scene P-inside the Pool during the Winter 
Looking down, the body senses perilousness when the eye meets the glass floor and acknowledges the elevation of its location. As one pays closer attention, the ambiguity of the indoor/outdoor relationship increases since half of the glass floor has a view of the interior, and the other half has a view of the exterior, divided by a concrete wall.

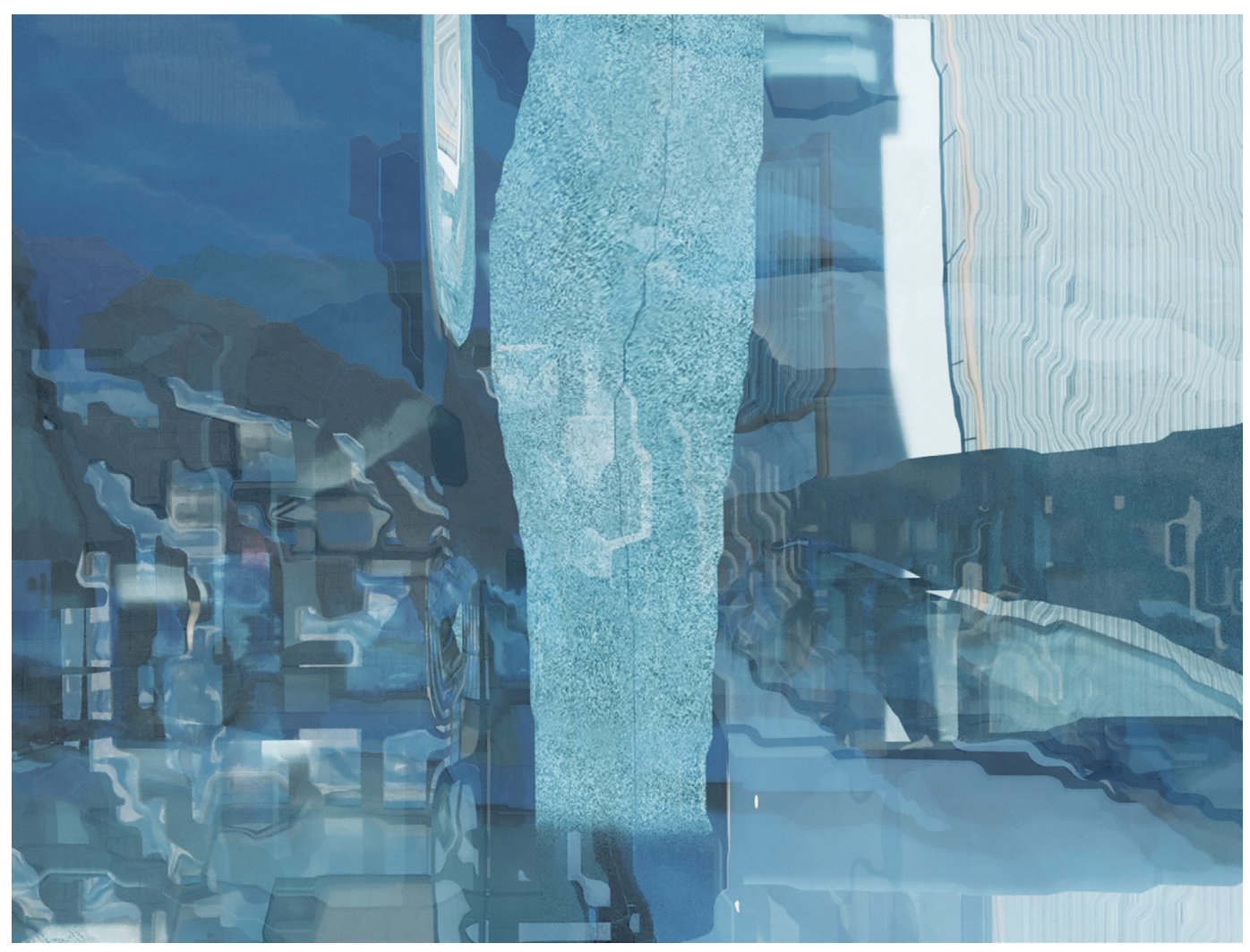

Figure 109: Scene Q - The Abstraction Created by the Water during the Summer 


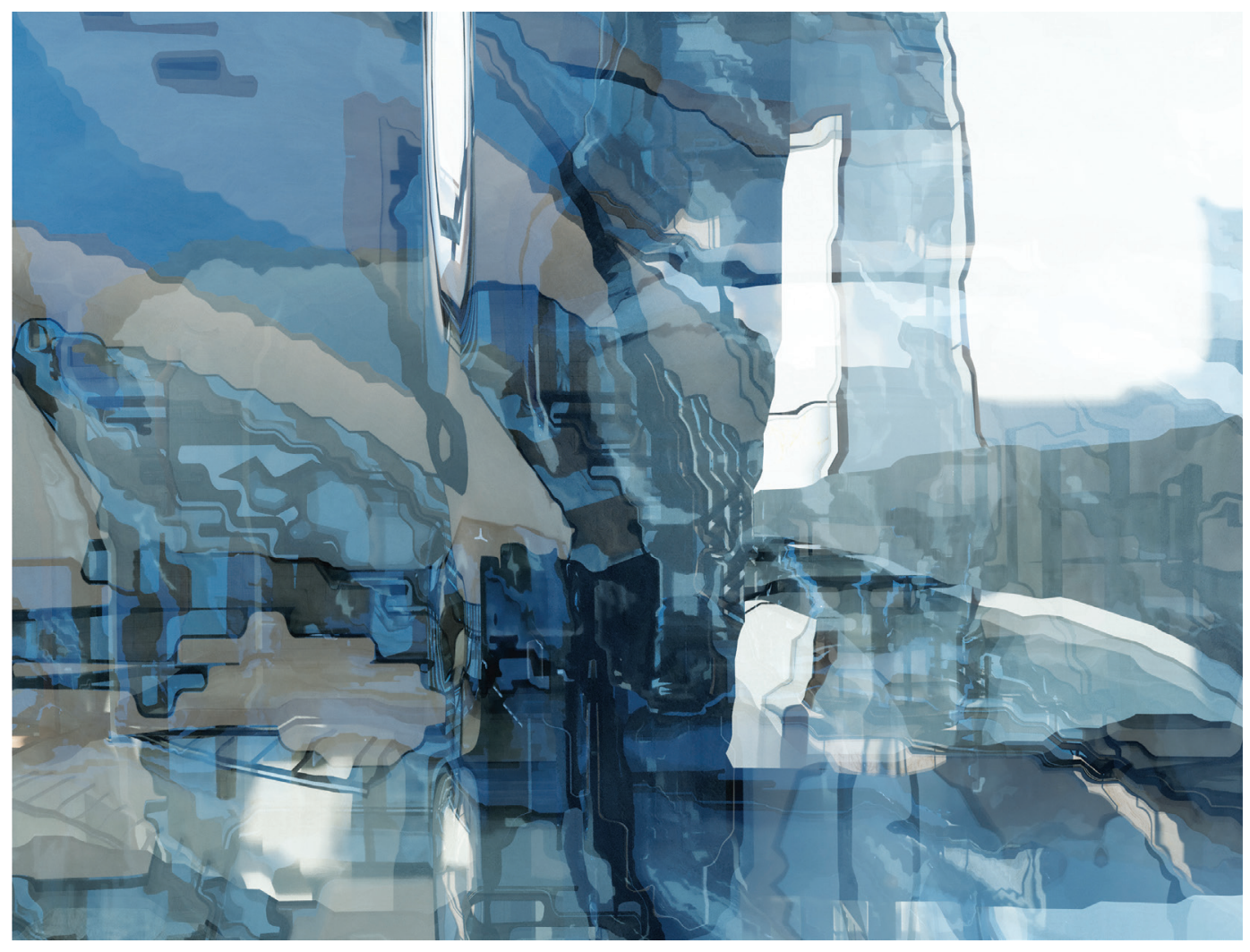

Figure 110: Scene Q - The Abstraction Created by the Water during the Winter 
As one looks up from the pool, the angled mirror is visible through the glazed roof, covering half of the pool. The mirror provides a visual cue to the level above, the fur room, as well as the pool itself. The eye also perceives the flowing water on the top level and questions the connection between the water splashing into the pool with the one above.

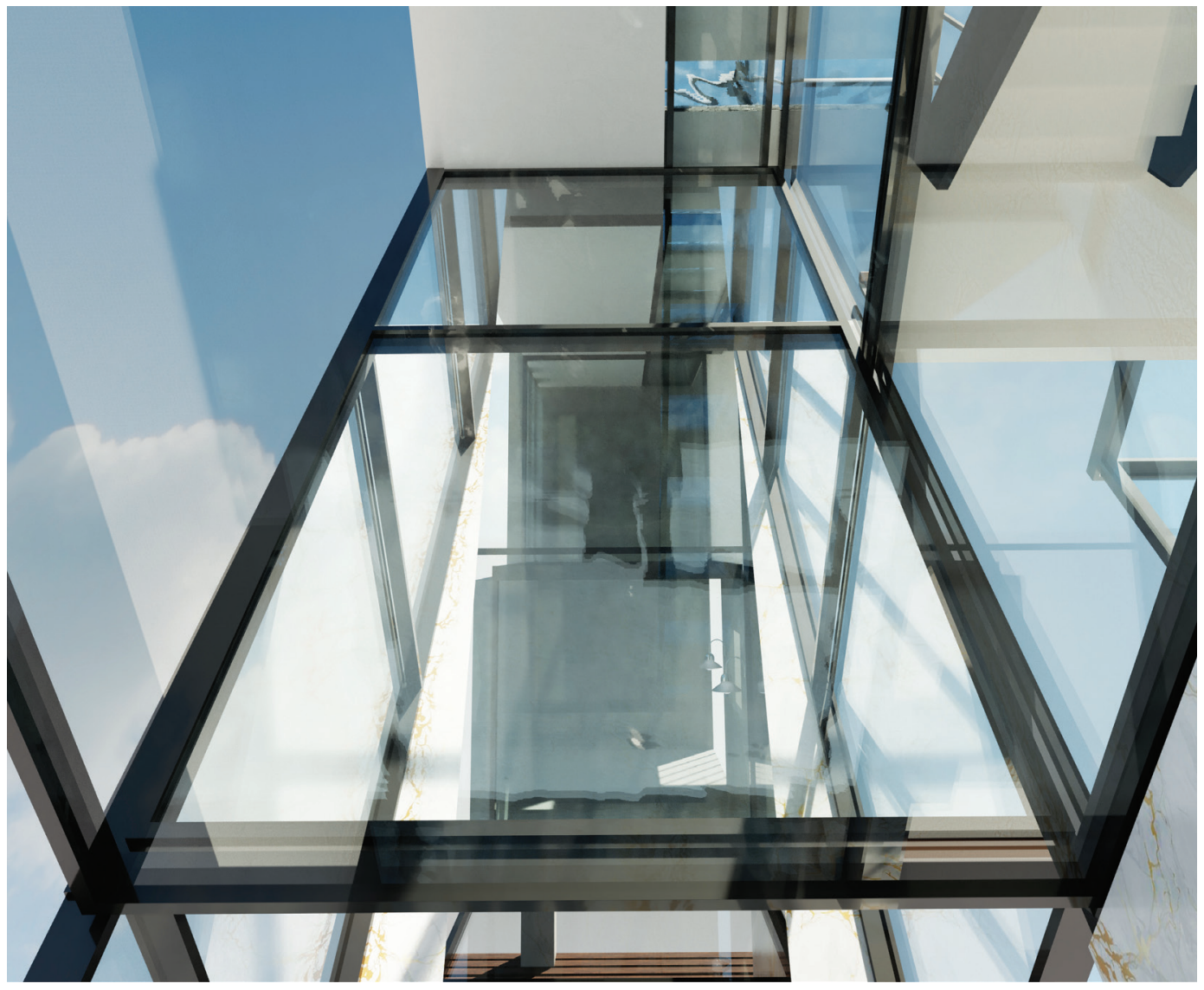

Figure 111: Scene R - Looking up from the Pool, Seeing the Reflections in the Mirror 


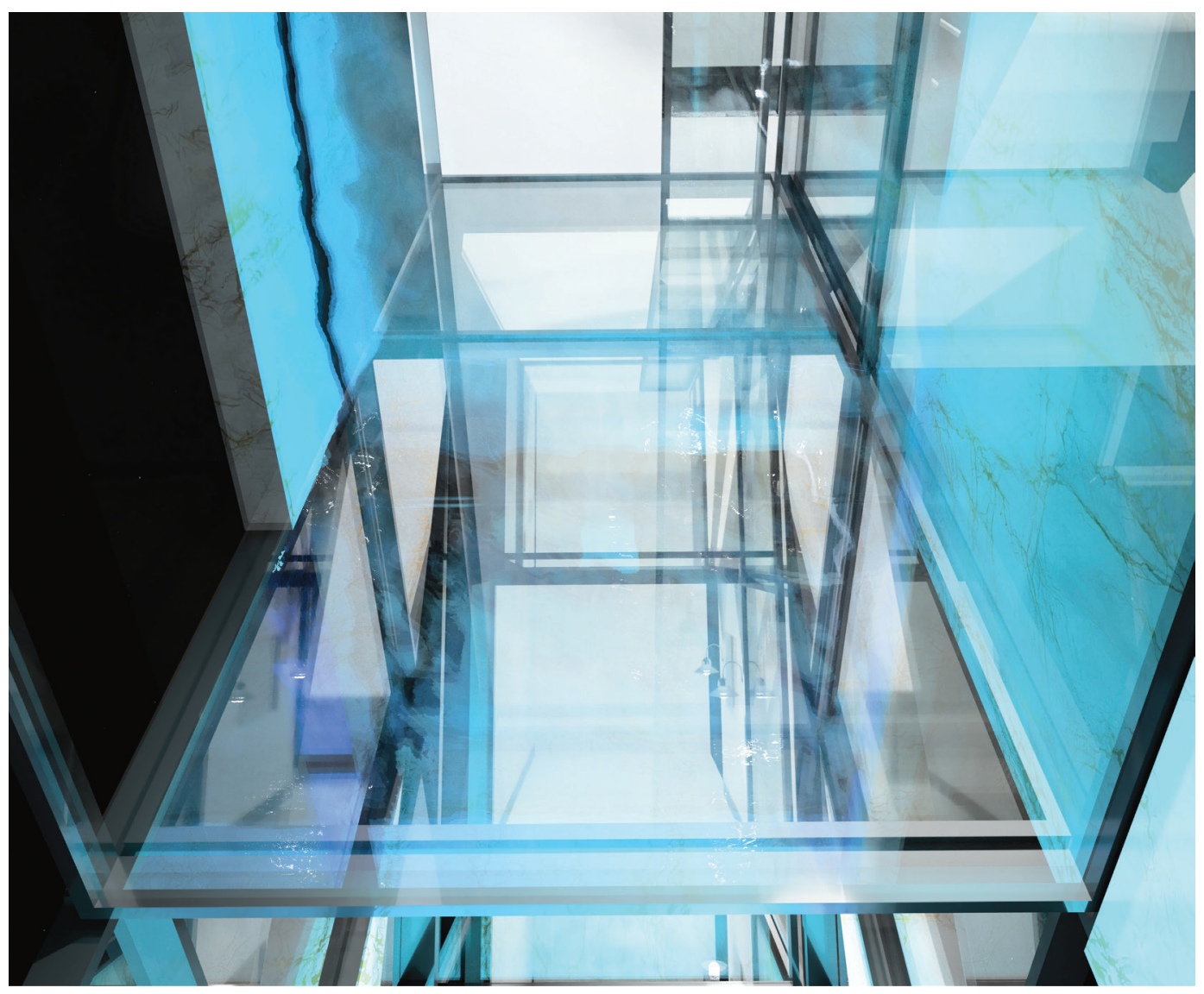

Figure 112: Scene R-Looking up from the Pool, Seeing the Reflections in the Mirror during the Night 
The immersion of the body in the water not only distorts the way the eyes perceive space, but also it disconnects the senses from the totality of space, by blocking out the sound, the air, the light, and the mind. The return back from abstraction to the state of awareness requires an exaggerated activation of the senses.

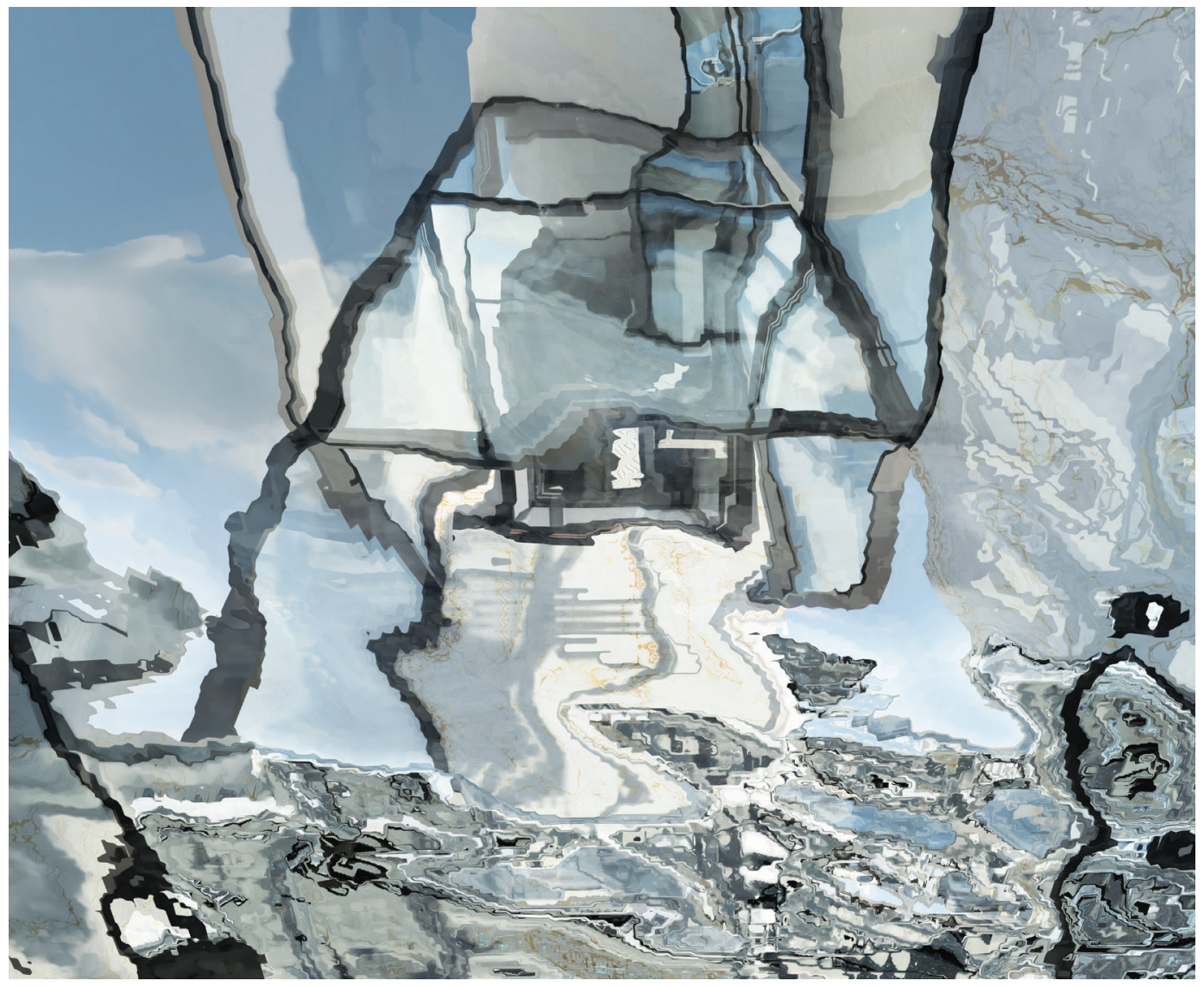

Figure 113: Scene S - View from under the Water Distorting the Space 


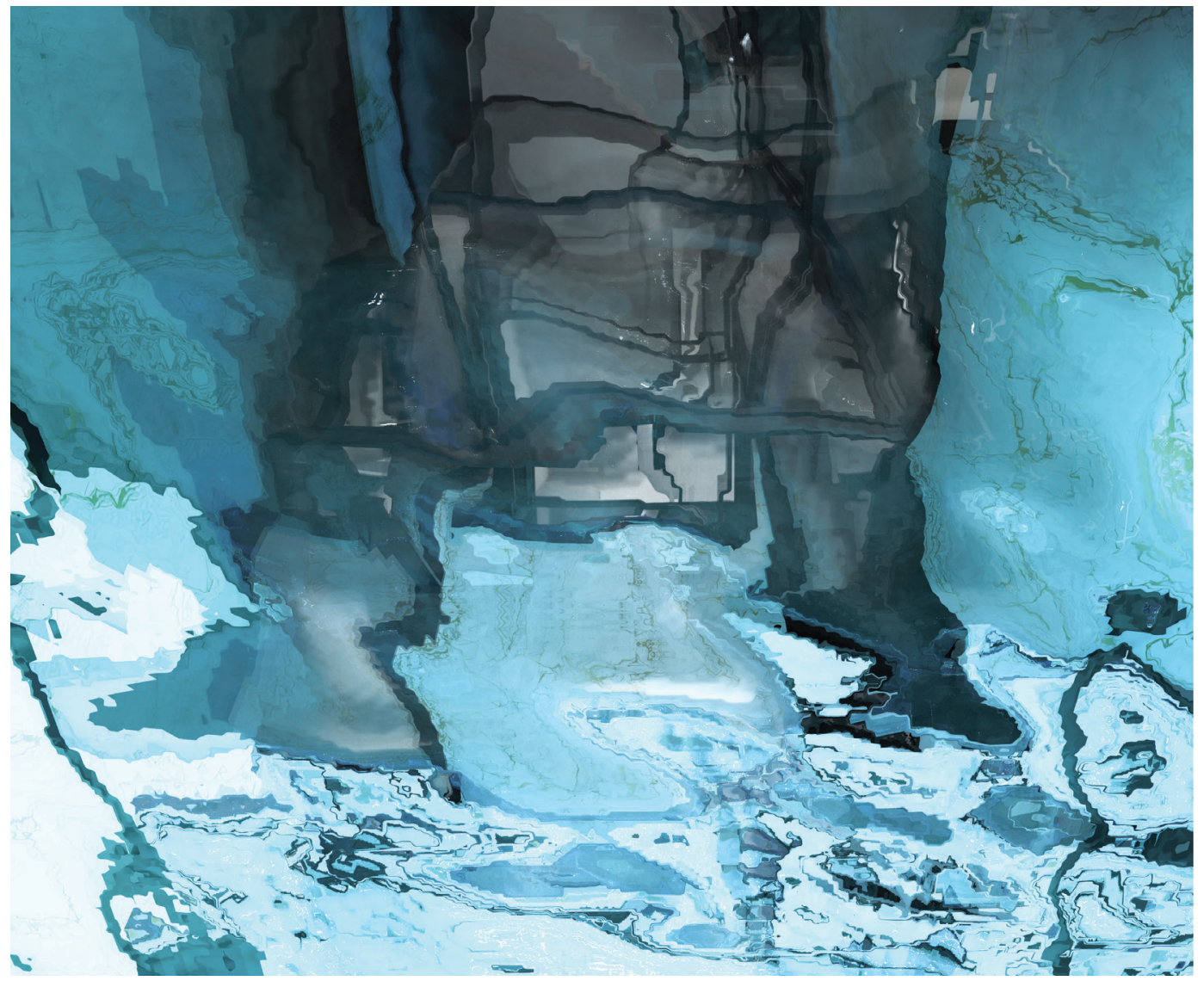

Figure 114: Scene S - View from under the Water Distorting the Space during the Night 
The next level is divided into two sections. The first section is accessible only by means of the ramp from the previous level, and the second section can be reached using the stairs. The two parts have no access to each other. Also, the first section does not have access to the next level, and one has to go back to the previous level and take the stairs to reach the following level. 


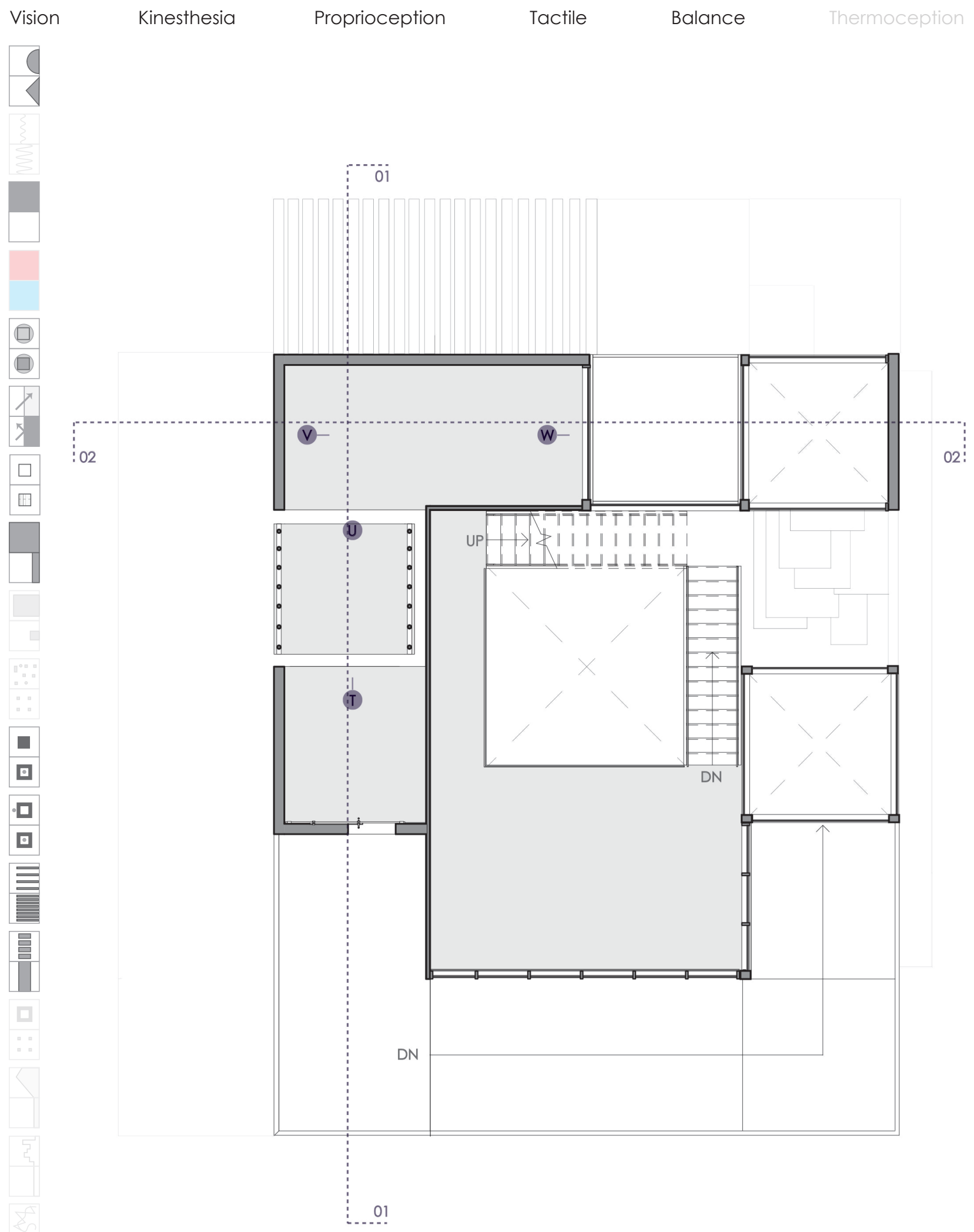

Figure 115: Tenth Floor Plan 
The Unstable Floor
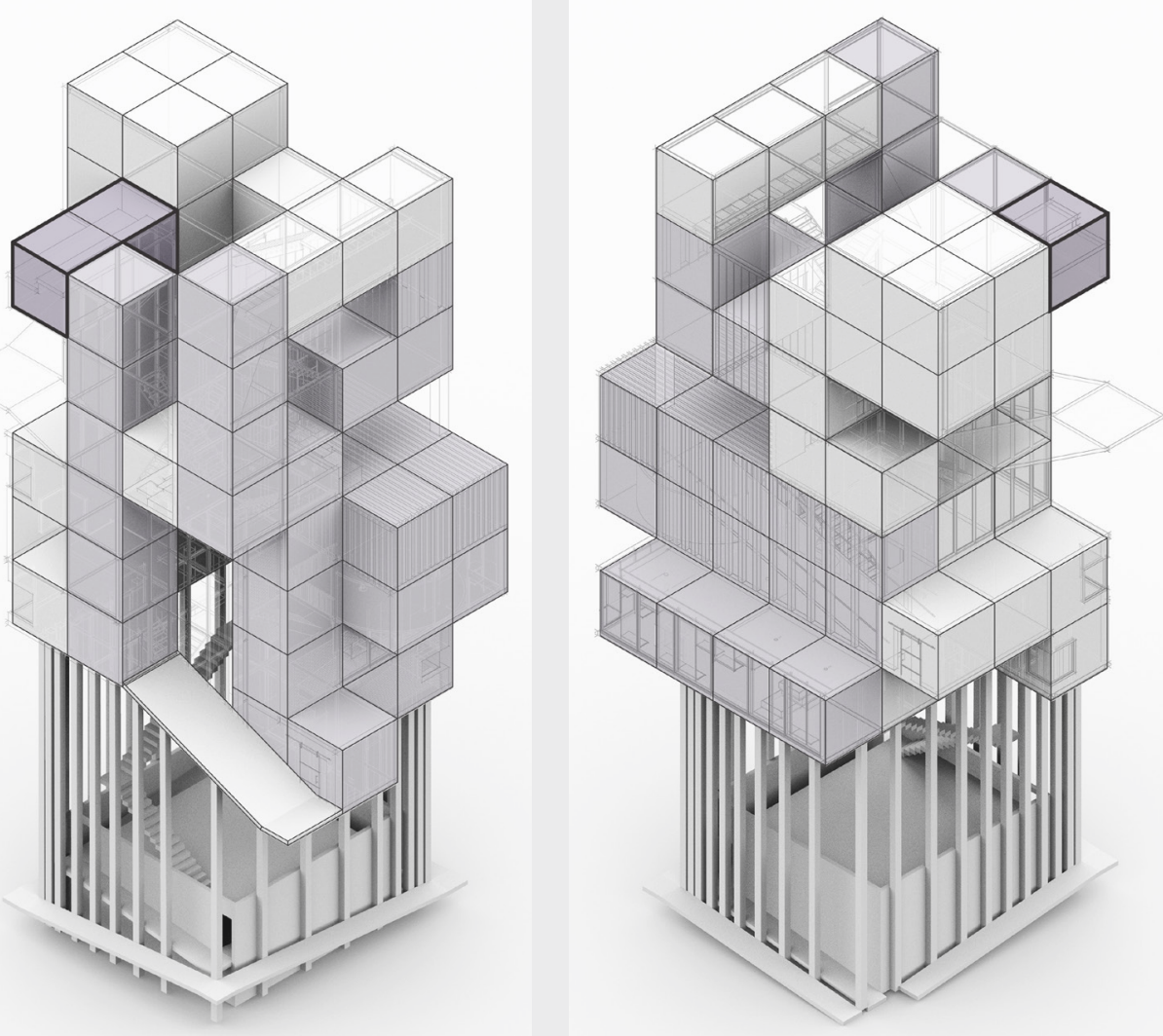

Figure 116: The Unstable Floor 
If the ramp is taken, the unstable floor impacts the sense of balance drastically. One has to pause constantly to maintain her balance and continue as she feels stable. It can be considered a painful experience, or a pleasant one, depending on how one feels in space.

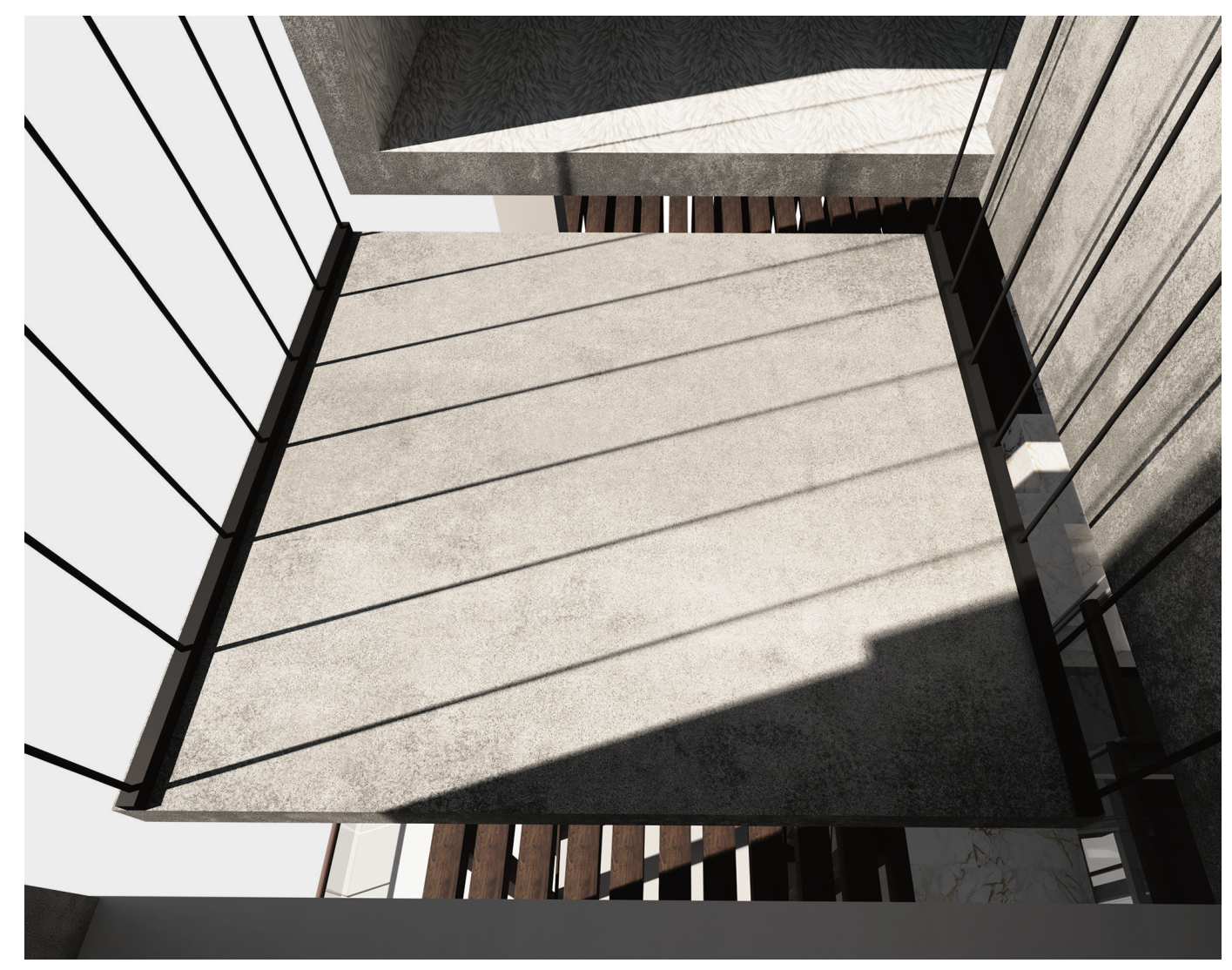

Figure 117: Scene T-View of the Unstable Floor 
As one feels stable enough to look up, the flowing water once again becomes visible. The tension between inside and outside intensifies the experience.

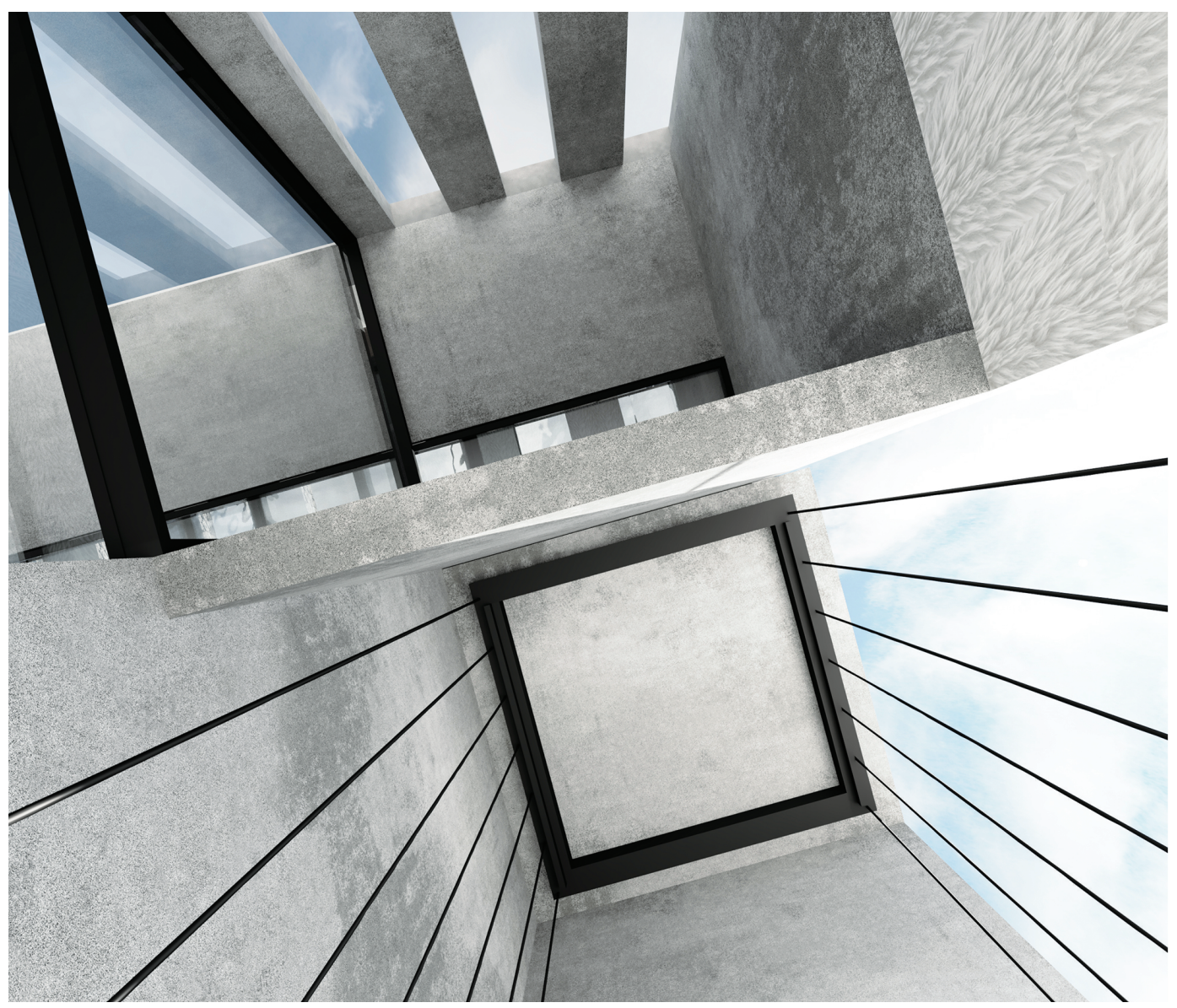

Figure 118: Scene U - Looking up from the Unstable Floor 
The Fur Room
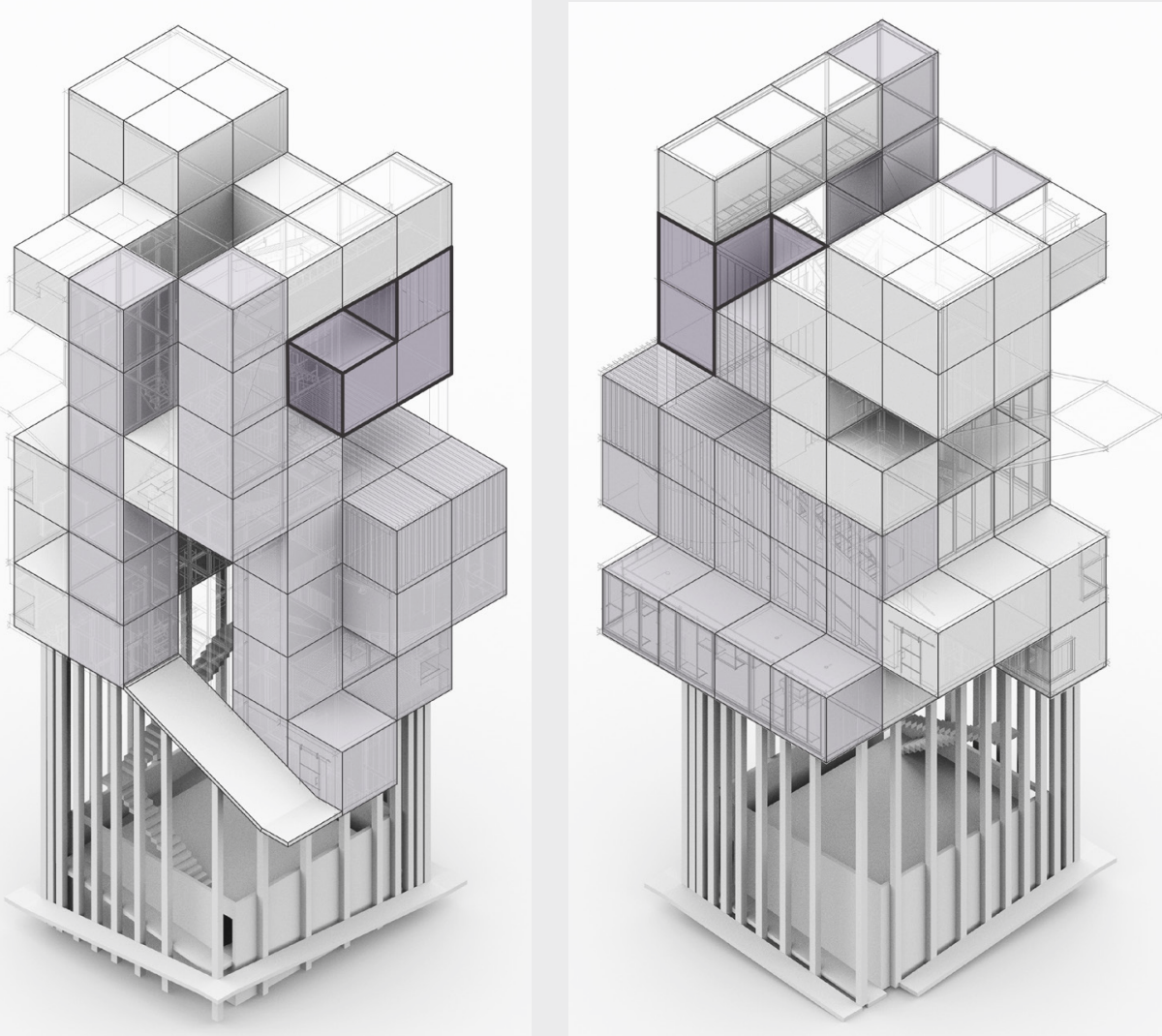

Figure 119: The Fur Room 
Stepping off the unstable floor, the softness of fur exaggerates the feeling of comfort as it immediately follows a high level of discomfort, the unstable floor. The mirror reflects an image of the pool to dislocate and attract people visually.

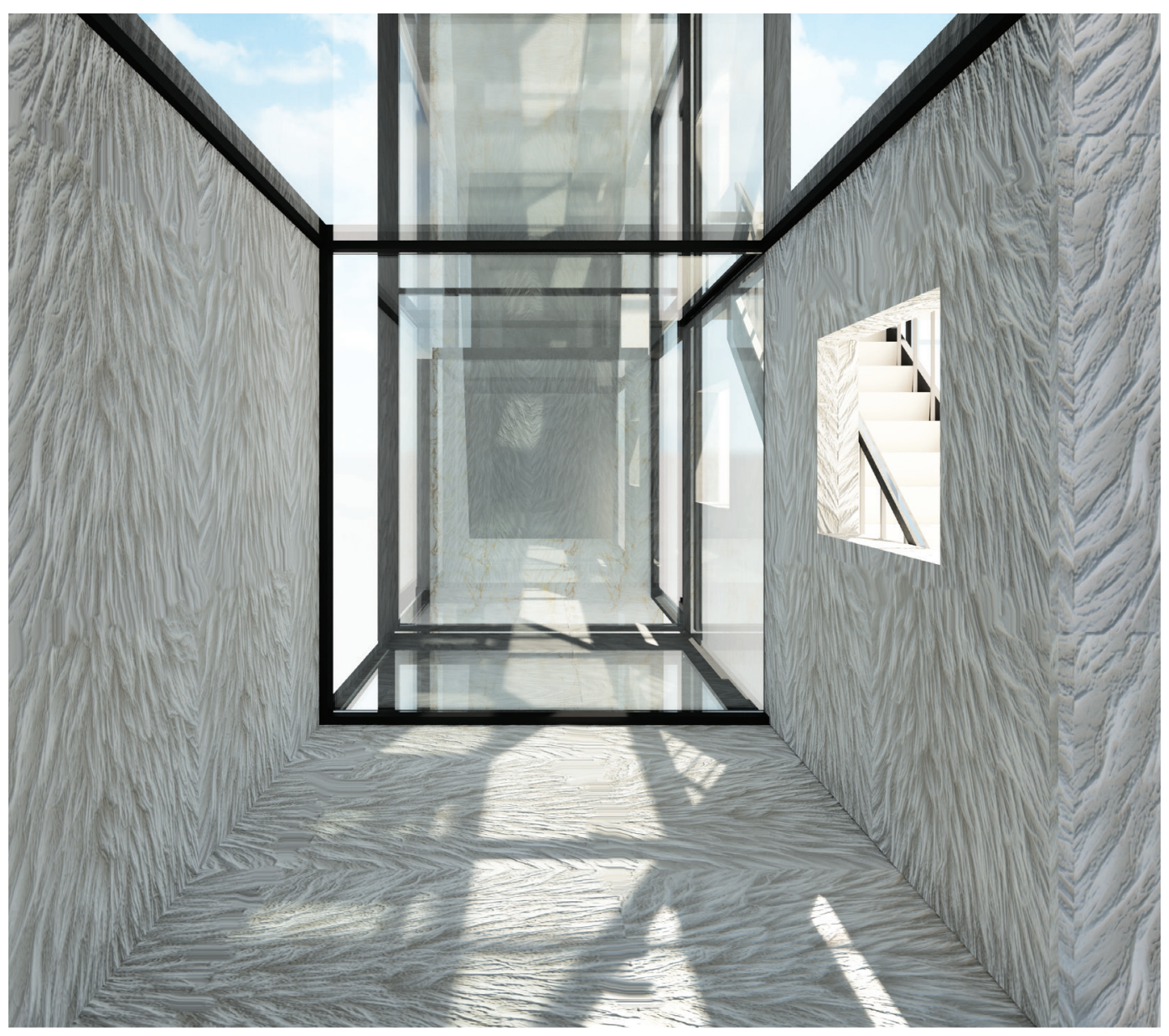

Figure 120: Scene V-Inside the Fur Room, Looking Towards the Mirror 
If one has already experienced the pool, she feels dislocated since the reflection is higher in space than the location of the body. If one has not experienced the pool, then the reflection attracts the explorer to find the location of the pool.

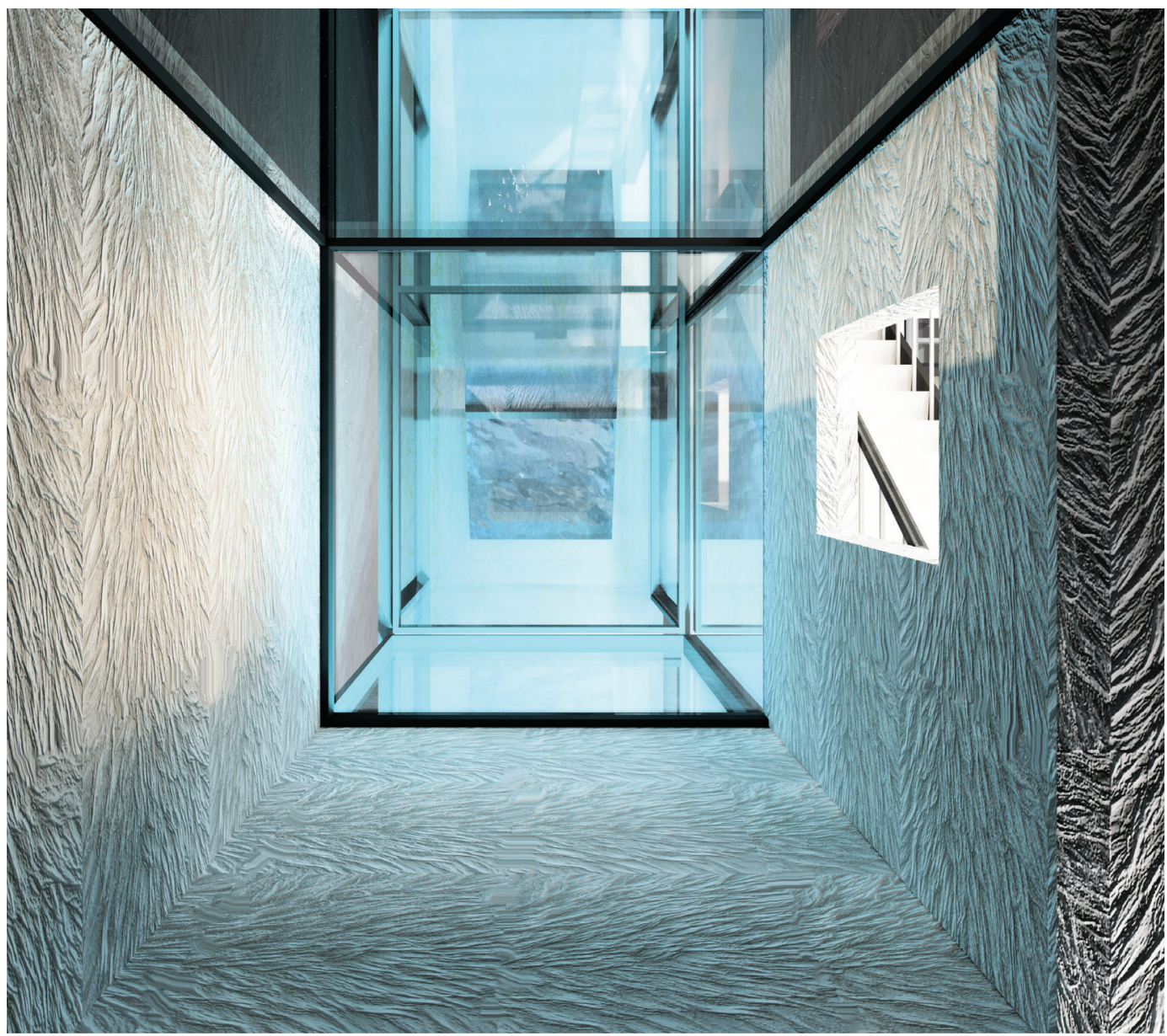

Figure 121: Scene V-Inside the Fur Room, Looking Towards the Mirror, during the Night 
Moving forward in the fur room, the observer can now have a view of the pool.

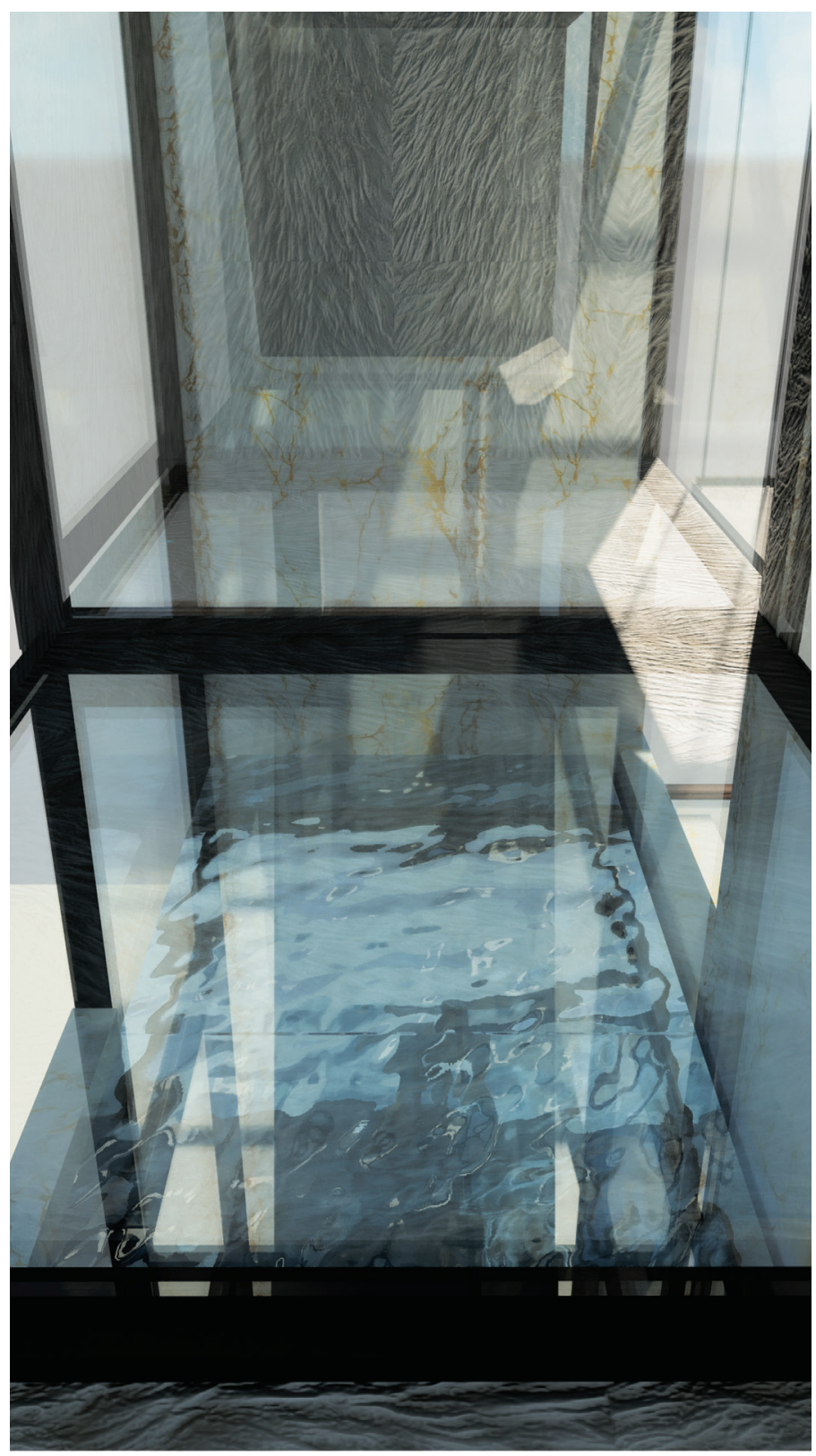

Figure 122: Scene W-Looking down to the Pool from the Fur Room 


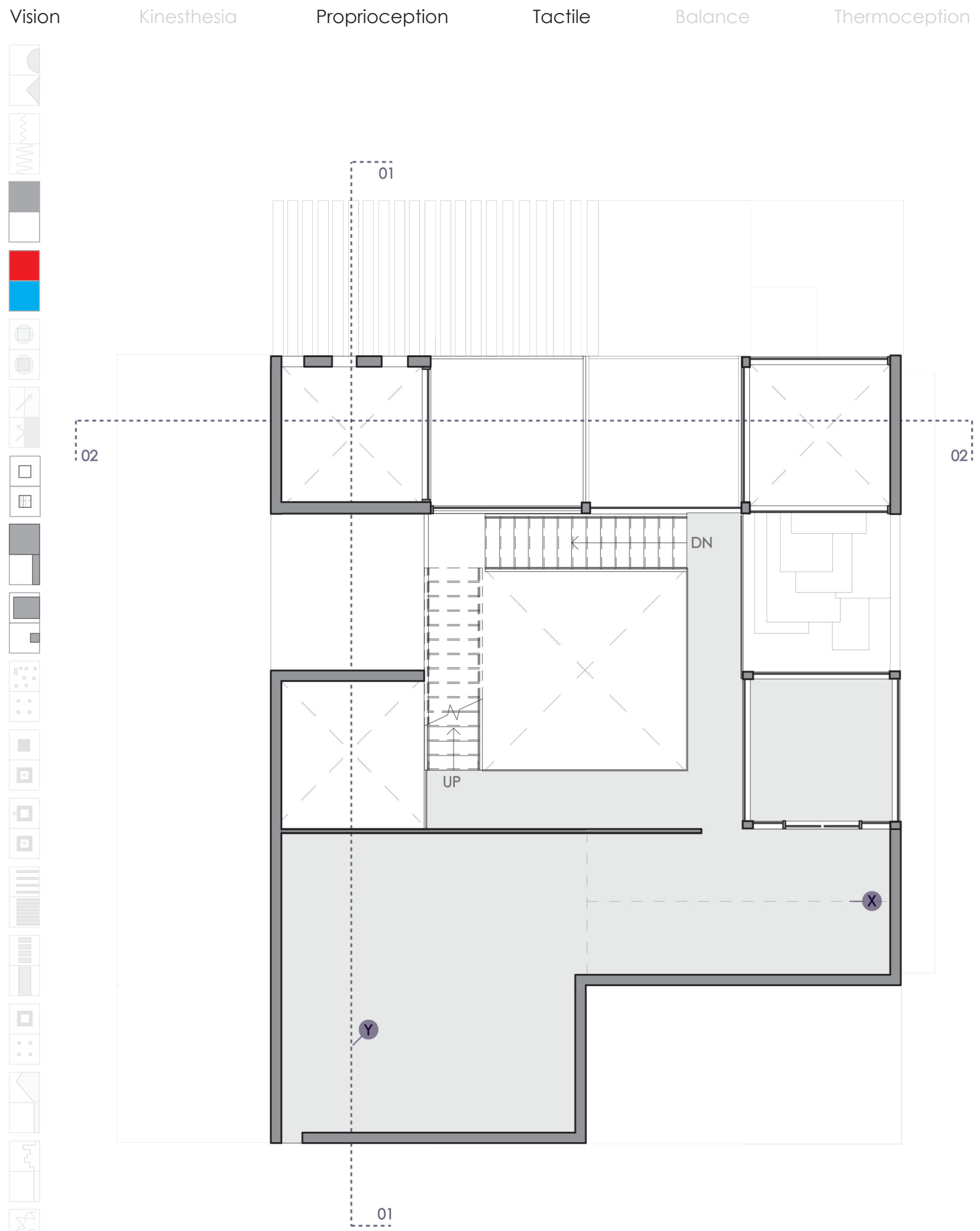

Figure 123: Eleventh Floor Plan 
The Room of Compression
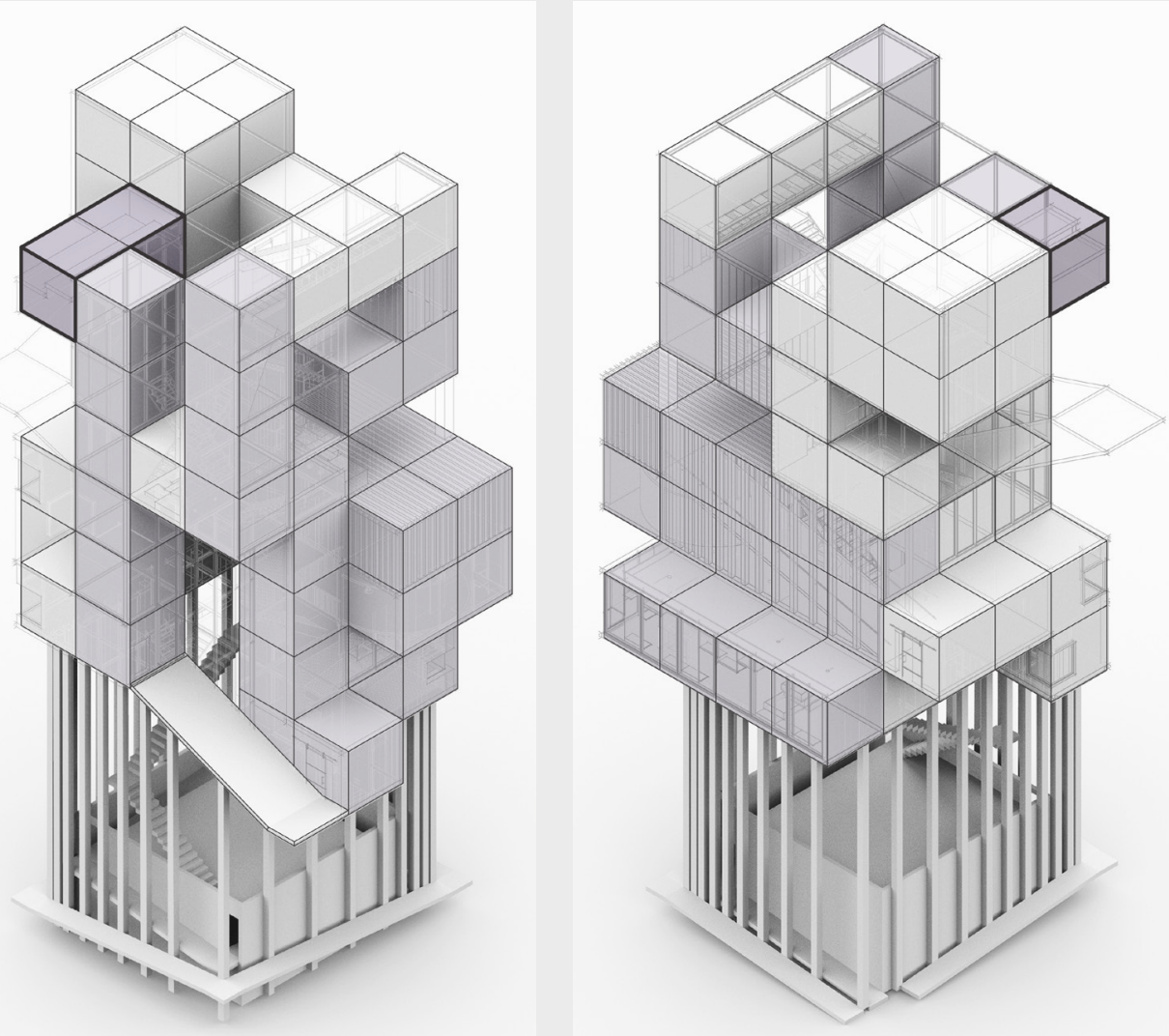

Figure 124: The Room of Compression 
Getting off the elevator, one now enters the next level, a very compressed space that requires bending of the body or some different way of moving on one side due to the low ceiling. Concrete surfaces invite the visitor to touch and experience the texture.

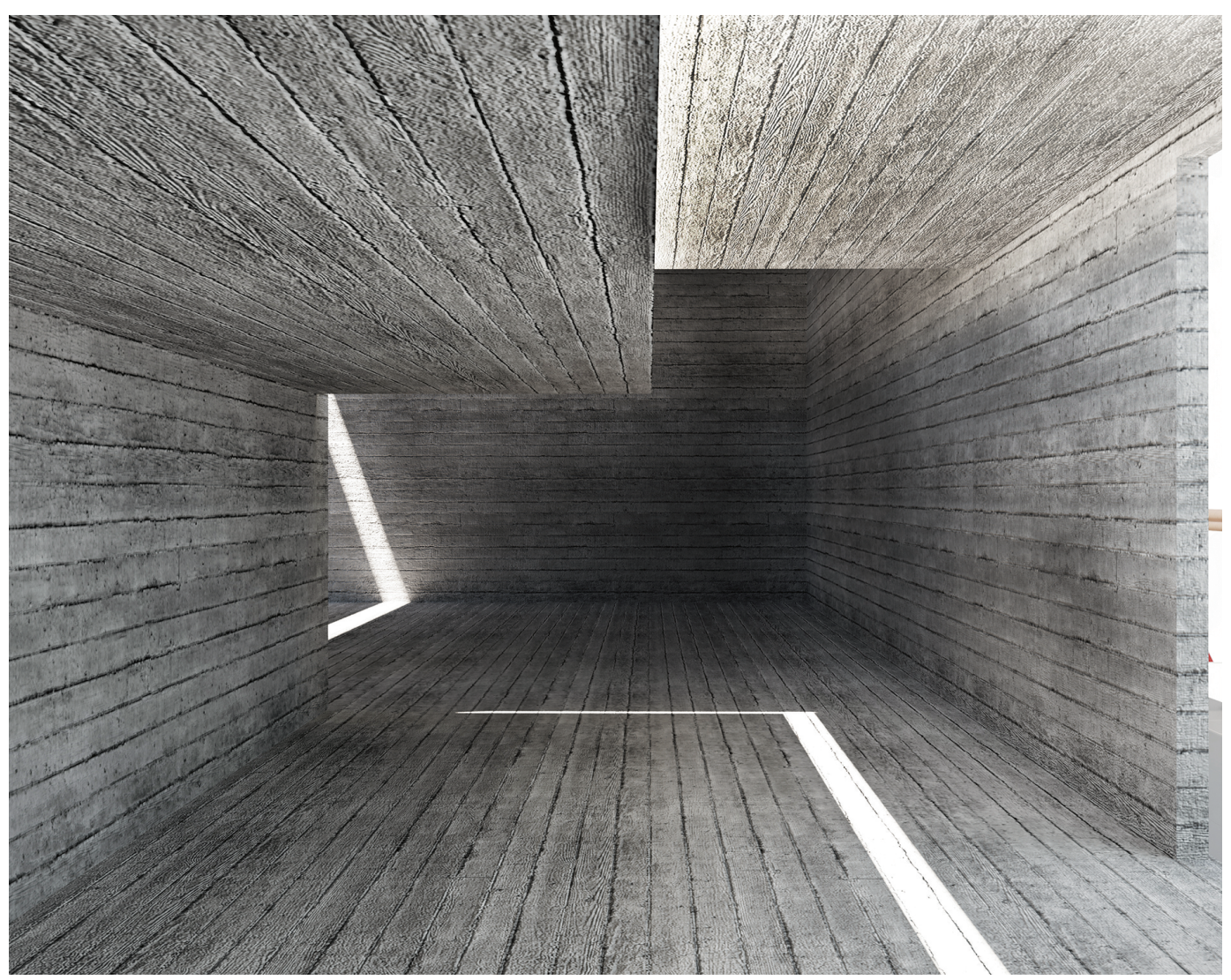

Figure 125: Scene X-Inside the Compressed Room, Feeling the Texture of Concrete 
The Room of Expansion
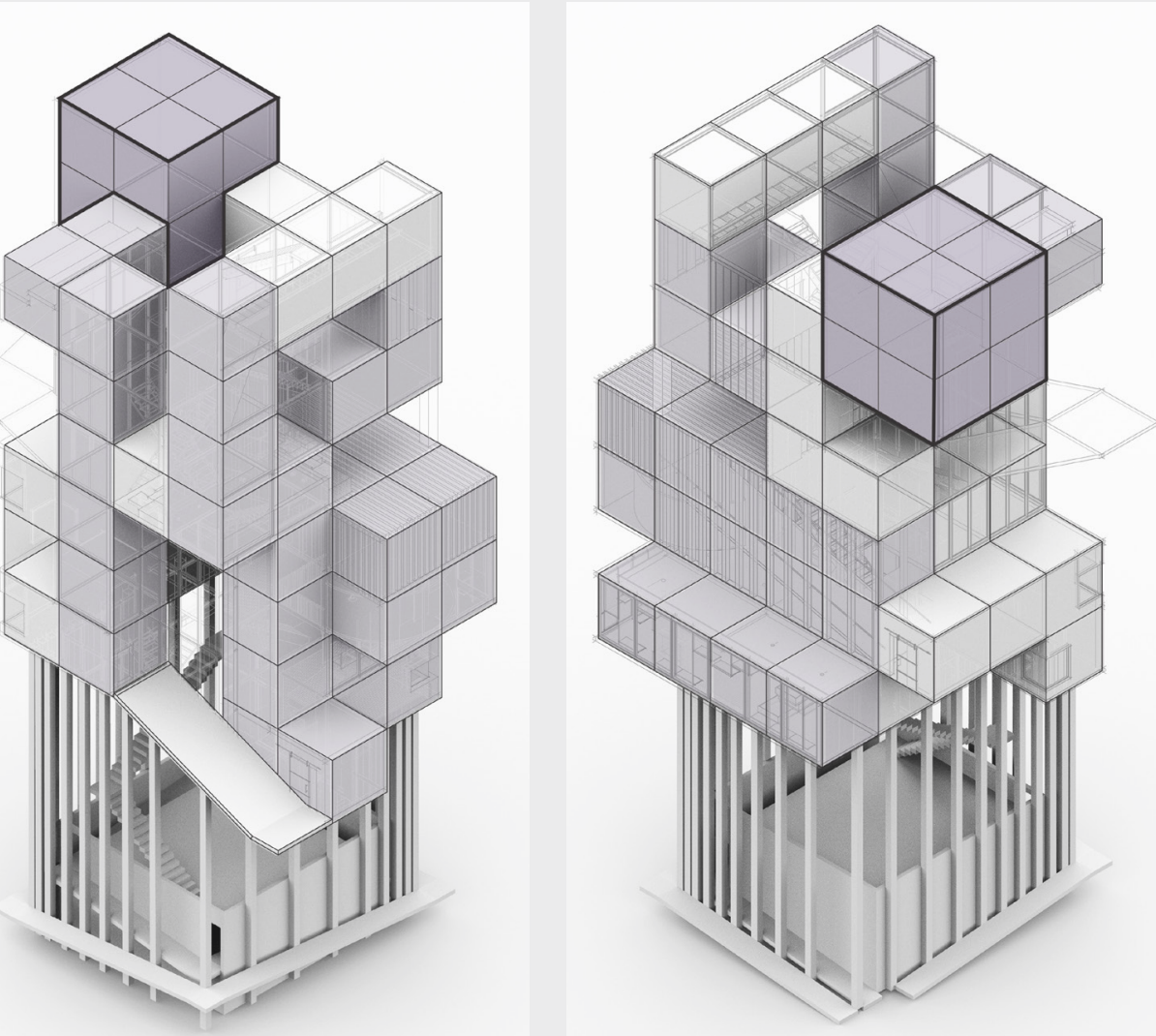

Figure 126: The Room of Expansion 
As one takes the next few steps, she enters the expansive room. The effect of light on the textured concrete animates the space during the day. The space is interpreted as a pure mass of shadow and the strips of light hollow out the darkness. The spaciousness of the room and the play of light encourage the individual to linger in the space.

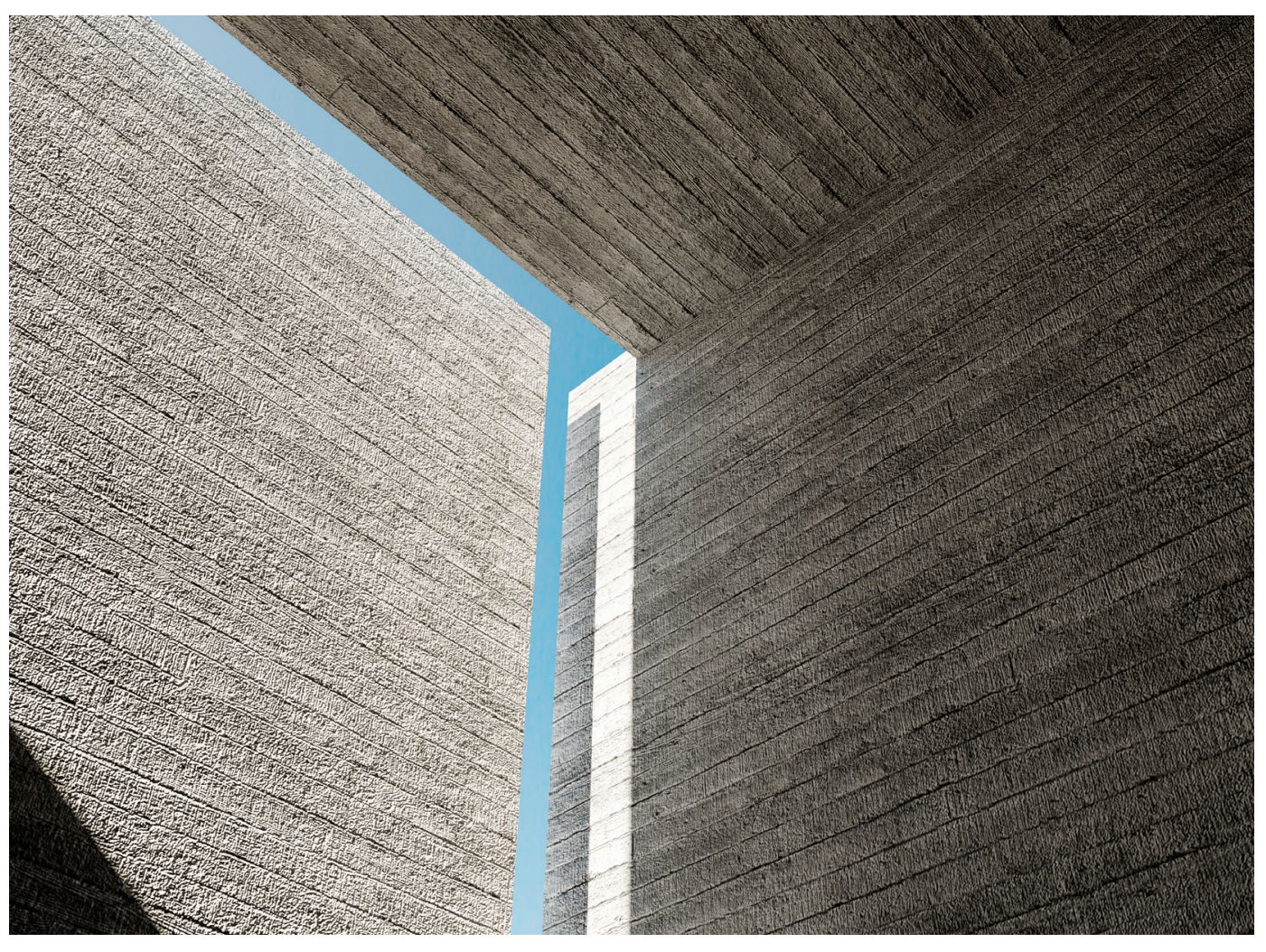

Figure 127: Scene Y-Play of Light Animating the Room of Expansion - 8 am 


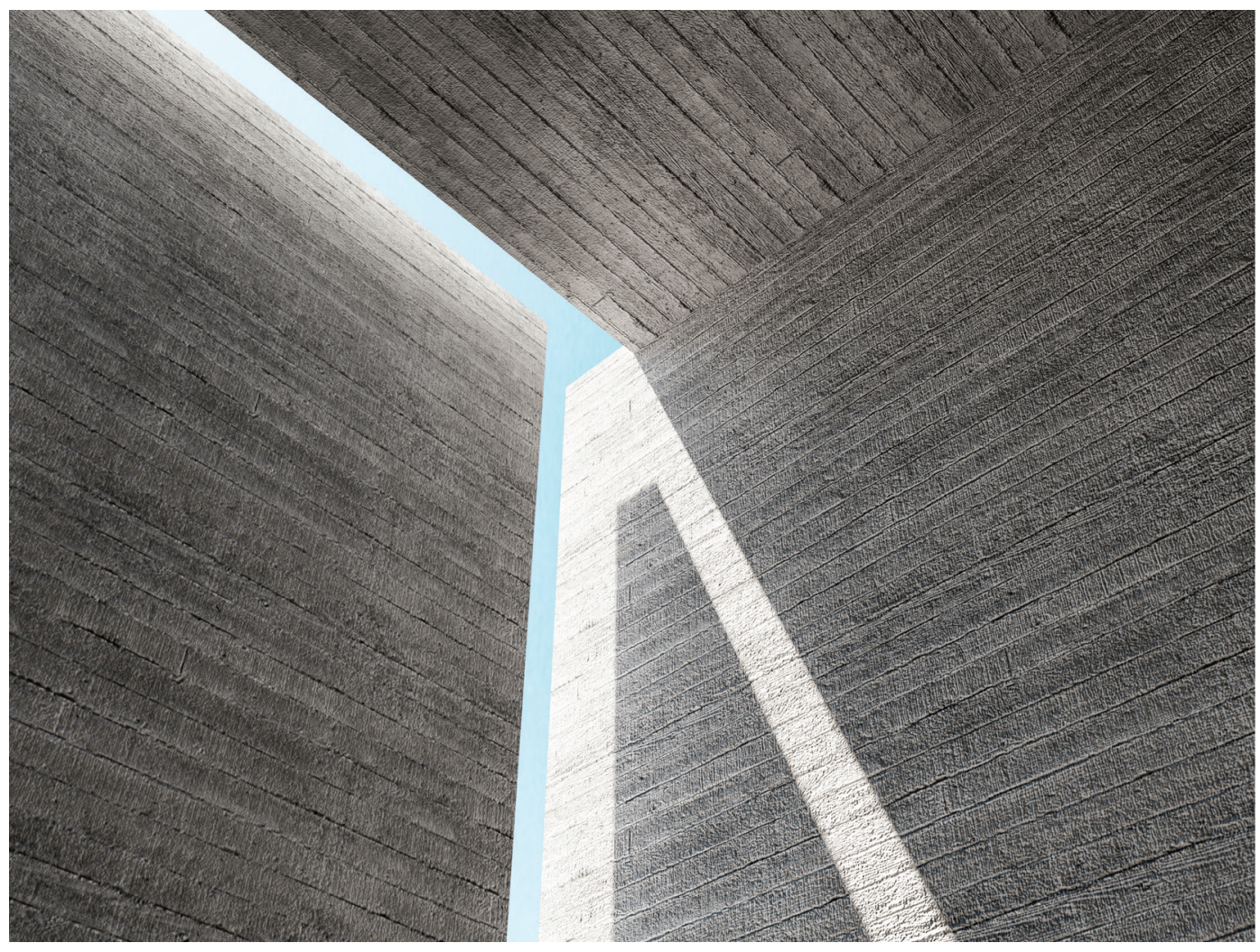

Figure 128: Scene Y - Play of Light Animating the Room of Expansion - 10 am 


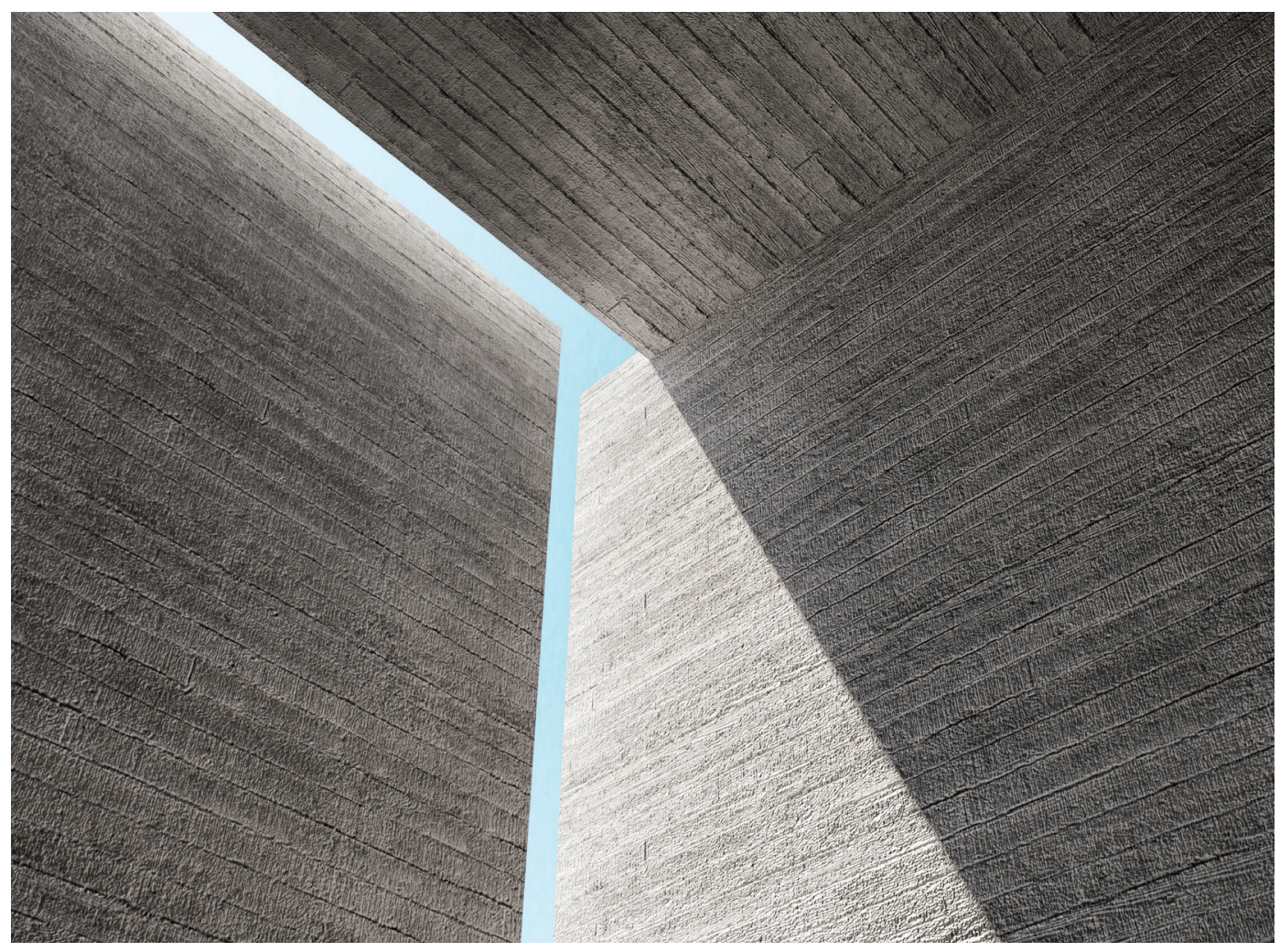

Figure 129: Scene Y - Play of Light Animating the Room of Expansion - 12 pm 


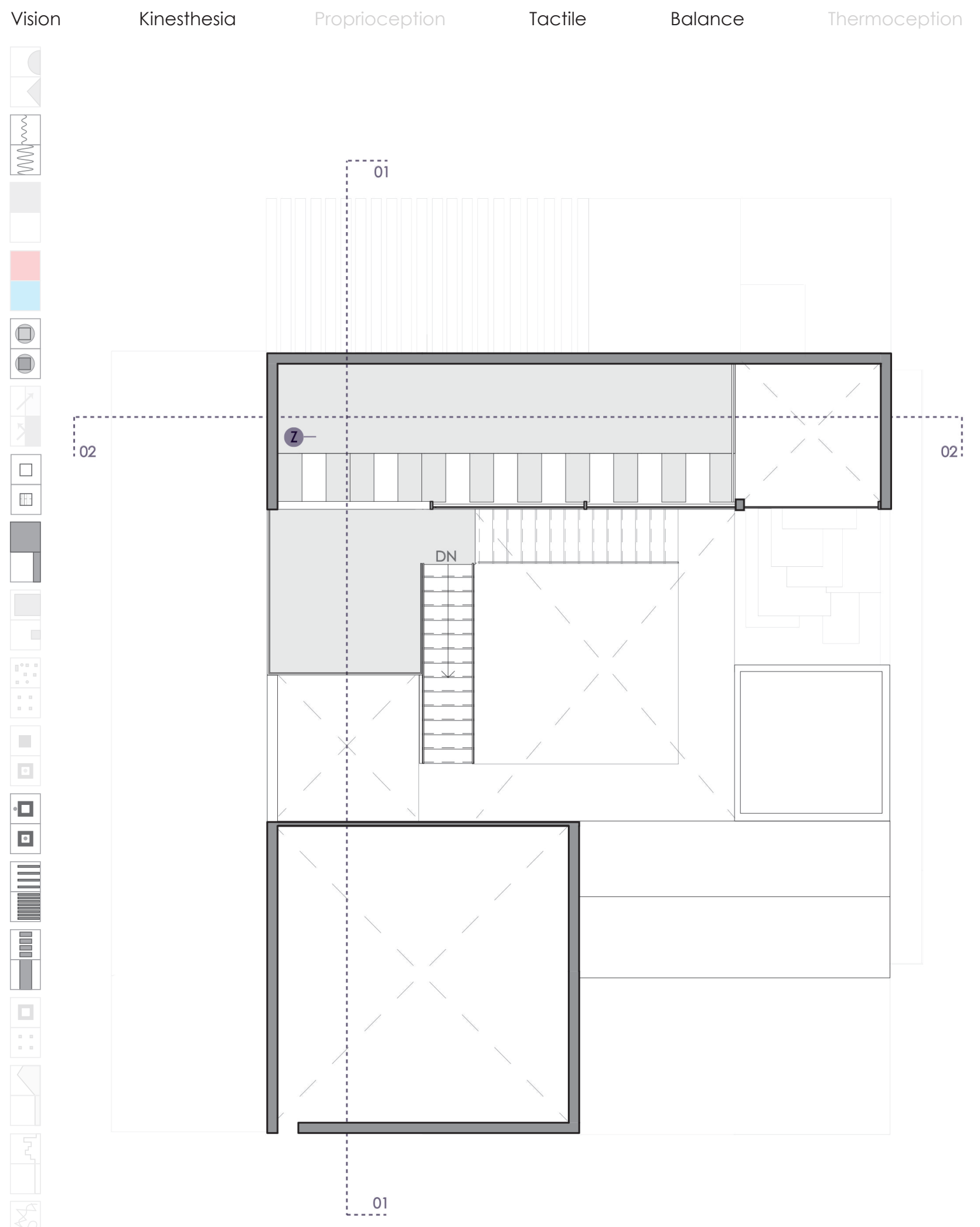

Figure 130: Twelfth Floor Plan 
The Stepstones on Water
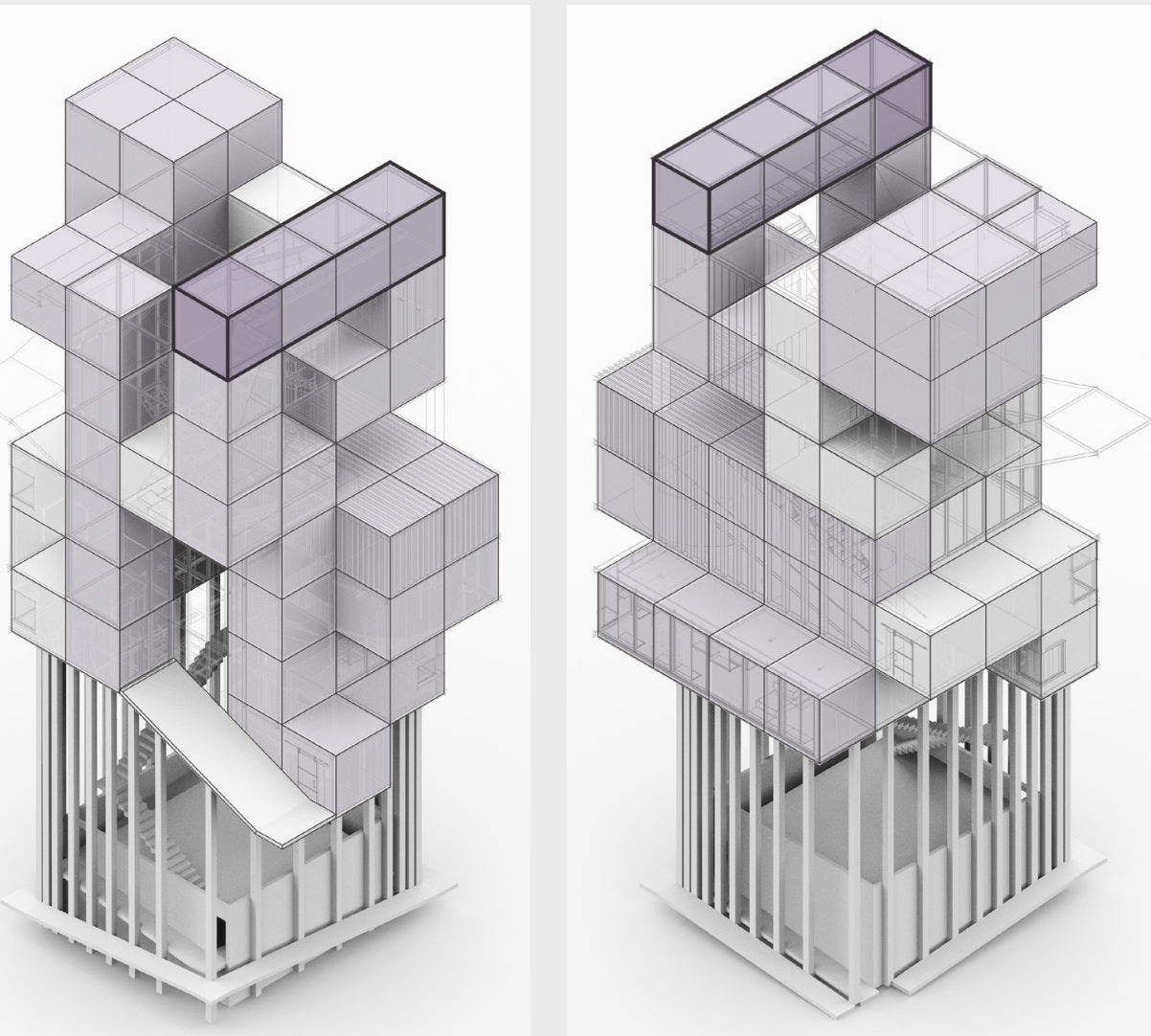

Figure 131: The Stepstones on Water 
On the next level, stepping onto the floor covered with fieldstone, one becomes conscious of the drastic change in materiality. As she traverses the stepstones on the water, the body's equilibrium and balance are stimulated and hence slow down the motion and magnify actions in space. The visitor's focus is entirely on how the feet touch the fieldstone. The stream of flowing water and its melodic sound landing on the angled mirror, and eventually in the pool, lures one towards the edge. As she looks down, the flowing water is visible but the pool is hidden by the mirror.

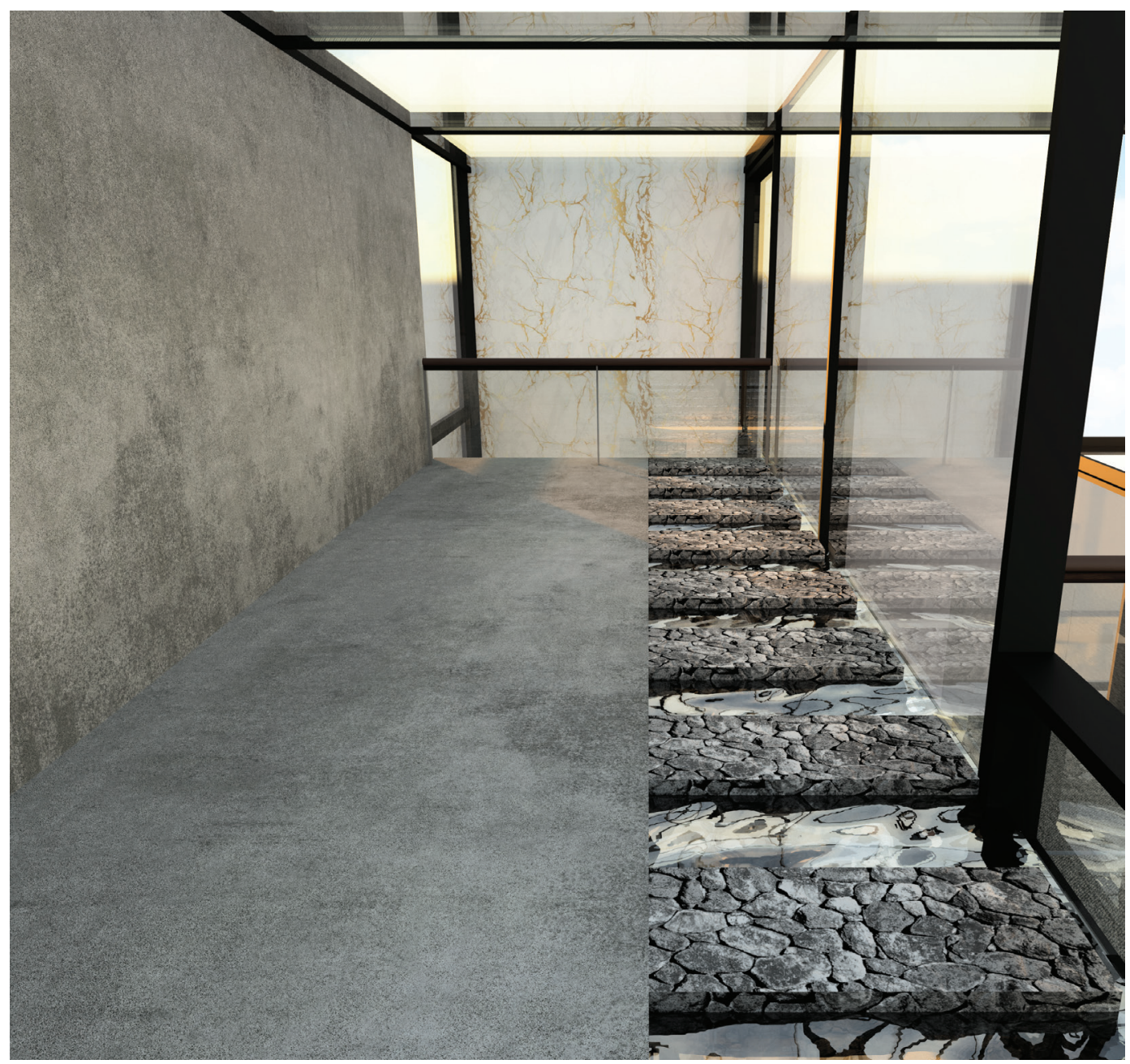

Figure 132: Scene Z - View of the Stepstones on Water 
The journey never comes to an end. The subject can explore spaces that have not yet been experienced while descending the building. The level of complexity of this machine allows for diverse experiential journeys, both moving upwards and downwards. In addition, the order in which the spaces are encountered varies the experience. Even though the same path can be repeated, the way the body interacts with the affordances will be different every time. Each space can be interpreted as static or kinetic, depending on how the body perceives it through the interconnection of senses. This haptic machine establishes a tool kit and a set of methods for application in actual material architecture. 


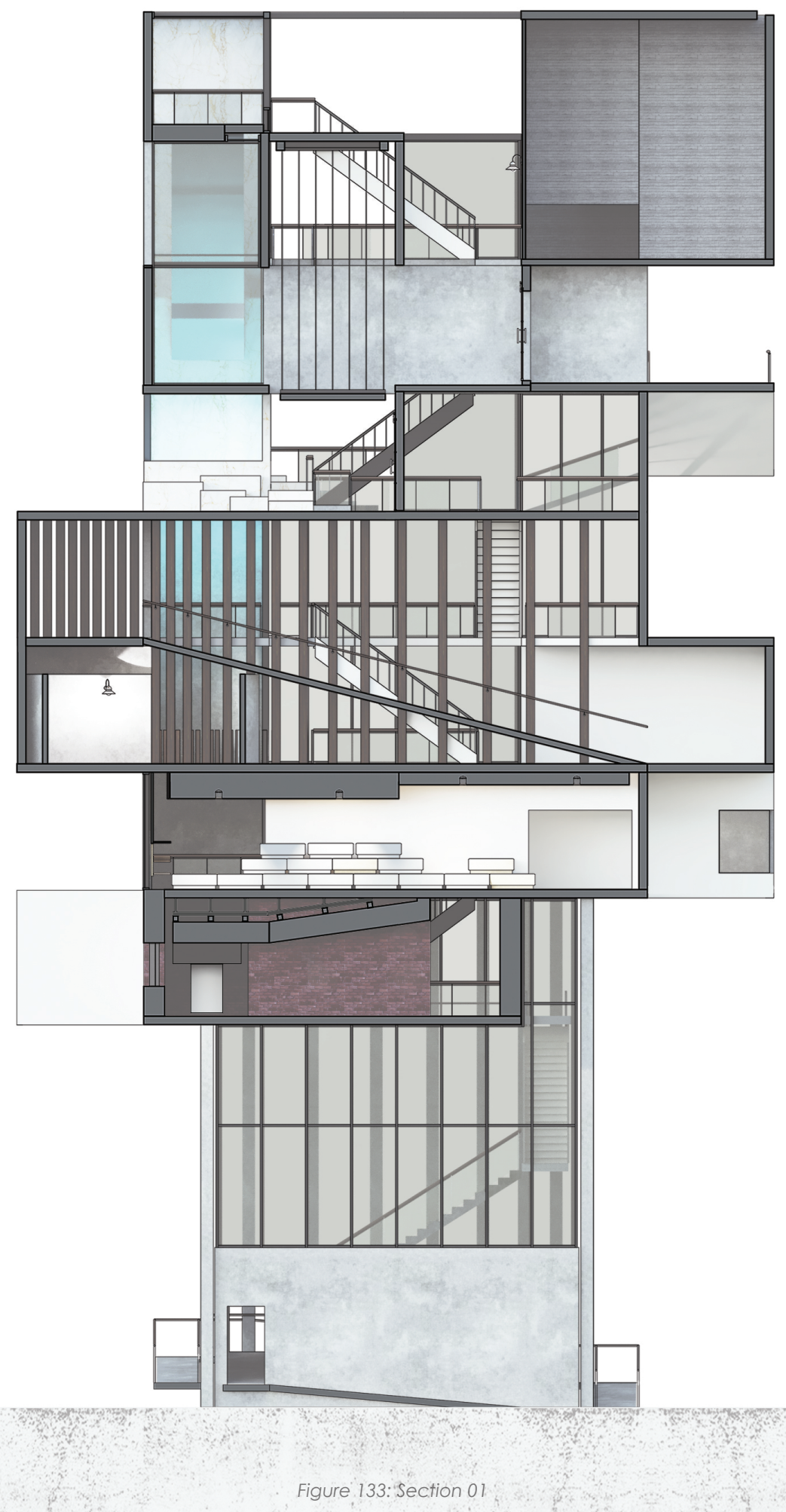




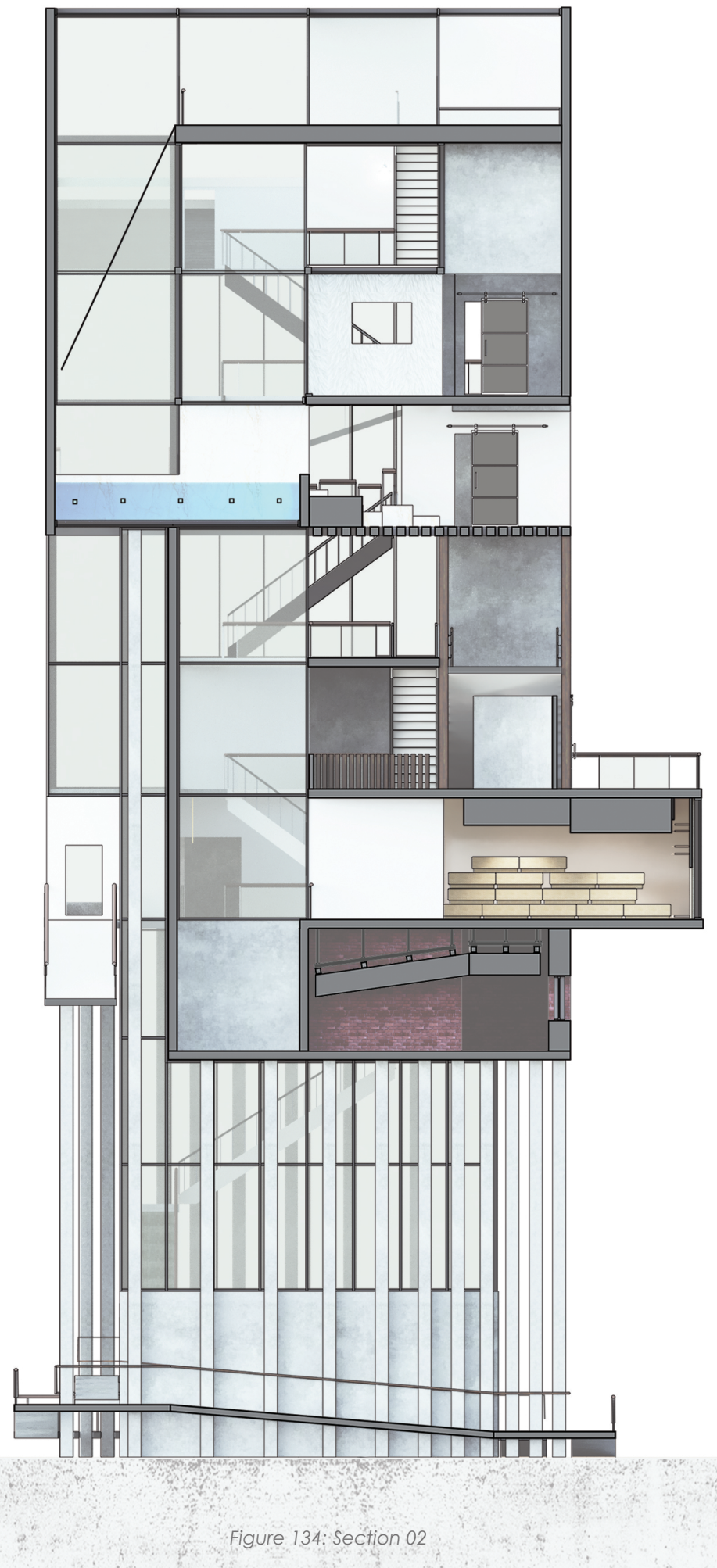




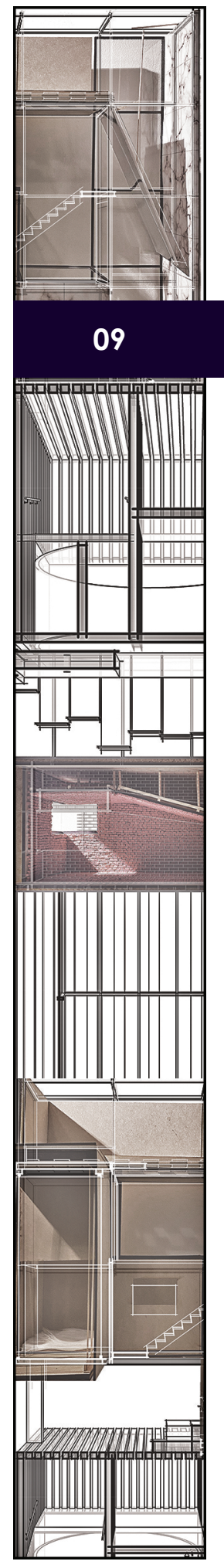




\section{Speculation}

The journey can be uncomfortable, ambiguous, and sometimes even risky. It might require us to break out of our regular habits and therefore demands our conscious awareness. It is in the state of awareness that one encounters unexpected opportunities and experiences the totality of space.

The analysis of the case studies allowed for the formulation of the Library of Spatial Binaries, which was then used to explore haptic space. Even though the physical manifestation of these binaries is objective, the response to these conditions is subjective; therefore, the outcome of haptic space and how different bodies interact with its spatial qualities, is always unknown. Thus, one of the challenges for this thesis was to avoid prescriptive architecture and focus on the optional multisensorial experience.

In contemporary society, sensory realms have been suppressed, and priority has been given to vision since it is the most dominant of the senses. However, this suppression and the distance from the human body in architecture can be considered as a missed opportunity. The totality of space is experienced, not only through visual perception but through the interconnection between vision and other bodily senses, haptic perception.

The primary premise of the design project is to explore corporeality in architecture and discover possibilities that exists within an architectural platform to propose haptic spaces that encourage a complete human experience. These spaces enhance the experience of spatial qualities, both visually and bodily, and consequently support 
subjective actions in space. This was accomplished by studying and engaging the somatosensory system as well as vision in the production of a series of spaces with different visual and haptic qualities. All the design work, the experiential section, the haptic tool kit and the design proposal, are products of this design experiment.

Our daily habits are impacted by the concept of "time poverty," which is created by the accelerated society, where there is pressure to maximize efficiency and save time.' In the chaos of our society, it is always about the end result, and not the journey. Then, why should one bother to bring consciousness into architecture, which is continuously responsive to this accelerated society?

The brain is programmed in a way that repeats behaviours and adapts to its environment, and when the body adapts, it stops sending sensory signals to the brain. Repeated movements change the physical body on a cellular level to best accommodate the behaviours. In the past, behaviours were less a product of convenience and more an immediate bond between body and mind. Now, the body is reliant on its comfort and therefore, "successful design" is to remove all barriers. However, this design lacks spatial opportunities for the pleasure of a self-created journey as well as failing to maintain its users' sensory capacity. The correction of these habits and behaviours is possible through engaging one's body consciousness to achieve better self-awareness. ${ }^{2}$

Our body is an essential dimension of our humanity since it is a necessary instrument for our perception, thoughts, and actions. For Shusterman, "just as skilled builders need expert knowledge of their tools, we need better somatic knowledge to improve our understanding and performance in the arts and human sciences". ${ }^{3}$ In

Gleick, James. The Acceleration of Just about Everything. 227.

Shusterman. 119.

lbid. 26. 
order to educate and enrich our lived humanistic experience, architectural space, in which our actions and movements take place, can possibly cultivate improved somatic awareness. The body training in architectural space should never be concluded since learning never concludes ${ }^{4}$ as there are always possibilities for refinement.

On the other hand, an essential dimension of architecture is how it contributes to the subjective and lived experience of its users. As Walter Benjamin explains, "the aura" is perceived through the senses by experiencing the atmosphere of space. ${ }^{5}$ The answer is not to fill in the atmosphere of our everyday lives with interruptions and obstacles, or to give attention to all of our bodily actions; the answer is to take into consideration the opportunities that the somaesthetic senses embody, and to incorporate them in everyday architecture as much as possible to augment the experienced atmosphere.

Therefore, the thesis project presents a conceptual framework, using a haptic machine, to portray and incorporate these possible spatial opportunities. Each extreme condition can be selected and implied into everyday architecture to enhance the architectural experience, without being as disruptive as their current manifestations. The challenge ahead is to keep a balance between implying these opportunities and maintaining a functional space for everyday use. Focusing on the body enables us to not only appreciate the visual but also the multi-sensorial experience of moving in space. With haptic space, the intent is to make an individual conscious of the spatial qualities and reinforce the engagement of the body with the totality of space.

Ibid. 205.

Benjamin, Walter. "The Work of Art in the Age of Mechanical Reproduction." 5. 


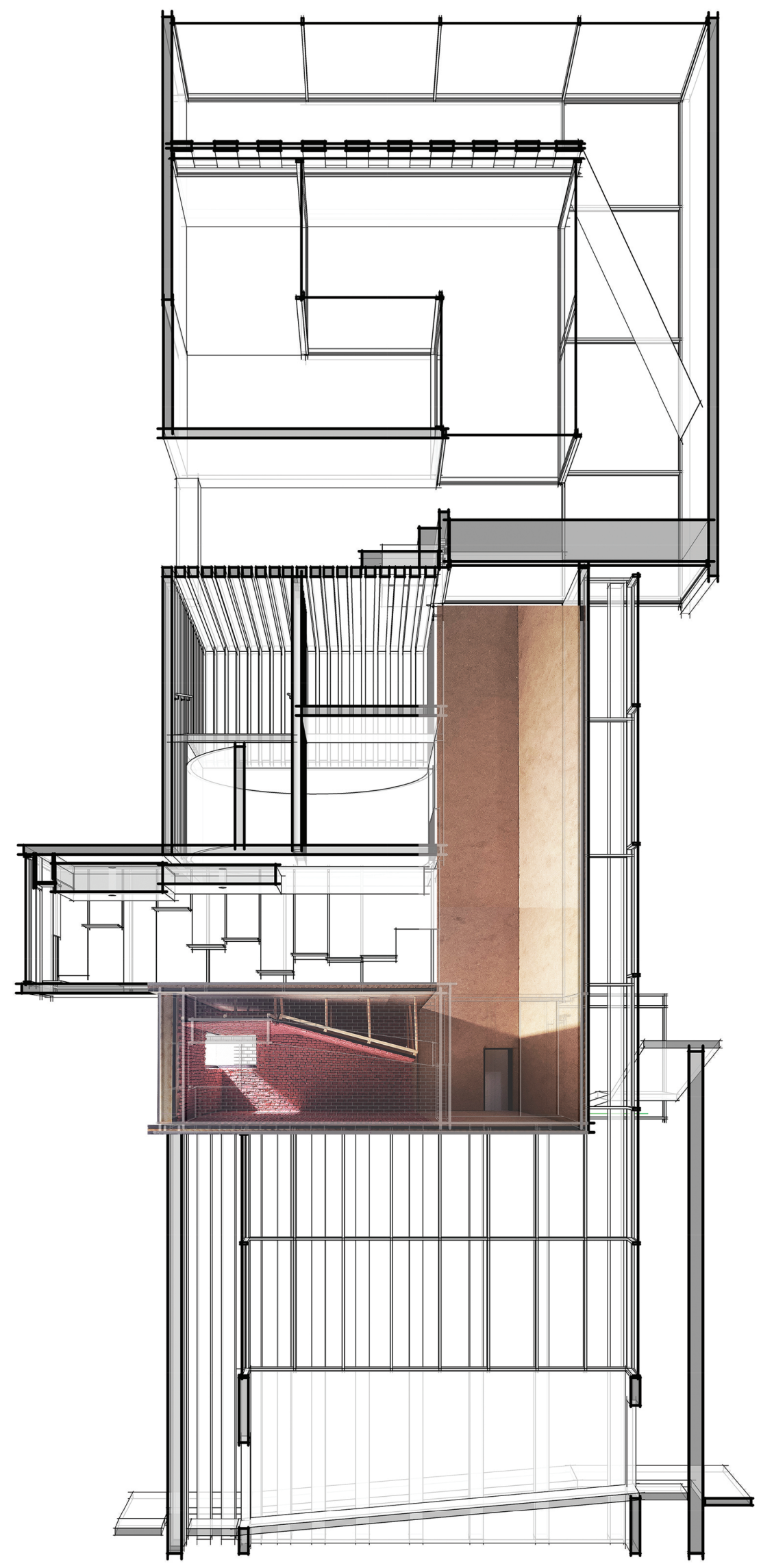




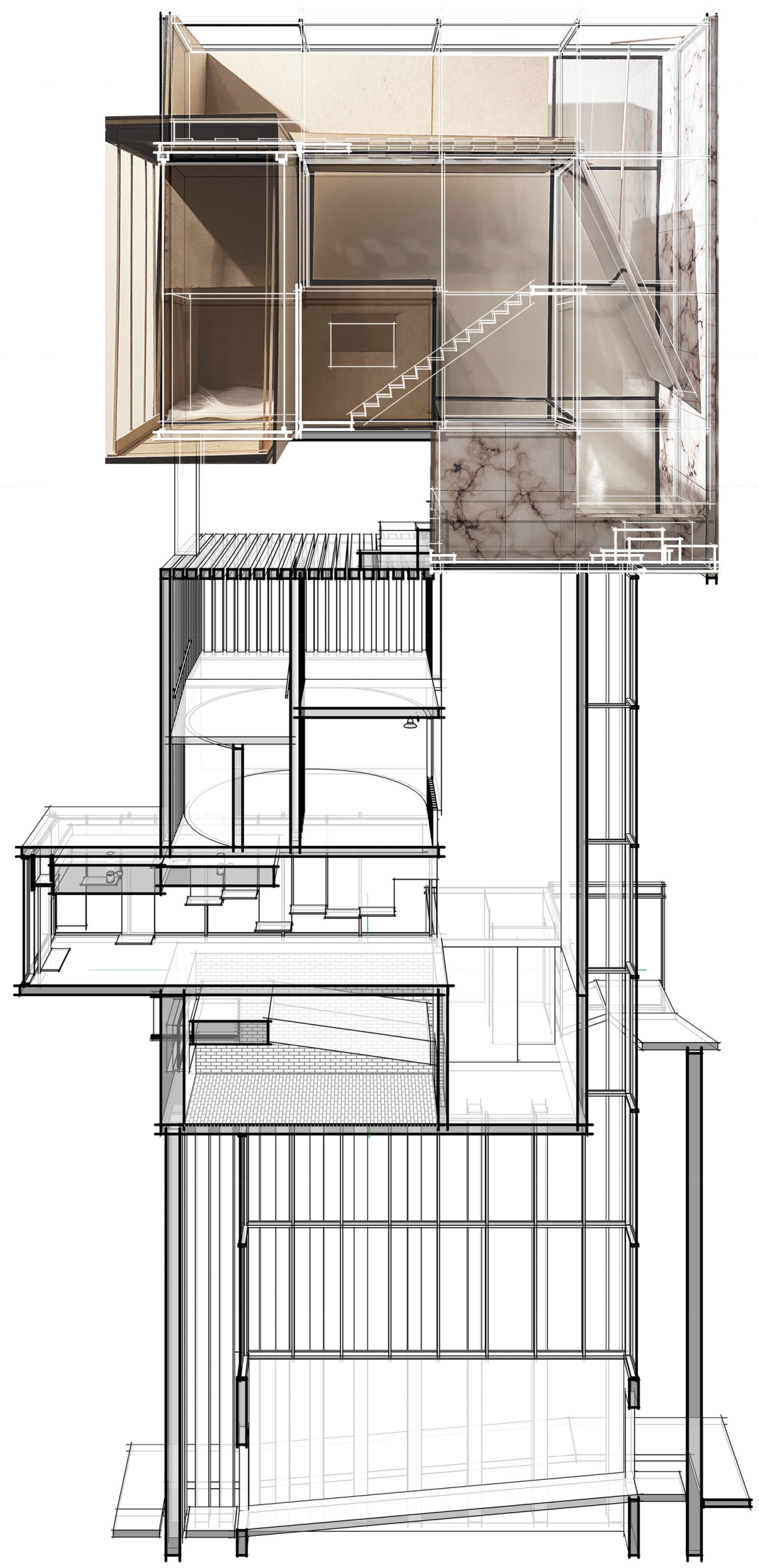




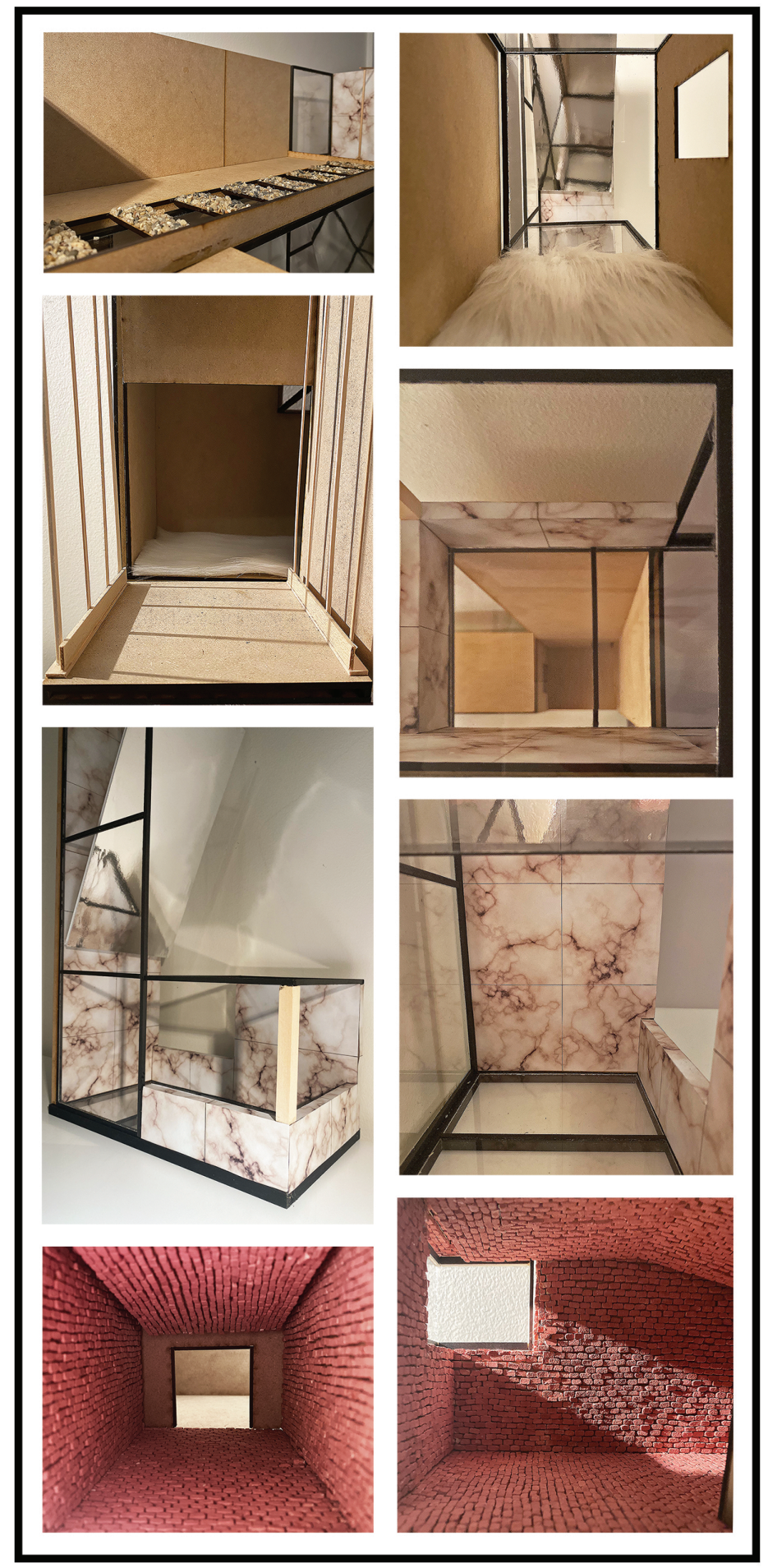

Figure 135-137: Physical Models of the Machine 
Appendices

Appendix A - The Experiential Section

Appendix B - The Experiential Video

Appendix C - The Haptic Tool Kit

\section{Appendix A}

Appendix A - The Experiential Section

The experiential section brings in the spatial binaries to achieve attractions and aversions, parallactic space, and perilous space to create conscious movement through a sequence of spaces. Each space/element focuses on a specific condition and has a unique impact on haptic perception. 
narrow pathway

cold and expansive exterior

compressed interior

warmth of the brick walls

texture of brick

glass floor overlapped pathways

dead end

small window

view of the trees outside
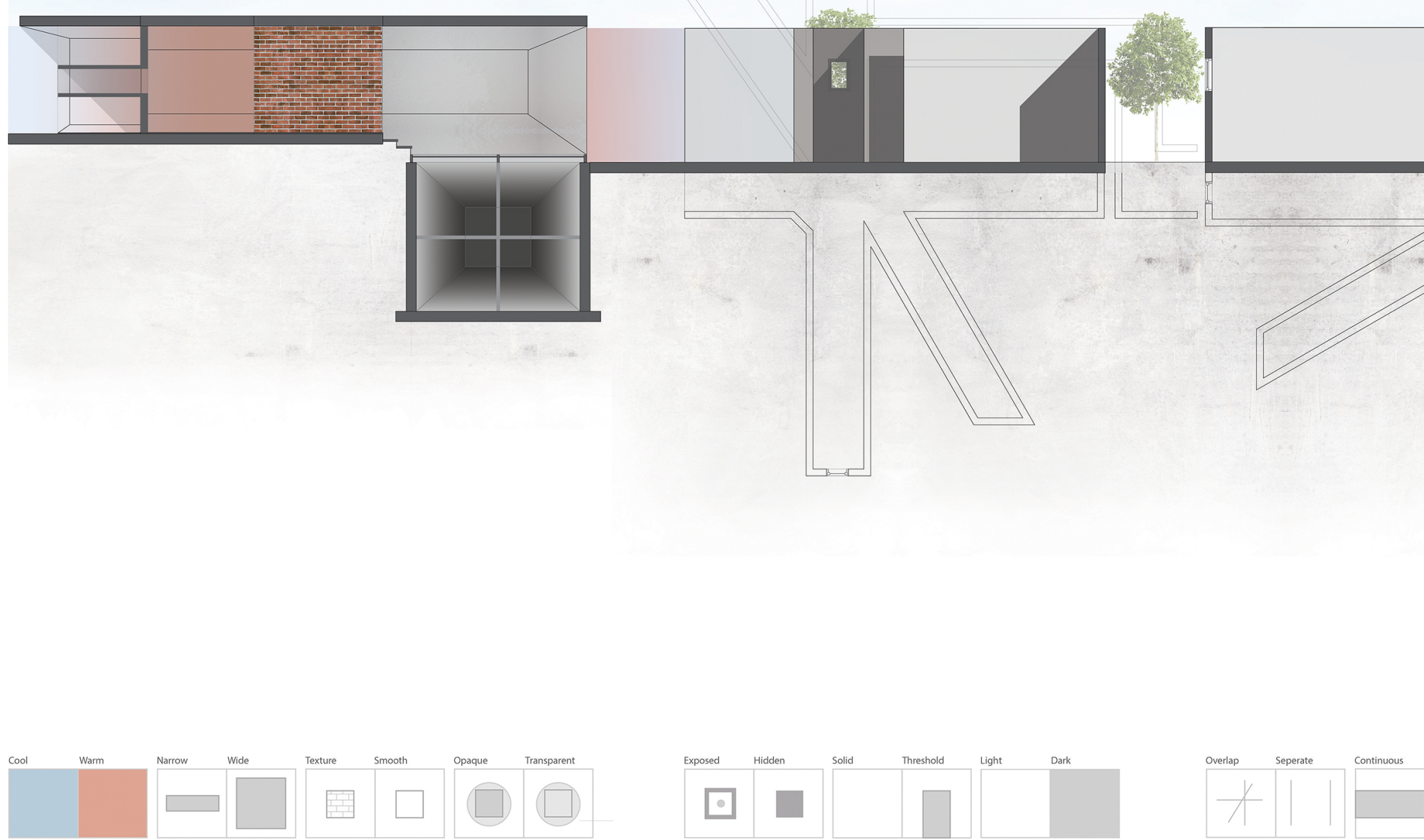
light and shadow

water as a visual cue

red wall dark interior

uneven and interrupted floor

sloped roof

marble

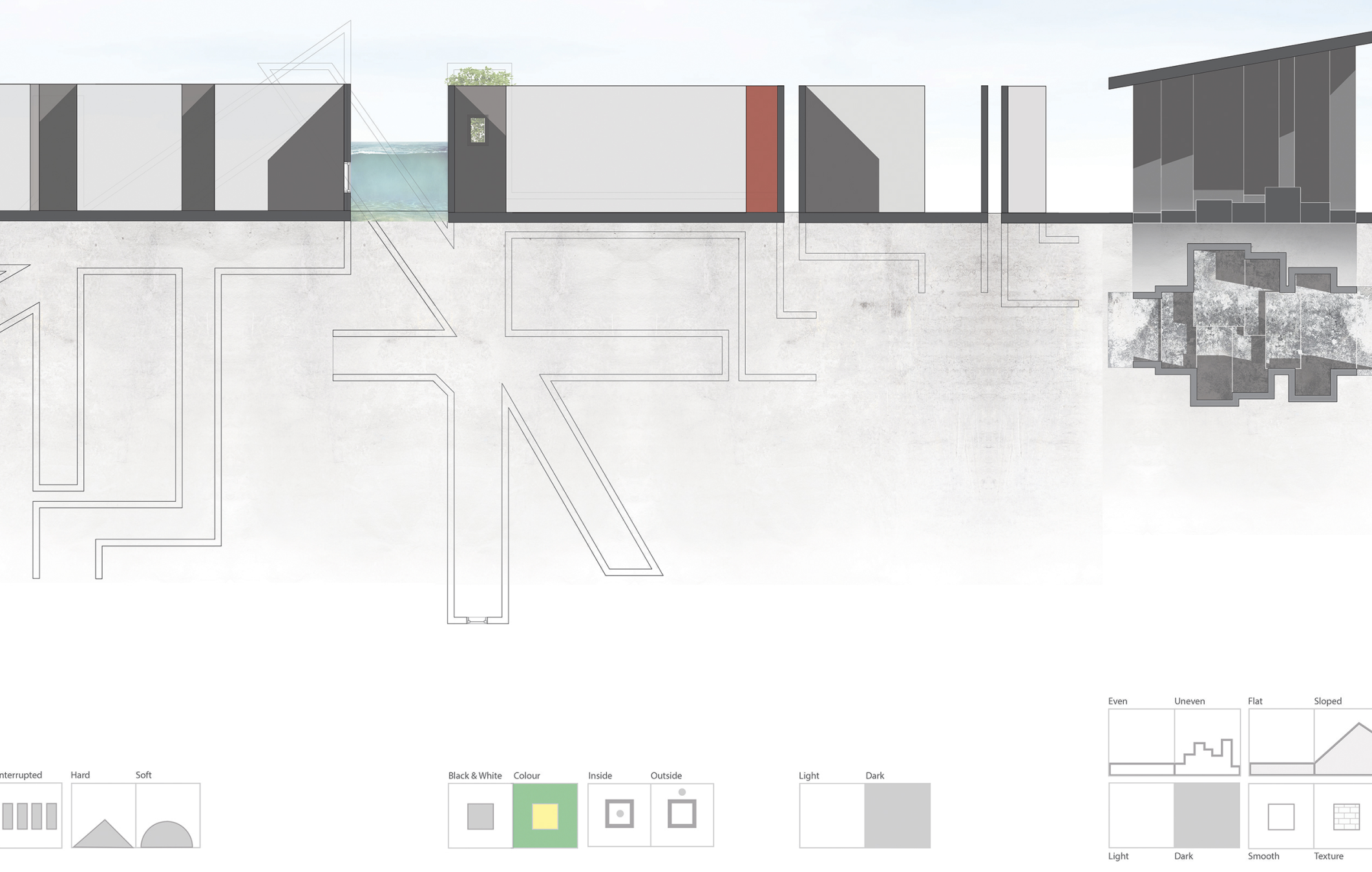


interrupted floor

narrow pathway

breath of fresh air

expansive space

up and down indoors and outdoors

transparent and solid walls

narrow pathways

labyrinth

voids in the walls

light and shadow
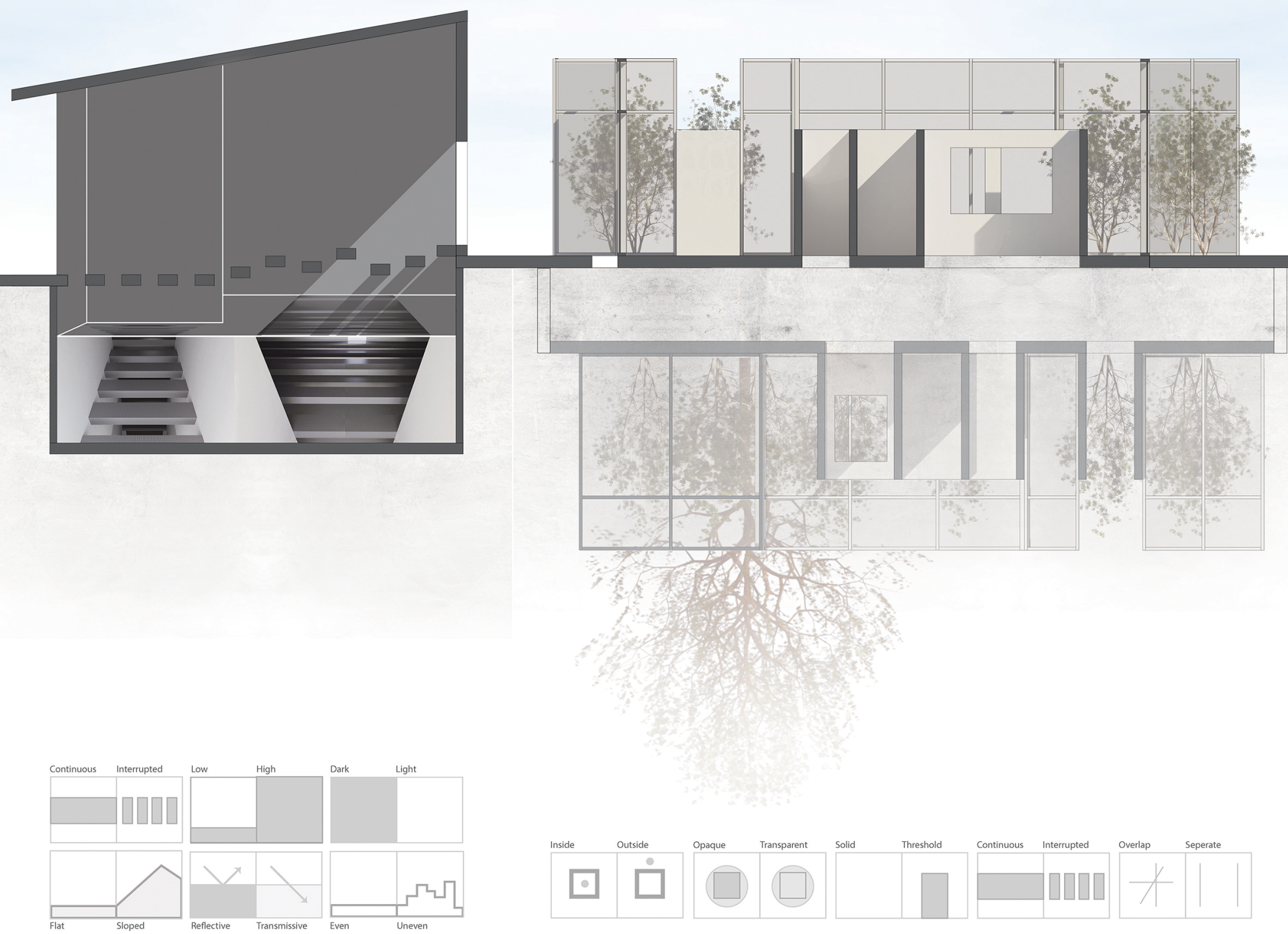
threshold

low red wall

compressed and dark staircase

change of material

open to above

red curved wall

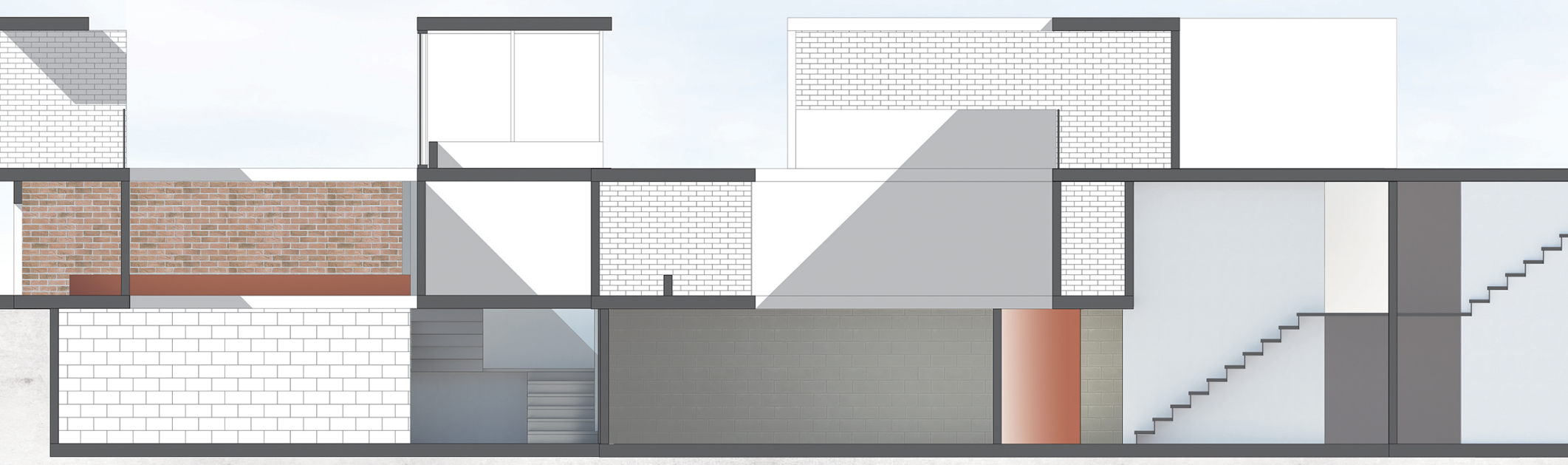


change of material

open to below

opaque and transparent ramp, a slide, or a running track

change in the rhythm of columns

red room

smaller dark room
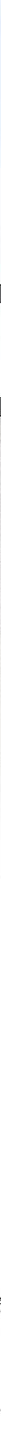
rhythm

decrescendo of columns

effect of shadows
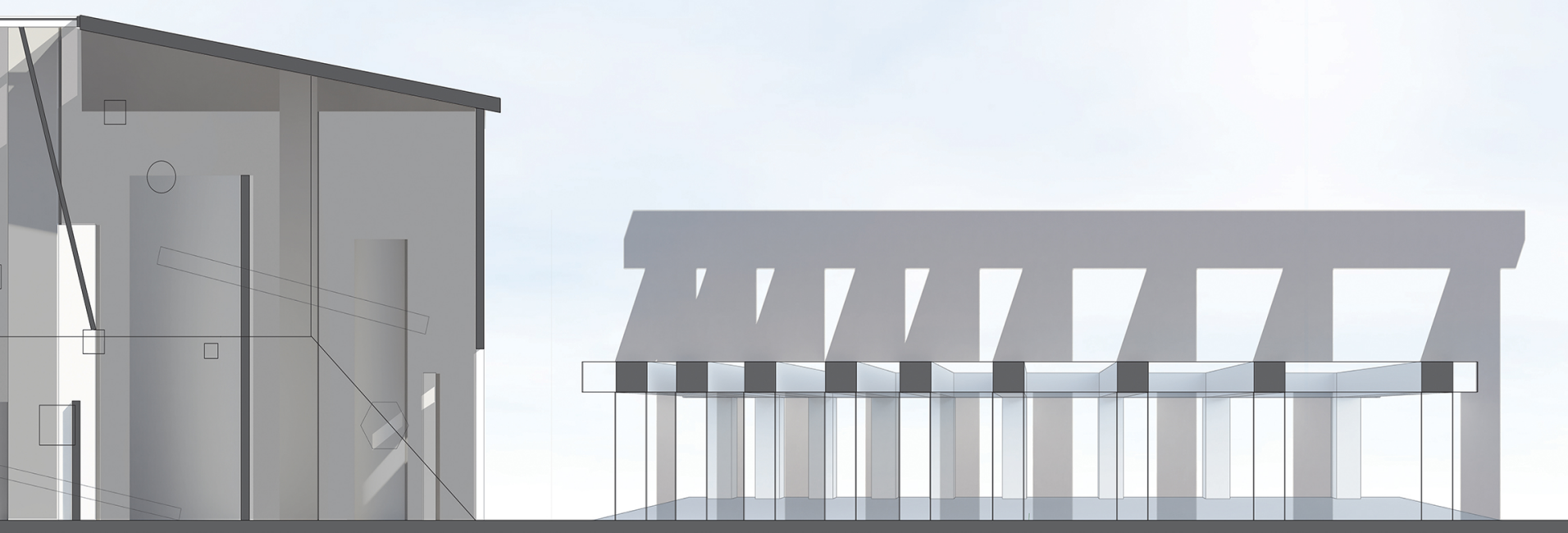

Siste
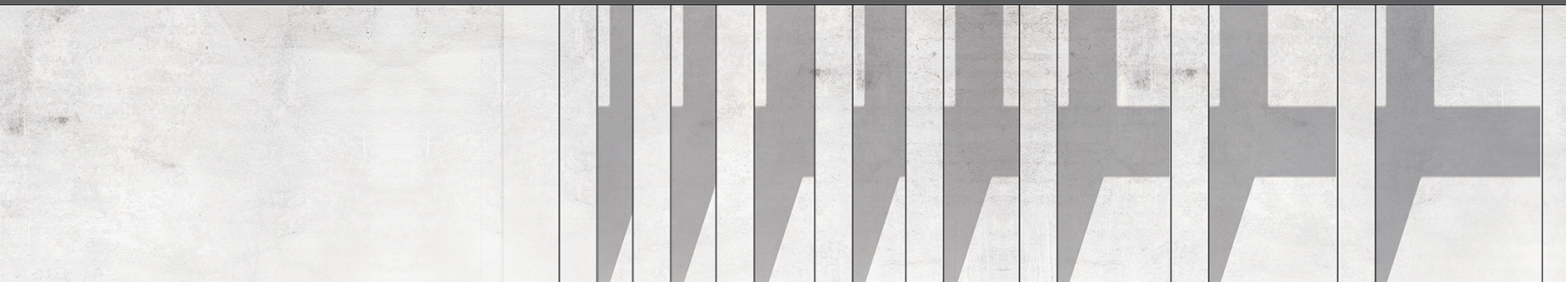

Emp
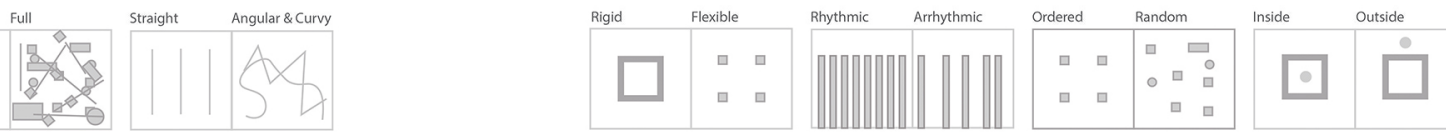


\section{Appendix B}

Appendix B - The Experiential Video

The video depicts the experiential section

in three-dimensions. 


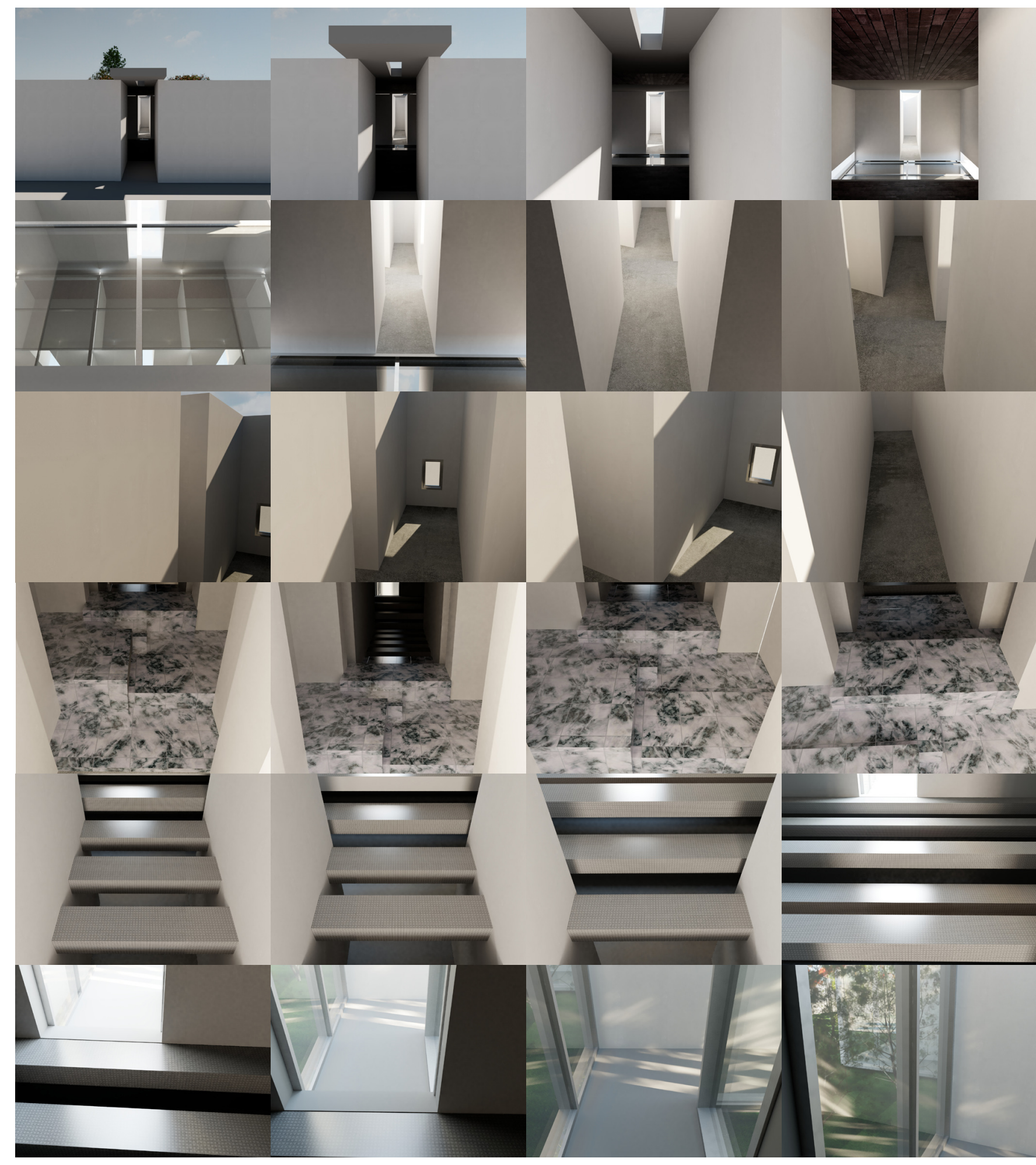




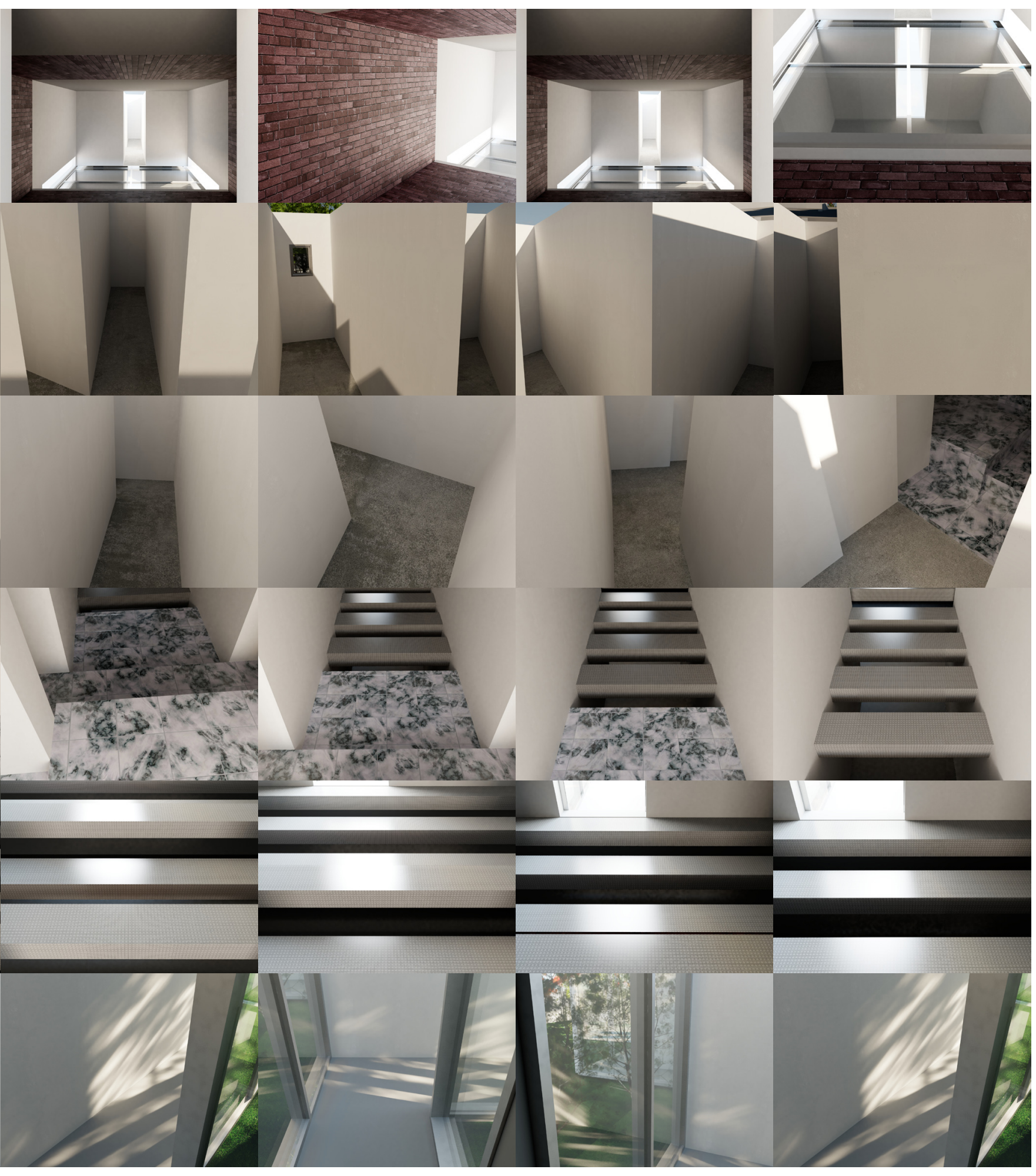




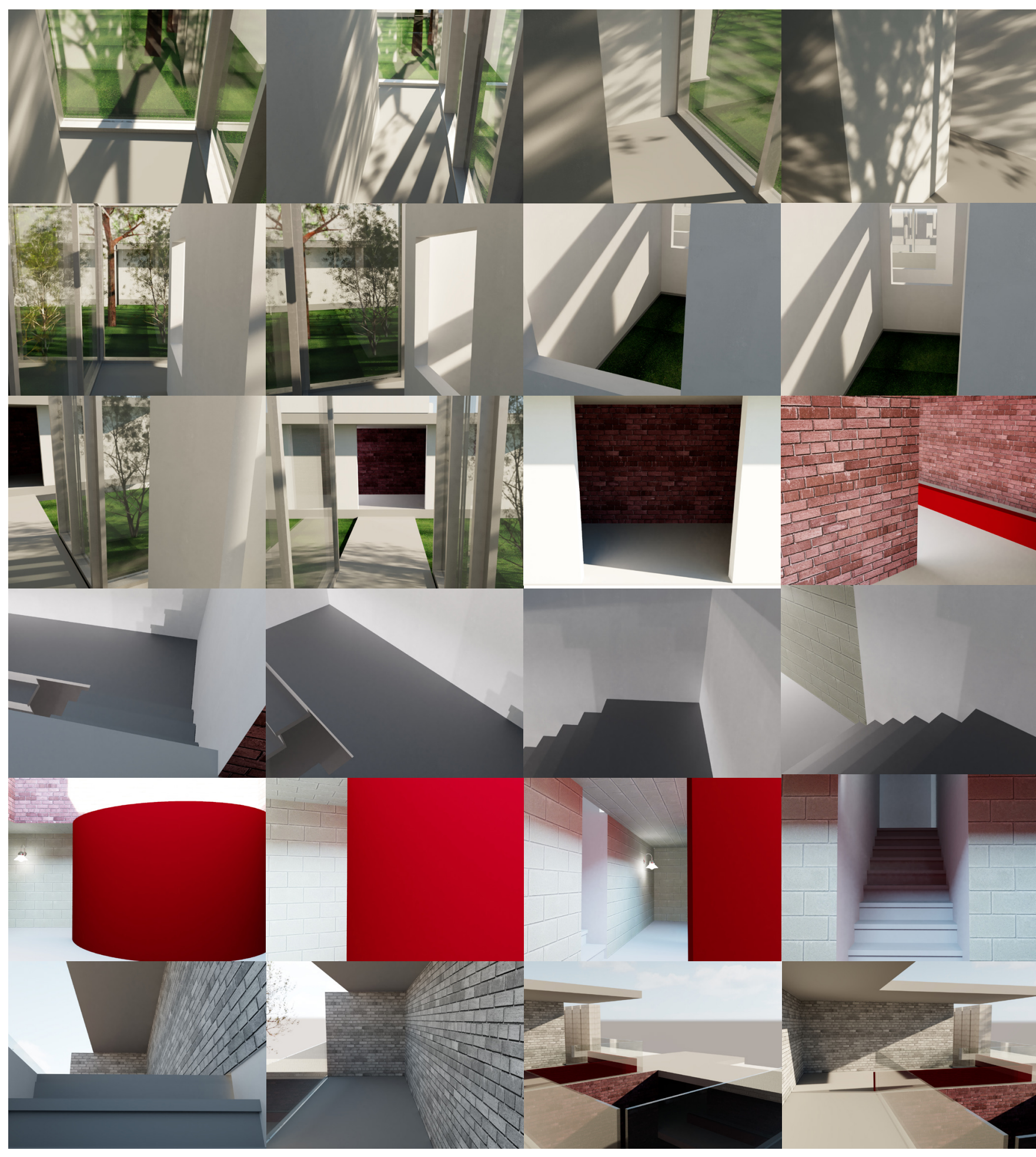




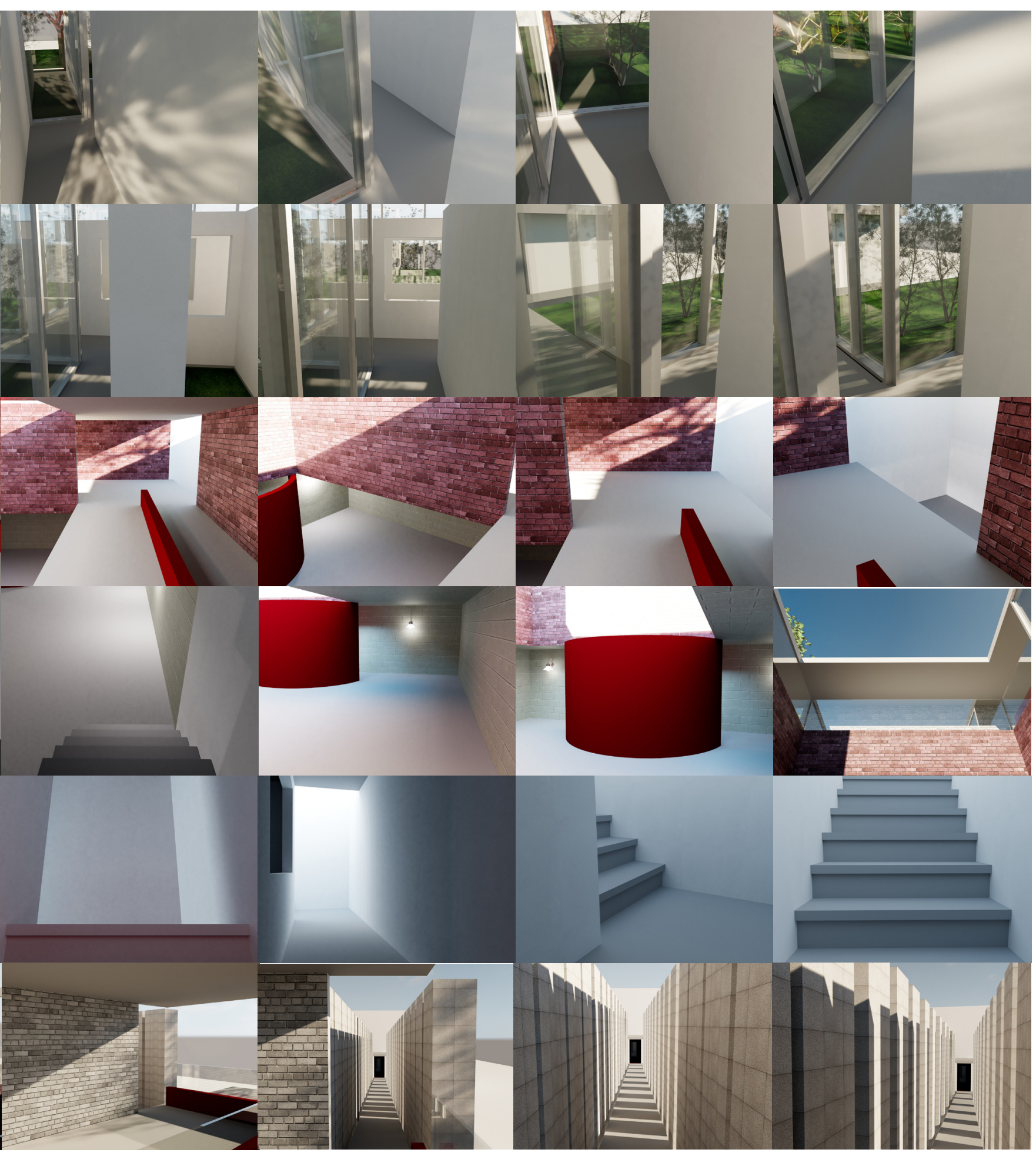




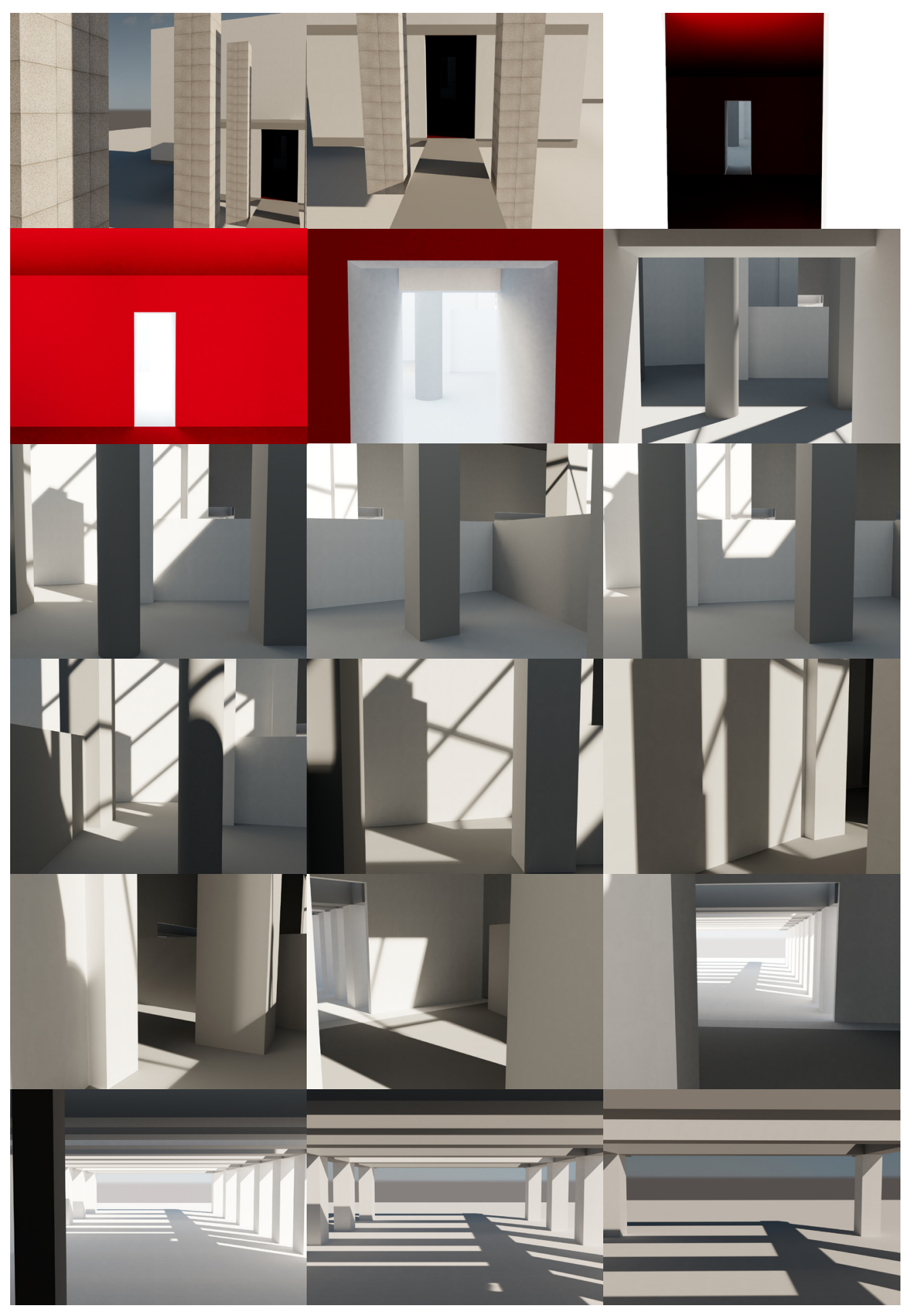




\section{Appendix C}

Appendix C - Haptic Tool Kit

The haptic tool kit allows for the reconstruction of space from different spatial binaries applied to architectural elements. Each space consists of five planes, individually highlighting one spatial quality. The experiences are then created based on a journey through these spaces, including parallax, perilous qualities, and attractions and aversions. 

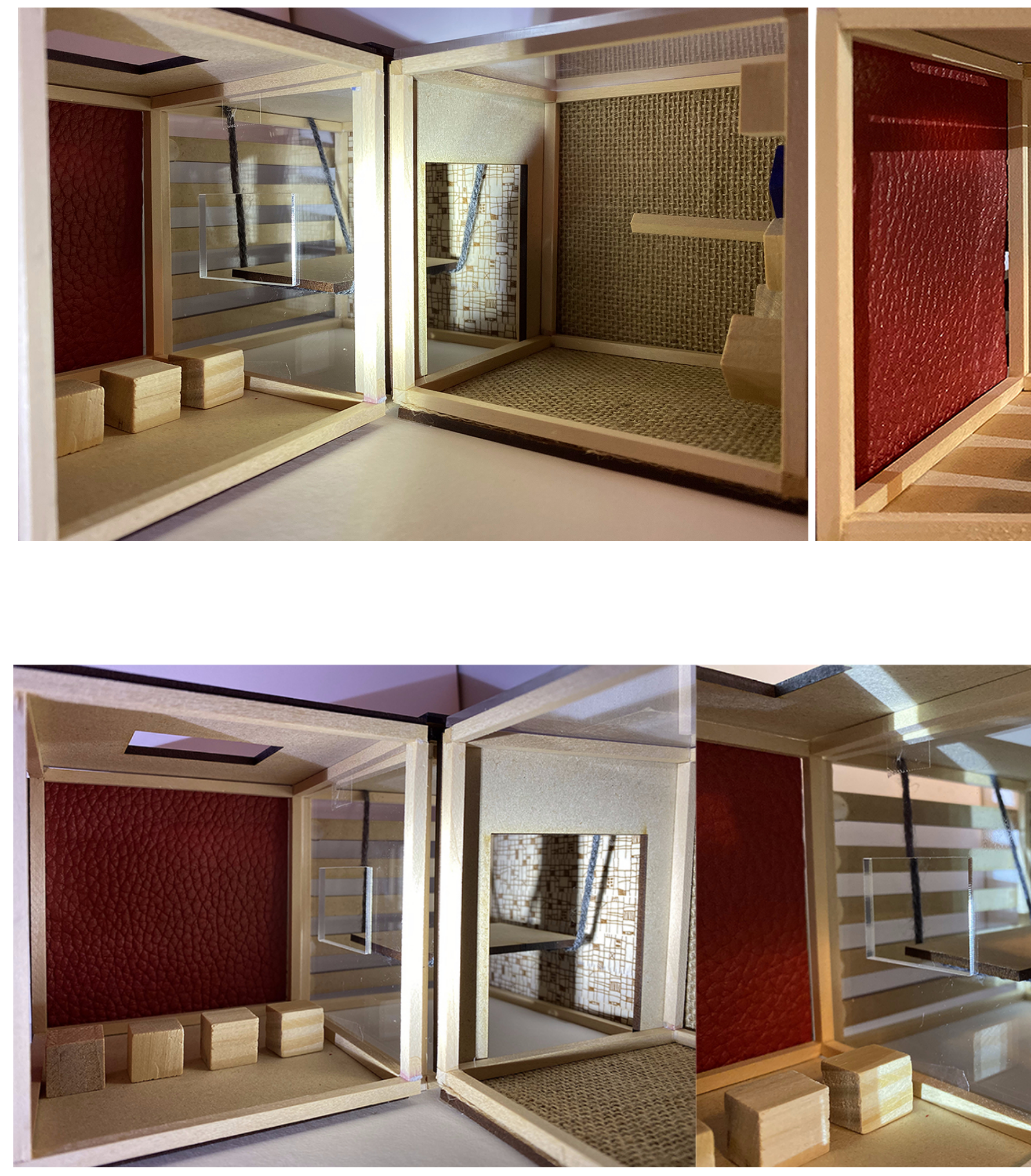

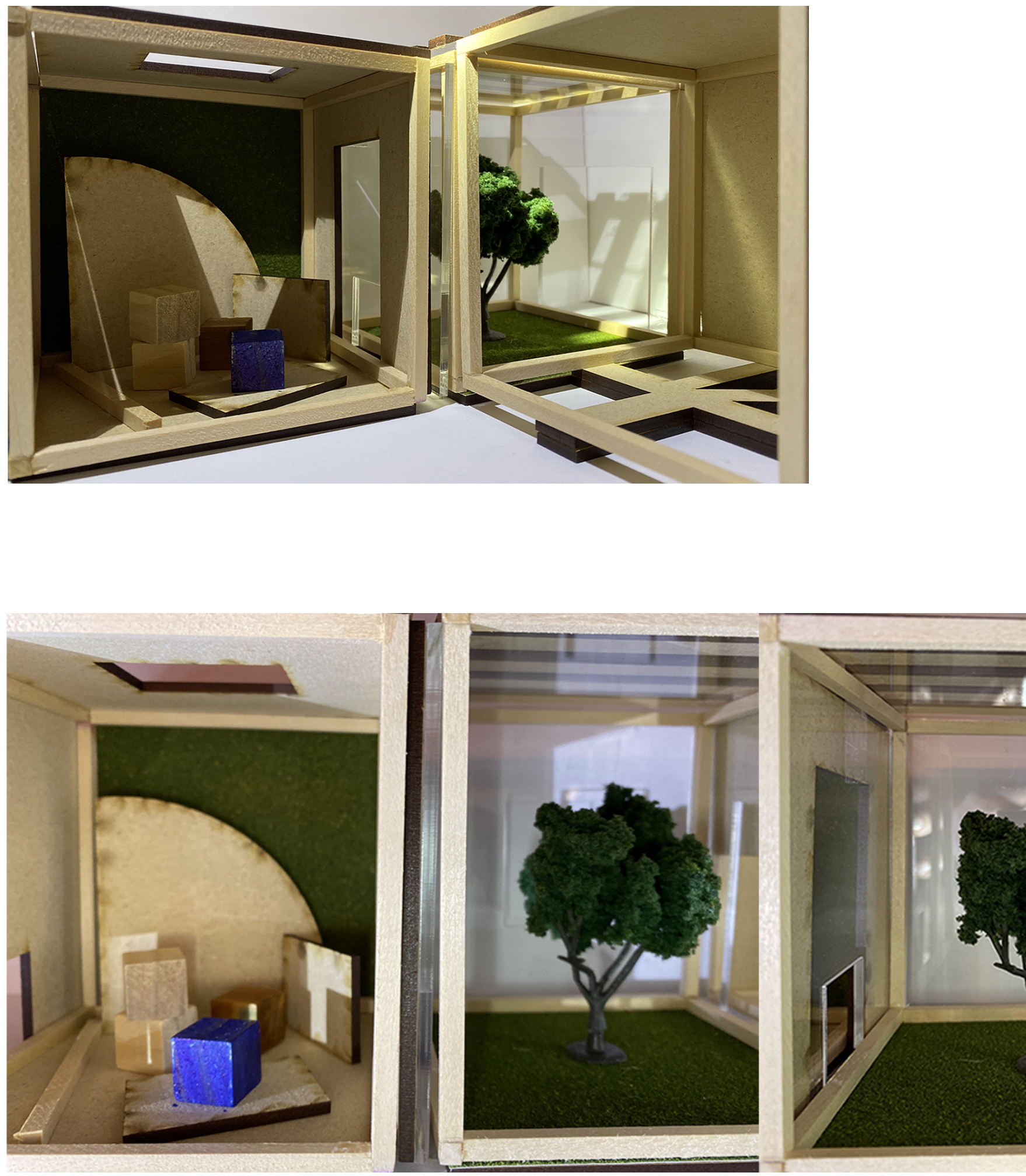
grass wall

full floor

void in the roof

interrupted roof

grass floor

transparent wall

threshold in the wall

solid wall \& roof

overlapped floor

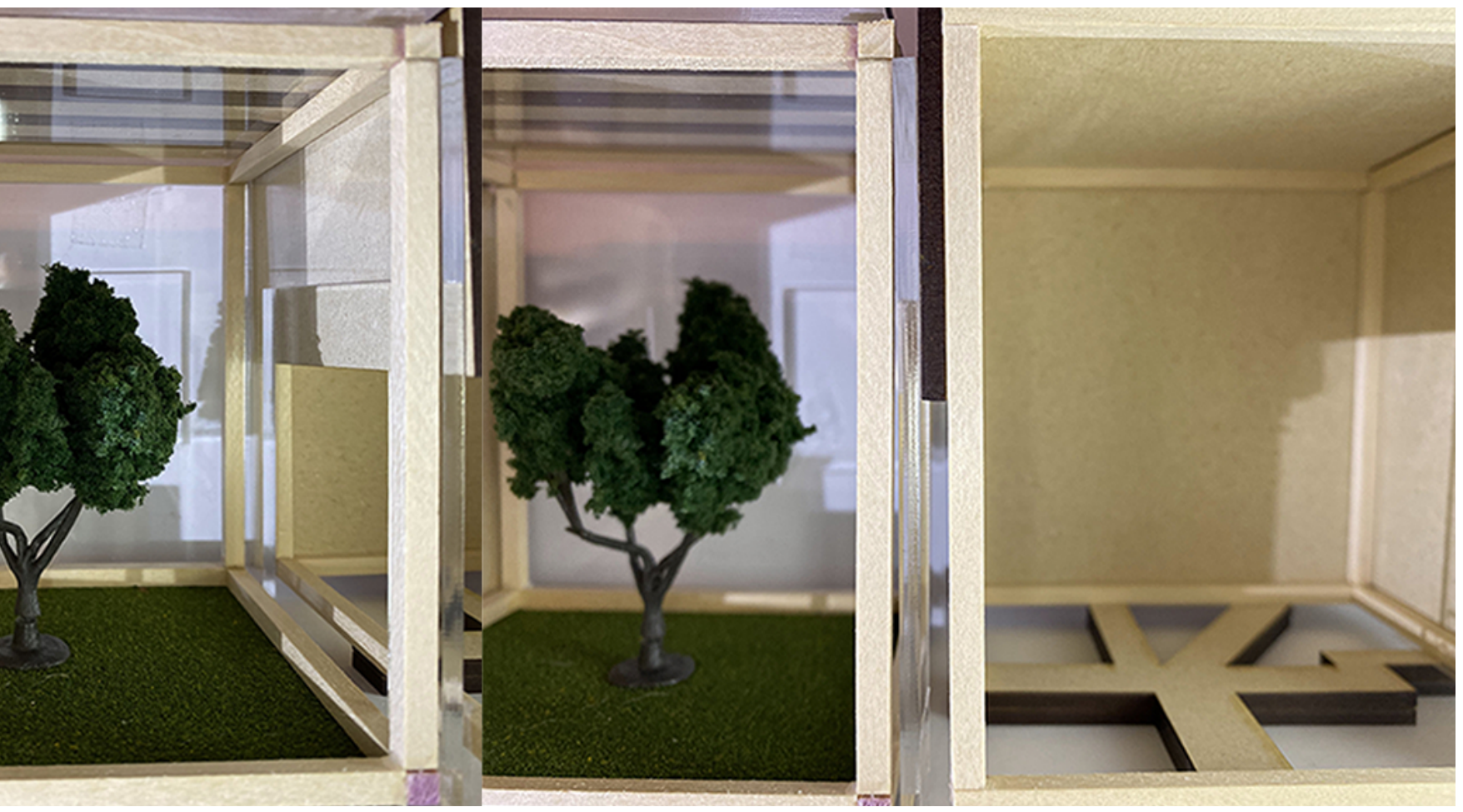



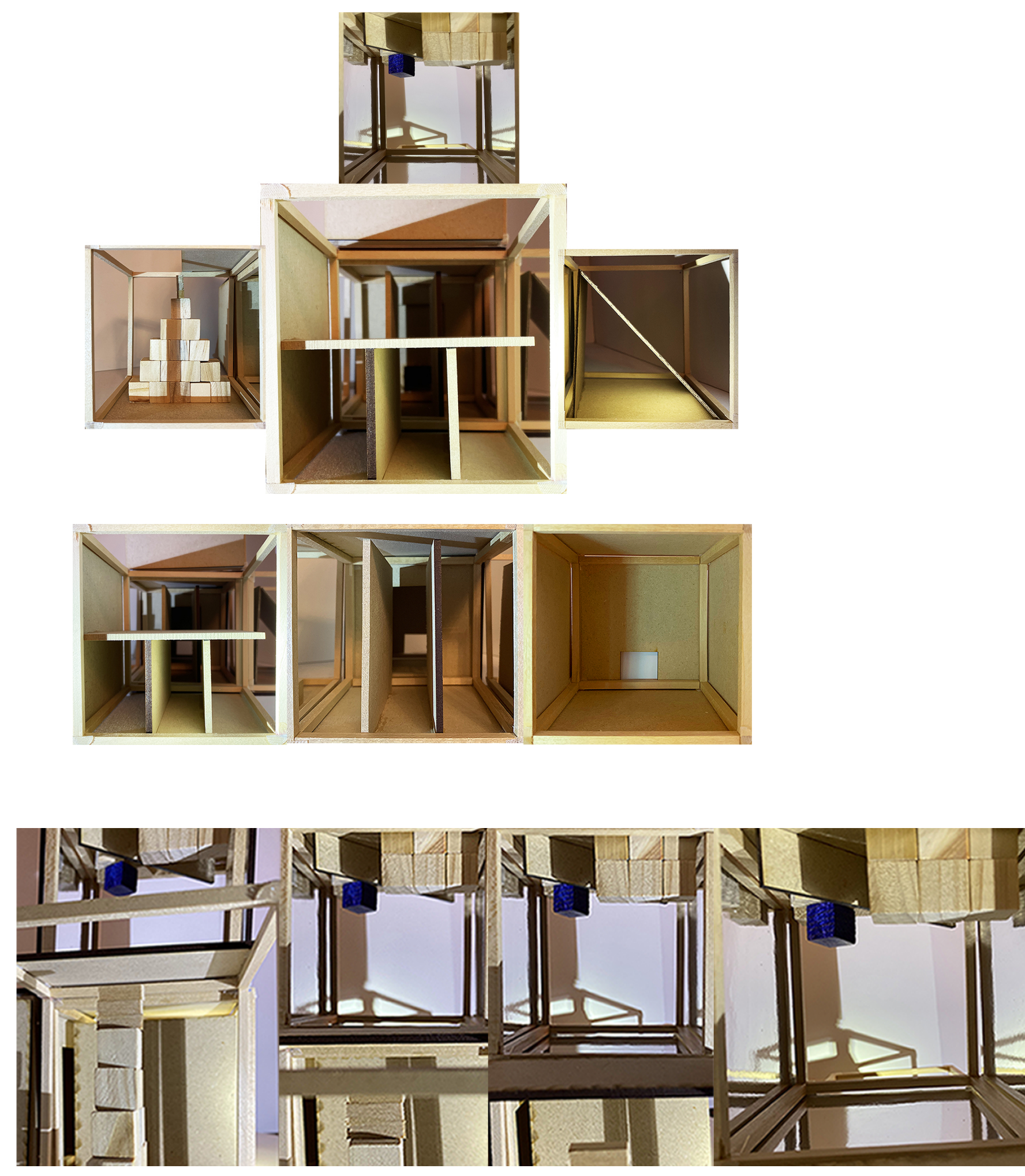
sloped floor

uneven floor

uneven wall

angular walls

curved roof

textured wall

labyrinthic walls

red wall

glass roof transparent floor

high \& low floors

high \& low walls

void in the wall

inverted columns

rhythmic columns

void in the floor

random columns

solid roof
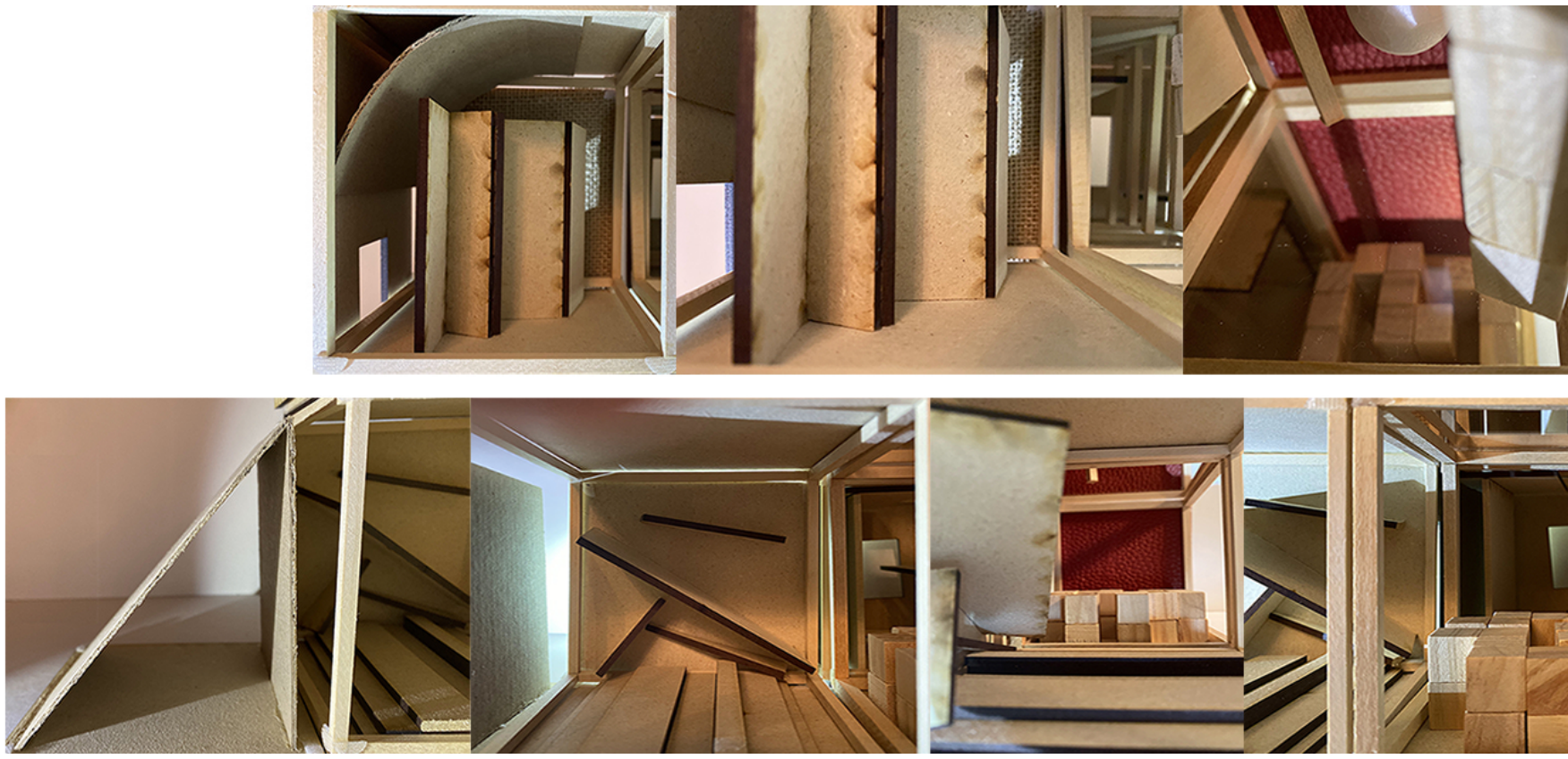

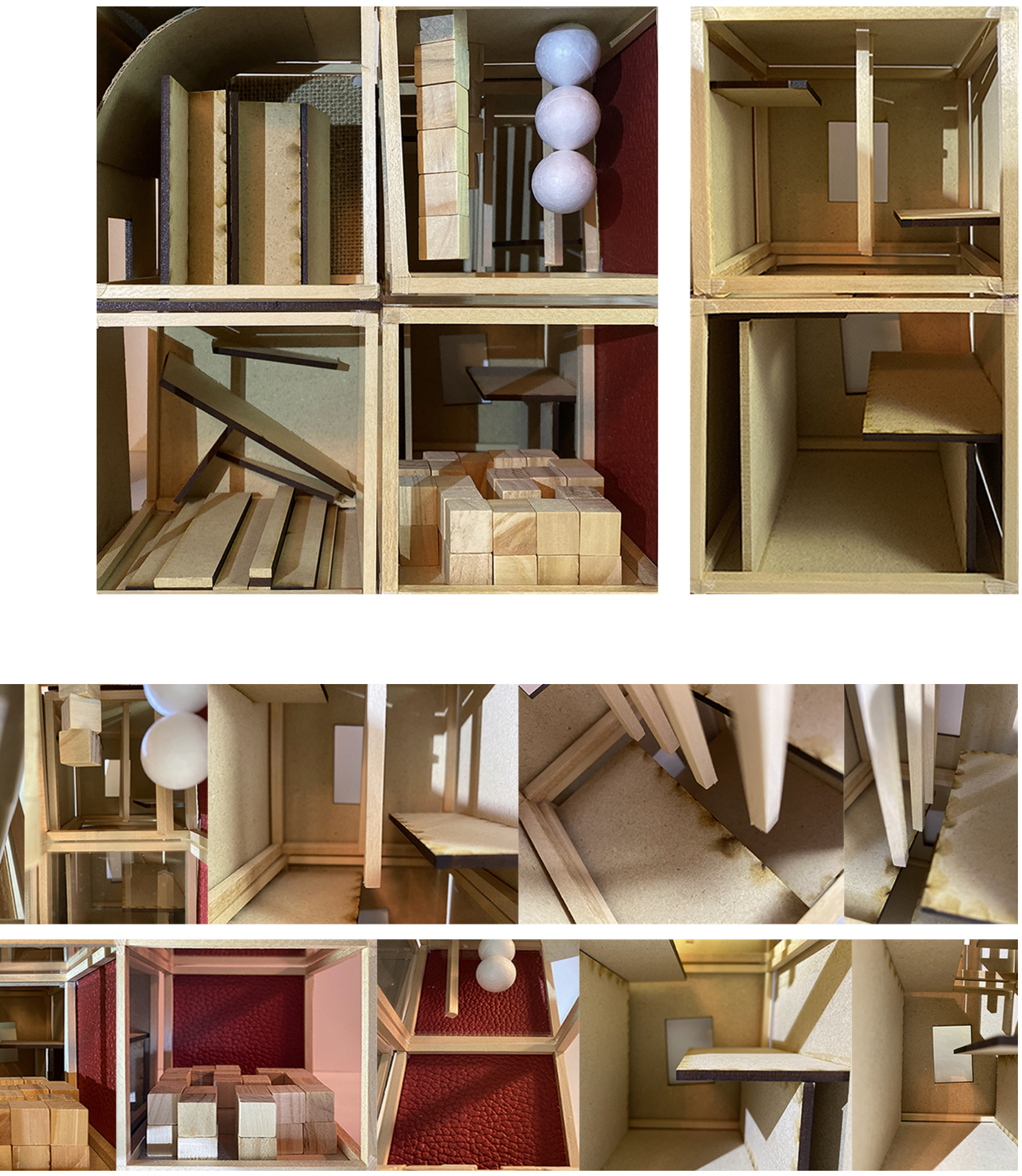


\section{Glossary of Terms}

Affordances - the opportunities for engagement with our environment that generate actions.

Attractions and aversions - the spatial qualities and opportunities, affordances, can impact the movement of people towards them or away from them.

Corporeal architecture - an approach to architecture that emphasizes the human body as the basis for design and spatial articulation.

Distance receptors - receptors that examine distant objects, such as the eyes.

Exploratory movement - movements to pick up information.

Exteroception - provides information about the surroundings of the body through exteroceptors.Exteroceptors are in the sense organs such as the eyes, ears, mouth, and skin and provide information such as touch, pressure, light, sound and taste.

Haptic perception - bodily perception, not only the act of touch, but also the three-dimensional exploration of space through proprioception, kinesthesia, vestibular sense, thermoreception, and nociception.

Haptic space - space that enhances the bodily experience of spatial qualities by focusing on interconnections between haptic perception, somatosensory senses and vision and, consequently, its interdependence on bodily movements.

Holes in vision - refer to limitations of sight and when the body tries to compensate for these limitations using other senses to seek confirmation and understand the totality of our surroundings.

Immediate receptors - receptors that monitor the immediate world and sense closeness and immediacy through skin, membranes and muscles. 
Interoception - provides information about the inside of the body through interoceptors. Interoceptors are inside the internal organs and provide data such as blood pressure and heartbeat.

Kinesthesia - the sensation of movement or strain in joints of one's body.

Limitation of frontality - our inability to see what is behind us.

Nociception - the feeling of pain.

Parallactic space - space that deals with the concept of parallax and considers the location and movement of viewers.

Parallax - the displacement of the background of an object, as well as the optical axis, due to the perceived movement of that object from one position to another.

Performatory movement - movements to accomplish behaviour.

Perilous space - space that provides opportunities for bodily actions that go against the habitual patterns of movement.

Proprioception - awareness of the position of one's body.

Spatiality - the concept of spatiality merges space and movement of the body and derives its value from this interaction. It has a direct impact on how bodies perceive and act in space.

Somaesthetics - a critical study of the use of one's body in spatial experience. The term soma means body and aesthetics, a Greek word, means sensory perception.

Somatosensory system - is composed of receptors and processing centres to produce haptic perception.

Thermoception - the sensation of heat and cold and monitoring internal body temperature.

Vestibular sense - located in the inner ear, interacts with the information provided by proprioception and kinesthesia and informs us about the body's orientation relative to gravity as well as movement of the body. 


\section{Works Cited}

Admin, lalab. "Proprioception Interaction: Upgrade Human Perception with Prothesis." Interactive Architecture Lab. Bartlett School of Architecture, UCL, July 10, 2015. http://www.interactivearchitecture.org/proprioception-interactionupgrade-human-perception-with-prothesis.html.

Aguiar, Douglas. "Space, Body AND Movement Notes on the Research of Spatiality in Architecture." Arqtexto/Propar 8, November 2006, 74-94. https:// www.researchgate.net/publication/327164114_SPACE_BODY_AND_MOVEMENT_ notes_on_the_research_of_spatiality_in_architecture\#fullTextFileContent.

AHH. "Centraal Beheer Offices, Apeldoorn." AHH , n.d. https://www.ahh.nl/index. php/en/projects2/12-utiliteitsbouw/85-centraal-beheer-offices-apeldoorn.

Benjamin, Walter. "The Work of Art in the Age of Mechanical Reproduction." In Illuminations, edited by Hannah Arendt, translated by Harry Zohn, 1-26. New York: Schocken Books, 1969. https://web.mit.edu/allanmc/www/benjamin.pdf.

Brown, David. "The Forgotten Sense - Proprioception." Dbl Review, July 2006, 20-24. http://www.caoms.org/images/2010/TheForgottenSense-Proprioception. pdf.

Cambridge University. "Richard Shusterman - Thinking Through the Body." YouTube video, 8:05. 2012. https://www.youtube.com/watch? $v=f O u 32 u X \times 201$

Daly, Ann. Critical Gestures: Writings on Dance and Culture. Middletown, CT: Wesleyan University Press, 2002.

Erwine, Barbara. Creating Sensory Spaces: The Architecture of the Invisible. New York: Routledge, Taylor \& Francis Group, 2017. 
Ferreira, Maria Da Piedade, Duarte Cabral De Mello, and José Duarte. "The Grammar of Movement: A Step Towards a Corporeal Architecture." Nexus Network Journal 13 (February 26, 2011): 131-49. https://link.springer.com/content/ pdf/10.1007/s00004-011-0058-4.pdf.

Fiederer, Luke. "AD Classics: Kiasma Museum of Contemporary Art / Steven Holl Architects." ArchDaily. ArchDaily, April 19, 2016. https://www.archdaily. com/784993/ad-classics-kiasma-museum-of-contemporary-art-steven-hollarchitects.

Franck, Karen A., and Bianca Lepori. Architecture from the inside Out: From the Body, the Senses, the Site, and the Community. Chichester: Wiley-Academy, 2007.

Frascari, Marco. Monsters of Architecture: Anthropomorphism in Architectural Theory. Savage, Mar.: Rowman \& Littlefield, 1991.

Gibson, James J., and Fredrick A Buckland. "An after-Effect in Haptic Space Perception." Quarterly Journal of Experimental Psychology 15, no. 3 (September 1, 1963): 145-54. https://www.tandfonline.com/doi/abs/10.1080/1747021630841632.

Gibson, James J., and Leonard Carmichael. The Senses Considered as Perceptual Systems. Westport, CT: Greenwood Press, 1983.

Gleick, James. Faster: The Acceleration of Just about Everything. London: Abacus, 2011.

González, María Francisca. "Calgary Central Library / Snøhetta." ArchDaily. ArchDaily, November 5, 2018. https://www.archdaily.com/905263/calgarycentral-library-snohetta.

Hall, Edward T. The Hidden Dimension. Gloucester, MA: Peter Smith Pub, 1992.

Hiskey, Daven. "Humans Have a Lot More Than Five Senses." Today I Found Out, May 31, 2016. http://www.todayifoundout.com/index.php/2010/07/humanshave-a-lot-more-than-five-senses/.

Holl, Steven, Juhani Pallasmaa, and Alberto Pérez-Gómez. Questions of Perception: Phenomenology of Architecture. San Francisco: William Stout, 2008.

Holl, Steven. Parallax. Basel: Birkhäuser, 2000. 
Holl, Steven. "Steven Holl Architects." Tesseracts if Time - A Dance for Architecture. Accessed August 30, 2019. http://www.stevenholl.com/projects/tesseracts-oftime.

Humphrey, Doris, and Barbara Pollack. The Art of Making Dances. London: Dance Books, 1997.

Jay, Martin. Downcast Eyes: The Denigration of Vision in Twentieth Century French Thought. Berkeley, CA: Univ. of California Press, 2009.

Käufer, Stephan, and Anthony Chemero. Phenomenology: An Introduction. Cambridge: Polity, 2016.

Kavanagh, Donncha. "Ocularcentrism and Its Others: A Framework for Metatheoretical Analysis." SAGE Journals 25, no. 3 (March 1, 2004): 445-64. https://journals.sagepub.com/doi/10.1177/0170840604040672.

KPMB. "The Joseph L. Rotman School of Management Expansion, University of Toronto." KPMB, n.d. http://www.kpmb.com/project/the-joseph-I-rotman-schoolof-management-expansion-university-of-toronto/.

Kroll, Andrew. "AD Classics: Villa Savoye / Le Corbusier." ArchDaily. ArchDaily, October 27, 2010. https://www.archdaily.com/84524/ad-classics-villa-savoye-lecorbusier.

Kwang-ho, Kim. "A Study on the Concept of Prospect in Frank Lloyd Wright's Works." 2018. https://www.jstage.jst.go.jp/article/jaabe/1/1/1_1_297/_pdf

Lalonde, Dani. "Case Study. Thermal Baths. Peter Zumthor." 2012. https:// danilalonde.files.wordpress.com/2012/12/danifinalcasestudy.pdf.

Le Corbusier. The City of To-Morrow and Its Planning. New York: Dover, 1987.

Lupton, Ellen, and Andrea Lipps. The Senses: Design beyond Vision. New York, NY: Copper Hewitt, Smithsonian Design Museum, 2018.

Lynch, Patrick. "Steven Holl and Jessica Lang's 'Tesseracts of Time' Explores the Relationship Between Architecture and Dance." ArchDaily, October 11, 2016. https://www.archdaily.com/797079/steven-holl-and-jessica-langs-tesseracts-oftime-explores-the-relationship-between-architecture-and-dance. 
Mather, Lindsey. "The House of Our Dreams Is for Sale in East Hampton, New York." Architectural Digest. Architectural Digest, February 7, 2019. https://www. architecturaldigest.com/story/bioscleave-house-for-sale-east-hampton-new-york.

Merleau-Ponty, Maurice. Phenomenology of Perception. London: Forgotten Books, 2015.

Minner, Kelly. "AD Classics: Chapel of St. Ignatius / Steven Holl Architects." ArchDaily. March 01, 2011. https://www.archdaily.com/1 15855/ad-classicschapel-of-st-ignatius-steven-holl-architects.

Nussbaumer, Linda L. Human Factors in the Built Environment. New York, NY: Fairchild Books, An Imprint of Bloomsbury Publishing, 2018.

O'Grady, Elena. "The Therme Vals / Peter Zumthor." ArchDaily. ArchDaily, February 11, 2009. https://www.archdaily.com/13358/the-therme-vals.

Onniboni, Luca. "Museum Querini Stampalia Foundation by Carlo Scarpa." Archiobjects, December 24, 2016. https://archiobjects.org/museum-querinistampalia-foundation-carlo-scarpa-venice/.

Orientalarchitecture. "Heian Jingu Shrine, Kyoto, Japan." Asian Architecture, n.d. https://www.orientalarchitecture.com/sid/204/japan/kyoto/heian-jingu-shrine.

Orientalarchitecture. "Katsura Imperial Villa, Kyoto, Japan." Asian Architecture, n.d. https://www.orientalarchitecture.com/sid/206/japan/kyoto/katsura-imperialvilla.

Pallasmaa, Juhani. The Eyes of the Skin. Chichester: Wiley.

Perez, Adelyn. "AD Classics: Exeter Library (Class of 1945 Library) / Louis Kahn." ArchDaily. ArchDaily, June 9, 2010. https://www.archdaily.com/63683/ad-classicsexeter-library-class-of-1945-library-louis-kahn.

Peters, Michael Brady. "Constructing the Experience of Movement." Master of Architecture Thesis. Dalhousie University, 2001.

Plummer, Henry. The Experience of Architecture . London:

Thames \& Hudson, 2016. https://books.google.ca/

books?id=sfx8DQAAQBAJ\&printsec=frontcover\&source=gbs_ge 
summary_r\&cad=0\#v=onepage \&q\&f=false.

Samuel, Flora. Le Corbusier and the Architectural Promenade. Basel: Birkhäuser, 2010.

Sbriglio, Jacques. Le Corbusier: the Villa Savoye. Basel: Birkhäuser, 2007. https:// books.google.ca/books?id=aHNICWAAQBAJ\&printsec=frontcover\&source=gbs_

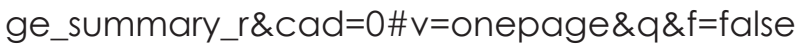

Seattle University. "Seattle University." Virtual Tour - Chapel of St. Ignatius - Seattle University. https://www.seattleu.edu/chapel/virtual-tour/blessed-sacramentchapel/.

Shusterman, Richard. Thinking through the Body: Essays in Somaesthetics. Cambridge: Cambridge University Press, 2012.

Tapia, Daniel. "Amazon Spheres / NBBJ." ArchDaily. ArchDaily, July 1, 2019. https://www.archdaily.com/920029/amazon-spheres-nbbj.

Tschumi, Bernard. The Manhattan Transcripts. London: Academy, 1994.

V., Bill. "Toronto Reference Library at 40: Raymond Moriyama and the Original Architecture." Toronto Reference Library Blog, November 2, 2017. https:// torontopubliclibrary.typepad.com/trl/2017/11/were-turning-40-and-we-lookgood-.html.

Valenzuela, Karen. "New Halifax Central Library / Schmidt Hammer Lassen Architects Fowler Bauld \& Mitchell." ArchDaily. ArchDaily, December 16, 2014. https://www.archdaily.com/577039/new-halifax-central-library-schmidt-hammerlassen. 


\section{Works Considered}

Agrest, Diana. "Architecture from Without: Body, Logic, and Sex." In Architecture from Without: Theoretical Framings for a Critical Practice. Cambridge, MA: MIT Press, 1993.

Awan, Nishat, Tatjana Schneider, and Jeremy Till. Spatial Agency: Other Ways of Doing Architecture. London: Routledge, 2011.

Barbara, Anna, and Anthony Perliss. Invisible Architecture: Experiencing Places through the Sense of Smell. Milano: Skira, 2006.

Bell, Michael J. Slow Space. New York: Monacelli Press, 1998.

Blesser, Barry, and Linda-Ruth Salter. Spaces Speak, Are You Listening?

Experiencing Aural Architecture. Cambridge: MIT Press, 2009.

Cousins, Mark. Story of Looking. Place of Publication Not Identified: CANONGATE Books, 2019.

Devlieger, Patrick. Blindness and the Multi-sensorial City. Antwerp: Garant, 2006.

Dodds, George, and Robert Tavernor. Body and Building: Essays on the Changing Relation of Body and Architecture. Erscheinungsort Nicht Ermittelbar: M I T Pr, 2005.

Dolins, Francine L., and Robert W. Mitchell. Spatial Cognition, Spatial Perception: Mapping the Self and Space. Cambridge, UK: Cambridge Univ Press, 2014.

Erwine, Barbara. Creating Sensory Spaces: The Architecture of the Invisible. New York: Routledge, Taylor \& Francis Group, 2017. 
Gibson, James J. Psychological Review: Observations on Active Touch. 6th ed. Vol. 69. Cornell University, 1962.

Heylighen, Ann, and Megan Strickfaden. " $\{\mid m\}$ Materiality: Designing for More Sense/s." SAGR Journals 15, no. 3 (July 23, 2012): 180-85. https://www. researchgate.net/publication/236899913_Immateriality_Designing_for_More_ Senses.

Kovar, Zuzana. Architecture in Abjection; Bodies, Spaces, and their Relations. I.B.Tauris., 2017.

Merleau-Ponty, Maurice. The Primacy of Perception : And Other Essays on Phenomenological Psychology, the Philosophy of Art, History and Politics.

Evanston, III. : Northwestern Univ. Pr., 1964.

Pallasmaa, Juhani, and Michael Wynne-Ellis. The Architecture of Image Existential Space in Cinema. Helsinki: Rakennustieto, 2007. 